Universidad de Lima

Facultad de Ingeniería Industrial

Carrera de Ingeniería Industrial

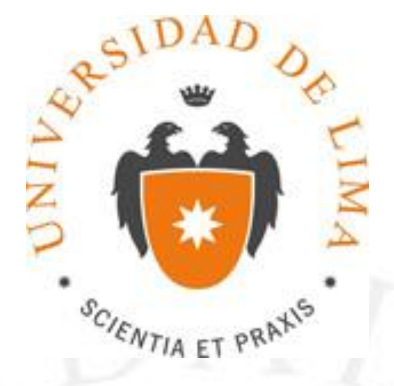

\title{
ESTUDIO DE PRE-FACTIBILIDAD PARA LA INSTALACIÓN DE UNA PLANTA PARA LA FABRICACIÓN DE CELDAS DE ELECTRÓLISIS
}

Trabajo de investigación para optar el título profesional de ingeniero industrial

\author{
Coquis Sanchez-Concha, Rodrigo \\ 20090273 \\ Ure Fainzilber, Danny Alexander \\ 20091154
}

Asesor

Victor Manuel Sotelo Neyra

Lima - Perú

Agosto del 2016 


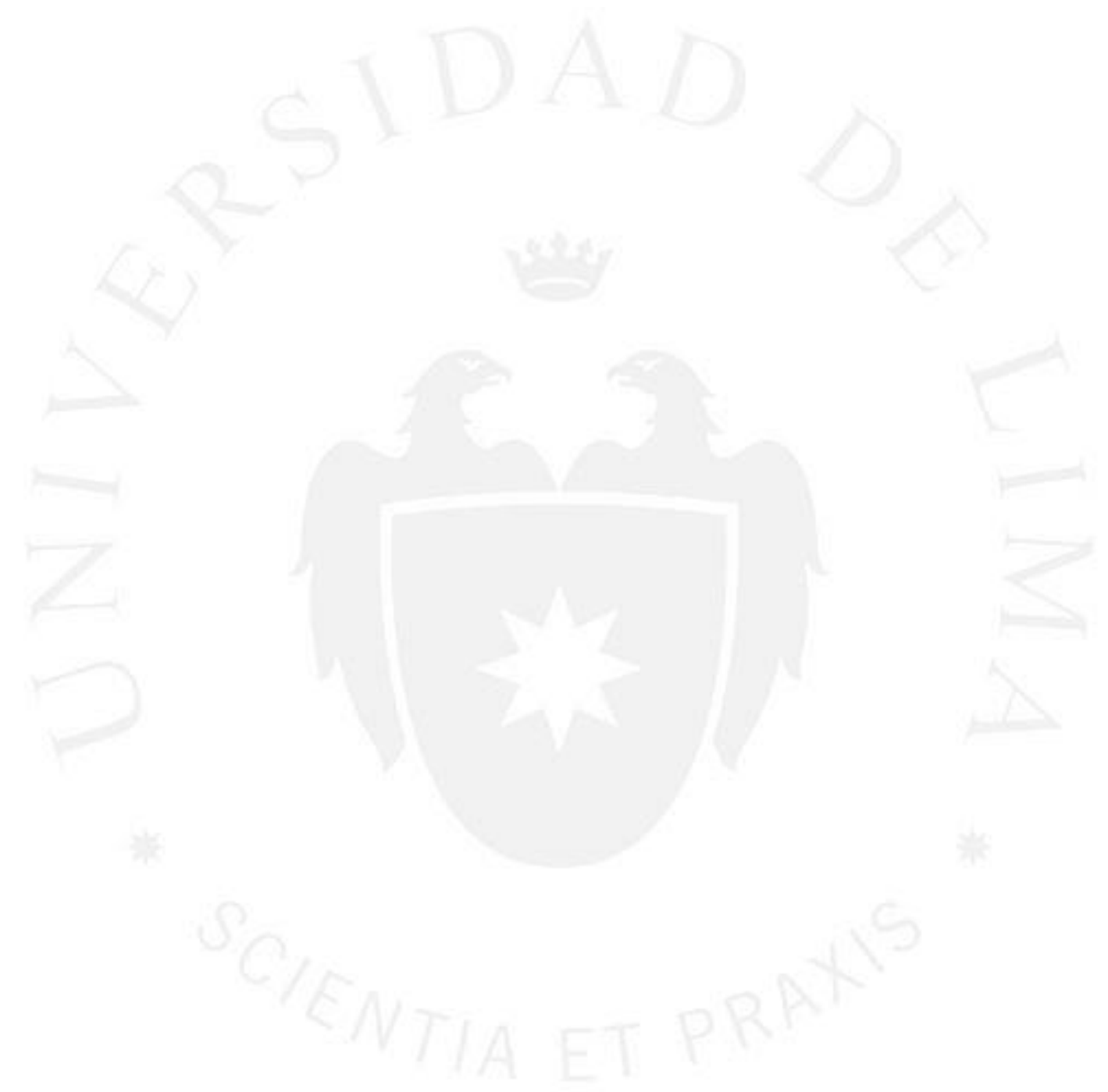




\section{ESTUDIO DE PRE-FACTIBILIDAD PARA LA INSTALACIÓN DE UNA PLANTA PARA LA FABRICACIÓN DE CELDAS DE ELECTRÓLISIS}




\section{TABLA DE CONTENIDO}

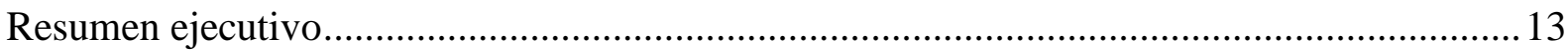

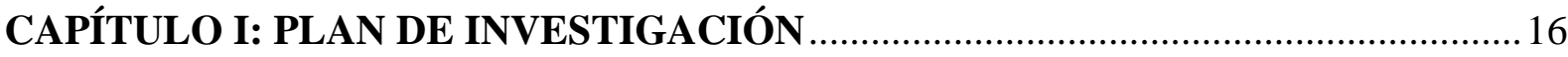

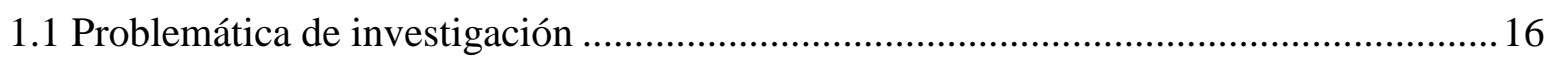

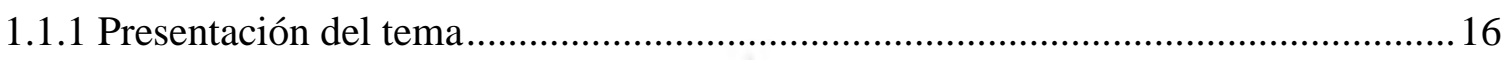

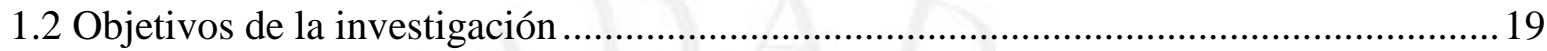

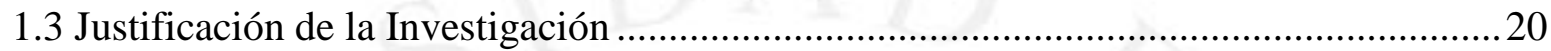

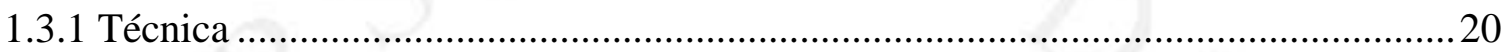

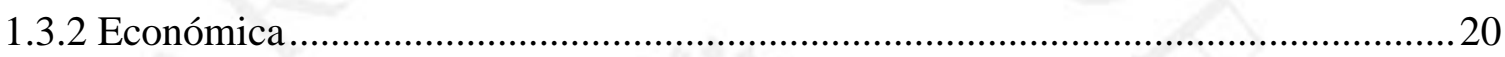

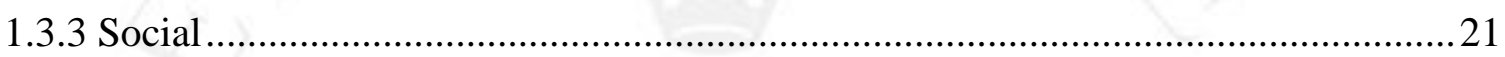

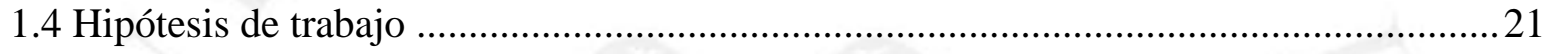

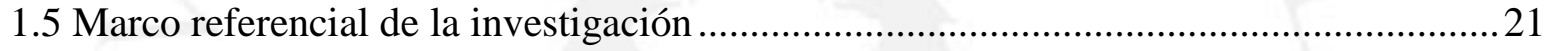

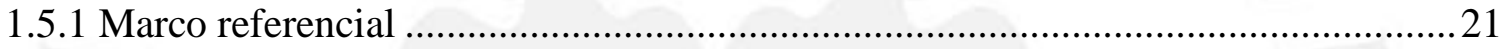

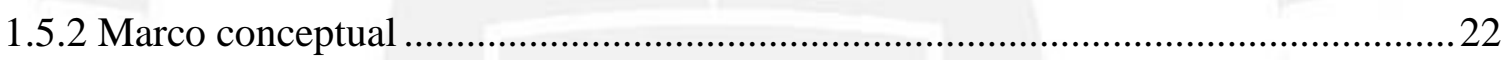

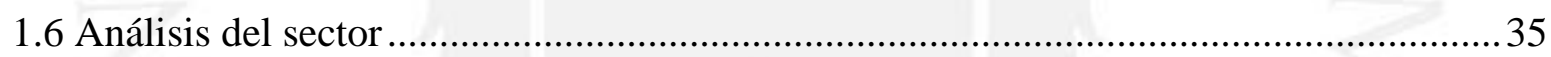

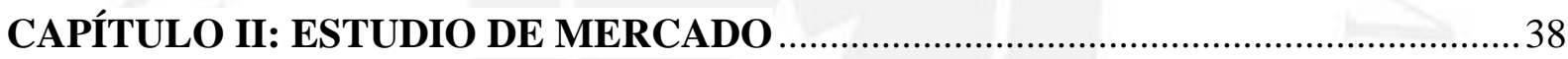

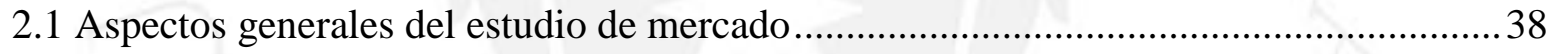

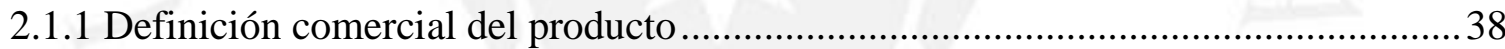

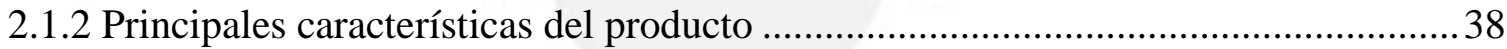

2.1.3 Determinación del área geográfica que abarcará el estudio....................................45

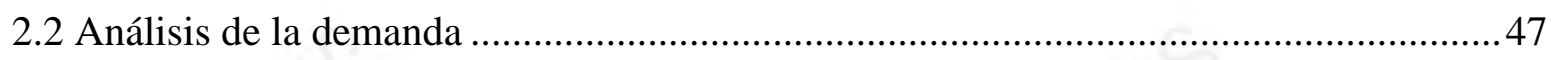

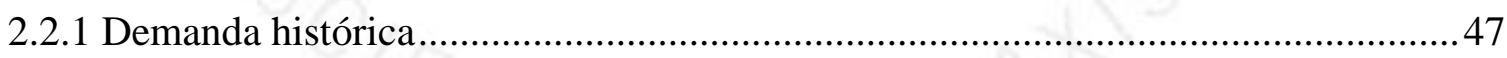

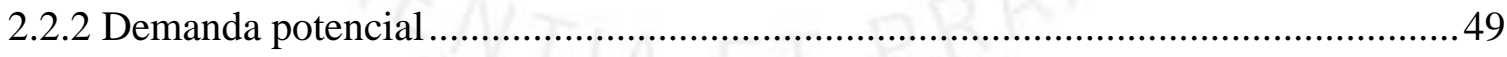

2.2.3 Proyección de la demanda y metodología del análisis ............................................50

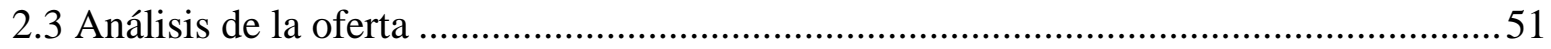

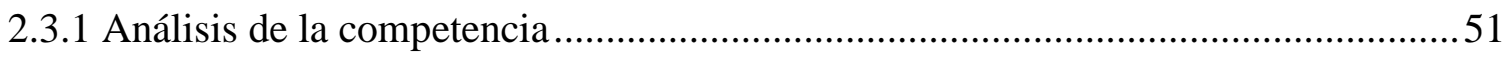

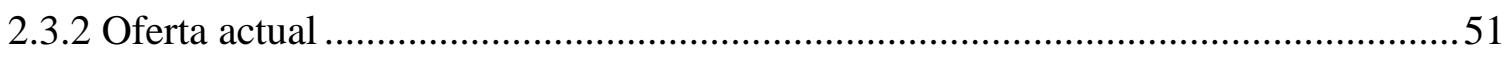

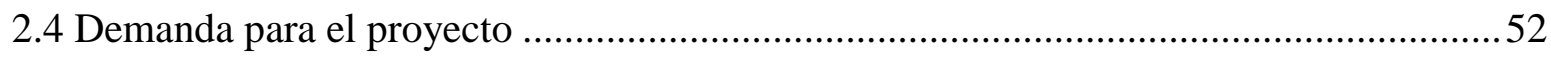

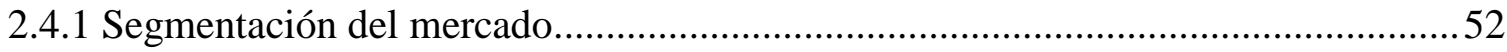

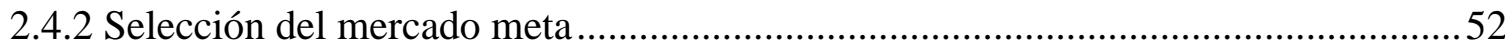

2.4.3 Determinación de la demanda para el proyecto .......................................................53 
2.5 Estrategia de comercialización 63

2.5.2 Análisis de precios 65

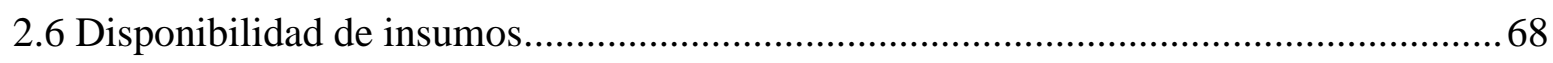

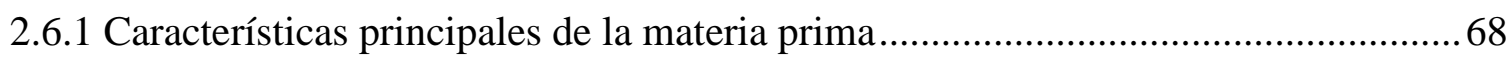

2.6.2 Potencialidad del recurso en la zona de influencia del proyecto.............................6 68

CAPÍTULO III: LOCALIZACIÓN DE PLANTA 69

3.1 Análisis de los factores de localización 69

3.2 Posibles ubicaciones de acuerdo a factores predominantes . .70

3.3 Evaluación y selección de localización. . .73

3.3.1 Evaluación y selección de la macro localización .................................................. 73

3.3.2 Evaluación y selección de la micro localización.................................................... 75

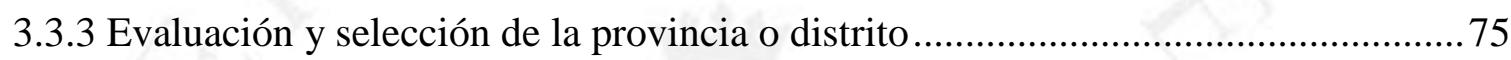

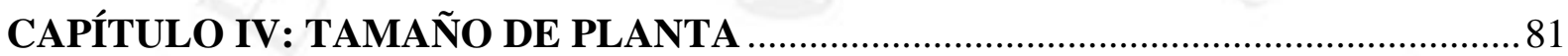

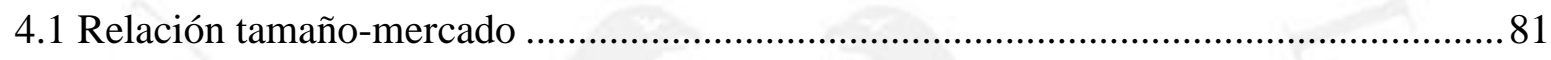

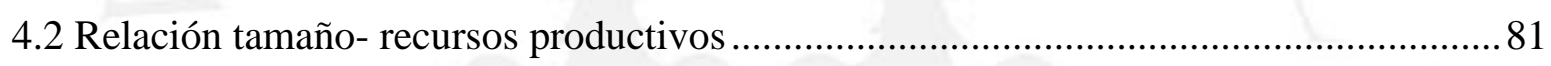

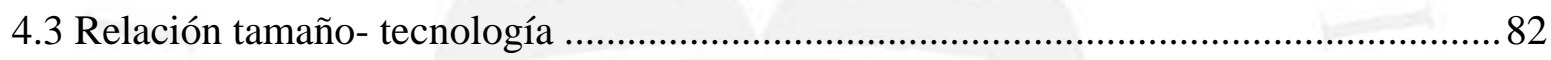

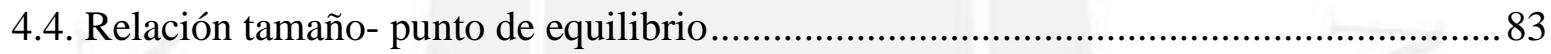

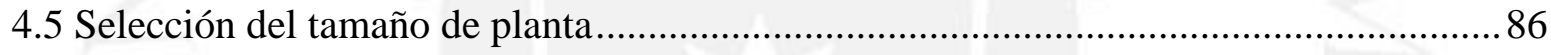

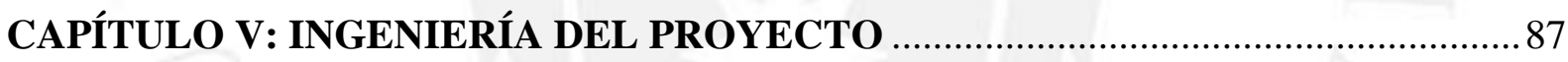

5.1 Definición del producto basada en sus características de fabricación ............................ 87

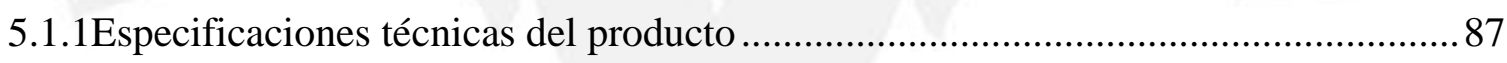

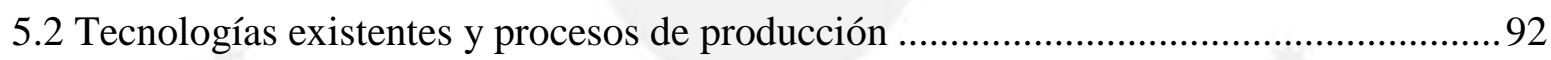

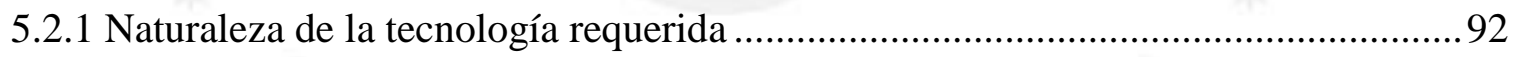

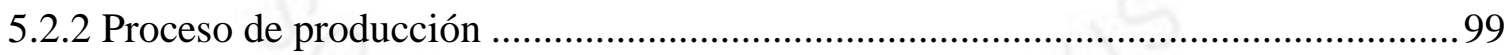

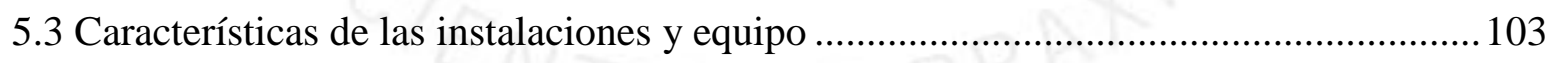

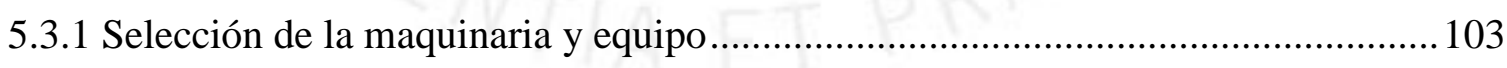

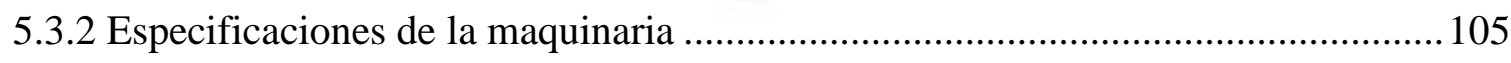

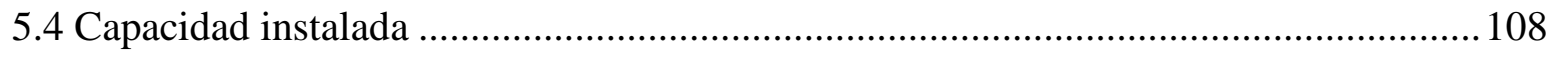

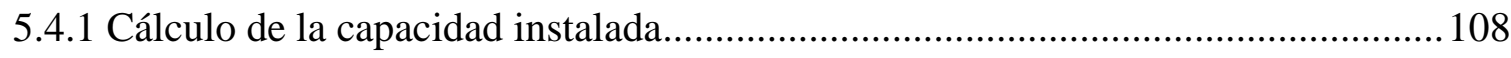

5.4.2 Cálculo detallado del número de máquinas requeridas .......................................... 109

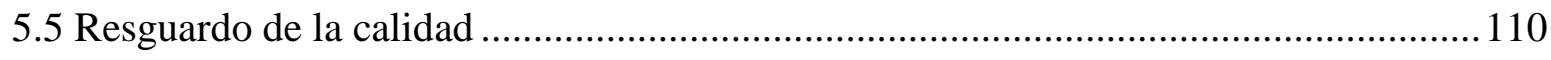

5.5.1 Calidad de la materia prima, de los insumos, del proceso y del producto .............. 110

5.5.2 Medidas de resguardo de la calidad en la producción...........................................112 


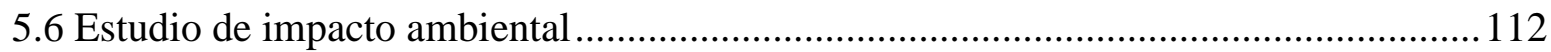

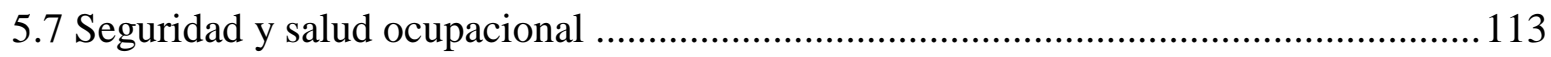

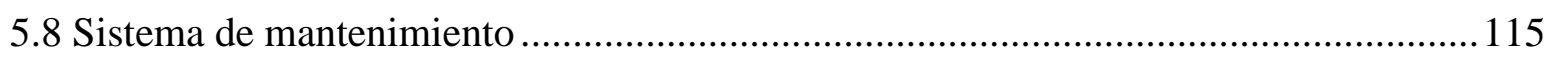

5.9 Programa de producción para la vida útil del proyecto ...........................................118

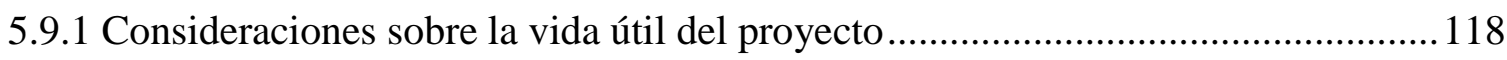

5.9.2 Programa de producción para la vida útil del proyecto..........................................119

5.10 Requerimiento de insumos, personal y servicios ...................................................... 119

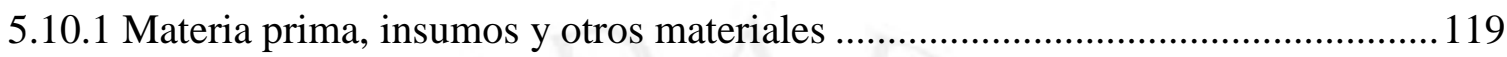

5.10.2 Servicios: energía eléctrica, agua, vapor, combustible, etc............................... 121

5.10.3 Determinación del número de operarios y trabajadores indirectos ...................... 122

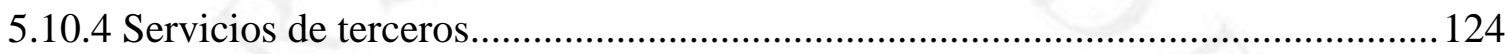

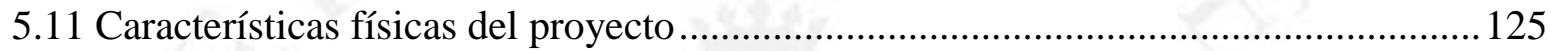

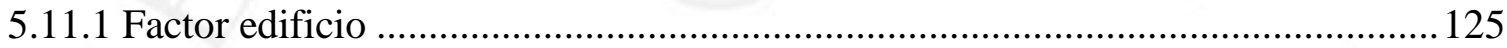

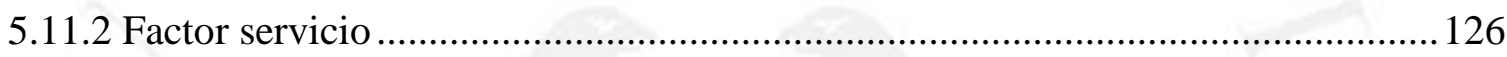

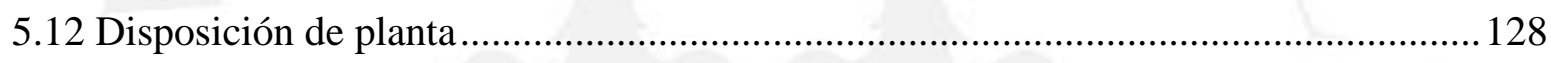

5.12.1 Determinación de las zonas físicas requeridas ................................................. 128

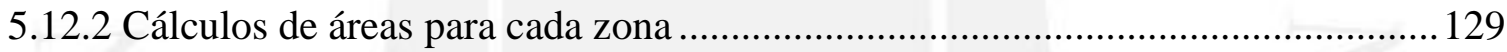

5.12.3 Dispositivos de seguridad industrial y señalización.......................................... 132

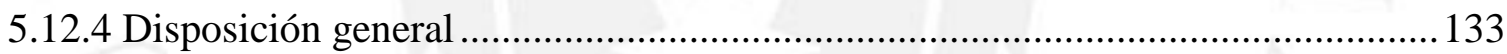

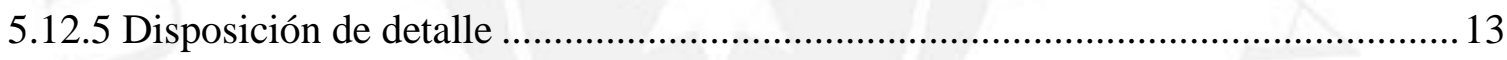

5.13 Cronograma de implementación del proyecto ..................................................... 139

CAPÍTULO VI: ORGANIZACIÓN ADMINISTRATIVA .......................................... 139

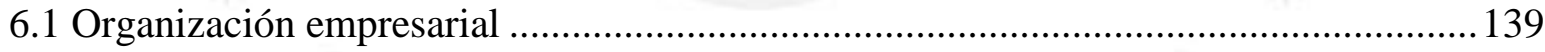

6.2 Requerimiento de personal directo, administrativo y de servicios ............................. 139

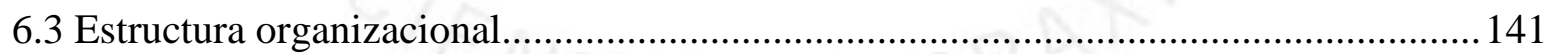

CAPÍTULO VII: ASPECTOS ECONÓMICOS Y FINANCIEROS ............................ 141

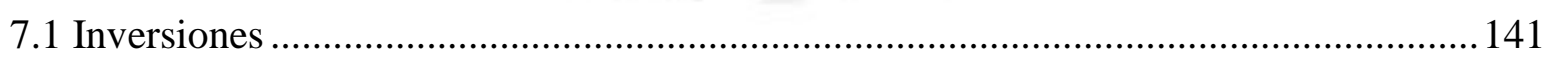

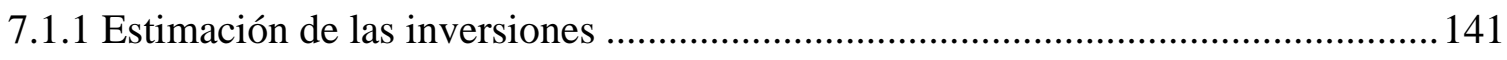

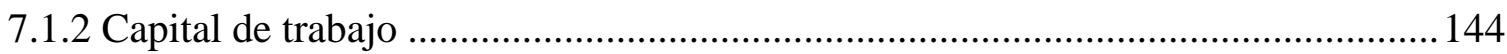

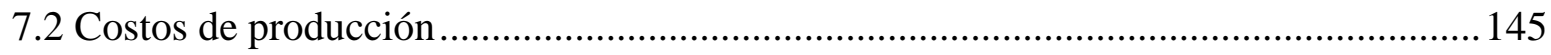

7.2.1 Costos de materias primas, insumos y otros materiales ........................................ 145

7.2.2 Costo de los servicios (energía eléctrica, agua, combustible, etc.) ........................ 147

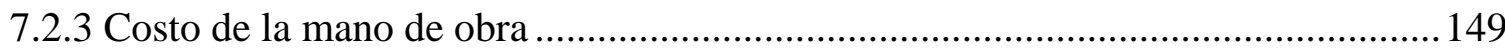




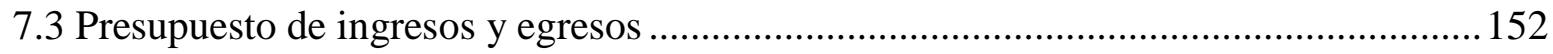

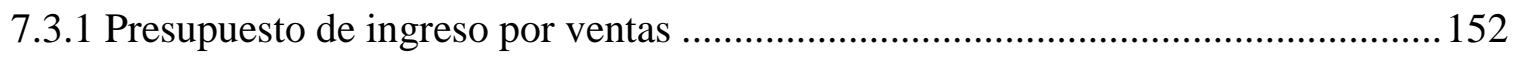

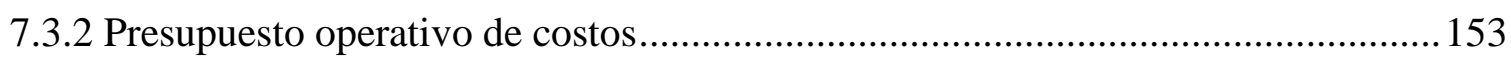

7.3.3 Presupuesto operativo de gastos administrativos (ventas, marketing, distribución,

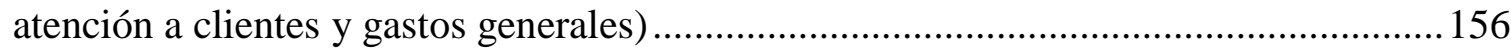

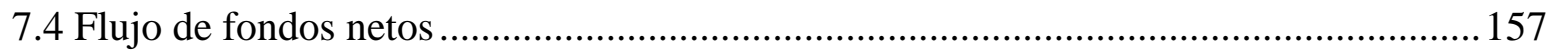

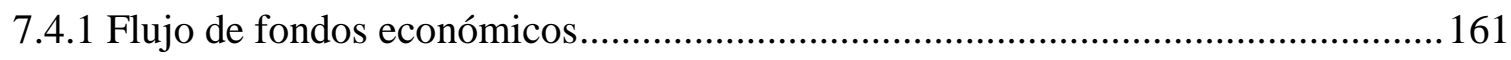

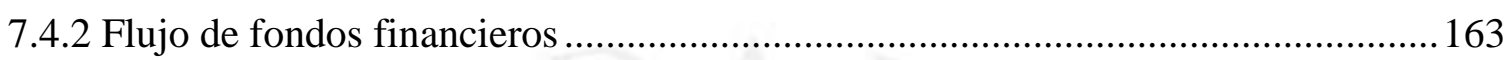

CAPÍTULO VIII: EVALUACIÓN ECONÓMICA Y FINANCIERA DEL PROYECTO

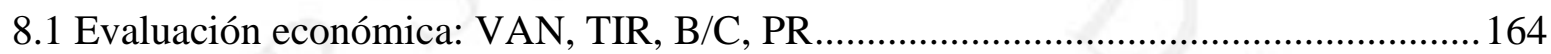

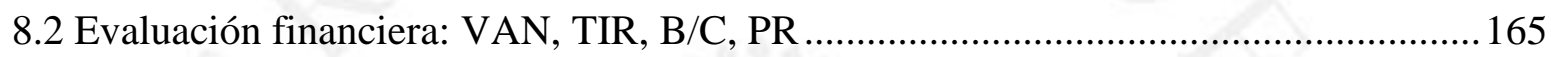

8.3 Análisis de los resultados económicos y financieros del proyecto ............................... 166

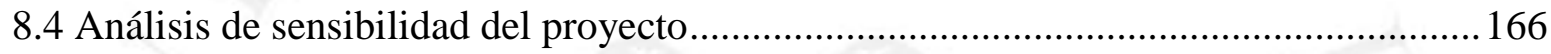

CAPÍTULO IX: EVALUACIÓN SOCIAL DEL PROYECTO …................................ 173

9.1 Identificación de las zonas y comunidades de influencia del proyecto ........................ 174

9.2 Impacto en la zona de influencia del proyecto...................................................... 174

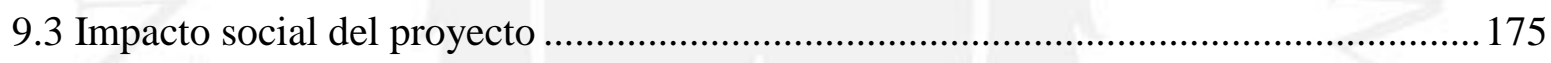

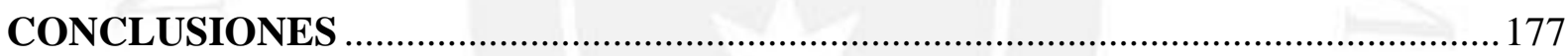

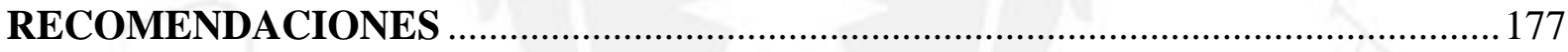

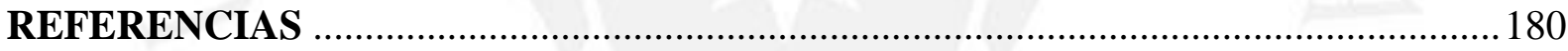

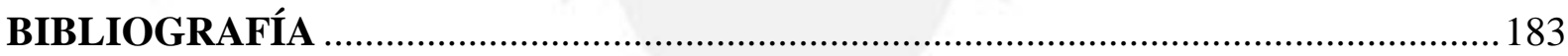

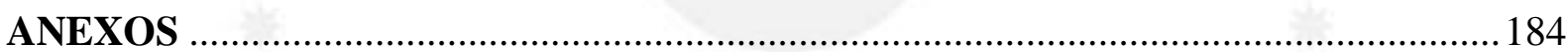




\section{ÍNDICE DE FIGURAS}

Figura 1.1: Ahorro de combustible mediante el indicador SFC (Specific Fuel Consumption) de un motor de pruebas Diesel.

Figura 1.2: Evidencia de la reducción de emisiones de CO de un motor de pruebas Diesel. .. 17

Figura 1.3: Ilustración del Proceso de Electrólisis del Agua...................................................2 23

Figura 1.4: Velocidad de Encendido de distintos combustibles...........................................24

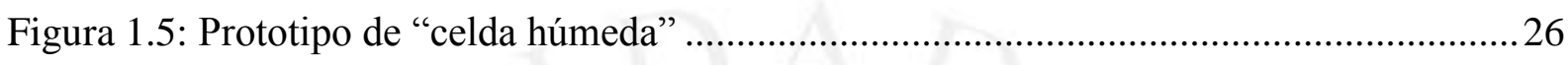

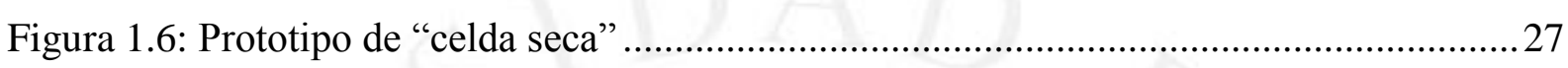

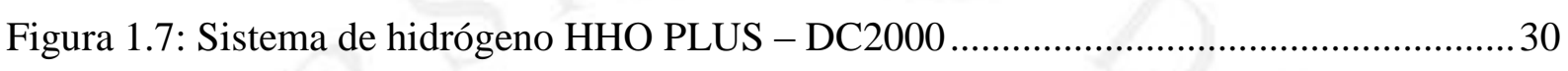

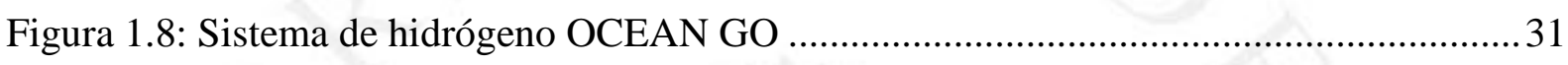

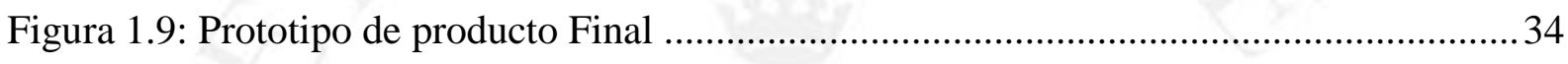

Figura 2.1: Marca de sistemas de hidrógeno vehicular ......................................................... 38

Figura 2.2: Velocidad de encendido de distintos combustibles.............................................. 39

Figura 2.3: Funcionamiento de los sistemas GLP y GNV vehicular ................................... 44

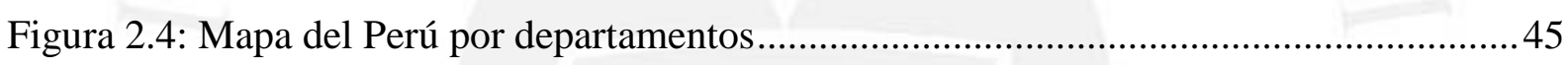

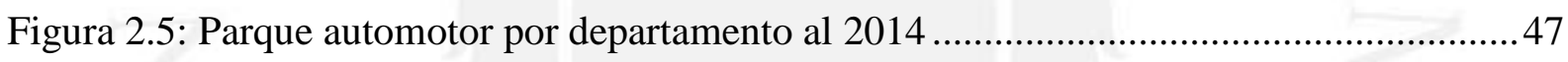

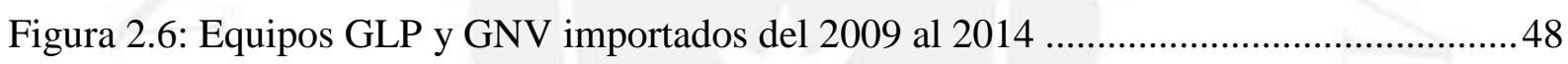

Figura 2.7: Proyección de la demanda potencial de sistemas de hidrógeno vehicular.............51

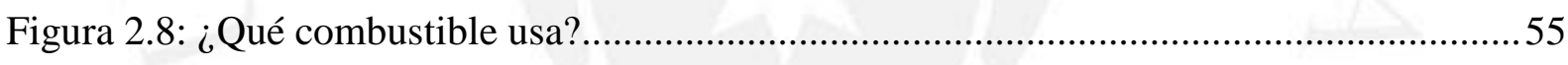

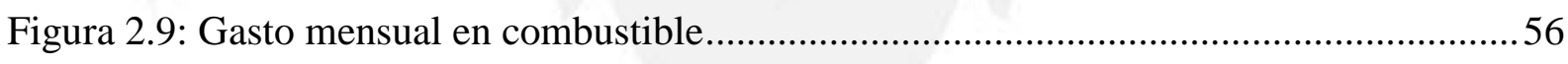

Figura 2.10: ¿Compraría un sistema que reduzca su consumo de combustible? .....................57

Figura 2.11: ¿Compraría un sistema que aumente la potencia de su vehículo? .......................58

Figura 2.12: ¿Compraría un sistema que aumente la potencia de su vehículo? ........................59

Figura 2.13: ¿Compraría un sistema que reduzca su consumo de combsutible, aumente la potencia de su vehículo y alargue el periodo de vida de su motor? .......................................60

Figura 2.14: ¿Cuánto estaría dispuesto a pagar por el sistema? .............................................. 61

Figura 2.15: ¿Qué tan interesado estaría en comprar un sistema que reducirá el consumo de combustible de su vehículo, aumentará la potencia y alargará el periodo de vida de su motor?

Figura 2.16: Sistema de hidrógeno HHO PLUS - DC2000 ............................................... 71

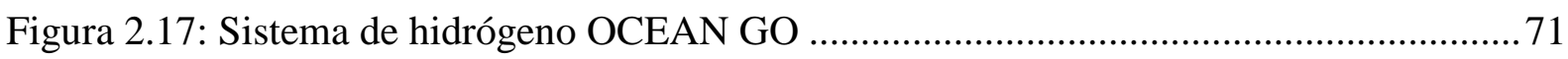


Figura 3.1: Parque automotor por províncias

Figura 3.2: M2 en zonas industriales por sectores de Lima Metropolitana.............................77

Figura 3.3: Vías y centros de dinamismo económico en Lima Metropolitana..........................78

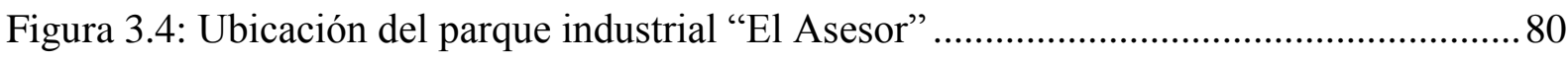

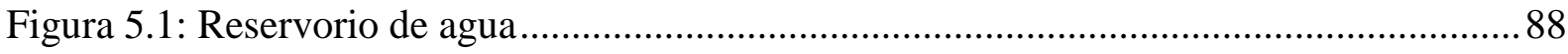

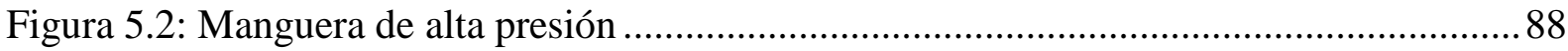

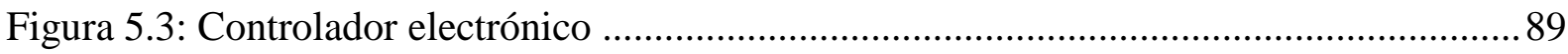

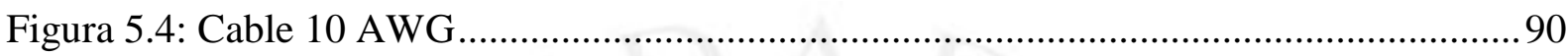

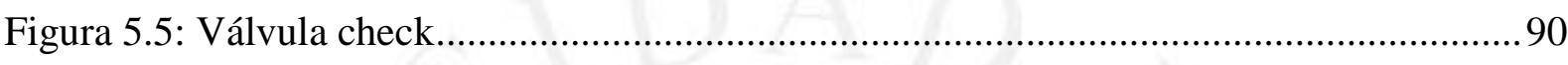

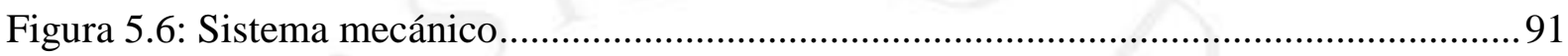

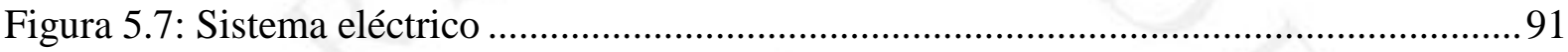

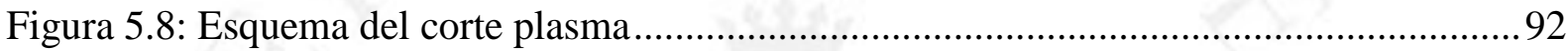

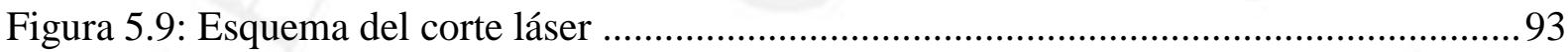

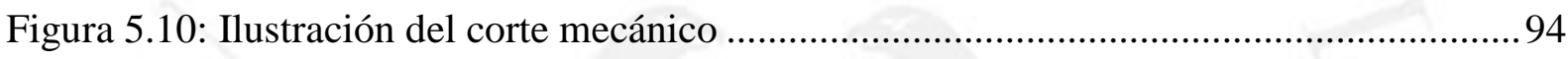

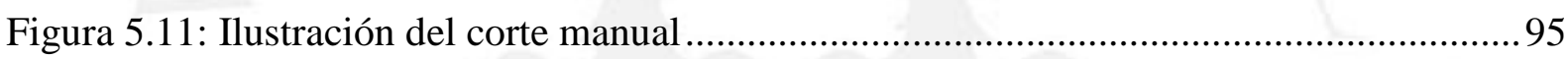

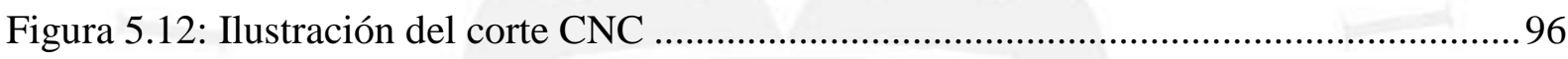

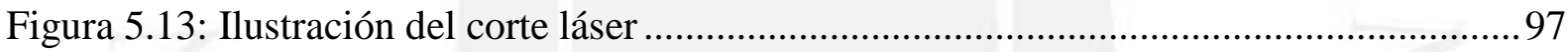

Figura 5.14: Ilustración de la máquina de prensa hidráulica .................................................98

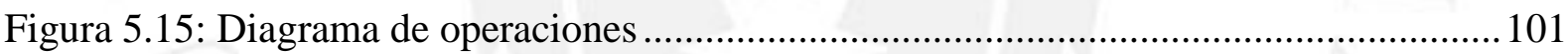

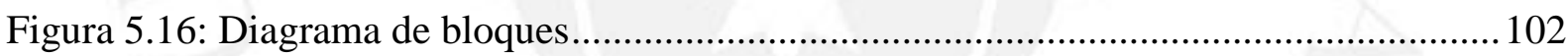

Figura 5.17: Máquina de corte a láser modelo SW-200HZ fabricada por la compañía

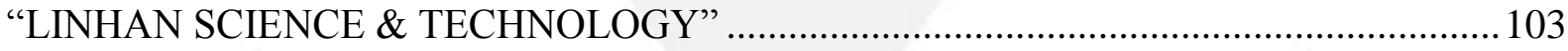

Figura 5.18: Máquina de corte plasma modelo SW-1530S fabricada por la compañía

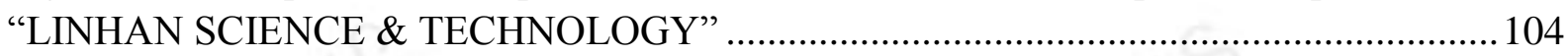

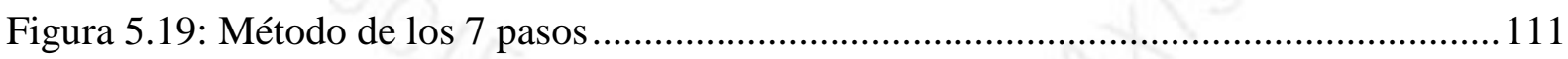

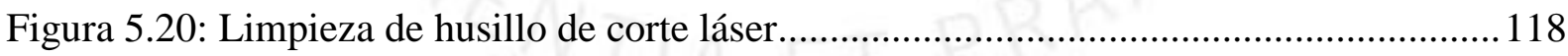

Figura 5.21: Representación de un rombo de la tabla relacional......................................... 134

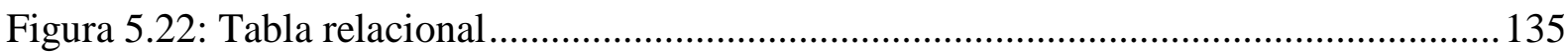

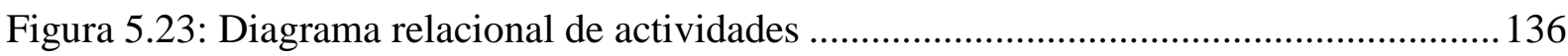

Figura 5.24: Plano de planta de producción de celdas de electrólisis (1er piso) .................... 136

Figura 5.25: Plano de planta de producción de celdas de electrólisis (2do piso) .....................136

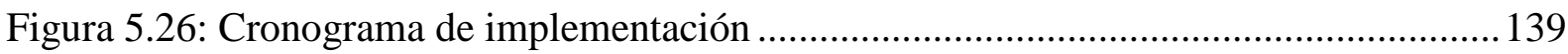

Figura 6.1: Organigrama de la estructura administrativa de la planta de producción de celdas de electrólisis 


\section{ÍNDICE DE TABLAS}

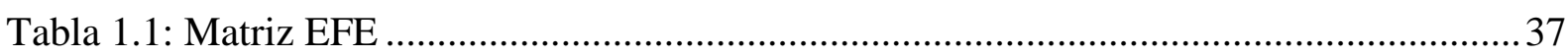

Tabla 2.1: Distribución del parque automotor por departamento al 2014 ...............................46

Tabla 2.2: Equipos GLP y GNV importados del 2009 al 2012 ............................................ 48

Tabla 2.3: Proyección de la demanda potencial de sistemas de hidrógeno vehicular ...............50

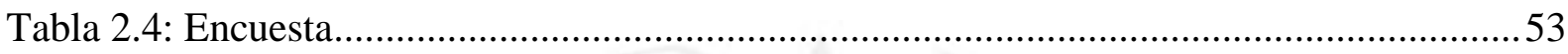

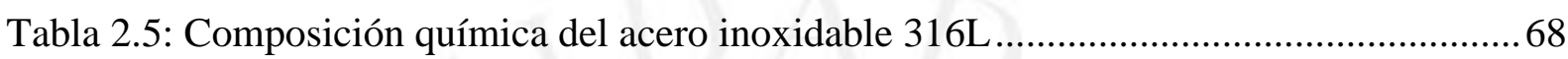

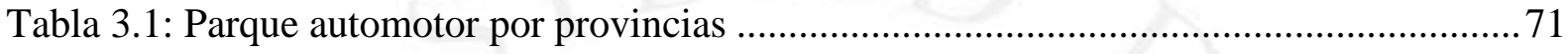

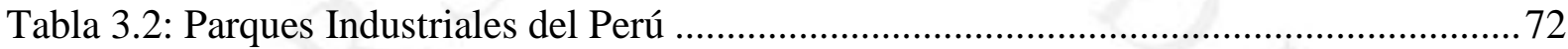

Tabla 3.3: Codificación de los factores de localización ........................................................... 73

Tabla 3.4: Reglas de calificación en matriz de enfrentamiento para macro localización .........74

Tabla 3.5: Matriz de enfrentamiento para macro localización .................................................. 74

Tabla 3.6: Escala de calificación de los factores de macro localización ..................................74

Tabla 3.7: Ranking de factores para determinar macro localización ….................................. 75

Tabla 3.8: Costo por $\mathrm{m} 2$ en zonas industriales por sectores de Lima Metropolitana...............76

Tabla 3.9: M2 en zonas industriales por sectores de Lima Metropolitana .............................. 76

Tabla 3.10: Escala de calificación de los factores de macro localización................................78

Tabla 3.11: Ranking de factores para determinar macro localización ....................................79

Tabla 3.12: Ranking de factores para determinar macro localización ....................................79

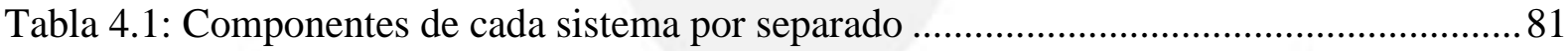

Tabla 4.2: Proveedores para los 3 componentes más importantes del "Sistema de hidrógeno

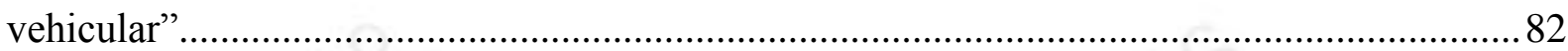

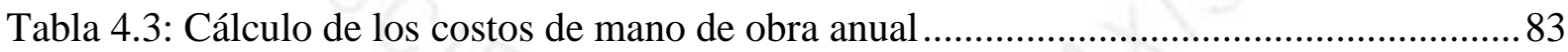

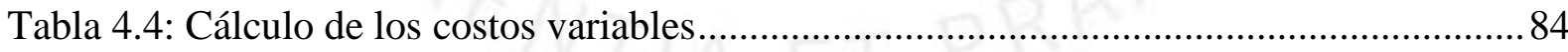

Tabla 4.5: Estimación de los costos fijos totales anuales ..................................................... 85

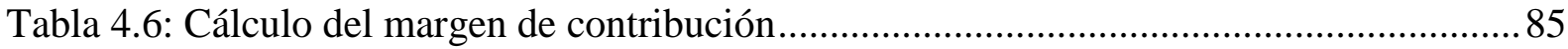

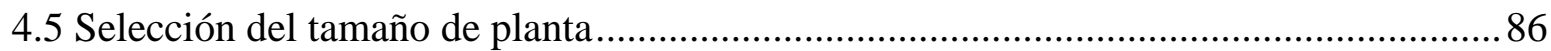

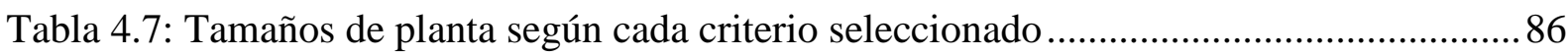

Tabla 5.1: Composición química del acero inoxidable 316L ............................................... 87

Tabla 5.2: Características de la máquina de corte láser modelo SW-200HZ ........................ 105

Tabla 5.3: Especificaciones técnicas de la máquina de corte láser modelo SW-200HZ ........ 106

Tabla 5.4: Características de la máquina de corte plasma modelo SW-1530S ..................... 107 
Tabla 5.5: Especificaciones técnicas de la máquina de corte plasma modelo SW-1530S ..... 108

Tabla 5.6: Cálculo de número de máquinas ..................................................................... 109

Tabla 5.7: Requisitos legales por categoría de impacto ambiental...................................... 113

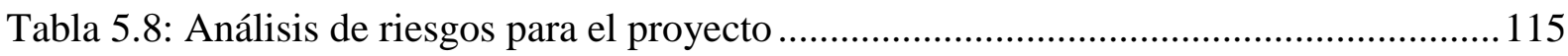

Tabla 5.9: Cuadrillas de mantenimiento correctivo y reactivo............................................. 116

Tabla 5.10: Procedimiento de implementación de mantenimiento preventivo ....................... 117

Tabla 5.11: Plan de producción del proyecto ….....................................................................119

Tabla 5.12: Plan de requerimiento de materia prima........................................................... 120

Tabla 5.13: Plan de requerimiento de insumos directos ..................................................... 121

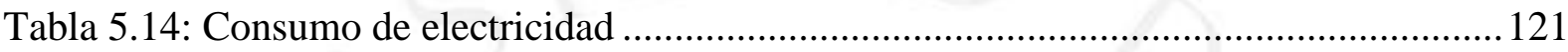

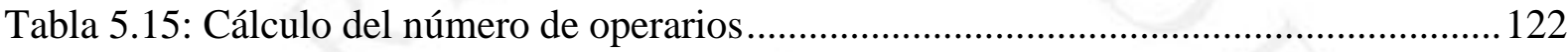

Tabla 5.16: Mano de obra directa e indirecta para la planta.................................................. 123

Tabla 5.17: Trabajadores administrativos requeridos para el proyecto ............................... 124

Tabla 5.18: Cálculo del coeficiente de evolución....................................................................... 129

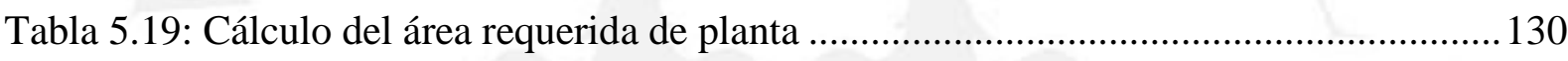

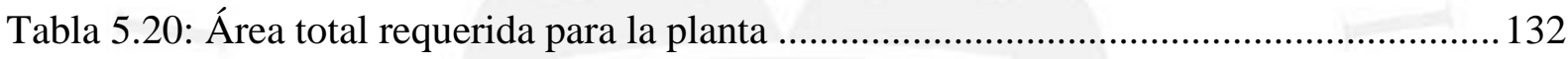

Tabla 5.21: Colores empleados en señales de seguridad................................................... 133

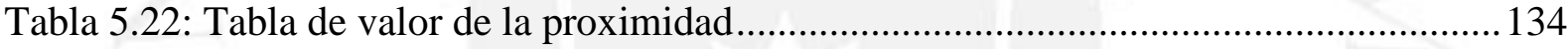

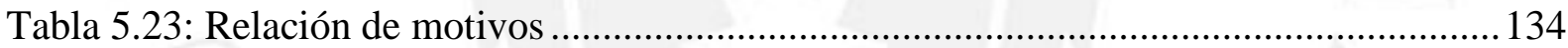

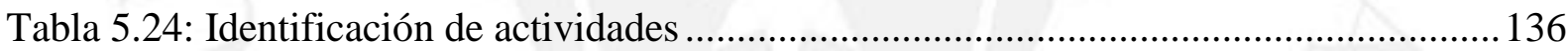

Tabla 6.1: Trabajadores requeridos para el proyecto ....................................................... 139

Tabla 7.1: Relación de inversiones en máquinas y equipos fabriles ................................... 141

Tabla 7.2: Relación de inversiones en infraestructura........................................................ 142

Tabla 7.3: Inversión en equipos e implementos de oficina ….............................................. 143

Tabla 7.4: Relación de inversiones en activos intangibles .................................................... 143

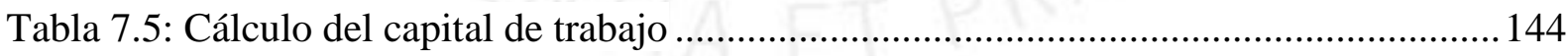

Tabla 7.6: Cálculo de la inversión total ................................................................................... 145

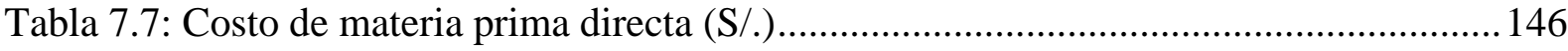

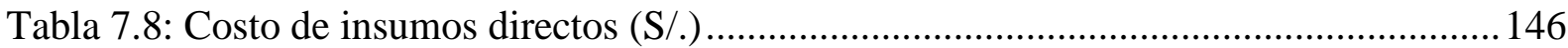

Tabla 7.9: Tarifa MT3 de energía eléctrica ........................................................................ 147

Tabla 7.10: Costo de servicios consumidos y contratados (S/.) …...................................... 148

Tabla 7.11: Remuneración de la mano de obra directa (S/.) ................................................. 149

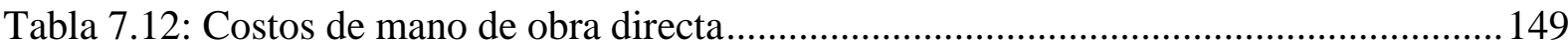


Tabla 7.13: Remuneración de la mano de obra indirecta (S/.) .......................................... 150

Tabla 7.14: Costo de mano de obra indirecta (S/.) ........................................................... 150

Tabla 7.15: Remuneración del personal administrativo (S/.) ........................................... 151

Tabla 7.16: Sueldos y salarios del personal administrativo................................................ 152

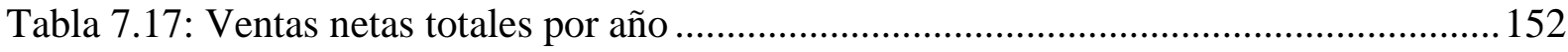

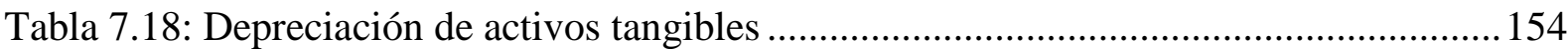

Tabla 7.19: Depreciación de activos intangibles ................................................................. 155

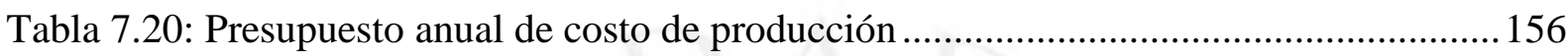

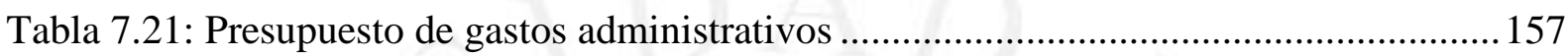

Tabla 7.22: Cálculo de costo promedio ponderado de capital.............................................. 157

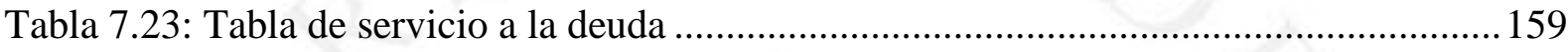

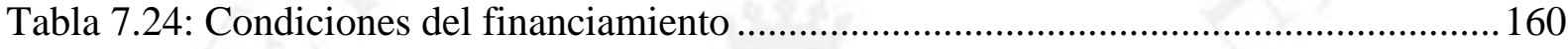

Tabla 7.25: Estados de resultados para la vida útil del proyecto........................................... 161

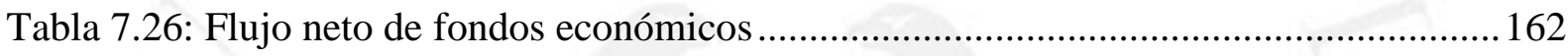

Tabla 7.27: Flujo neto de fondos financieros ...................................................................... 163

Tabla 8.1: Determinación del valor actual neto económico del proyecto .............................. 164

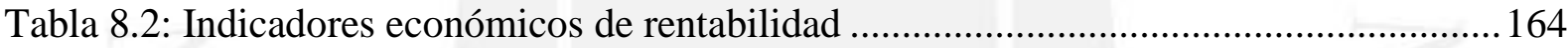

Tabla 8.3: Determinación del valor actual neto financiero del proyecto.............................. 165

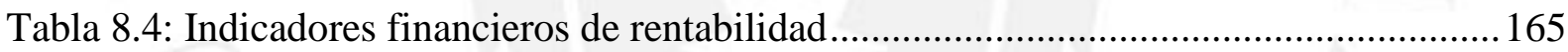

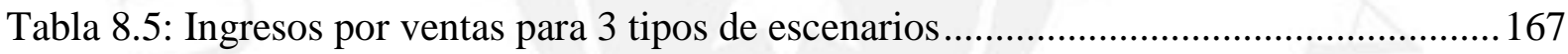

Tabla 8.6: Estados de resultados para la vida útil del proyecto - escenario optimista ........... 168

Tabla 8.7: Flujo neto de fondos económicos - escenario optimista ..................................... 169

Tabla 8.8: Indicadores económicos de rentabilidad - escenario optimista ............................ 169

Tabla 8.9: Estados de resultados para la vida útil del proyecto - escenario medio ................ 170

Tabla 8.10: Flujo neto de fondos económicos - escenario medio ........................................... 171

Tabla 8.11: Indicadores económicos de rentabilidad - escenario medio ................................ 171

Tabla 8.12: Estados de resultados para la vida útil del proyecto - escenario pesimista ......... 172

Tabla 8.13: Flujo neto de fondos económicos - escenario pesimista ..................................... 173

Tabla 8.14: Indicadores económicos de rentabilidad - escenario medio ................................ 173

Tabla 9.1: Evaluación social del proyecto......................................................................... 175 


\section{RESUMEN EJECUTIVO}

Lima Metropolitana es la ciudad más contaminada de Sudamérica. La antigüedad de su parque automotor y del sistema de transporte ha ocasionado que el aire que respira su población sea nocivo, lo cual se refleja en la cantidad de enfermedades respiratorias de las que sufre su población. (El Comercio, 2014)

Numerosas investigaciones científicas describen cómo la adición de gas hidrógeno como combustible dual a los ciclos de combustión Diesel y Otto logra elevar la eficiencia de la combustión reduciendo las emisiones contaminantes, a la vez que se eleva la performance del motor, generando ahorro de combustible y aumento de la potencia.

El presente estudio evalúa la implementación de una fábrica de celdas de electrólisis, el equipo principal para conformar un sistema de hidrógeno vehicular. Estos dispositivos se adicionan al automóvil para obtener los resultados anteriormente descritos.

En el estudio de mercado se establece y define el producto, sus propiedades, y se segmenta el mercado. Además, se calcula la demanda objetivo que se espera satisfacer.

En la sección de estudios técnicos, se analiza la disponibilidad de los insumos necesarios para la elaboración del producto, también se determina la ubicación ideal de la planta analizando diferentes factores de localización. Y finalmente se determina el tamaño de planta teniendo en cuenta si existen restricciones establecidas por los insumos, el mercado, la inversión, el financiamiento o el punto de equilibrio.

En la sección de ingeniería del proyecto - análisis del proceso, se define técnicamente el producto, se establece el método de producción y tecnología a utilizar, asimismo se determina la capacidad instalada, el posible impacto ambiental y las técnicas aplicadas para lograr la mejor productividad en las operaciones.

En la sección de inversión se determinan la cantidad de inversión (propia y financiada) y en qué se va a emplear. Es decir, se presenta el estimado de la inversión fija tangible, inversión fija intangible y el capital de trabajo, lo que permite dar una aproximación de los requerimientos financieros del proyecto. 
En la sección de presupuestos de ingresos y egresos, se muestran y calculan todos los presupuestos propiamente dichos necesarios para la marcha del proyecto, así como también los estados financieros.

Finalmente, en cuanto a la sección de análisis económico y financiero, se elaboran estados financieros proyectados y se realiza la evaluación económica y financiera que determinará la viabilidad del proyecto en relación al nivel de rentabilidad pronosticado. 


\section{EXECUTIVE SUMMARY}

Lima is the most polluted city in South America. The age of its fleet and transport system has caused the air its population breathe to be harmful, which is reflected in the number of respiratory diseases suffered by them. El Comercio (2014)

Numerous scientific researches describe how the addition of hydrogen gas as a dual fuel in Diesel and Otto combustion cycles help achieve improvements in efficiency of combustion, reducing pollutant emissions, while the engine performance rises, leading to fuel savings and increased power.

This study evaluates the implementation of a factory for manufacturing electrolysis cells, which are to main equipment of vehicular hydrogen systems. These devices are fitted into cars to obtain the results described above.

The market study defines the product, its properties, and shows the market target. In addition, the expected demand is calculated.

In the technical studies section, the availability of technological inputs and raw materials necessary for product development is analyzed. The ideal location of the plant is also determined. Finally, the productive capability is determined by analyzing some restrictions established by inputs, market, investments, financing or breakeven.

In the engineering section, the product is technically defined and the production line, it's capability and technology is established. Also, the environmental impact and the techniques used to achieve the best productivity are determined.

In the investment section, the amount of financial resources (own and financed) are determined. Furthermore, the estimated tangible fixed investment, fixed investment and intangible working capital are determined in order to estimate the financial requirements of the project.

In the budgeting section, incomes and expenses and all budgets necessary are determined for the proper progress of the project, as well as the financial statements.

Finally, in the section of economic and financial analysis, financial statements are projected in order to determine the feasibility of the project in relation to the level of profitability forecast is made. 


\section{CAPÍTULO I: PLAN DE INVESTIGACIÓN}

\subsection{Problemática de investigación}

\subsubsection{Presentación del tema}

El tema a desarrollar en este trabajo es el estudio preliminar para la instalación de una planta de fabricación de celdas de electrólisis.

La relevancia de este trabajo como proyecto de investigación en ingeniería industrial reside en que se aplicarán las distintas metodologías aprendidas a lo largo de las asignaturas propias de la carrera para poder entender investigaciones y bibliografía disponibles para diseñar un producto competitivo en el mercado con aplicaciones versátiles, comprendiendo todas sus características físico-químicas como sus atractivos comerciales; además, de poder diseñar una línea de producción óptima para la fabricación y posterior comercialización de las celdas de electrólisis.

El presente trabajo de investigación se elabora en base a la necesidad latente de las personas de ahorrar dinero en el consumo de combustible, mejorar el vehículo que manejan y reducir la contaminación del medio ambiente. Por lo cual se planea desarrollar un posicionamiento frente al público de taxistas y personas que buscan reducir sus gastos mensuales teniendo un producto confiable y de alta calidad que sea ofrecido, instalado y mantenido con un servicio que asegure la satisfacción del cliente.

A nivel mundial viene surgiendo una nueva tecnología, los sistemas de hidrógeno vehicular, la cual cuenta con los beneficios de generar un ahorro de combustible, aumentar la potencia del motor y reducir las emisiones de gases contaminantes de los vehículos ( Yilmaz, A., 2010) 
Figura 1.1

Ahorro de combustible mediante el indicador SFC (Specific Fuel Consumption) de un motor de pruebas Diesel.

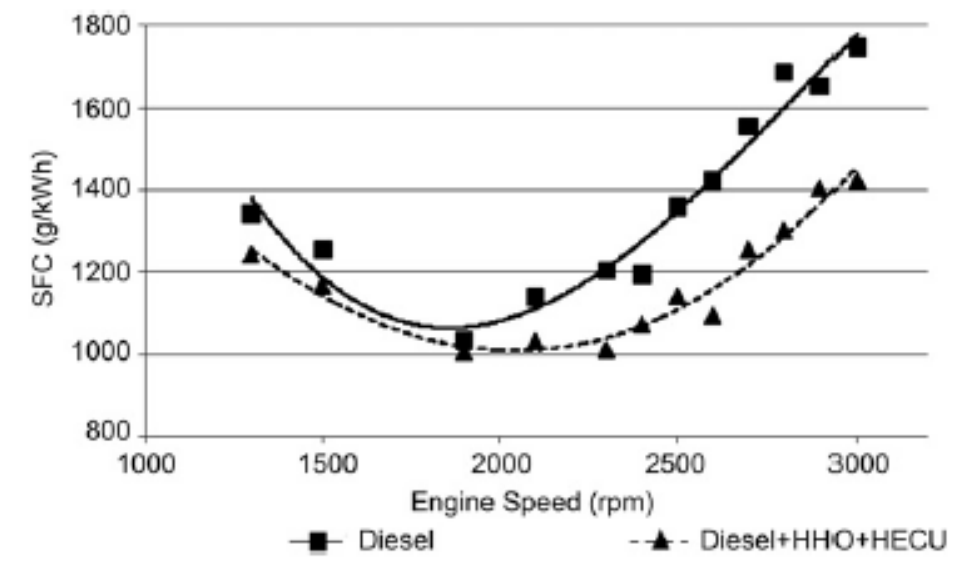

Fuente: Yilmaz, A., (2010)

Figura 1.2

Evidencia de la reducción de emisiones de CO de un motor de pruebas Diesel.

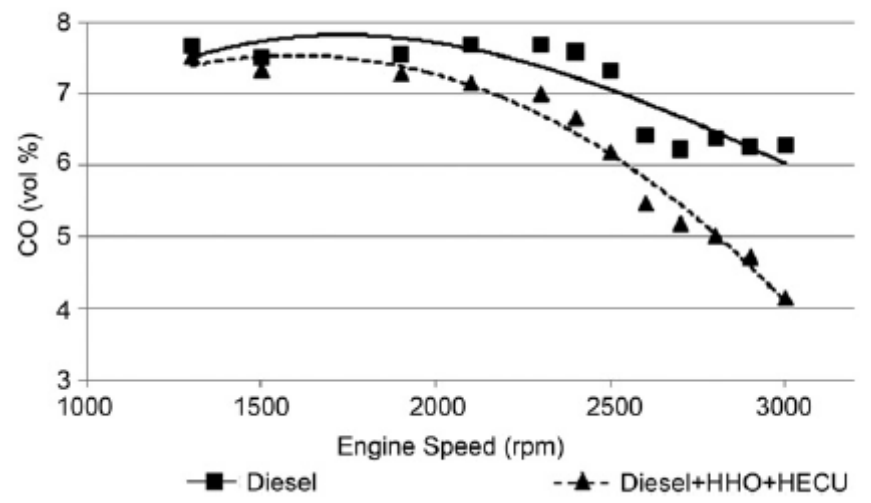

Fuente: Yilmaz, A., (2010)

La parte central de estos sistemas es la celda de electrólisis, encargada de disociar el agua destilada en hidrógeno y oxígeno, una mezcla de gases, combustible y comburente, que al ser inyectada al cilindro mediante la admisión de aire, enriquece la mezcla de combustible y genera los beneficios anteriormente mencionados. 
Se ha visto por conveniente producir el tipo de celda conocido como celda seca o "Dry Cell”, puesto que es más segura y eficiente.

Actualmente sólo una empresa dedica sus recursos a introducir este sistema al mercado nacional, por lo que se estaría tratando de un mercado nuevo y latente, de poca competencia y altas posibilidades de alcanzar un buen posicionamiento logrando una penetración de mercado y una operación comercial para lograr que el proyecto resulte rentable.

Más aún, existen menos de 4 empresas formales en la región sudamericana dedicadas a la fabricación de este producto, generalmente, estas empresas trabajan importando estos sistemas, por lo que producirlos sería una ventaja competitiva en el mercado peruano debido al liderazgo de precios gracias a la ausencia de gastos logísticos internacionales y ausencia de pago de aranceles; teniendo la ventaja de poder abastecer la demanda local de manera ágil.

El mercado de Lima metropolitana será la zona de introducción del producto, buscando ampliar la extensión de cobertura de mercado a nivel nacional y posteriormente a nivel internacional.

Actualmente, este producto es ofrecido en 20 países como Grecia, España, Estados Unidos, Latvia, Estonia, Colombia, Brasil, Portugal, entre otros; por fabricantes que tienen operaciones de más de 6 años como los productores de los sistemas de las marcas Drive H20, HHO PLUS, Ocean Go, entre otros.

Por todo lo mencionado se llega a la conclusión que la fabricación de celdas de electrólisis seca para formar parte de un sistema de hidrógeno vehicular es una buena idea de negocio para desarrollar.

EL producto propuesto para el estudio se define de la siguiente manera:

- Producto básico:

Celda de electrólisis seca para agua destilada que genera ahorro en consumo de combustible para carros a gas. 
- Producto real:

Celda de electrólisis seca de 4 semi celdas en paralelo, cada una compuesta por 6 placas en serie, de configuración - $\mathrm{NNNN}+$, para funcionamiento de $13.6 \mathrm{~V}$ a $14.0 \mathrm{~V}, 8 \mathrm{~A}$ y de flujo de gas HHO de 1 litro por minuto.

Tendrá tapas laterales transparentes de acrílico.

El sistema será empacado en una caja de cartón corrugado con diseños y figuras explicativos de la tecnología. Será de marca H2PRO.

- Producto aumentado:

Sistema de hidrógeno vehicular H2PRO, que servirá para reducir el consumo de combustible, aumentar la potencia del motor y reducir las emisiones de gases nocivos para el medio ambiente.

Las ventas serán al por mayor a través de una red de distribuidores por lo que el servicio de instalación será realizado por estos. Sin embargo, se brindará el servicio de capacitación a los distribuidores para realizar una correcta instalación, mantenimiento y ofrecimiento comercial del sistema H2PRO, además del transporte de los bienes de la fábrica a los talleres. Asimismo, se dará seguimiento post venta a toda venta que se realice para asegurar la adecuada instalación de los sistemas como garantía por defectos de fábrica de un año.

El CIIU correspondiente al negocio sería 29290, correspondiente a la denominación "FAB. OTRO TIPO MAQUIN. USO ESPECIAL."

\subsection{Objetivos de la investigación}

\section{Objetivo general:}

El objetivo principal de la presente investigación es determinar la pre viabilidad técnica, económica, financiera y social de la instalación de una planta para la fabricación de celdas de electrólisis.

\section{Objetivos específicos:}

Los objetivos específicos de la presente investigación son: 
- Determinar la pre viabilidad técnica de la instalación de una planta para la fabricación de celdas de electrólisis.

- Determinar la pre viabilidad económica, financiera y comercial de la instalación de una planta para la fabricación de celdas de electrólisis.

- Determinar la pre viabilidad social de la instalación de una planta para la fabricación de celdas de electrólisis.

\subsection{Justificación de la Investigación}

\subsubsection{Técnica}

Existen tres tecnologías para producir celdas de electrólisis: procesos automatizados, procesos semi-automatizado y el proceso manual. Se utilizará el sistema semi-automatizado ya que se trabajará los operarios de corte con máquinas $\mathrm{CNC}$ (control numérico computarizado) y las operaciones de ensamble serán hechas a mano. El control de calidad y la carga, descarga y movilización de materias primas, productos en proceso y productos terminados serán llevados a cabo por los mismos operarios.

Existe personal altamente calificado la utilización de las máquinas de corte $\mathrm{CNC}$, y su mantenimiento. Por otro lado, no se necesita mayor instrucción para las operaciones de ensamble o transporte.

Disponibilidad de maquinarias y equipos de procedencia china, apropiado para la producción de celdas de electrólisis. Es viable adquirirlas ya que el Perú es un país abierto al comercio internacional y posee un tratado de libre comercio con dicho país.

La materia prima a utilizar para este proyecto son acero inoxidable SAE 316L, planchas de caucho de $1 \mathrm{~mm}$ de espesor y planchas de acrílico de $10 \mathrm{~mm}$ de espesor. Estas pueden ser fácilmente obtenidas en el mercado limeño ya que existen proveedores de estos insumos a precios que permiten tener un alto margen.

\subsubsection{Económica}

Desde la perspectiva económica, se debe decir que el Perú está creciendo económicamente de manera continua (INEI, 2015), por lo que es un mercado interesante en el cual invertir. 
Además, los precios de los combustibles son elevados con respecto a los de la región, por lo que un producto que permita reducir el gasto de este insumo sería aceptado por el mercado.

Haciendo una proyección preliminar, al necesitarse poca materia prima, mano de obra poco especializada y en general los costos de fabricación son bajos, por lo que se podría tener un alto margen de ganancias. Por esto último se podría decir preliminarmente que esta es una atractiva idea de negocio.

\subsubsection{Social}

El proyecto a investigar tiene un impacto social positivo, ya que se crearán puestos de trabajo, lo que conlleva a aumentar el bienestar social. Por otro lado, un beneficio que tiene la instalación de estos equipos en carros movilizados por motores a combustión interna es que se reducen las emisiones de gases contaminantes, por lo que se tiene un impacto medio ambiental al poder funcionar los carros sin contaminar a sobremanera el medio ambiente, además de generar ahorro en consumo de combustible lo que beneficiará la economía de las personas y la rentabilidad de los taxistas.

Por otro lado, la instalación de esta fábrica aportaría a uno de los objetivos del país que extender el sector industrial.

\subsection{Hipótesis de trabajo}

La hipótesis central del presente trabajo es que la instalación de una planta de fabricación de celdas de electrólisis es factible desde la perspectiva económica, financiera, tecnológica y social.

\subsection{Marco referencial de la investigación}

\subsubsection{Marco referencial}

Las investigaciones realizadas referidas al tema tomadas en consideración son:

- Klinge Ambrosini, Franko (2000) "Estudio de pre-factibilidad para la implementación de una empresa de sistemas duales de GLP en vehículos a gasolina." Tesis en ingeniería industrial. Lima: Universidad de Lima. Similitudes: Contiene un estudio relacionado a la aplicación técnica y comercial de un negocio relacionado con tecnologías para aumentar la economía del 
uso del automóvil. Diferencias: Este estudio se basa en la instalación de una tecnología distinta a la estudiada en el presente trabajo, y se desarrolla en otro contexto cronológico.

- Peña Valladares, Carlos Eduardo (2011) "Estudio preliminar para la instalación de una planta metalmecánica para la fabricación de tubos casing para la industria petrolera "Seminario I de ingeniería industrial. Lima: Universidad de Lima. Similitudes: se trata de una empresa con procesos de transformación física de metales. Diferencias: El producto final es distinto y, más aún, es comprendido por una mayor cantidad de materias primas.

- Córdova Ramos, Henry (2012) "Implementación de una planta de fabricación y comercialización de electrodos "Tesis en ingeniería industrial. Lima: Universidad de Lima. Similitudes: En este trabajo se presentan procesos de transformación física de metales. Diferencias: Los insumos y el producto final son distintos.

- Campos Morote, Marco Antonio (2006) "Metodología para la implantación eficaz de un sistema de gestión de la calidad en una mediana empresa del sector metalmecánico" Tesis en ingeniería industrial. Lima: Universidad de Lima. Similitudes: El tema central es el proceso metalmecánico y se ven temas calidad asociados al proceso y gestión del proceso y negocio. Diferencias: Se trata de una mejora, a diferencia del presente trabajo que es un estudio preliminar para la instalación de una planta y se ven temas de calidad.

\subsubsection{Marco conceptual}

Las celdas de electrólisis son equipos que cumplen la función de disociar el agua $(\mathrm{H} 2 \mathrm{O})$ en hidrógeno $(\mathrm{H} 2)$ y oxígeno $(\mathrm{O} 2)$ mediante la aplicación de tensión eléctrica a este fluido. Este proceso es conocido como electrólisis: 
Figura 1.3

Ilustración del Proceso de Electrólisis del Agua.

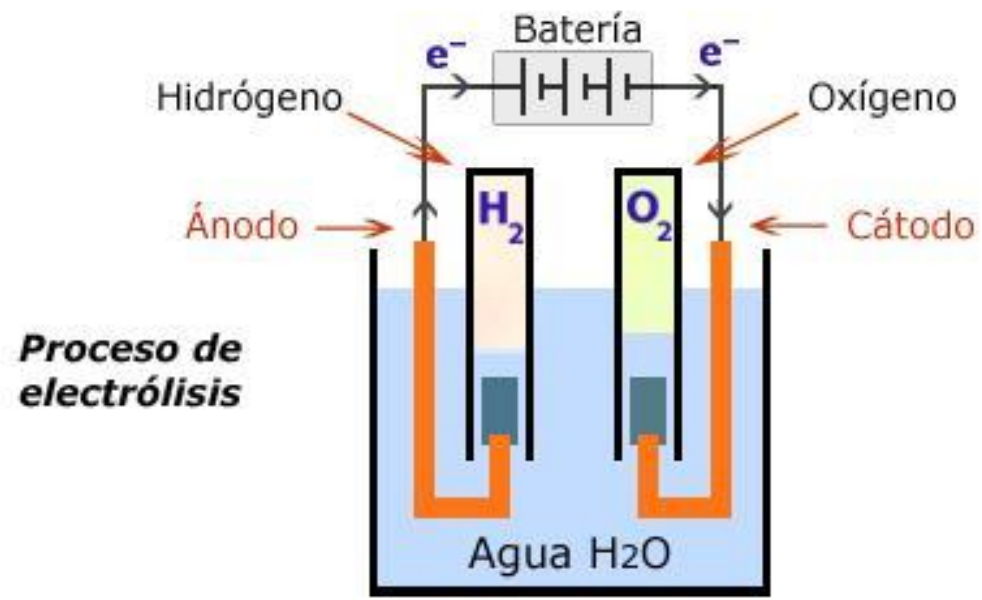

Fuente: Campi, n.d., (2012)

Un campo de aplicación de este dispositivo es el parque automotriz. Dado que los productos de la electrólisis del agua son combustible (hidrógeno) y comburente (oxígeno), se pueden añadir a la mezcla de combustible, mediante su inserción por la admisión de aire del motor teniendo los siguientes beneficios:

- Combustión más completa del combustible fósil:

El hidrógeno facilita que se desarrolle una combustión que tiende a ser más completa, por parte del combustible fósil.

En los motores Otto, la bujía emite un arco eléctrico y enciende el combustible. Dicho encendido no es homogéneo y muchas veces no se llega a producir una combustión totalmente completa. El hidrógeno, al ser un combustible mucho más volátil, se enciende más rápido que la gasolina y es esta energía, sumada a la de la chispa, que permite que se desarrolle una explosión más completa. 
Figura 1.4

Velocidad de Encendido de distintos combustibles.

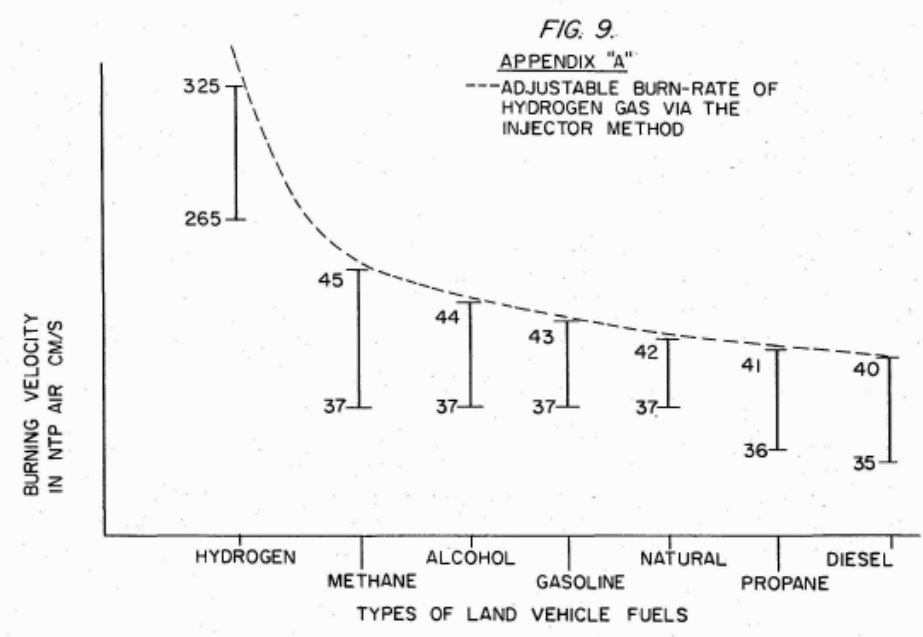

Fuente: Meyer S., (1991)

\section{Chispa $\rightarrow$ Explosión de combustible fósil}

La reacción en cadena producida es de la siguiente manera:

Chispa $\rightarrow$ Explosión del Hidrógeno $\rightarrow$ Explosión de combustible fósil.

- Aumento de la potencia:

Una combustión completa libera una mayor cantidad de energía que una incompleta (ej.: combustión del propano, completa: $890 \mathrm{kj} / \mathrm{mol}$, incompleta: $769.5 \mathrm{kj} / \mathrm{mol}$ ). Siendo uno de los beneficios descritos el desarrollar una combustión más completa por parte del combustible, se entiende por extensión que se libera una mayor cantidad de energía por parte del combustible lo cual se percibe en un aumento de la potencia a la hora de conducir. Además, el hidrógeno per se aporta energía a la combustión.

- Reducción de emanación de gases contaminantes:

El proceso de combustión completa de gasolina tiene como producto vapor de agua (H2Ov) y CO2:

$$
\text { Combustible fósil }+\mathrm{O} 2 \rightarrow \mathrm{H} 2 \mathrm{O} v+\mathrm{CO} 2+\text { Energía }
$$


Por otro lado, el proceso de combustión incompleta tiene como productos $\mathrm{CO}, \mathrm{C}$ y vapor de agua $(\mathrm{H} 2 \mathrm{Ov})$ :

$$
\text { Combustible fósil }+\mathrm{O} 2 \rightarrow \mathrm{H} 2 \mathrm{O} v+\mathrm{CO}+\mathrm{C}+\text { Energía }
$$

Siendo un proceso mucho más contaminante al producirse partículas de coque sólidas y monóxido de carbono.

Como se mencionó anteriormente, la aplicación de esta tecnología propicia una combustión más completa y por consiguiente menos contaminante.

- Mayor economía del combustible:

Al producirse combustiones completas, se aprovecha la totalidad de la energía química del combustible, lo cual supone que se tendrá un mayor rendimiento en kilometraje por litro de combustible.

- Reducción de vibraciones del motor:

Al estar presente el hidrógeno en la combustión, ésta se lleva a cabo de manera más uniforme, lo cual se evidencia en que el motor reduce la intensidad de sus vibraciones.

\section{Estado del arte:}

La presente investigación tiene como objeto de estudio la manufactura y comercialización de electrolizadores con aplicación automotriz. Se define un electrolizador o celda de electrólisis como un reactor químico que cuenta con electrodos, están acondicionadas para contener una solución acuosa, cuya disposición de sus partes y su diseño mecánico de fluidos permite desarrollar un proceso de electrólisis en él.

Comercialmente, estos sistemas han sido catalogados como "kits HHO", "Sistemas de hidrógeno vehicular", entre otras denominaciones.

Dentro del estado del arte de esta tecnología se pueden encontrar patentes que describen "Un sistema de generación de hidrógeno a bordo" que datan de los años 70s en adelante. En tal sentido, se puede afirmar que es una tecnología de patente libre, al ser públicas desde hace más de 20 años. Por ejemplo, una de las primeras publicaciones hechas por la NASA (Cassidy, 1977 ): "Emissions and total energy consumption of a multicylinder piston engine running on gasoline and a hydrogen-gasoline mixture", en el cual se demuestra 
el aumento de potencia y torque de un motor multicilindro, al igual que la reducción del consumo de combustible y el aumento de su eficiencia, gracias a la aplicación de un sistema de generación de hidrógeno al funcionamiento del motor.

Existen dos tipos de electrolizadores: los de celda húmeda y los de celda seca.

Se llama "celda húmeda" a las celdas de electrólisis o electrolizadores cuya configuración de electrodos se sumerge directamente en la solución de electrolito contenida en un reservorio.

Figura 1.5

Prototipo de "celda húmeda"

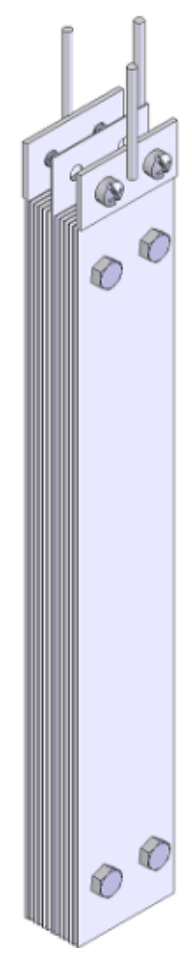

Fuente: Google Images, (2011)

Por otro lado, la denominación de celda seca se debe a que "los electrodos no están sumergidos en un baño de electrolito. Más bien, las placas paralelas están separadas y selladas por una serie de empaquetaduras, y el electrolito se bombea a través de la celda." (Romero, 2014). 
Figura 1.6

Prototipo de "celda seca"
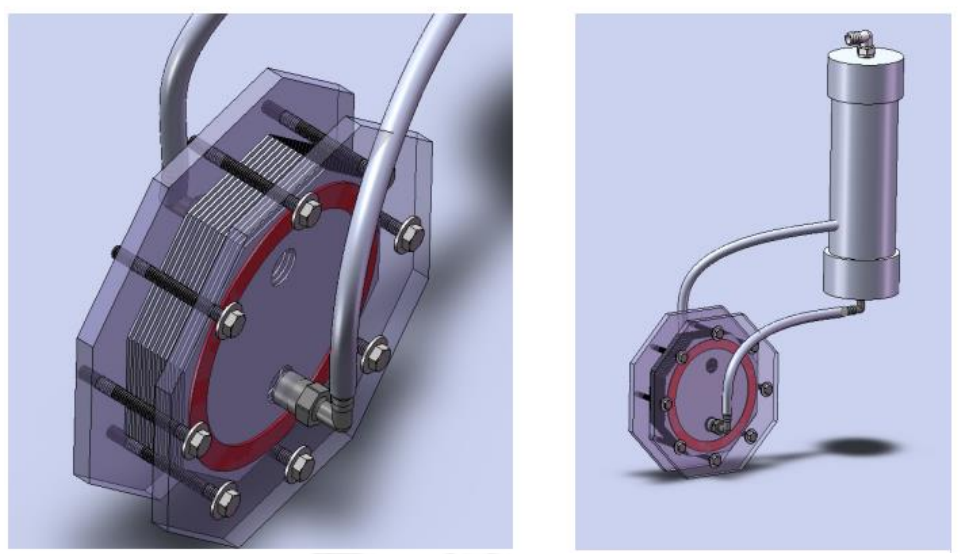

Fuente: Google Images, (2011)

Más aun, existen patentes recientes que delimitan el estado del arte de la tecnología de sistemas de hidrógeno vehicular, como:

- US 20150107990 A1

Sistema de hidrógeno vehicular caracterizado porque comprende " un generador de HHO; una olla Zeer que está configurada para reducir la temperatura en el interior del generador de HHO por evaporación de agua sobre una superficie de la olla Zeer; un radiador dentro de la olla Zeer que enfría una solución electrolítica para el generador de HHO; una bomba y un tanque de depósito que está en comunicación de fluido con el radiador para bombear la solución electrolítica desde el radiador de vuelta al generador HHO; y un separador de partículas que se instala aguas abajo del generador de HHO para eliminar el vapor de hidrógeno y gas oxígeno generado en el generador de HHO, en qué lugar la olla Zeer comprende solamente el agua dentro de una región de la evaporación del agua, y el generador de HHO está abierto al medio ambiente con el fin de permitir que el vapor de agua, gas hidrógeno y gas oxígeno para salir del generador de HHO.” (Samrgandi, N., 2013)

- US 8303798 B2

Sistema de hidrógeno vehicular caracterizado porque comprende "una batería; un recipiente conectado a al menos una célula; dicha célula cuenta con una pluralidad de placas, cada una formada a partir de un solo material, y cada placa de la pluralidad de placas dispuestas en paralelo entre sí para formar una fila, la pluralidad de placas que incluyen; una placa positiva que tiene un primer lado y un segundo lado conectado a un terminal positivo de 
la batería dispuesta en el centro de la fila; una primera placa de montaje doble que tiene una primera negativa y una segunda placa negativa que tiene una separación de 0,125 pulgadas entre ellos, conectado a un terminal negativo de la batería y dispuesto en un primer extremo extrema de la fila; una segunda placa de montaje doble que tiene una primera negativa y una segunda placa negativa que tiene una separación de 0,125 pulgadas entre ellos, conectado a un terminal negativo de la batería y dispuesto en un segundo extremo de la fila; un primer conjunto de tres de una pieza placas neutras eléctricamente aislados dispuestos entre el primer lado de la placa positiva y el primer montaje de doble placa; un segundo conjunto de tres placas neutras eléctricamente aisladas dispuestas entre el segundo lado de la placa positiva y el segundo conjunto de doble placa; en el que el agua en una solución electrolítica introducido en la célula se convierte en gas de hidrógeno para su uso en un motor de combustión de gas o diesel.”( Dees, J., 2009)

\section{- US $8168047 \mathrm{~B} 1$}

Sistema de hidrógeno vehicular caracterizado porque comprende "una carcasa de célula para la retención de agua en ella misma; una pluralidad de placas de electrodo positivo dispuestas dentro de la carcasa de célula, las placas de electrodo positivo conectado a un polo positivo, el polo positivo adaptado para la conexión a la fuente de energía eléctrica; una pluralidad de placas de electrodo negativo dispuestos en el interior de la carcasa de células, las placas de electrodo negativo conectados a un polo negativo, el polo negativo adaptados para la conexión a la fuente eléctrica, cada una de las placas de electrodo negativo indexadas con y espaciado entre cada una de las placas de electrodo positivo; un orificio de descarga de hidrógeno dispuesto en la carcasa celular y adaptado para la conexión al sistema de combustible; y una varilla de placa móvil unido a las placas negativas, un extremo de la varilla que se extiende hacia fuera desde la carcasa de la célula y adaptado para la unión al sistema de combustible del vehículo, la varilla placa móvil mover las placas de electrodo negativo hacia las placas de electrodo positivo durante la aceleración del vehículo, el varilla placa móvil moviendo las placas de electrodo negativo lejos de las placas positivas durante la desaceleración del vehículo y de inactividad.” (Smith, J., 2008)

- US 20140014049 A1

Sistema de hidrógeno vehicular caracterizado porque comprende "una fuente de alimentación; un generador de HHO, impulsado por la fuente de alimentación, que comprende 
al menos una estructura de generación de $\mathrm{HHO}$, dispuesto para recibir una solución de electrolito líquido y la salida de gas HHO; un módulo contenedor de la solución líquida acoplada al generador de HHO, configurado para sostener y bombear la solución de electrolito líquido y para separar el gas HHO desde la salida de solución de electrolito líquido residual desde el generador de $\mathrm{HHO}$; un secador de acoplado para recibir el gas de $\mathrm{HHO}$ desde el módulo contenedor de la solución y separación de gas líquido para eliminar la humedad y / o partículas en el gas de HHO; un tanque de presión acoplado para recibir el gas de HHO de la secadora y almacenar una cantidad de gas de HHO en un nivel superior a una presión de presión atmosférica ambiente; y un dispositivo carburador acoplado al tanque de presión, el dispositivo carburador siendo operable para regular una velocidad a la que el gas de HHO desde el tanque de presión fluye al motor de combustión interna.” (Allen, T., 2012)

- WO 2011124921 A1

Sistema de hidrógeno vehicular caracterizado por "Un proceso para enriquecer un combustible de hidrocarburos para su uso en un motor de combustión interna, comprendiendo el procedimiento: (i) la generación de gas de hidrógeno y gas oxígeno; (ii) poner en contacto un combustible de hidrocarburo líquido con el gas de hidrógeno y gas oxígeno a una presión mayor que la presión atmosférica de tal manera que al menos algo el gas hidrógeno y al menos una parte del gas se introduce oxígeno en el combustible de hidrocarburos para producir un hidrocarburo enriquecido combustible." (Colin, D., 2010) 
Por otro lado existen los siguientes sistemas de hidrógeno comerciales ofrecidos en el mercado mundial:

- HHO PLUS - DC2000

\section{Figura 1.7}

Sistema de hidrógeno HHO PLUS - DC2000

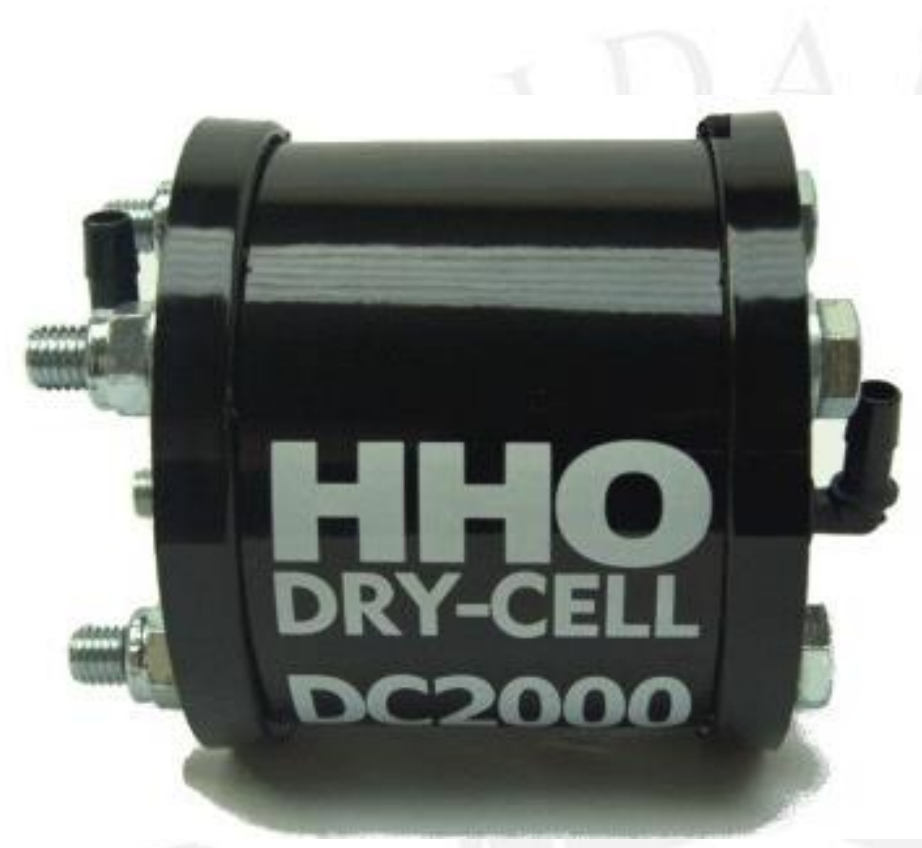

Fuente: HHO Plus Lda., (2008)

Especificaciones técnicas:

- Tipo de generador: Dry Cell (celda seca);

- Tamaños estándar: 110x110x150 mm;

- Placas: 19

- Tensión: 12V

- Conexión estándar eléctrica de la celda:

$$
\text { + NNNNN - NNNNN + NNNNN - }
$$

(N - Placa neutra) 
- Producción de Hidrógeno: 2,0 litros por minuto (25A)

- Alimentación eléctrica óptima: 12-15

(HHO Plus Lda., 2008)

- OCEAN GO

Figura 1.8

Sistema de hidrógeno OCEAN GO

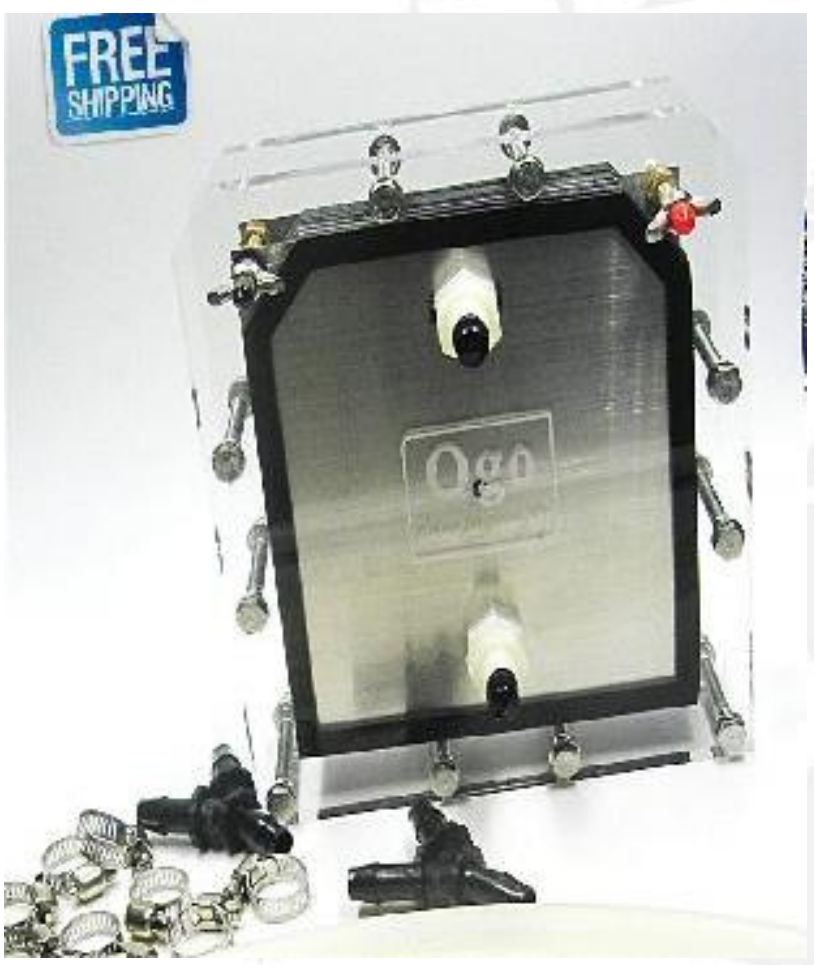

Fuente: Ocean Go Ltda., (2014)

Especificaciones técnicas:

11 placas de placas de acero inoxidable 316L

* Demensions: $19 * 19 * 12 \mathrm{~cm}$

* Alta temperatura de fundición de placas finales acrílico

* Cuatro conexiones de 3/8" en ángulo de 90 grados NPT 
* Dos conexiones de 3/8" NPT en Y

* Empaquetaduras de $2.5 \mathrm{~mm}$ de espesor de neopreno

* Peso neto: $3.5 \mathrm{~kg}$

* Nuestra Dry Cell es ampliable.

* Acero inoxidable tamaño de la placa es de $15,2 * 15,2 \mathrm{~cm}(6 * 6$ pulgadas $)$.

* Espesor de placas: $1 \mathrm{~mm}$ (cepillado)

* Producción: 1LPM a 5LPM.

* Trabajar en 12v a 35v 10A a 70amp.

* Accesorios incluidos: 2 piezas de 3/8 Conexiones Verdadero Y, 8pcs de abrazaderas de manguera, 4 secciones de tubería de alta presión .( Ocean Go Ltda. 2014)

Por otra parte, existen numerosas publicaciones científicas en las que se analiza el diseño de estos electrolizadores y el efecto de su implementación en motores a combustión interna, como los siguientes estudios:

- "Reduction of fuel consumption in gasoline engines by introducing HHO gas into intake manifold"

Este es un estudio publicado en la revista Hydrogen Energy en el año 2010 por el autor Ammar A. Al Rousan. Este concluye que la inyección de hidrógeno y oxígeno producidos a partir de la electrólisis reduce el consumo de combustible y, por ende, la contaminación emanada por el carro.

- “AN EXPERIMENTAL ANALYSIS OF S.I ENGINE PERFORMANCE WITH HHO AS A FUEL"

Este es un estudio publicado en la IJRET (International Journal of Reaserch in Engineering and Technology) por los autores Dhananjay Babariya , Jay Oza, Bhavin Hirani y Gaurang Akbari. Este concluye que el uso de gas HHO en un motor a gasolina genera una reducción del consumo de combustible de $20 \%$, reduce la emisión de gases contaminantes, aumenta la potencia en 5,7\% y aumenta la eficiencia térmica en alrededor de $5 \%$. 
- “An Empirical Study for Achieving Economies of Scale by Utilization of (HHO) Hydrogen Hydroxy Gas as Additional Fuel"

Este es un estudio publicado en el Journal of Energy Technologies and Policy por los autores Raees Ahmad Lodhi, Ahmad Nawaz y Rizwan Raheem Ahmed. Este concluye que gracias a añadir gas $\mathrm{HHO}$ a la mezcla aire combustible, se puede reducir el consumo de combustible en un rango de $25 \%$ a $28 \%$.

El producto a desarrollar está compuesto por dos placas de acrílico de $10 \mathrm{~mm}$ de espesor que serán colocadas a los extremos como tapas de la celda, luego estará compuesta por 8 placas de acero inoxidable SAE 316L de $1 \mathrm{~mm}$ de espesor, que cumplirán la función de electrodos y reguladores de voltaje, estas tendrán la siguiente configuración:

$$
-\mathrm{NNNN}+\mathrm{NNNN}-\mathrm{NNNN}+\mathrm{NNNN}-
$$

Entiéndase por esto que habrá placas conectada al polo positivo de la batería y otras al negativo, habiendo entre cada positivo y negativo cuatro placas sin conexión directa a la batería, las cuales se conectarán eléctricamente mediante una disolución acuosa de $\mathrm{KOH}$ al $3 \%$ en peso. En este caso, el hidróxido de potasio $(\mathrm{KOH})$ permite el flujo de electrones a través del agua. Estas placas estarán separadas por empaquetaduras de caucho de $1 \mathrm{~mm}$ de espesor, los cuales cumplirán un rol de aislantes. Se colocarán conexiones para las mangueras de alimentación en ambos extremos.

El proceso de producción de este dispositivo será comprendido por las siguientes actividades:

- Recepción de la materia prima:

Los insumos (planchas de acrílico, pernos, tuercas, planchas de acero, planchas de caucho y conexiones) son recibidos de los distintos proveedores.

- Corte de materiales:

Las planchas de Acero, de caucho y acrílico son cortadas a las medidas correspondientes a las especificaciones técnicas del producto mediante las máquinas de corte CNC por plasma o laser según sea conveniente. 
- Lijado:

Las placas de acero cortadas por plasma serán lijadas para tener una superficie y bordes más uniformes, al igual que para aumentar el área superficial electro activa.

- Control de calidad:

Se inspeccionarán las piezas para verificar que los cortes se realizaron de manera correcta. Se inspeccionará el producto final de igual manera para asegurar que cumpla con las especificaciones técnicas y cumpla con un control six sigma.

- Ensamble:

Se ensamblarán las piezas para tener el producto final.

- Encajado:

El producto se guardará en una caja de cartón.

- Almacenamiento:

Los productos se almacenarán en el almacén de productos terminados.

Figura 1.9

Prototipo de producto Final

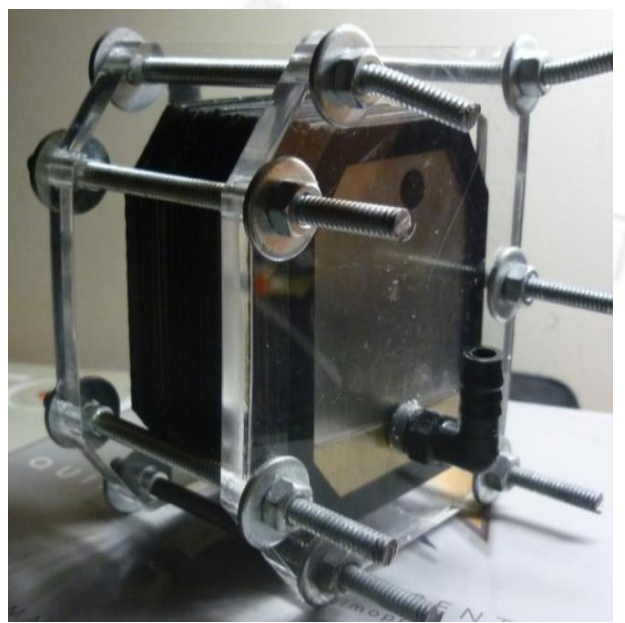

Elaboración Propia 


\subsection{Análisis del sector}

- Proveedores:

Actualmente, se cuenta en el mercado nacional con proveedores de las distintas materias primas que requiere el proceso. Para la compra planchas de Acero inoxidable SAE 316L, se tiene a JAHESA SA y JN ACEROS SA. Para el insumo de las planchas de caucho aislante está CODIZA SA. Para las planchas de acrílico está presente en el mercado NOREM - PLAST PERUANA SA. Por otro lado, los pernos y tuercas se pueden adquirir en SERFAIN SRL, La casa del Perno SA, entre otras. Las mangueras se consiguen ROATSA. El resto de insumos no existen en el mercado nacional, pero se encuentra amplia oferta en el mercado internacional. La capacidad de negociación con estos proveedores es bastante baja, ya que tienen precios fijos y una amplia cartera de clientes.

- Competencia:

En el mercado peruano actualmente solo existe una empresa formal que ofrece este producto, la cual es JOSELID INDUSTRIAL SAC. No existe información disponible con respecto a sus niveles de ventas, pero en el portal "Operatividad aduanera" de la Sunat, se muestra que el año 2013 importaron mercancías por un valor FOB total de S/ 32452.94 y S/ 104213.71 en el año 2014 considerando un tipo de cambio de S/.2.99 (SUNAT, 2015). Se debe mencionar que esta compañía importa los sistemas que ofrece y los vende a un precio de 2000 USD. Debido a sus altos precios y baja penetración se considera que es una competencia de baja intensidad. Asimismo, se infiere que existirán pocas compañías que puedan ingresar al mercado para comercializar estos productos ya que son tecnológicamente avanzados, requieren de capacitación intensiva y de know how para la fabricación apropiada de los sistemas.

\section{- Rivalidad:}

La rivalidad existente en el mercado es poca, ya que solo existe un competidor formal que vende estos productos sin ser el principal giro comercial de su empresa. Por otro lado, los competidores informales no representan una fuerte competencia ya que estos principalmente ofrecen sus productos en sitios web de e-commerce como Mercado Libre y OLX, presentando un número menor de 50 ventas realizadas por publicación. Cabe resaltar que los productos 
ofrecidos muestran un aspecto rudimentario y no estandarizado. Por ello se concluye que la rivalidad de los competidores es baja.

- Productos sustitutos:

Los productos sustitutos de esta propuesta son los equipos de conversión automotriz a GLP y GNV, ya que cumplen la función de ahorrar gastos en combustibles al pasar del uso de gasolina o petróleo a un combustible más barato. Cabe mencionar que este equipo de ahorro de combustible es compatible con los sistemas de GLP y GNV, por lo que también podría ser considerado un producto complementario al apuntar hacia el mismo horizonte, el ahorro de combustible y ser tecnológicamente compatibles. Por lo que se infiere que esta es una amenaza de nivel bajo.

\section{- Clientes:}

Se define como potencial cliente toda aquella persona natural o jurídica que tenga un automóvil o una flota de vehículos y desee reducir gastos en combustible, mejorar la performance del motor y/o reducir sus emisiones contaminantes, dentro del mercado geográfico seleccionado. Cabe mencionar que esta tecnología es compatible con vehículos a gasolina, diésel, GNV o GLP.

Dentro del marco de este estudio, se enfocarán los esfuerzos comerciales en el rubro de taxistas ya que estos gastan en promedio S/ 800 mensuales en GNV o GLP y acuden generalmente a talleres en clústeres automotrices como La Victoria (Óvalo Arriola, Av. México) o Santiago de Surco (Av. Tomás Marsano). Cabe mencionar que más allá de de las tecnologías de gas vehicular, no existen otros alternativas para ahorrar en gasto de combustible por lo que el poder de negociación de los clientes es bajo.

Luego de analizar las 5 fuerzas de Porter, se determina que se cuenta con un escenario favorable para la implementación de este proyecto.

Además, se optó por desarrollar una matriz EFE para analizar los factores externos por los que el proyecto propuesto se vería afectado y poder determinar y/o corroborar que se tiene un escenario favorable para el desarrollo de esta empresa. 
Tabla 1.1

Matriz EFE

\begin{tabular}{|c|c|c|c|}
\hline Factores determinantes del éxito & Peso & Calificación & $\begin{array}{c}\text { Peso } \\
\text { Ponderado }\end{array}$ \\
\hline \multicolumn{4}{|l|}{ Oportunidades } \\
\hline 1. Taxistas buscan ahorrar combustible & 0.1 & 5 & 0.5 \\
\hline $\begin{array}{l}\text { 2. Regulaciones medioambientales cada vez son más } \\
\text { rigurosas }\end{array}$ & 0.1 & 3 & 0.3 \\
\hline 3. No existen competidores formales en el mercado & 0.1 & 3 & 0.3 \\
\hline 4. Se dispone de oferta de materias primas & 0.1 & 3 & 0.3 \\
\hline $\begin{array}{l}\text { 5. Talleres automotrices buscan nuevos productos } \\
\text { para vender }\end{array}$ & 0.1 & 4 & 0.4 \\
\hline \multicolumn{4}{|l|}{ Amenazas } \\
\hline $\begin{array}{l}\text { 1. Incredulidad del público objetivo frente a } \\
\text { beneficios de la tecnología }\end{array}$ & 0.1 & 2 & 0.2 \\
\hline 2. Facilidad de importar tecnologías del extranjero & 0.1 & 4 & 0.4 \\
\hline $\begin{array}{l}\text { 3. Dificultad para encontrar financiamiento para } \\
\text { proyecto empresarial }\end{array}$ & 0.1 & 2 & 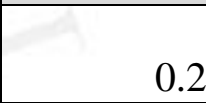 \\
\hline 4. Alto poder de negociación de los proveedores & 0.1 & 1 & 0.1 \\
\hline $\begin{array}{l}\text { 5. Alta necesidad de inversión en capacitación a } \\
\text { talleres }\end{array}$ & 0.1 & 1 & +2 \\
\hline \multicolumn{3}{|l|}{ Total } & 2.8 \\
\hline
\end{tabular}

Elaboración Propia

Por lo expuesto anteriormente, se concluye que el sector es atractivo para la inversión en la comercialización de la tecnología propuesta. 


\section{CAPÍTULO II: ESTUDIO DE MERCADO}

\subsection{Aspectos generales del estudio de mercado}

\subsubsection{Definición comercial del producto}

El producto en estudio se definirá comercialmente como Sistema de hidrógeno vehicular H2PRO, que servirá para reducir el consumo de combustible, aumentar la potencia del motor y reducir las emisiones de gases nocivos para el medio ambiente.

Marca y sello distintivo de este producto será la siguiente:

Figura 2.1

Marca de sistemas de hidrógeno vehicular

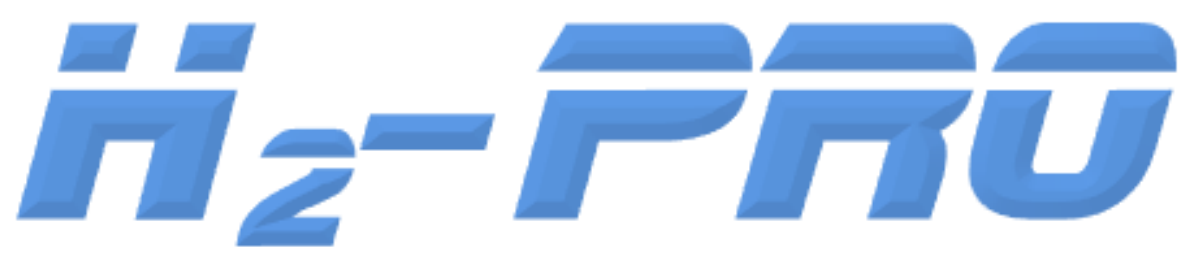

Elaboración Propia

Este sistema será empacado dentro de una caja de cartón corrugado.

\subsubsection{Principales características del producto}

\subsubsection{Usos y propiedades}

La producción de este sistema, para motivos de este estudio, se orientará a la aplicación en automóviles.

Al instalar este sistema en un vehículo se obtienen los siguientes beneficios:

- Combustión más completa del combustible fósil:

El hidrógeno facilita que se desarrolle una combustión que tiende a ser más completa, por parte del combustible fósil.

En los motores Otto, la bujía emite un arco eléctrico y enciende el combustible. Dicho encendido no es homogéneo y muchas veces no se llega a producir una combustión 
totalmente completa. El hidrógeno, al ser un combustible mucho más volátil, se enciende con una mayor velocidad laminar de explosión que la gasolina y es esta energía, sumada a la de la chispa, cataliza una oxidación más eficiente.

Figura 2.2

Velocidad de encendido de distintos combustibles.

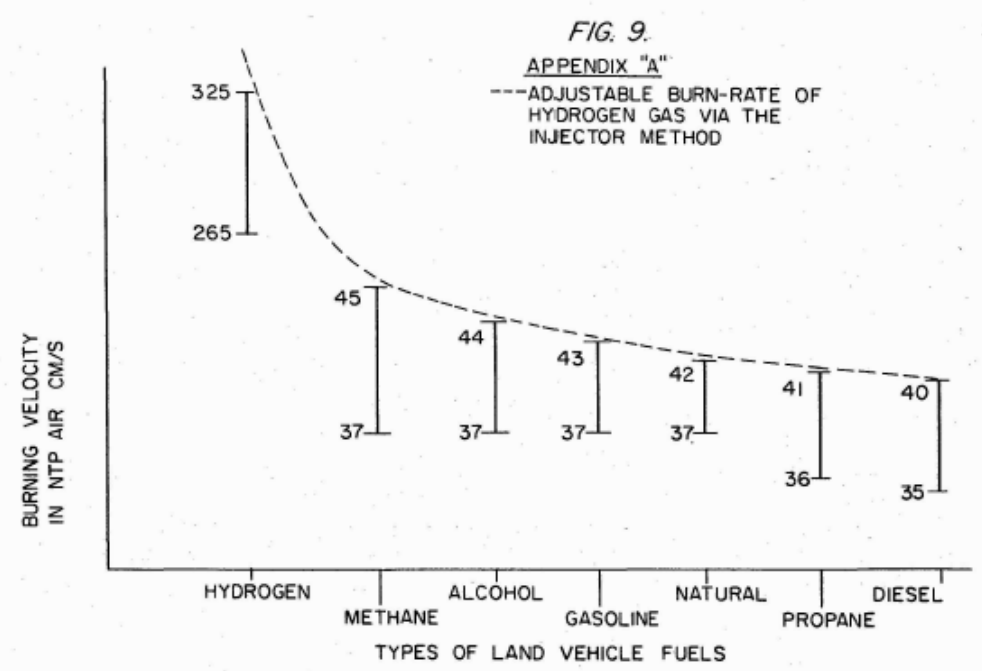

Fuente: Meyer, S., (1991)

Chispa $\rightarrow$ Explosión de combustible fósil

La reacción en cadena producida es de la siguiente manera:

Chispa $\rightarrow$ Explosión del Hidrógeno $\rightarrow$ Explosión de combustible fósil.

- Aumento de la potencia:

Una combustión completa libera una mayor cantidad de energía que una incompleta. Siendo uno de los beneficios descritos el desarrollar una combustión más completa por parte del combustible, se entiende por extensión que se libera una mayor cantidad de energía por parte del combustible lo cual se percibe en un aumento de la potencia a la hora de conducir. Además, el hidrógeno per sé aporta energía a la combustión. 
Según la bibliografía a revisada, el aumento de potencia es de entre 5\% y $6 \%$.

Fuente: Yilmaz, A., (2010)

- Reducción de emanación de gases contaminantes:

El proceso de combustión completa de gasolina tiene como producto vapor de agua (H2Ov) y CO2:

Combustible fósil $+\mathrm{O} 2 \rightarrow \mathrm{H} 2 \mathrm{O} v+\mathrm{C} 02+$ Energia

Por otro lado, el proceso de combustión incompleta tiene como productos $\mathrm{CO}, \mathrm{C} \mathrm{y}$ vapor de agua $(\mathrm{H} 2 \mathrm{Ov})$ :

Combustible fósil $+\mathrm{O} 2 \rightarrow \mathrm{H} 2 \mathrm{O} v+\mathrm{C} 0+\mathrm{C}+$ Energia

Siendo un proceso mucho más contaminante al producirse partículas de coque sólidas.

Como se mencionó anteriormente, la aplicación de esta tecnología propicia una combustión más completa y por consiguiente menos contaminante.

Ahora, existiendo hidrógeno en la combustión, la formación de vapor de agua es mayor $(\mathrm{H} 2 \mathrm{O}$ v) con respecto a una combustión estándar:

Combustible fósil $+\mathrm{H} 2+\mathrm{O} 2 \rightarrow \mathrm{H} 2 \mathrm{O} v+\mathrm{C} 02+$ Energia

- Economía del combustible:

Al liberarse casi la totalidad de la energía del combustible, aumentando la eficiencia del carro, se produce un ahorro del combustible. Este oscila entre un $15 \%$ a $25 \%$ dependiendo del vehículo donde se instale.

- Alargamiento del periodo útil aceite lubricante

Los motores de combustión interna utilizan un aceite que cumple la función de lubricar y refrigerar las piezas mecánicas con el objetivo de propiciar el correcto funcionamiento de los mismos y prevenir fallas por desgaste de rozamientos. Este aceite lubricante se encuentra presente en el pistón para lubricar su carrera, esta exposición a resultados de combustión provoca que se contamine al recorrer superficies con remanentes de carbono, tomando el característico color oscuro que tiene un aceite gastado. El remanente más perjudicial son las partículas de carbono (C) o también conocidas como hollín. 
Como se explicó anteriormente, esta tecnología reduce la formación de estas partículas (dado que se generan combustiones completas, sin subproductos cómo el material particulado) y también las remueve (gracias a la formación de vapor de agua, subproducto de las combustiones completas). Como consecuencia de esto el aceite se contamina de una manera significativamente más lenta.

- Alargamiento de periodo útil de bujías

Las bujías son las encargadas de emitir una chispa para que se inicie la combustión en motores Otto. El electrodo del que sale esta chispa se encuentra expuesto a la combustión, siendo también afectado por los remanentes de carbono propios de la combustión incompleta. Estos remanentes actúan en contra de la conductividad de esta pieza, lo cual actúa en detrimento de su funcionamiento (y por consiguiente del motor) y a mediano plazo hay que reemplazarlas.

Por las mismas propiedades mencionadas en el apartado anterior se producen explosiones con menos remanentes de carbono perjudiciales para las bujías.

- Reducción de vibraciones del motor

Como se mencionó anteriormente el hidrógeno propiciaba una combustión más completa y uniforme. Esto tiene repercusión en la distribución de las fuerzas liberadas con la explosión provocando que estas se repartan de una manera más uniforme en el sistema cilindro-pistón. Como consecuencia de esto, se reducen las vibraciones del motor.

Al vibrar menos, se extiende el tiempo de vida del motor. Esto se debe a que al vibrar las piezas están sometidas a un estrés mecánico superior. Además, los tornillos tienden a aflojarse lentamente, y al producirse esto se puede abrir una luz entre ciertas piezas lo cual puede propiciar choques y desgaste prematuros.

- Seguridad

El hidrógeno es un combustible muy volátil y para esta aplicación se encuentra en estado gaseoso, por lo cual al someterse a alguna fuente de energía (chispa) podría estallar.

Como se mencionó anteriormente, el hidrógeno es producido en el mismo carro a partir de agua destilada, esto implica que solo existen pocas cantidades de este gas presentes en el motor, lo que implica que si llegase a explotar, esto no liberaría una cantidad 
significativa de energía por lo que no sería una explosión letal y tampoco sería una gran amenaza para las demás partes del automóvil.

Por otro lado, el sistema cuenta con una válvula check en la manguera por la cual se transporta el hidrógeno hacia la admisión de aire, solo permitiendo que el flujo sea del reservorio hacia la admisión. En tal sentido, si se produce una explosión dentro del motor que emane hacia afuera, esta válvula impediría el retorno de dicha fuerza impulsora. Muy probablemente esta válvula quede estropeada al producirse esta eventualidad, pero es de costo bajo y fácil instalación. Cabe mencionar que obviando agentes externos al motor, esta situación solo sería evidencia de falla en el sistema de válvulas.

\section{- Fácil instalación}

Los equipos de este sistema son de fácil instalación ya que no ocupan gran cantidad de espacio y se acoplan con pocas modificaciones a un sistema Otto tradicional. Una de las grandes ventajas es que no se necesita un tanque de almacenamiento de gas hidrógeno ya que este se produce en el mismo vehículo, a comparación de los sistemas de GLP y GNV que deben contar con un tanque de volumen considerable y mangueras que recorran toda la longitud del vehículo. Las mangueras empleadas en este sistema son de corta longitud debido a que se instala generalmente en la misma zona que el motor. Una complicación que se puede presentar a la hora de la instalación es que el producto no se pueda acoplar a la superficie y necesite de soportes de acero que deben de ser fabricados a medida de las necesidades.

- Ruido

Al producirse una combustión más uniforme y al producirse menos cantidad de vibraciones, el sonido de operación del motor disminuye.

- Olor

Como consecuencia de la reducción de emisiones de gases contaminantes, se aprecia un cambio significativo en el olor de los gases de combustión y que no se emiten hidrocarburos ni material particulado como subproductos de escape.

Por otra parte, se debe mencionar que el producto tiene un tiempo de vida de 3 años. Una vez culminado ese periodo, los electrodos deben ser reemplazados para que la electrólisis pueda seguir ocurriendo de manera eficiente. Por otra parte, el producto consumible de la 
electrólisis es el agua, por ello, se debe rellenar con agua el reservorio para que pueda suceder la electrólisis. Otro factor por el que el reservorio siempre debe mantenerse lleno es porque al consumirse el agua y mantenerse una cantidad constante de hidróxido, la concentración de este aumentará, lo que incrementará la intensidad de corriente que fluya por los electrodos, afectando la eficiencia de la electrólisis y pudiendo dañar la tarjeta de control.

Este producto se diferenciará de sus productos sustitutos y competidores de mercado ya que genera ahorro de combustible y generará aumento de potencia al mismo tiempo. Asimismo, será ofrecido con un servicio de instalación y post venta de primera calidad gracias a la capacitación constante que se le dará a los distribuidores.

\subsubsection{Bienes sustitutos y complementarios}

El principal atractivo comercial de este producto es el ahorro en gasto de combustible, por lo que los productos sustitutos serían:

- Equipos de gas natural vehicular (GNV)

- Equipos de gas licuado de petróleo vehicular (GLP)

Estos sistemas cumplen la función de acondicionar el vehículo ara que pueda usar un combustible alternativo, sea gas natural vehicular (GNV) o gas licuado de petróleo (GLP). Tienen un funcionamiento bastante parecido entre sí, su mecánica y electrónica es similar. A continuación se presenta un esquema de ellos: 
Figura 2.3

Funcionamiento de los sistemas GLP y GNV vehicular

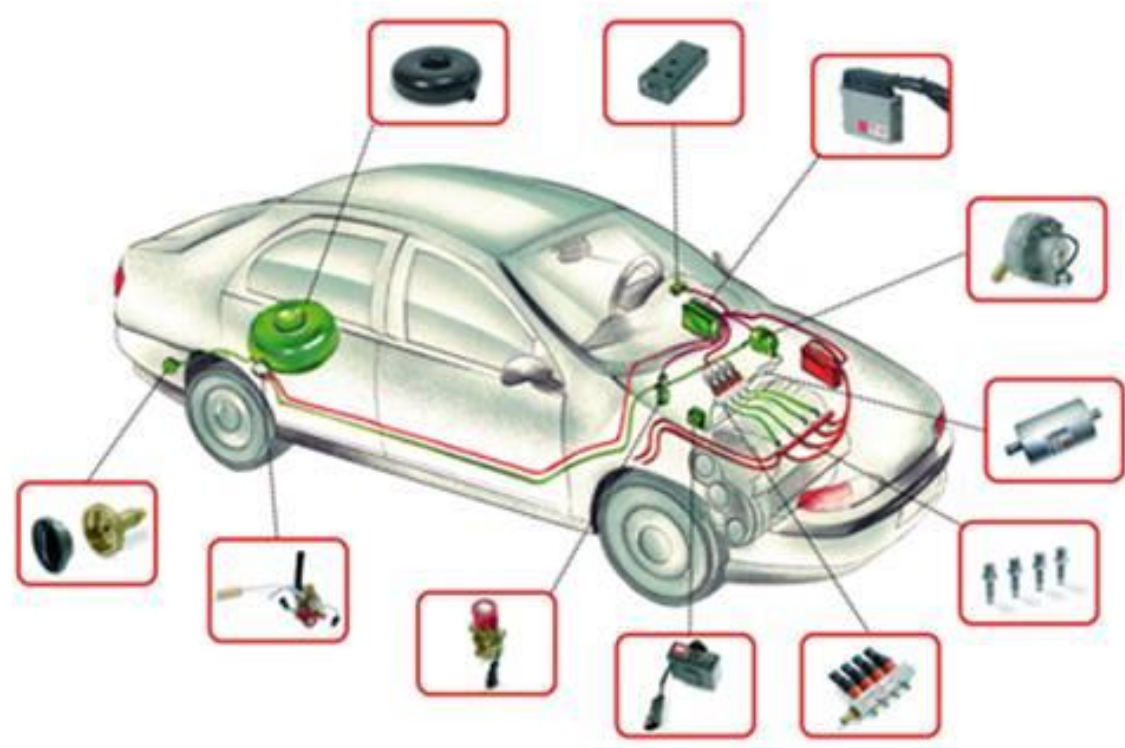

Fuente: GLP MADRID, (2013)

El ahorro en combustible obtenido al instalar estos sistemas se obtiene al usar un combustible más barato que el precedente en el vehículo. De tal manera, se logra ahorrar en promedio un $50 \%$. Se debe mencionar también que, generalmente, se experimenta una pérdida de potencia al cambiar la gasolina por un gas. En muchos casos, el usar GNV puede causar daños a largo plazo en el vehículo debido a las altas temperaturas que se desarrollan con su uso, desgastando la culata y los asientos de las válvulas.

Por otro lado, los bienes complementarios serían:

- Agua destilada

- Hidróxido de potasio

Esto se debe a que el sistema es alimentado con el agua como materia prima para generar los gases aditivos. Por otro lado, el hidróxido de potasio cumple la función de electrolito, necesario para que la electricidad pueda actuar sobre el agua.

Esto se debe a que el sistema se alimenta de estos para funcionar. 


\subsubsection{Determinación del área geográfica que abarcará el estudio}

Para determinar el área geográfica que abarcará el estudio, se analizará que departamento del Perú tiene el mayor parque automotor.

Figura 2.4

Mapa del Perú por departamentos

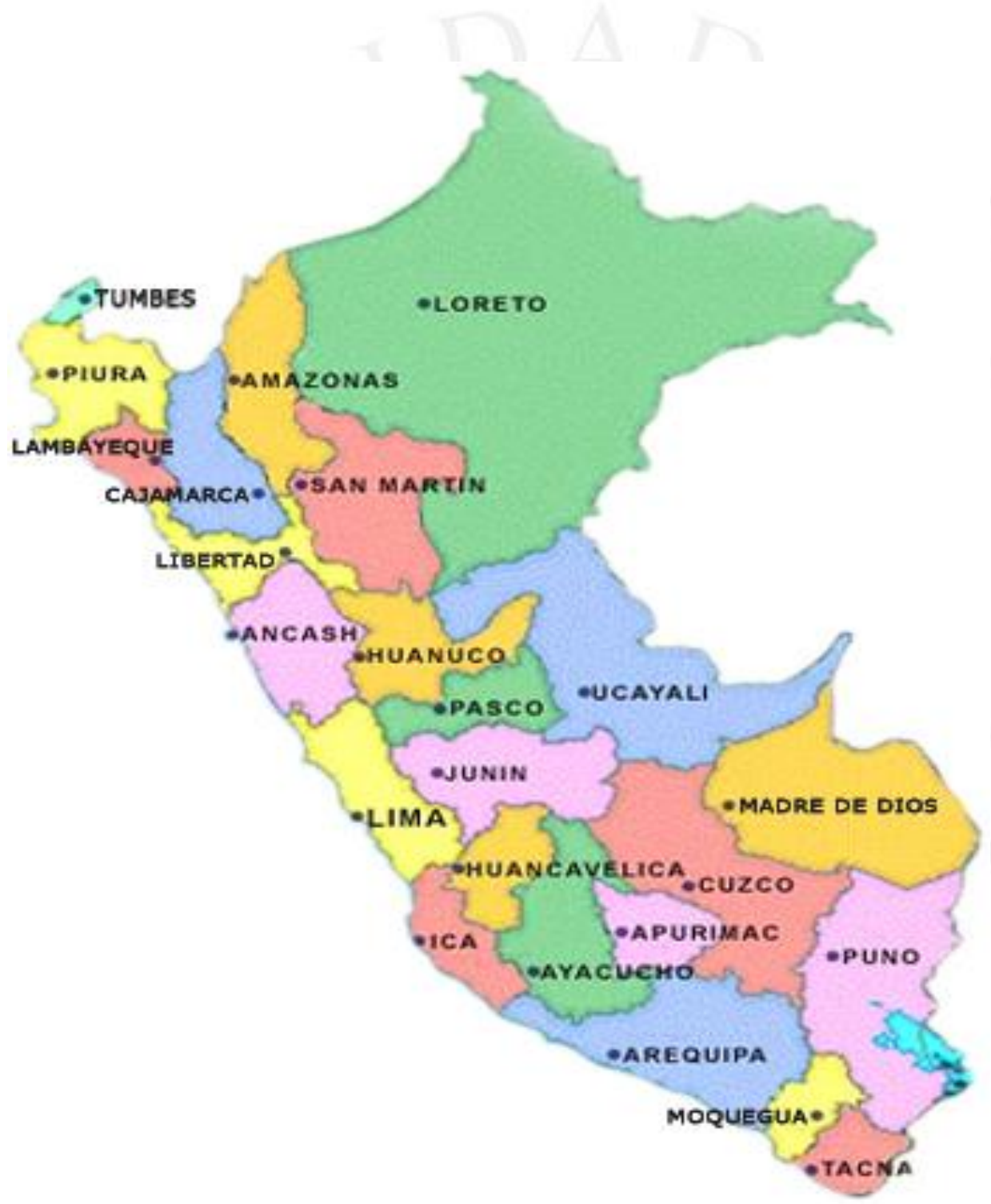

Fuente: SERPERUANO, (2016) 
Tabla 2.1

Distribución del parque automotor por departamento al 2014

\begin{tabular}{|l|r|}
\hline Departamento & Parque Automotor \\
\hline Amazonas & 2,314 \\
\hline Ancash & 29,573 \\
\hline Apurímac & 4,139 \\
\hline Arequipa & 164,302 \\
\hline Ayacucho & 6,021 \\
\hline Cajamarca & 22,664 \\
\hline Cuzco & 64,820 \\
\hline Huancavelica & 1,315 \\
\hline Huánuco & 14,911 \\
\hline Ica & 26,439 \\
\hline Junín & 61,933 \\
\hline La Libertad & 178,433 \\
\hline Lambayeque & 61,896 \\
\hline Lima y Callao & $1,590,755$ \\
\hline Loreto & 5,533 \\
\hline Madre de Dios & 1,136 \\
\hline Moquegua & 14,979 \\
\hline Pasco & 6,956 \\
\hline Piura & 49,576 \\
\hline Puno & 45,056 \\
\hline San Martín & 11,648 \\
\hline Tacna & 47,180 \\
\hline Tumbes & 3,372 \\
\hline Ucayali & 8,745 \\
\hline
\end{tabular}

Fuente: MTC, (2015) 
Figura 2.5

Parque automotor por departamento al 2014

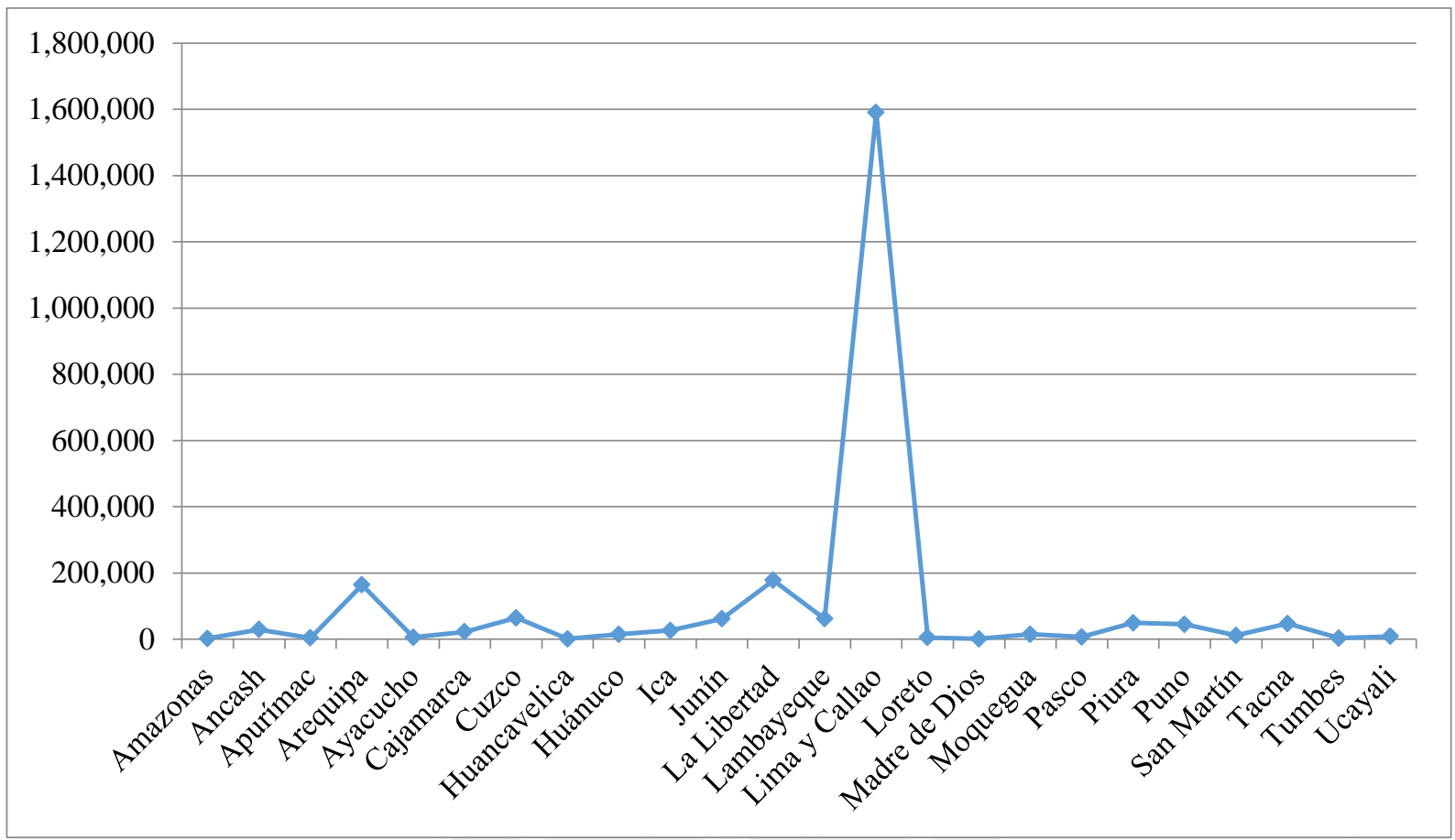

Fuente: MTC, (2015)

Se aprecia claramente que el departamento con mayor parque automotor es Lima y Callao, en tal sentido, el estudio se realizará dentro de la delimitación de este territorio

\subsection{Análisis de la demanda}

\subsubsection{Demanda histórica}

\subsubsection{Importaciones / exportaciones}

Al año pasado se importaron 113 equipos similares al que se comercializarán en este proyecto. Este dato fue proporcionado por la única empresa importadora de estos sistemas.

Es importante mencionar que los equipos utilizados para las conversiones a GNV y GLP son importados de distintas partes del mundo. Estos se encuentran registrados en una misma partida arancelaria (84.09.91.00). La cantidad de equipos importados se detalla en la siguiente tabla: 
Tabla 2.2

Equipos GLP y GNV importados del 2009 al 2012

\begin{tabular}{|c|c|}
\hline Año & Equipos Importados \\
\hline 2010 & 43,149 \\
\hline 2011 & 49,755 \\
\hline 2012 & 72,543 \\
\hline 2013 & 77,393 \\
\hline 2014 & 87,799 \\
\hline
\end{tabular}

Elaboración Propia

Figura 2.6

Equipos GLP y GNV importados del 2009 al 2014

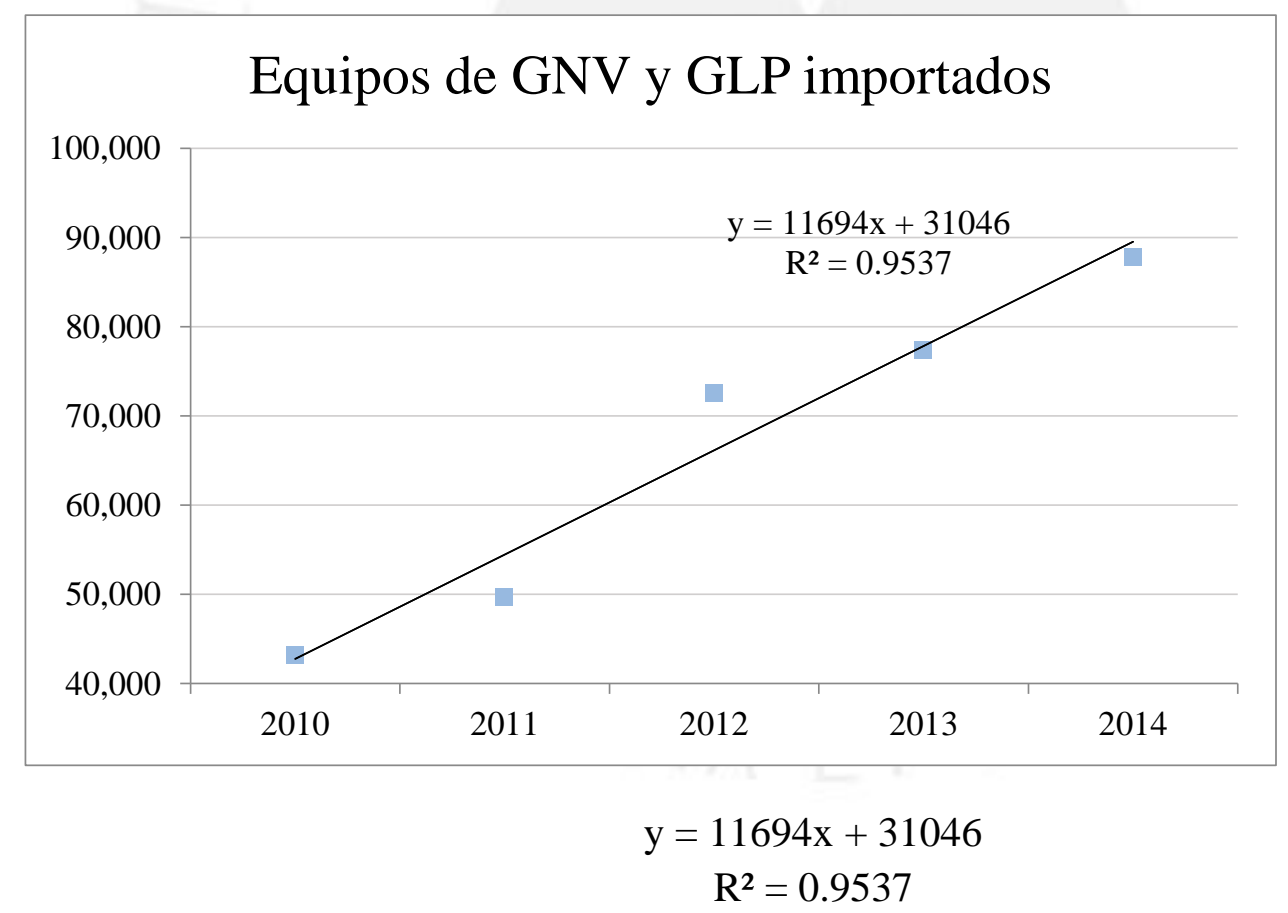

Elaboración Propia

Se aprecia además, un comportamiento lineal con respecto a su crecimiento. 


\subsubsection{Producción}

En el Perú no se fabrican estos dispositivos. Se debe decir que tampoco se fabrican equipos de GNV ni de GLP.

\subsubsection{Demanda interna aparente (DIA)}

La demanda interna aparente actual de sistemas de hidrógeno vehicular es de 113 unidades. Por otro lado, la demanda interna aparente, asumiendo como inexistente la variación de inventarios, de los sistemas de GNV y GLP es de 87,799 unidades.

\subsubsection{Demanda potencial}

\subsubsection{Patrones de consumo}

Los taxistas, en su gran mayoría utilizan sistemas de GNV ya que son los que les generan mayor ahorro de combustible, a pesar de reducir la potencia del vehículo y aumentar su necesidad de mantenimiento. Esta inversión suele ser rentable en el mediano plazo. A partir de ello se aprecia un patrón repetitivo de búsqueda de reducción de gastos de combustible. Otros productos que se ofrecieron en el mercado con menor éxito fueron los ahorradores magnéticos y los aditivos para combustibles, los cuales no tuvieron éxito debido a su falta de eficacia. Un tema importante a mencionar es la resistencia al cambio y a la asimilación de nuevas tecnologías del mercado. Esto afectaría directamente el proyecto, ya que no se ha comercializado de manera masiva estos sistemas de hidrogeno para vehículos.

\subsubsection{Determinación de la demanda potencial}

Para determinar la demanda potencial se realizará una comparación con la demanda de equipos de gas natural. A pesar de que a un vehículo con este sistema se le puede adicionar un sistema de hidrógeno vehicular, se decidió la comparación con este equipo ya que solo se encuentra disponible en la zona geográfica del estudio y porque ofrece el mismo beneficio comercial, el ahorro. Además, se realizará una interpolación con el beneficio en términos de ahorro para hacer este cálculo, tomando en cuenta las siguientes premisas: que es más atractivo comprar un equipo de ahorro en combustible mientras este genere el mayor ahorro, y que es más atractivo comprar uno de estos equipos mientras más barato sea. Se considera que la primera premisa es mucho más importante que las segunda.

En la actualidad, se realizan 25000 conversiones a GNV al año (Gestión, 2012). El costo promedio de estas conversiones (de quinta generación) es de 3800 nuevos soles, y un precio tentativo de mercado para los sistemas de hidrógeno vehicular es 1700 nuevos soles. 
Por otro lado, las conversiones a GNV suponen un ahorro del 50\% del gasto en combustible, mientras los sistemas de hidrógeno ahorran el $25 \%$.

Teniendo estos datos se modela matemáticamente la aproximación de la siguiente manera:

$$
\text { Demanda Potencial }=25000 *(0.25 / 0.5)^{\wedge} 2 *(3800 / 1700)=13790 \text { equipos al año }
$$

\subsubsection{Proyección de la demanda y metodología del análisis}

Para realizar la proyección de la demanda potencial se asumirá que el mercado objetivo crecerá de manera proporcional al crecimiento del parque automotor de la ciudad de Lima. El ministerio de transportes ha determinado que este $4.8 \%$ (ESTADISTICA) de manera interanual, en tal sentido las demandas anules aproximadas se detallan en las siguientes tablas:

Tabla 2.3

Proyección de la demanda potencial de sistemas de hidrógeno vehicular

\begin{tabular}{|c|c|}
\hline Año & Demanda anual \\
\hline 2017 & 13,790 \\
\hline 2018 & 14,452 \\
\hline 2019 & 15,146 \\
\hline 2020 & 15,873 \\
\hline 2021 & 16,634 \\
\hline
\end{tabular}

Elaboración Propia 
Figura 2.7

Proyección de la demanda potencial de sistemas de hidrógeno vehicular

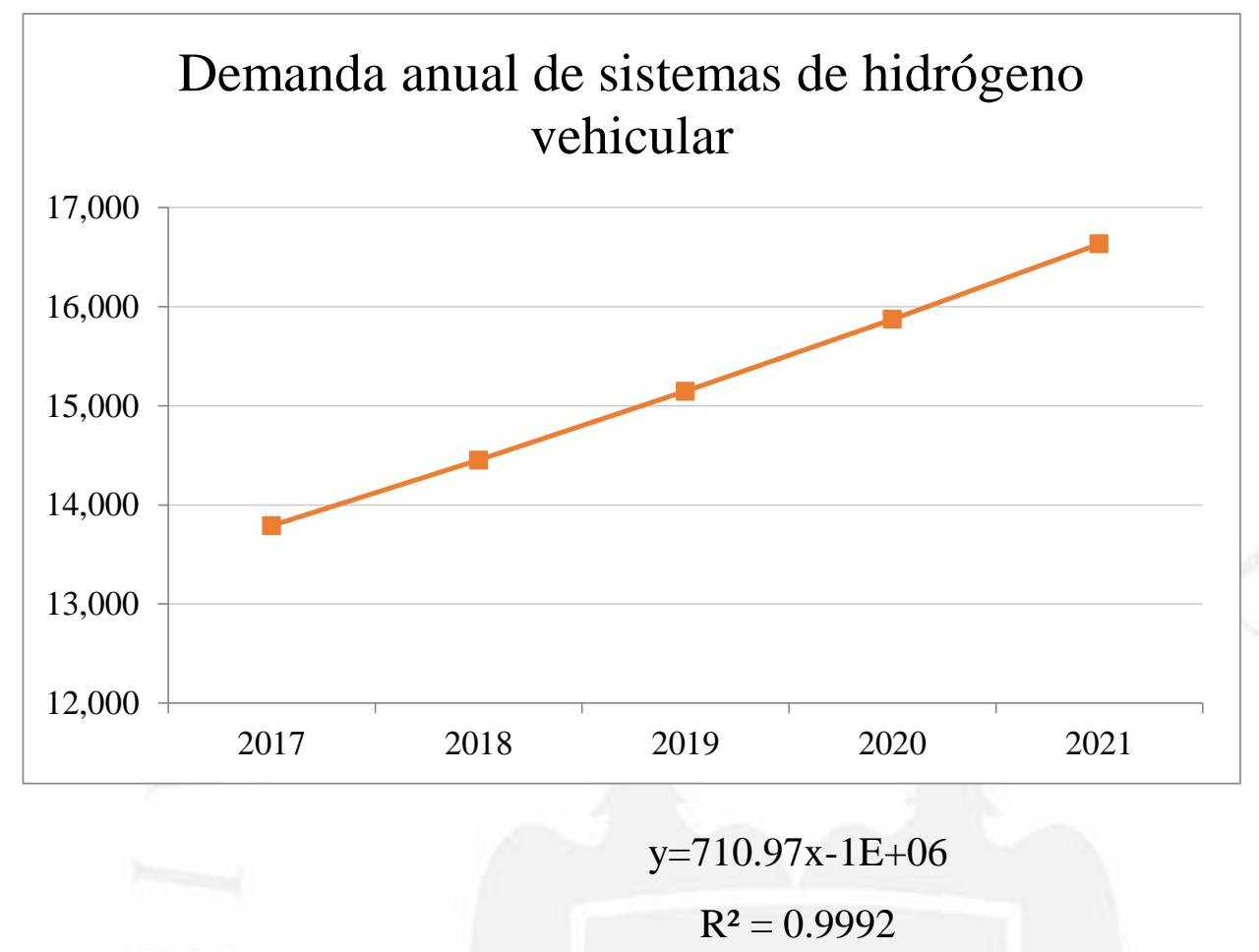

Elaboración Propia

\subsection{Análisis de la oferta}

\subsubsection{Análisis de la competencia}

La única empresa formal que ofrece este producto en el mercado nacional es "Joselid Industrial SAC”. Esta lo importa de un productor de EEUU.

\subsubsection{Oferta actual}

La empresa nacional "Joselid Industrial SAC" fue fundada el 2 de febrero del 2012 siendo una sociedad anónima cerrada. Se desempeña en el sector económico de "venta mayorista maquinaria, equipo, equipo y materiales", teniendo como CIIU: 51502, y se presenta activo en comercio exterior como importador. Sus instalaciones se ubican en el distrito de Santa Anita. Esta tiene como su principal giro de negocio la venta e instalación de plantas de procesamiento de arroz, siendo las celdas de electrólisis uno de sus productos secundarios con respecto a sus esfuerzos en ventas. Cabe mencionar que este producto es comercializado a partir del año 2012. Esta empresa vende los productos directamente al consumidor final (minorista). 


\subsection{Demanda para el proyecto}

\subsubsection{Segmentación del mercado}

- Psicográfica

El mercado elegido para este proyecto será, desde el punto de vista psicográfico, orientado hacia las personas que busquen ahorrar y economizar en gastos.

Socioeconómicamente se apuntará a personas de clase media y baja de los segmentos $\mathrm{B} 2, \mathrm{C} 1, \mathrm{C} 2$ y D1, principalmente taxistas.

- Demográfica

Demográficamente apuntará a personas que posean un vehículo que sean mayores de edad, hombres y mujeres.

- Geográfica

Con respecto a lo geográfico, se orientará a las personas que vivan en Lima metropolitana.

- Por beneficios

Como se mencionó anteriormente, este producto genera beneficios como ahorro de combustible, aumento de potencia y reducción de emisión de gases contaminantes. En este caso se optó por segmentar el mercado orientado hacia la primera necesidad, el ahorro en gastos de combustible ya que este es una de los principales costos del negocio de realizar taxi. Según un patrón de consumo, los taxistas adaptan su vehículo a GNV para poder ahorrar una cantidad significativa de dinero a pesar que estos sistemas generen un deterioro prematuro del motor, aumente la necesidad de mantenimiento y reduzca significativamente la potencia del motor. Lo mencionado anteriormente respaldaría la decisión de optar por la segmentación orientada hacia el ahorro de combustible.

\subsubsection{Selección del mercado meta}

El target de este proyecto serán las personas naturales y jurídicas que tengan un elevado gasto en consumo de combustible, entre las cuales pueden destacar taxistas, empresas de taxi o carga liviana, entre otros. 


\subsubsection{Determinación de la demanda para el proyecto}

Para determinar la demanda del proyecto se realizaron encuestas que tienen el siguiente formato:

El objetivo principal de la encuesta es determinar si el público objetivo compraría o no el Sistema H2PRO.

Tabla 2.4

Encuesta

\section{Encuesta hidrógeno vehicular}

Taxista

Particular

¿Qué combustible usa?

G90

G95

G97

GNV

GLP

DIESEL

¿Cuánto gasta mensualmente en combustible?

¿Compraría un sistema que reducirá el consumo de combustible de su vehículo?

Sí

No

¿Por qué no?

¿Compraría un sistema que aumentará la potencia de su vehículo?

Sí

No

¿Por qué no?

¿Compraría un sistema que alargará el periodo de vida de su motor?

Sí

No

¿Por qué no?

¿Compraría un sistema que reducirá el consumo de combustible de su vehículo, aumentará la potencia y alargará el periodo de vida de su motor?
Sí
No
¿Por qué no?

¿Cuánto estaría dispuesto a pagar por él?

2000 soles

2500 soles

3000 soles

Marca/Modelo:

Nombre:

Teléfono:

Elaboración Propia 
Siendo la pregunta clave del estudio la siguiente:

¿Compraría un sistema que reducirá el consumo de combustible de su vehículo, aumentará la potencia y alargará el periodo de vida de su motor?

$$
\text { Sí__ No }
$$

Elaboración Propia

Al tratarse de una pregunta de éxito o fracaso, la distribución más apropiada para modelar este comportamiento es la binomial. En tal sentido, el tamaño de muestra se determinará por la siguiente ecuación:

$\mathrm{n}=1.96^{\wedge} 2 *(\mathrm{p})^{*}(\mathrm{q}) /\left(\mathrm{E}^{\wedge} 2\right)$

p: \% de éxitos

q: \%de fracasos

E: Error del estudio

1.96: $\mathrm{Z}$ correspondiente a un nivel de confianza de $95 \%$

Tomando una muestra preliminar de 30 , y tomando un error de 5\%, se obtuvieron los siguientes resultados:

$\mathrm{p}=0.9333$

$q=0.0667$

$\mathrm{n}=1.96^{\wedge} 2^{*}(0.9333) *(0.0667) /\left(0.05^{\wedge} 2\right)=95.66=96$

Adicionalmente, con el objetivo de determinar la intención de compra se realizó la pregunta:

¿Siendo el 10 el máximo nivel y 1 el mínimo, del 1 al 10, que tan interesado estaría en Comprar un sistema que reducirá el consumo de combustible de su vehículo, aumentará la potencia y alargará el periodo de vida de su motor? 
Los resultados del estudio de mercado fueron los siguientes:

\begin{tabular}{|l|c|c|c|c|}
\hline $\begin{array}{l}\text { ¿Qué combustible } \\
\text { usa? }\end{array}$ & $\begin{array}{c}\text { Gasolina } \\
90\end{array}$ & GLP & GNV & total \\
\hline Cantidad & 1 & 3 & 92 & 96 \\
\hline
\end{tabular}

Figura 2.8

¿Qué combustible usa?

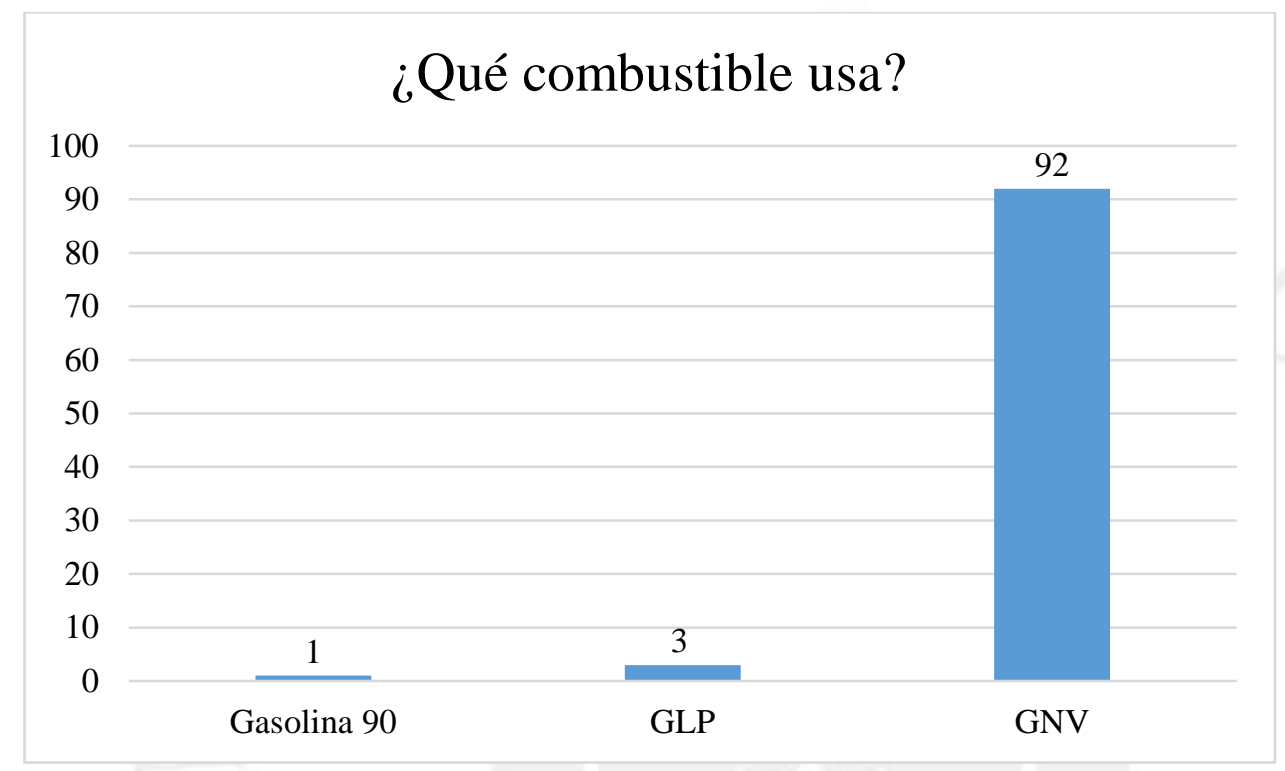

Elaboración Propia

Los datos muestran claramente que la mayoría de taxistas utilizan GNV.

\begin{tabular}{|l|c|c|c|c|c|}
\hline $\begin{array}{l}\text { Gasto mensual en combustible } \\
\text { (Soles) }\end{array}$ & 600 & 750 & 900 & 1000 & 1200 \\
\hline Cantidad & 10 & 75 & 4 & 5 & 2 \\
\hline
\end{tabular}


Figura 2.9

Gasto mensual en combustible

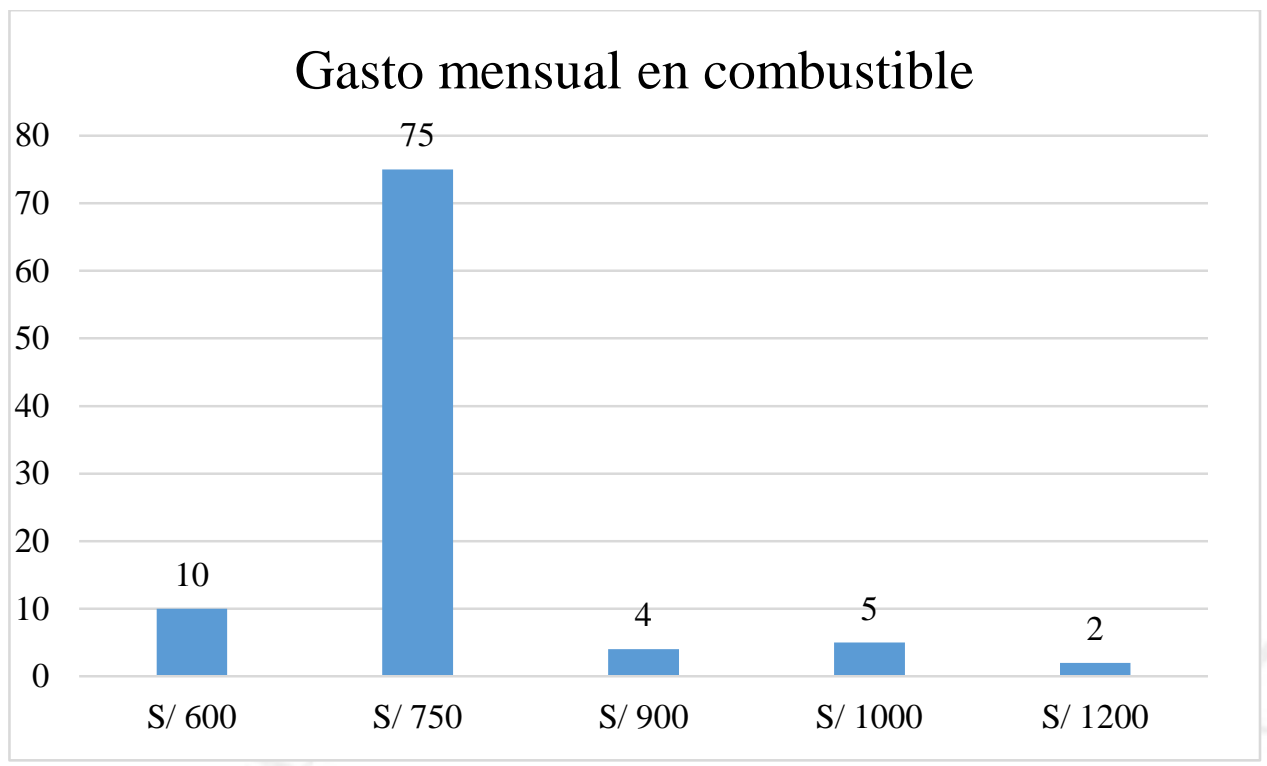

Elaboración Propia

Se aprecia claramente que la moda del consumo de combustible es de 750 soles mensuales.

\begin{tabular}{|l|c|c|}
\hline $\begin{array}{l}\text { ¿Compraría un sistema que reduzca } \\
\text { su consumo de combustible? }\end{array}$ & Si & No \\
\hline Cantidad & 90 & 6 \\
\hline
\end{tabular}


Figura 2.10

¿Compraría un sistema que reduzca su consumo de combustible?

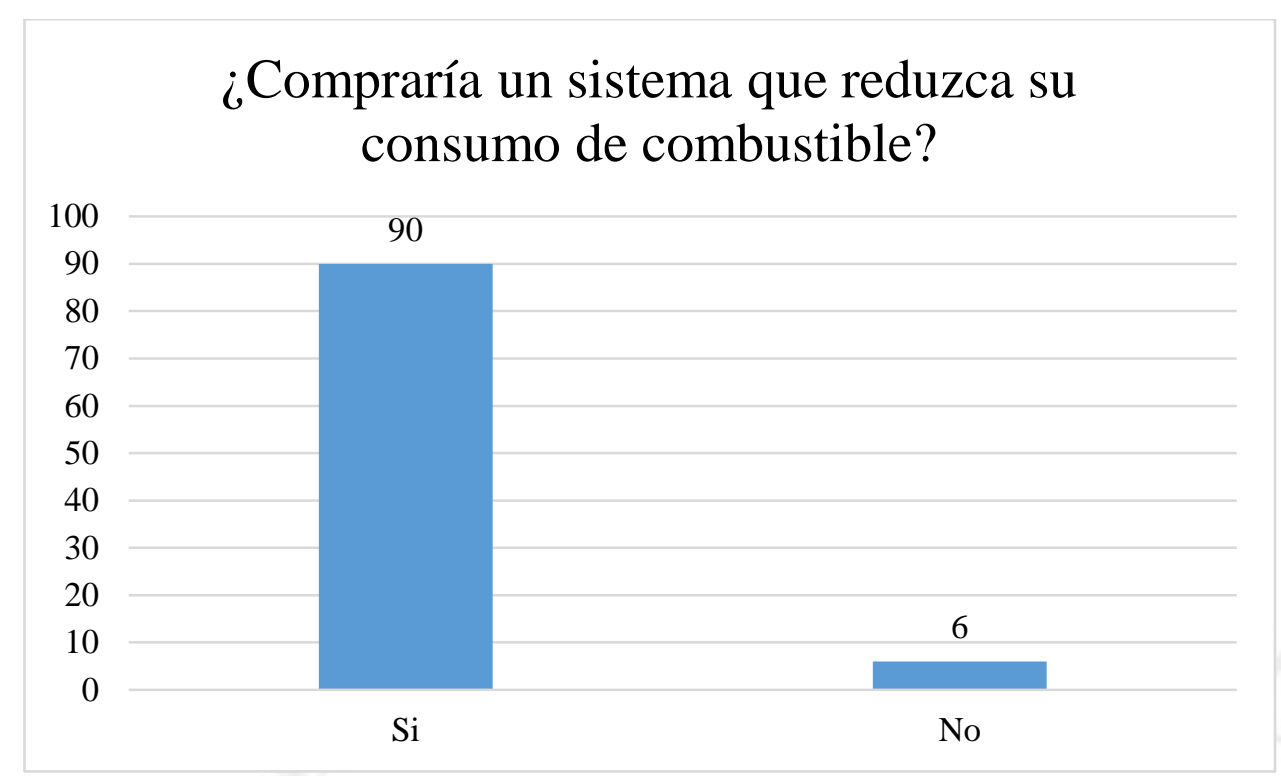

Elaboración Propia

Se aprecia claramente que la mayoría de taxistas comprarían un sistema que reduzca su consumo de combustible.

\begin{tabular}{|l|c|c|}
\hline $\begin{array}{l}\text { ¿Compraría un sistema que aumente } \\
\text { la potencia de su vehículo? }\end{array}$ & $\mathrm{Si}$ & No \\
\hline Cantidad & 81 & 15 \\
\hline
\end{tabular}


Figura 2.11

¿Compraría un sistema que aumente la potencia de su vehículo?

¿Compraría un sistema que aumente la potencia de su vehículo?

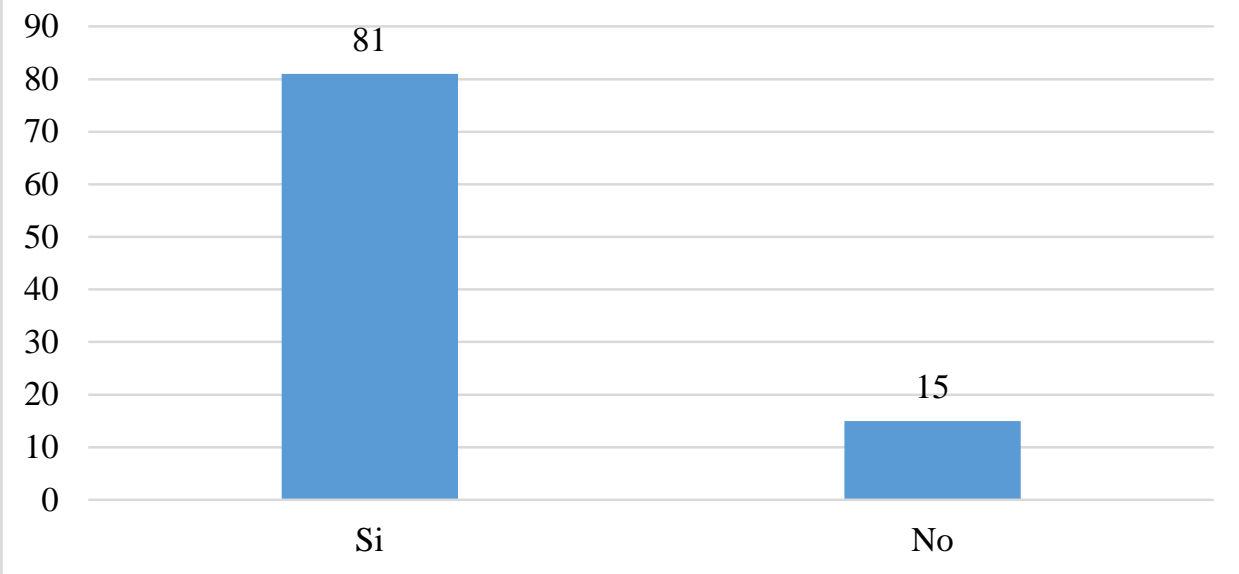

Elaboración Propia

Se aprecia que la mayoría de taxistas comprarían un sistema que aumente la potencia de su vehículo.

\begin{tabular}{|l|c|c|}
\hline $\begin{array}{l}\text { ¿Compraría un sistema que alargue } \\
\text { el periodo de vida de su motor? }\end{array}$ & $\mathrm{Si}$ & No \\
\hline Cantidad & 63 & 33 \\
\hline
\end{tabular}


Figura 2.12

¿Compraría un sistema que aumente la potencia de su vehículo?

¿Compraría un sistema que aumente la potencia de su vehículo?

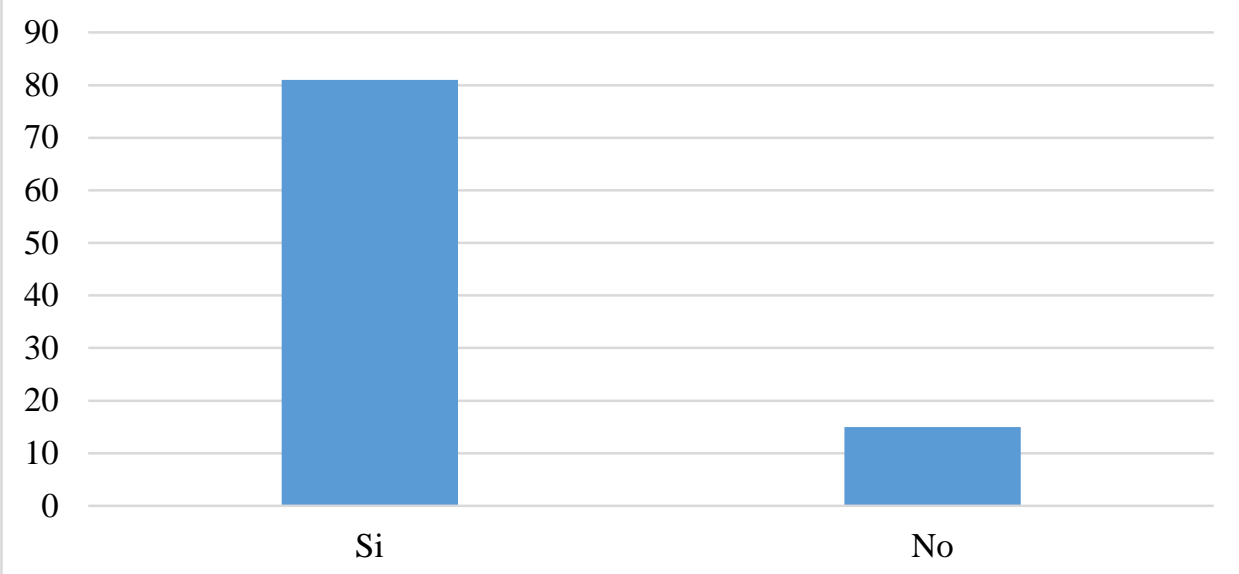

Elaboración Propia

Se aprecia que la mayoría de taxistas alargue el periodo de vida de su vehículo.

\begin{tabular}{|l|c|c|}
\hline $\begin{array}{l}\text { ¿Compraría un sistema que reduzca } \\
\text { su consumo de combustible, } \\
\text { aumente la potencia de su vehículo y } \\
\begin{array}{l}\text { alargue el periodo de vida de su } \\
\text { motor? }\end{array}\end{array}$ & $\mathrm{Si}$ & No \\
\hline Cantidad & 90 & 6 \\
\hline
\end{tabular}


Figura 2.13

¿Compraría un sistema que reduzca su consumo de combsutible, aumente la potencia de su vehículo y alargue el periodo de vida de su motor?

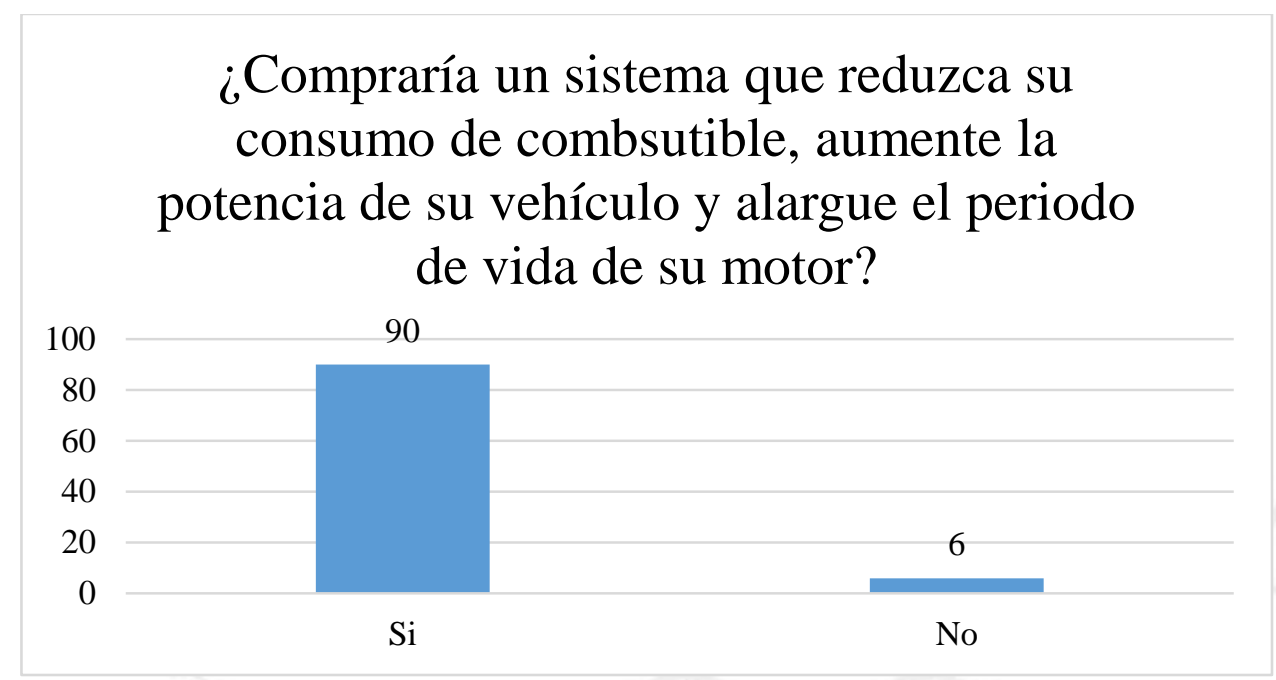

Elaboración Propia

Se aprecia claramente que la mayoría de taxistas comprarían un sistema que reduzca su consumo de combustible, aumente la potencia de su vehículo y alargue el tiempo de vida de su vehículo.

\begin{tabular}{|l|c|c|c|}
\hline $\begin{array}{l}\text { ¿Cuánto estaría dispuesto a pagar } \\
\text { por el sistema? }\end{array}$ & S/ 2000 & S/ 2500 & S/ 3000 \\
\hline Cantidad & 90 & 5 & 1 \\
\hline
\end{tabular}


Figura 2.14

¿Cuánto estaría dispuesto a pagar por el sistema?

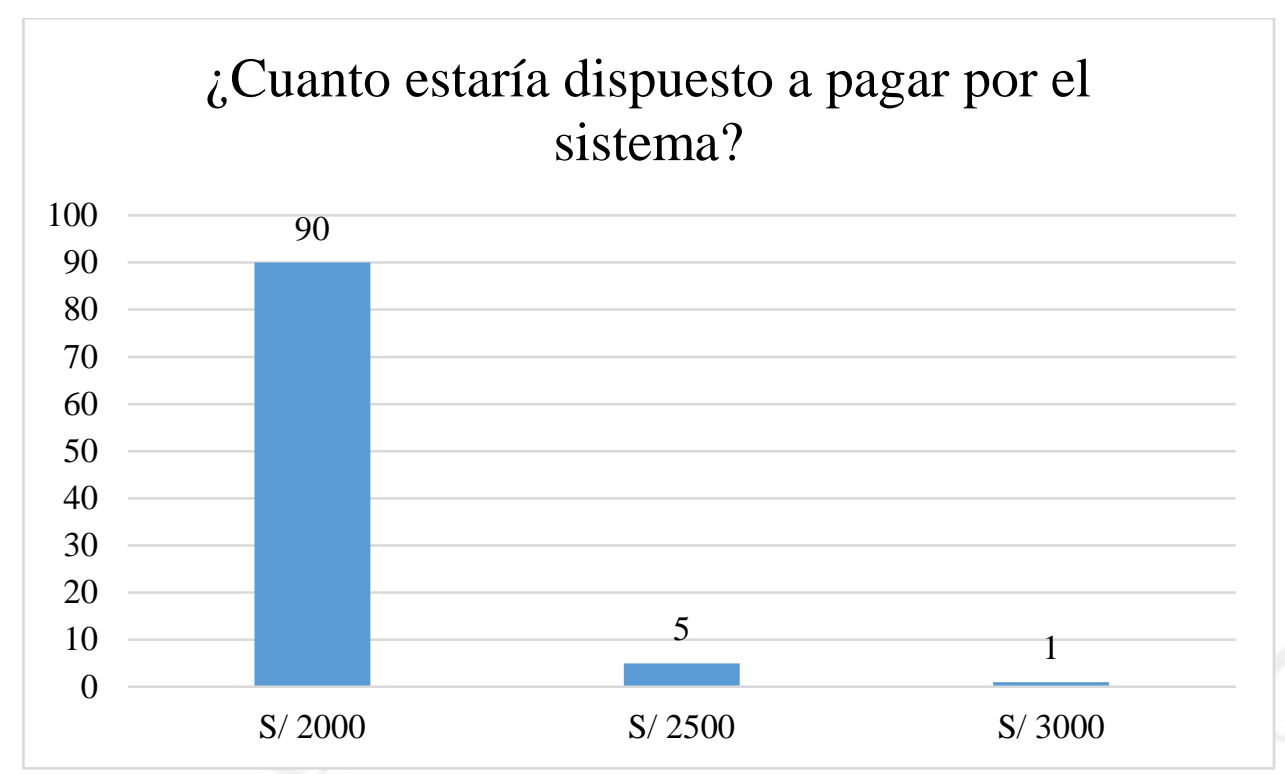

Elaboración Propia

Se aprecia claramente que la mayoría de taxistas estaría dispuesto a pagar 2000 soles por este sistema.

¿Qué tan interesado estaría en comprar un sistema que reducirá el consumo de combustible de su vehículo, aumentará la potencia y alargará el periodo de vida de su motor?

\begin{tabular}{|c|c|c|c|c|c|c|c|c|c|}
\hline 10 & 9 & 8 & 7 & 6 & 5 & 4 & 3 & 2 & 1 \\
\hline 36 & 27 & 16 & 10 & 3 & 1 & 3 & 0 & 0 & 0 \\
\hline
\end{tabular}


Figura 2.15

¿Qué tan interesado estaría en comprar un sistema que reducirá el consumo de combustible de su vehículo, aumentará la potencia y alargará el periodo de vida de su motor?

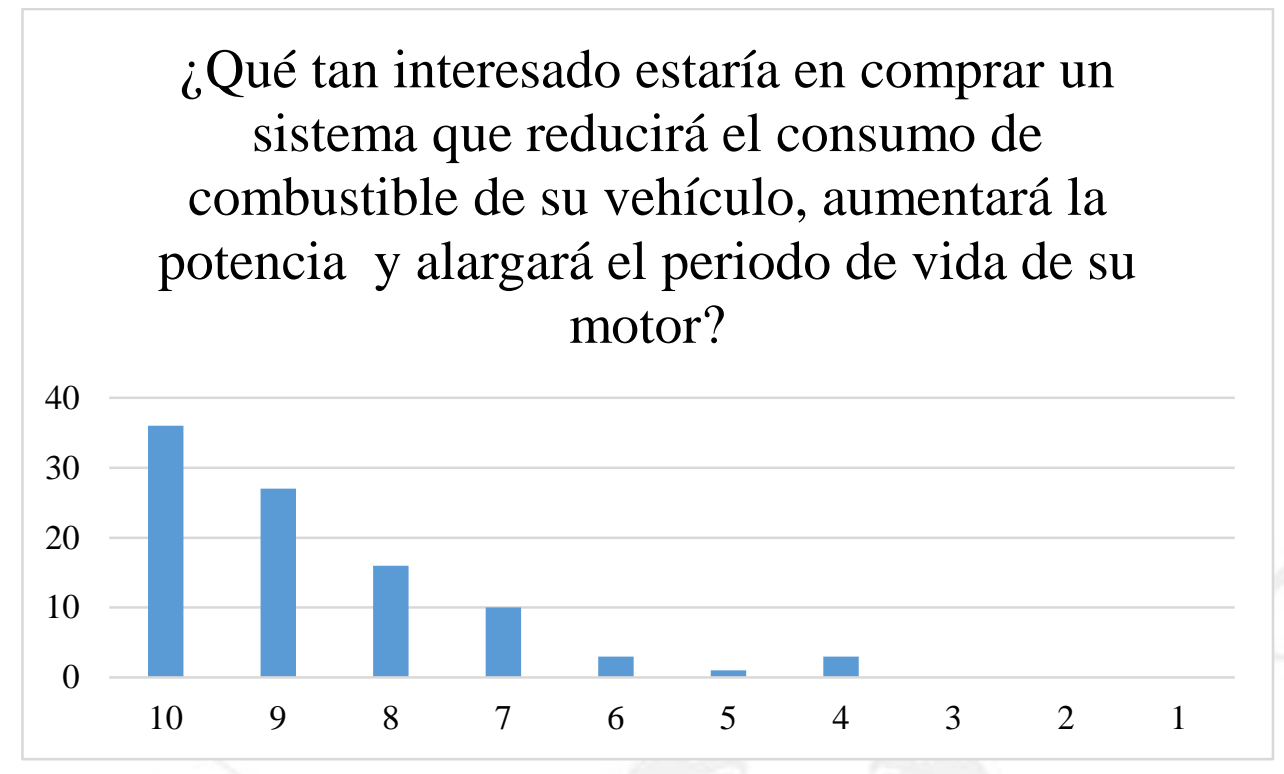

Elaboración Propia

Viendo los resultados totales se obtuvieron:

Éxitos: 90

Fracasos: 6

Por lo que la demanda del proyecto es del $93.75 \%$ de la población objetivo.

Ahora, para determinar el total de la población objetivo, se considerará la cantidad total de taxis empadronados en servicio de taxi metropolitano (SETAME), requisito para poder ofrecer el servicio de taxi de manera formal. Existen 150000 taxis empadronados (Comercio, 2012).

De tal modo, la demanda para el proyecto estaría reflejada el siguiente cálculo: $150,000 *(0.9375)=140675$ unidades

Más aun, sincerando la cantidad de interesados por la intención de compra encontrada se puede determinar la demanda según el cálculo:

$150,000 *(1.0 * 36+0.9 * 27+16 * 0.8+0.7 * 10+0.6 * 3+0.5 * 1+0.4 * 3)=125400$ unidades 


\subsection{Estrategia de comercialización}

\subsubsection{Análisis de las 4P's}

\section{Producto}

El producto fue detallado en capítulos anteriores.

\section{Precio}

El precio de cada sistema H2PRO será de 2000 soles. Este precio incluye el servicio de instalación y la garantía por defectos de fábrica por un año. La política de precio será mantener un precio fijo de cara al cliente en todos los puntos de venta por lo que no se podrá negociar con respecto a ese monto, más bien, la negociación será con respecto a la oferta de productos complementarios al sistema (ej. agua destilada para su abastecimiento) u otros productos o servicios ajenos a él (ej. Descuento en cambio de aceite, mantenimiento de frenos, etc.).

Con respecto a la percepción del valor del cliente, cabe decir que esta es una inversión que es principalmente motivada por el beneficio del ahorro de combustible, el cual oscila entre $20 \%$ a $30 \%$. Por otro lado, siendo 750 soles la moda del gasto mensual en consumo de combustible de taxistas, se generarán ahorros mensuales de entre 150 y 225 soles, por lo que la inversión realizada se recuperará entre 8 y 13 meses. Cabe mencionar que el ahorro se verá acompañado por otros beneficios como la extensión del periodo de vida del motor y el aumento de potencia, los cuales son difíciles de traducir en valor monetario al cliente.

El producto se distribuirá al por mayor a los distribuidores a un precio de 800 soles, de tal manera que tengan una alternativa tecnológica para realizar un buen negocio dentro de su marketing mix. De esta manera, realizando instalaciones de estos sistemas y vendiéndolos a 1695 soles (2000 soles incluyendo el IGV.).

Esto representa una estrategia agresiva de precio de penetración de mercado para asegurar de que sea una prioridad para el taller distribuidor la venta de estos sistemas. Asimismo, dentro del precio final se estima que el 10\% de la venta neta (169.5 soles) sea considerado como una comisión para el vendedor del taller para motivarlo a cerrar ventas y tomar como prioridad este producto frente a otros que pueda ofrecer el taller. Asimismo, el 
incurrirá en una inversión en mano de obra de 6 horas en promedio para la instalación del sistema en un carro, lo que les generará un costo de 70 soles. De esta manera, el taller tendría una utilidad de 655.5 soles por cada sistema instalado, lo que significa una rentabilidad del $81.19 \%$, lo cual es más rentable que instalar sistemas de GNV o GLP, los cuales rentabilizan entre $30 \%$ y $35 \%$ sobre la inversión. Esto es nuevamente parte de una estrategia de precio para asegurar de que los talleres distribuidores prioricen la venta del sistema de hidrógeno H2PRO frente a otros productos.

\section{Plaza}

El producto se comercializará a través de una red de distribuidores autorizados conformados principalmente por talleres que actualmente realizan conversiones de sistemas a gas (GNV y/o GLP) a donde acuden los taxistas a instalar estos sistemas y a realizar mantenimiento y regulaciones de los mismos, y talleres de mecánica ligera donde suelen realizar mantenimientos preventivos o correctivos. De esta manera se tendría una estrategia de distribución selectiva.

\section{Promoción}

La promoción de los sistemas H2PRO será realizada a través de pautas publicitarias en radios y en diarios. Estas serán enfocadas en los medios que sean de mayor audiencia y lectura de los taxistas.

Asimismo, se realizarán esfuerzos por participar en programas radiales y televisivos referentes al rubro automotriz de preferencia enfocados en el segmento de taxistas.

Se contará material publicitario en el punto de venta incluyendo banners explicativos y volantes, al igual que el esfuerzo de ofrecimiento del vendedor del local.

Asimismo, el ofrecimiento comercial será realizado por el asesor de ventas del propio taller, quien motivado por la comisión que recibirá, explicará y persuadirá al cliente para que adquiera la tecnología.

Se adoptará, también, como política de promoción el ofrecer un servicio de capacitación gratuita constante para asegurar que el distribuidor cuente con los conocimientos necesarios para atender de la mejor manera al cliente y para que los técnicos puedan instalar correctamente el sistema, de igual modo, se ofrecerá garantía de fábrica sobre defectos de manufactura. 
Asimismo, como política de comercialización se exigirá una alta calidad de servicio a la hora que el distribuidor atienda a potenciales clientes, al igual que este dé un servicio de instalación y mantenimiento de correcto que no genere disconformidades en el cliente final.

Finalmente, al tratarse de un producto altamente tecnológico y nuevo en el mercado, se buscará contar con certificaciones de laboratorios acreditados, como el laboratorio de motores de la Universidad Nacional de Ingeniería, que respalden la reducción del consumo de combustible y que aseguren que no existirán efectos colaterales a la hora de instalar esta tecnología. De esta manera, para exhibir estos resultados y ofrecer mayor explicación, se contará con un sitio web donde los interesados podrán acceder a esta información al igual que conocer los puntos de venta.

\subsubsection{Análisis de precios}

\subsubsection{Tendencia histórica de los precios}

No existe una tendencia histórica a nivel nacional ya que este producto aún no ha sido insertado al mercado peruano con éxito.

\subsubsection{Precios actuales}

Actualmente, la empresa presente en el mercado, mencionada anteriormente, ofrece el producto a 2000 USD, el servicio incluye la instalación y garantía de 3 años.

Con respecto a la oferta en el extranjero, existen los siguientes proveedores que ofrecen sistemas análogos a los propuestos a los siguientes precios: 
- Proveedor: HHO PLUS

Figura 2.16

Sistema de hidrógeno HHO PLUS - DC2000

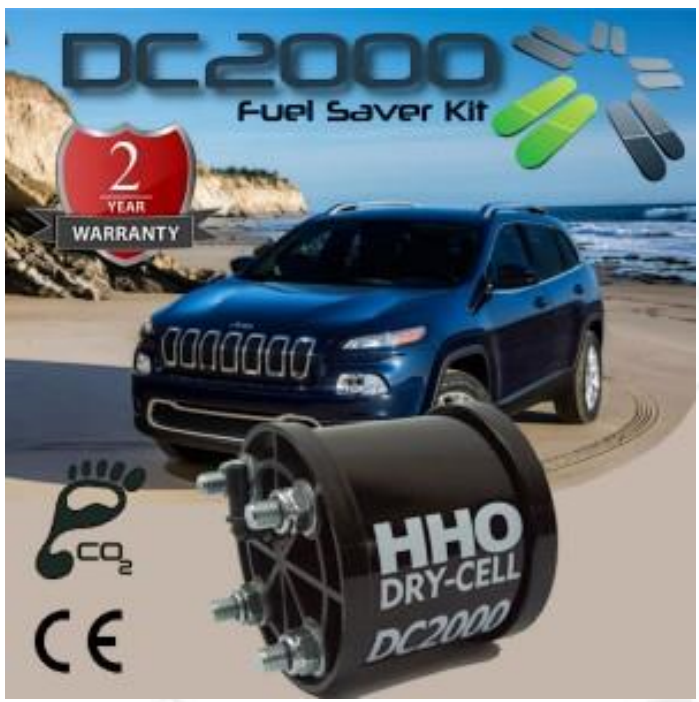

Fuente: HHO Plus Lda., (2008)

País de origen: Portugal

Precio FOB: 224.8 Euros (807.90 soles)

Precio CIF: 304.8 Euros (1095.40 soles)

Precio DDP: 1680.34 soles

Este producto no incluye el servicio de instalación.

Fuente: HHO Plus Lda., (2008) 
- Proveedor: Ocean GO

Figura 2.17

Sistema de hidrógeno OCEAN GO

OGO COMPLETE HHO SYSTEM

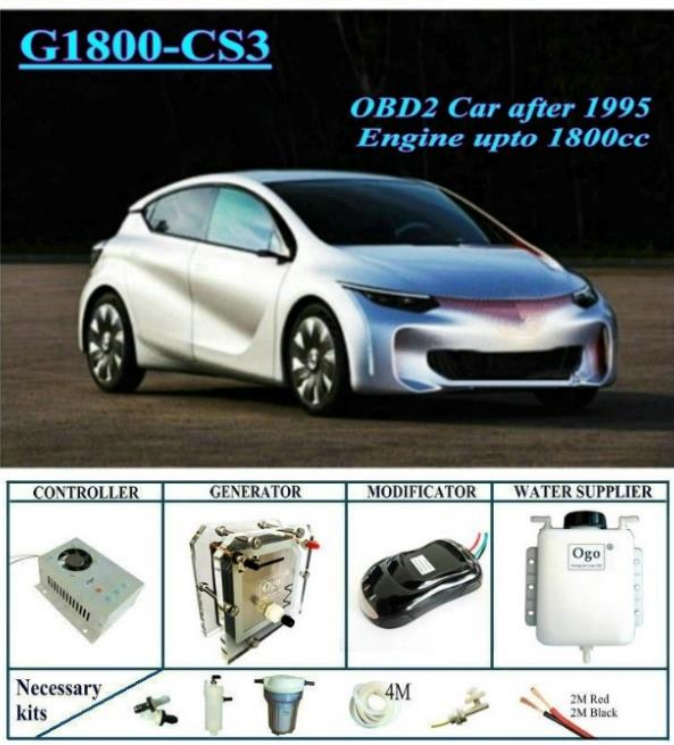

Fuente: Ocean Go Ltda., (2014)

País de origen: China

Precio FOB: 252.3 Dólares (832.59 soles)

Precio CIF: 327.3 Dólares (1080.09 soles)

Precio DDP: 502.08 Dólares (1656.86 soles)

Este producto no incluye el servicio de instalación.

Fuente: Ocean Go Ltda., (2014) 


\subsection{Disponibilidad de insumos}

\subsubsection{Características principales de la materia prima}

La materia prima para elaborar estos dispositivos es el acero inoxidable 3161.

Tabla 2.5

Composición química del acero inoxidable 316L

\section{Composición Química}

\begin{tabular}{c|c|c|c|c|c|c|c}
\hline$\% \mathrm{C}$ & $\% \mathrm{Mn}$ & $\% \mathrm{Si}$ & $\% \mathrm{Cr}$ & $\% \mathrm{Ni}$ & $\% \mathrm{Mo}$ & $\begin{array}{c}\% \mathrm{P} \\
\text { (máx.) }\end{array}$ & $\begin{array}{c}\% \mathrm{~S} \\
\text { (máx.) }\end{array}$ \\
\hline 0,035 & 2,00 & 1,00 & $16,0-18,0$ & $10,0-15,0$ & $2,0-3,0$ & 0,04 & 0,03 \\
& & & & & & & \\
\hline
\end{tabular}

Fuente: Aceros Otero, (2012)

\subsubsection{Potencialidad del recurso en la zona de influencia del proyecto}

Este recurso no tiene gran potencialidad, ya que es un producto importado. Existen 3 proveedores que ofrecen este producto en Lima metropolitana. 


\section{CAPÍTULO III: LOCALIZACIÓN DE PLANTA}

\subsection{Análisis de los factores de localización}

- Proximidad a la materia prima

Es uno de los factores más importantes ya que los distintos materiales deben contar con características técnicas específicas para poder asegurar la calidad del producto. Por ello, la disponibilidad de proveedores que ofrezcan un producto de calidad es muy deseable para tener un desarrollo industrial sin inconvenientes y evitar un sistema logístico complejo que implique el transporte de dichos insumos desde otra ciudad o, en su defecto, su importación.

- Cercanía al mercado

Un factor clave para el éxito de este proyecto industrial es la cercanía a quienes serán los consumidores finales, quienes serán los propietarios de vehículos, principalmente taxistas. Nuevamente, el factor logístico se presenta como un acápite cuya simplicidad beneficiará el desempeño industrial y comercial. Se debe contar, también, con vías como carreteras y avenidas de acceso asfaltadas para no afectar el tiempo de entrega ni el lead time de la cadena productiva.

- Disponibilidad de mano de obra

Al ser un proyecto industrial que incluye la transformación física de materias primas como plásticos y metales aplicando maquinaria especializada para dichos fines (corte laser, corte plasma, etc.), se deberá contar con personal capacitado en labores metal mecánicas, al igual que profesional docto en nociones químicas y administrativas para la debida gestión del proyecto.

- Abastecimiento de energía

La tecnología escogida se alimenta en su totalidad de energía eléctrica. Si bien la potencia instalada se estima que será de baja magnitud, es fundamental contar con el suministro electricidad, el cual debe ser de baja tensión (220V) para cumplir con las especificaciones técnicas de funcionamiento de la maquinaria selecta. 
- Disponibilidad de terreno

La disponibilidad de un espacio físico para la instalación de la fábrica es de suma importancia pues si no hay locales disponibles, la viabilidad del proyecto será simplemente nula. El local deba debe estar debidamente acondicionado para poder instalar la máquinas e implementos para la actividad fabril. El espacio necesario debe el necesario para poder cumplir con los requerimientos para poder ubicar la zona fabril, administrativa, estacionamiento de vehículos para el transporte, entre otros.

- Eliminación de desechos e impacto ambiental

El proceso productivo tiene como desechos metales y plásticos, los cuales deben ser reciclados para la óptima gestión ambiental del proyecto. Para tener una operación coherente con la afirmación anterior, lo óptimo será estar en una contexto industrial donde se cuente con fundiciones y plantas recicladoras.

- Reglamentos fiscales, legales y ambientales

Es de suma importancia tomar en cuenta la legislación vigente y la normativa a nivel local para la factibilidad de instalación de la fábrica. El proyecto debe desarrollarse según los lineamientos contemplados en la Ley de Formalización y Promoción de la Pequeña empresa $\left(N^{\circ} 27651\right)$, Ley de Seguridad y Salud en el Trabajo ( $\left.N^{\circ} 29783\right)$, entre otras.

- Condiciones de vida

La relevancia de este factor radica en el nivel comodidad básica que exige un empleado de todos niveles. Factores importantes son: vivienda, educación, alimentación, recreación y servicios de salud que se puedan ubicar en el entorno del proyecto.

\subsection{Posibles ubicaciones de acuerdo a factores predominantes}

De acuerdo a la metodología adoptada para el desarrollo de estudio se han definido dos posibles ubicaciones para las instalaciones para la instalación de la planta. Las dos alternativas son: Lima metropolitana, La Libertad, y Arequipa.

- Proximidad a la materia prima

Se eligió Lima Metropolitana por la cantidad de empresas que comercializan las materias primas (ej. JN Aceros SA, JAHESA, JEBEMSA, etc.). Por otra parte, Arequipa 
posee una mucho menor cantidad de oferta de los insumos industriales, aun así, existen proveedores donde se podría obtener el acero, caucho y demás productos (Aceros Comerciales, Mr Ingenieros Eirl, Imtesi SAC, etc,). Finalmente, La Libertad se encuentra en un escenario inferior al de Arequipa, ya que existen menos proveedores (Ingeniería Edwards, Comercial Rc SRL, K y G Representaciones Eirl).

- Cercanía al mercado

La mayor parte del parque automotor peruano de encuentra en la capital, luego en La Libertad, siendo seguida en volumen por la provincia de Arequipa.

Tabla 3.1

Parque automotor por provincias

\begin{tabular}{|l|r|r|}
\hline \multicolumn{1}{|c|}{ Provincia } & Vehículos & \multicolumn{1}{c|}{$\%$} \\
\hline Lima y Callao & $1,590,755$ & $65.63 \%$ \\
\hline La Libertad & 178,433 & $7.36 \%$ \\
\hline Arequipa & 164,302 & $6.78 \%$ \\
\hline Otros & 490,206 & $20.23 \%$ \\
\hline
\end{tabular}

Elaboración Propia

Figura 3.1:

Parque automotor por províncias

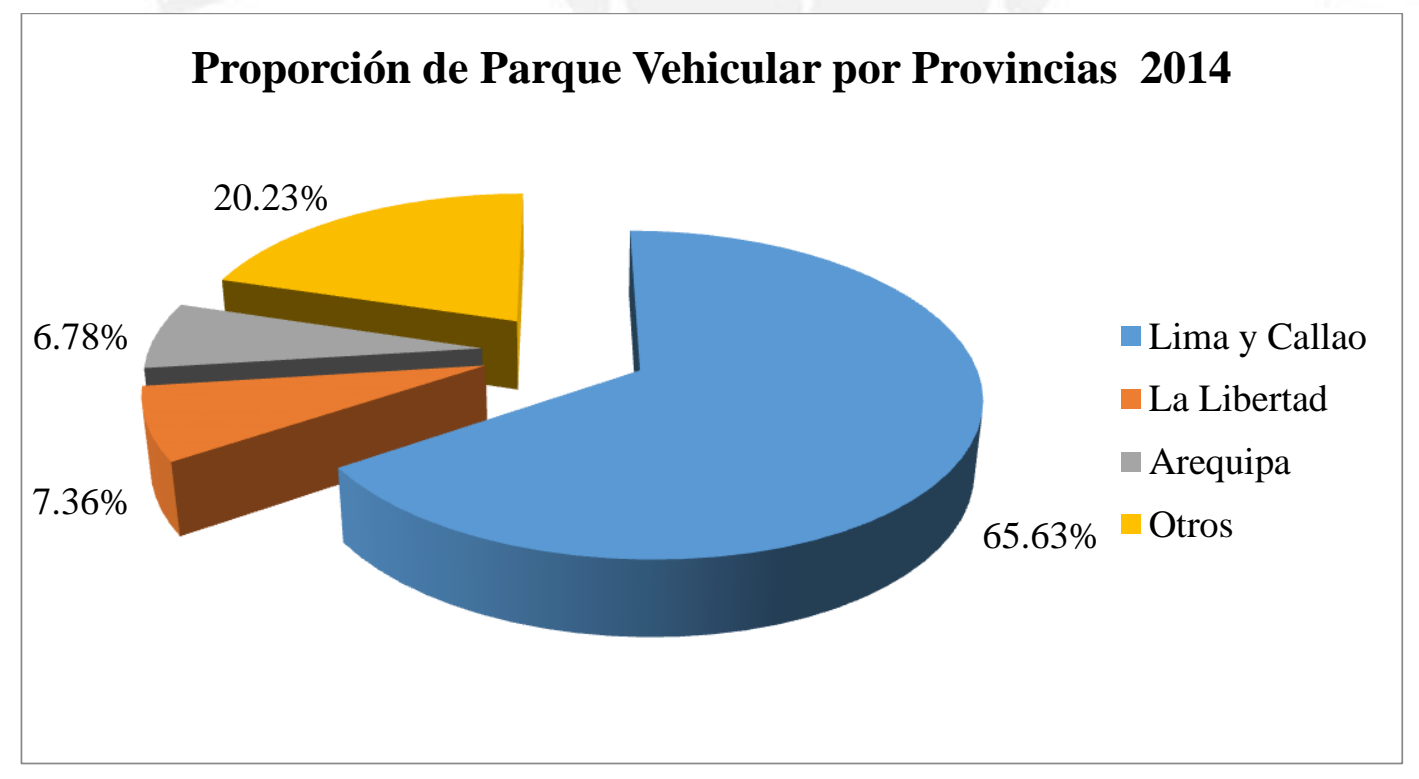

Elaboración Propia 
- Disponibilidad de terreno

Este es un factor esencial para tener una noción sobre la inversión inicial. Además, se debe tomar en cuenta que el costo por metro cuadrado va a afectar la rentabilidad del proyecto, por lo que se busca contar con un precio bajo para poder tener indicadores financieros auguradores. Por otro lado, se debe tomar en cuenta que un terreno con mejor ubicación puede significar un mayor costo, pero puede resultar siendo costo beneficioso al evaluar otros aspectos como el diseño de la red logística, cercanía al mercado, entre otros factores.

En los departamentos propuestos existe la presencia de parques industriales, lo cual es idóneo para el desarrollo del proyecto industrial. Se aprecia que en Lima existe una mayor cantidad que en La Libertad y en Arequipa. En los las provincias más desarrolladas se suele encontrar terrenos a un mayor costo, mientras que existen parques industriales que se encuentran en desarrollo que tienen un menor precio por metro cuadrado.

A continuación se presenta una relación de los parques industriales donde el proyecto se podría instalar:

Tabla 3.2

Parques Industriales del Perú

\begin{tabular}{|l|c|c|c|}
\hline Parque Industrial & Departamento & Provincia & Distrito \\
\hline Villa el Salvador & Lima & Lima & Villa el Salvador \\
\hline $\begin{array}{l}\text { Villa Maria del } \\
\text { Triunfo }\end{array}$ & Lima & Lima & $\begin{array}{c}\text { Villa Maria del } \\
\text { Triunfo }\end{array}$ \\
\hline Huaycan & Lima & Lima & Ate \\
\hline El Asesor & Lima & Lima & Ate \\
\hline Lomas de Carabayllo & Lima & Lima & Carabayllo \\
\hline Pachacutec & Lima & Lima & Ventanilla \\
\hline Ventanilla & Lima & Lima & Callao \\
\hline Infantas & Lima & Lima & Los Olivos \\
\hline AMINOR & La Libertad & Trujillo & Trujillo \\
\hline El Porvenir & La Libertad & Trujillo & El Porvenir \\
\hline Arequipa & Arequipa & Arequipa & Arequipa \\
\hline Rio Seco & Arequipa & Arequipa & Cerro Colorado \\
\hline El Palomar & Arequipa & Arequipa & Cerro Colorado \\
\hline APIMA & Arequipa & Arequipa & Paucarpata \\
\hline
\end{tabular}

Fuente: FENAPIP, (2014) 


\subsection{Evaluación y selección de localización}

La determinación de la ubicación de la planta involucra un análisis de la macro localización y micro localización. Para el primero se desarrollará empleando el método de ranking de factores para comparar cada uno de los criterios, tomando en cuenta su relevancia. Una vez definida la macro localización, se procederá a determinar la micro localización empleando la misma metodología.

\subsubsection{Evaluación y selección de la macro localización}

Para determinar la zona donde va a estar ubicada la planta se clasificarán los factores para determinar cuales tienen mayor importancia y por ello son los predominantes.

Para simplificar la elaboración de la tabla de enfrentamiento de factores, se codificarán los distintos factores a comparar.

Tabla 3.3

Codificación de los factores de localización

\begin{tabular}{|c|l|c|}
\hline $\mathrm{N}^{\circ}$ & \multicolumn{1}{|c|}{ Factor } & Código \\
\hline 1 & Proximidad a la materia prima & PMP \\
\hline 2 & Cercanía al mercado & $\mathrm{CM}$ \\
\hline 3 & Disponibilidad de terreno & DT \\
\hline
\end{tabular}

Elaboración Propia

Luego de asignar una codificación a cada factor, se desarrolló una matriz de enfrentamiento con el propósito de cuantificar la importancia o relevancia de cada factor para el posterior análisis de la ubicación. Para realizar la matriz y calificar los factores se utilizaron los siguientes criterios: 
Tabla 3.4

Reglas de calificación en matriz de enfrentamiento para macro localización

\begin{tabular}{|c|c|}
\hline Calificación & Descripción \\
\hline 1 & El factor es más importante que el factor comparado \\
\hline 0 & El factor es menos de importante que el factor comparado \\
\hline 1 & Importancia equivalente \\
\hline
\end{tabular}

Elaboración Propia

Tabla 3.5

Matriz de enfrentamiento para macro localización

\begin{tabular}{|c|c|c|c|c|c|}
\hline Factores & PMP & CM & DT & Conteo & Ponderación \\
\hline PMP & & 1 & 0 & 1 & $20 \%$ \\
\hline CM & 1 & & 1 & 2 & $40 \%$ \\
\hline DT & 1 & 1 & & 2 & $40 \%$ \\
\hline
\end{tabular}

Elaboración Propia

Finalmente se procedió a evaluar cada una de las localizaciones respecto a los factores de localización. Para ello se utilizó una escala de calificación en cada alternativa, se obtuvo un puntaje y se logró determinar la micro localización más recomendable.

Tabla 3.6

Escala de calificación de los factores de macro localización

\begin{tabular}{|c|c|}
\hline Escala & Calificación \\
\hline Excelente & 5 \\
\hline $\begin{array}{c}\text { Muy } \\
\text { bueno }\end{array}$ & 4 \\
\hline Bueno & 3 \\
\hline Regular & 2 \\
\hline Deficiente & 1 \\
\hline
\end{tabular}

Elaboración Propia 
Se procede a la calificación de las tres opciones en evaluación:

Tabla 3.7

Ranking de factores para determinar macro localización

\begin{tabular}{|c|c|c|c|c|c|c|c|}
\hline \multirow{2}{*}{ Factores } & \multirow{2}{*}{ Ponderación } & \multicolumn{2}{|c|}{ Lima } & \multicolumn{2}{|c|}{ La Libertad } & \multicolumn{2}{|c|}{ Arequipa } \\
\hline & & Calificación & Puntaje & Calificación & Puntaje & Calificación & Puntaje \\
\hline PMP & $20 \%$ & 5 & 1 & 2 & 0.4 & 3 & 0.6 \\
\hline $\mathbf{C M}$ & $40 \%$ & 5 & 2 & 3 & 1.2 & 2 & 0.8 \\
\hline DT & $40 \%$ & 4 & 1.6 & 2 & 0.8 & 3 & 1.2 \\
\hline Total & $100 \%$ & & 4.60 & 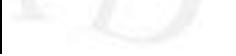 & 2.40 & & 2.60 \\
\hline
\end{tabular}

Elaboración Propia.

Finalmente se obtuvo que la localización recomendada para la instalación de la planta de fabricación de celdas de electrólisis sea en Lima ya que obtuvo mayor puntaje con respecto a sus pares de Arequipa y la Libertad.

\subsubsection{Evaluación y selección de la micro localización}

En el presente estudio tomará como referencia el apartado anterior, donde se escogió a la provincia de Lima como ubicación para este proyecto industrial. Más aún, el análisis de micro localización se realizará en Lima Metropolitana y Callao debido a que es el sector donde se concentra el mayor dinamismo económico de la provincia. Dentro de este espacio físico definido se escogerá el distrito donde sea conveniente realizar la instalación industrial.

\subsubsection{Evaluación y selección de la provincia o distrito}

Después de analizar la macro localización, se procederá a analizar la micro localización del proyecto industrial. Los tres Distritos propuestos son:

- Ate Vitarte

- Villa María del Triunfo

- Villa El Salvador

Para comparar estos tres distritos debemos definir métricas y asignarles pesos o niveles de importancia y así poder implementar la metodología de ranking de factores. 
Los factores a analizar serán:

- Costo del terreno

Este es un factor relevante ya que impactará directamente en los gastos operativos del proyecto y por consiguiente en la rentabilidad de este.

En las siguientes tablas se muestran el rango de precios por zona industrial en Lima metropolitana:

Tabla 3.8

Costo por m2 en zonas industriales por sectores de Lima Metropolitana

\begin{tabular}{|c|c|}
\hline Sectores de Lima & Rango de precios (USD/M2) \\
\hline Lima Norte & $250-550$ \\
\hline Lima Centro & $300-600$ \\
\hline Lima Este & $150-350$ \\
\hline Lima Sur & $150-400$ \\
\hline
\end{tabular}

Elaboración Propia

De la información presentada, se aprecia que el rango de precios es bastante similar entre Lima Este (Ate) y Lima Sur (VMT y VES), teniendo un rango pequeñamente menor y más económico el sector este.

- Disponibilidad de terreno

La importancia de este factor radica en que la oferta de terrenos dispondrá la factibilidad de adquirir uno para el montaje industrial. Para tener una noción de la distribución de estos locales, a continuación se presenta información relevante:

Tabla 3.9

M2 en zonas industriales por sectores de Lima Metropolitana

\begin{tabular}{|l|c|c|}
\hline \multicolumn{1}{|c|}{ Zona } & $\mathbf{m 2}$ & $\mathbf{\%}$ \\
\hline $\begin{array}{l}\text { Lima } \\
\text { centro }\end{array}$ & $3,004,638$ & 4.26 \\
\hline Lima Sur & $16,612,568$ & 23.58 \\
\hline Lima Este & $36,595,945$ & 51.93 \\
\hline Lima Norte & $5,706,819$ & 8.10 \\
\hline Callao & $8,544,968$ & 12.13 \\
\hline \multicolumn{1}{|c|}{ Total } & $\mathbf{7 0 , 4 6 4 , 9 3 8}$ & $\mathbf{1 0 0 . 0 0}$ \\
\hline
\end{tabular}

Elaboración Propia 
Se aprecia que en Lima Este hay más del doble de área industrial instalada que en Lima Sur, por lo que se presume que el distrito de Ate tendría ventaja sobre sus pares de VMT y VES.

Figura 3.2

M2 en zonas industriales por sectores de Lima Metropolitana

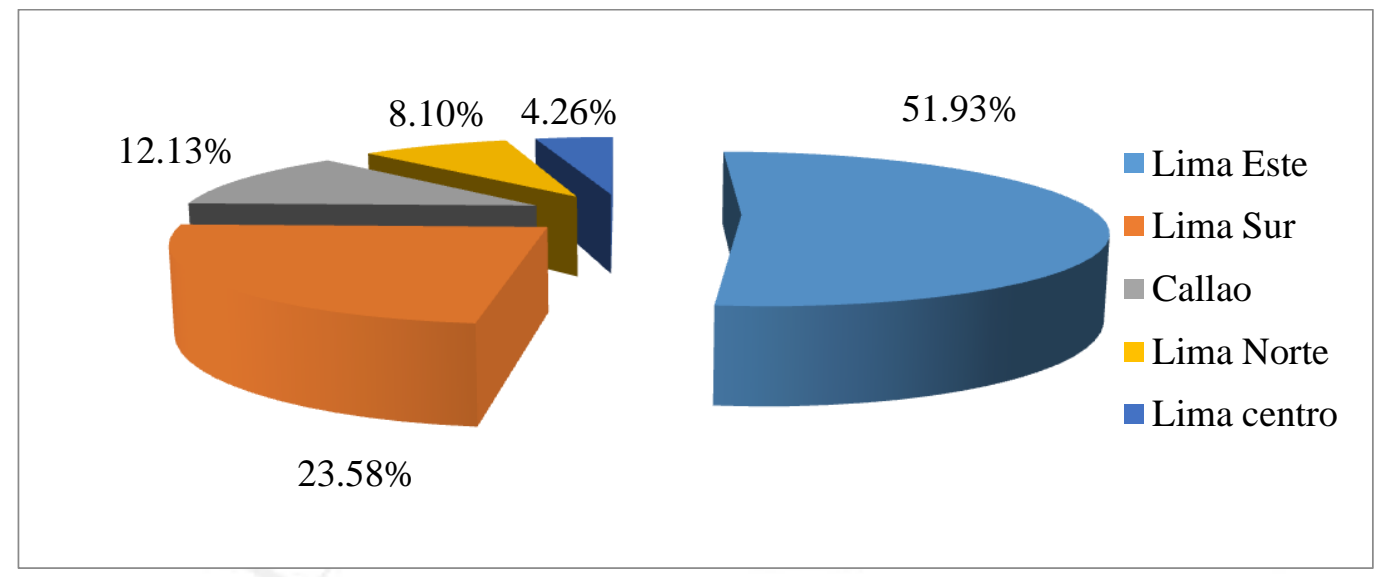

Elaboración Propia

- Facilidad de transporte

Para conocer el estado de las vías de acceso a los distritos en evaluación, se presenta la siguiente imagen, donde se aprecia de color verde las vías principales de Lima Metropolitana. 
Figura 3.3

Vías y centros de dinamismo económico en Lima Metropolitana

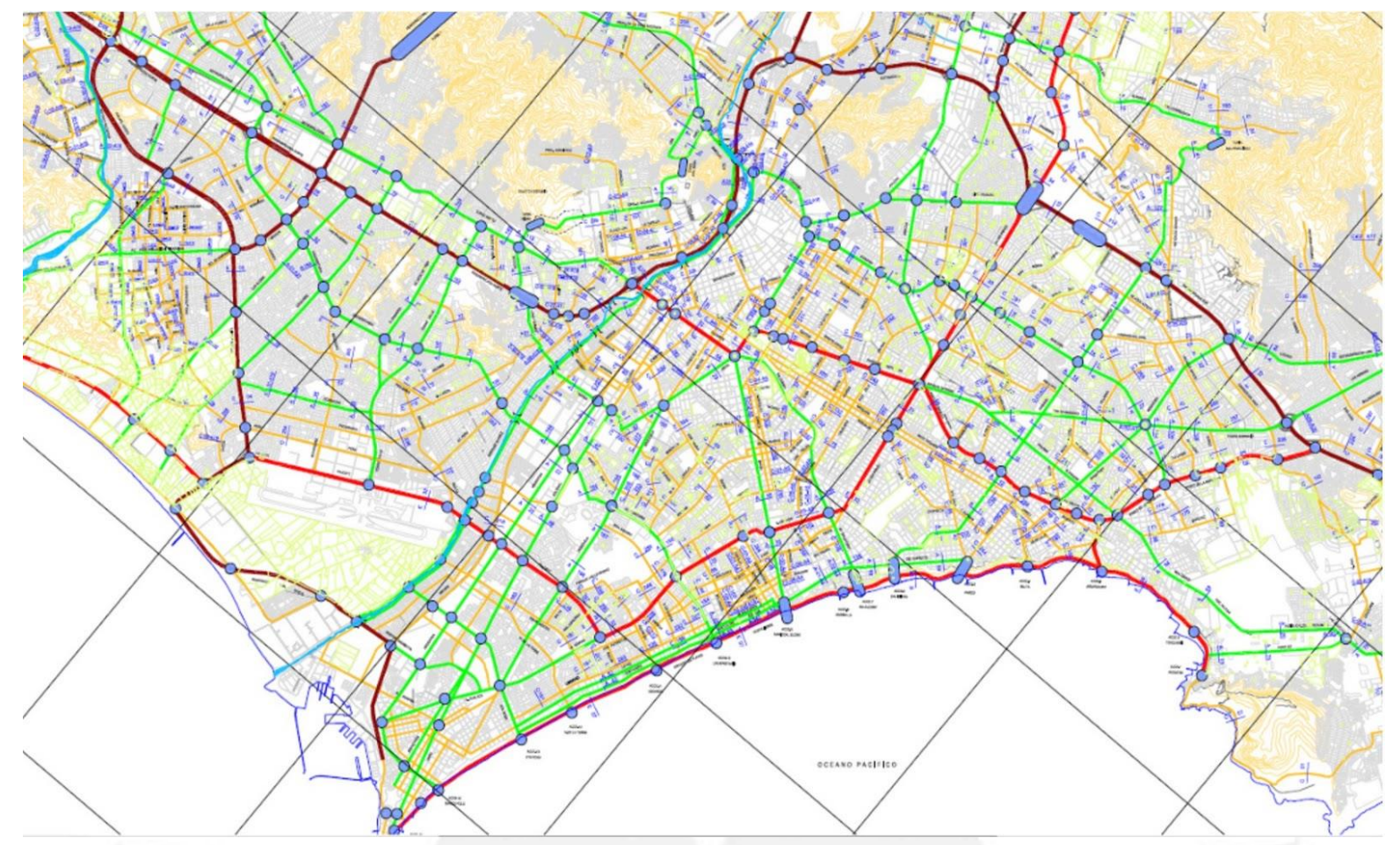

Fuente: Urbial, (2013)

Por otra parte, es relevante conocer que la principal vía de acceso a Ate es la carretera central, mientras que la de Villa María del Triunfo y Villa El Salvador es la carretera Panamericana Sur.

Para proceder con el análisis y la evaluación, a continuación se presentan los factores de mayor relevancia y su correspondiente codificación:

Tabla 3.10

Escala de calificación de los factores de macro localización

\begin{tabular}{|c|c|c|}
\hline $\mathbf{N}^{\circ}$ & Factor & Código \\
\hline $\mathbf{1}$ & Costo del terreno & CT \\
\hline $\mathbf{2}$ & Disponibilidad de terreno & DT \\
\hline $\mathbf{3}$ & Facilidad de transporte & FT \\
\hline $\mathbf{4}$ & Disponibilidad de servicios & DS \\
\hline
\end{tabular}

Elaboración Propia 
Se procede a comparar los distintos factores para determinar su importancia relativa.

Tabla 3.11

Ranking de factores para determinar macro localización

\begin{tabular}{|c|c|c|c|c|c|c|}
\hline Factores & CL & DT & FT & DS & Conteo & Ponderación \\
\hline CL & & 0 & 1 & 1 & 2 & $29 \%$ \\
\hline DT & 1 & & 1 & 1 & 3 & $43 \%$ \\
\hline FT & 0 & 0 & & 1 & 1 & $14 \%$ \\
\hline DS & 0 & 0 & 1 & & 1 & $14 \%$ \\
\cline { 5 - 7 } & & & & Total: & 7 & $100 \%$ \\
\hline
\end{tabular}

Elaboración Propia

Finalmente se procede a calificar las distintas opciones:

Tabla 3.12

Ranking de factores para determinar macro localización

\begin{tabular}{|c|c|c|c|c|c|c|c|}
\hline \multirow{2}{*}{ Factores } & \multirow{2}{*}{ Ponderación } & \multicolumn{2}{|c|}{ Ate } & \multicolumn{2}{c|}{ VMT } & \multicolumn{2}{c|}{ VES } \\
\cline { 3 - 8 } & & Calificación & Puntaje & Calificación & Puntaje & Calificación & Puntaje \\
\hline CL & $29 \%$ & 5 & 1.43 & 4 & 1.14 & 4 & 1.14 \\
\hline DT & $43 \%$ & 5 & 1.43 & 3 & 0.86 & 3 & 0.86 \\
\hline FT & $14 \%$ & 2 & 0.57 & 4 & 1.14 & 4 & 1.14 \\
\hline DS & $14 \%$ & 5 & 1.43 & 4 & 1.14 & 4 & 1.14 \\
\hline Total & $100 \%$ & & 4.86 & & 4.29 & & $\mathbf{4 . 2 9}$ \\
\hline
\end{tabular}

Elaboración Propia

Se concluye, al finalizar este análisis, que el distrito más indicado para ubicar la fábrica es Ate. Entrando más en detalle, la zona idónea para localizar la planta será el parque industrial "El Asesor", ya que su ubicación es más cercana al núcleo de Lima Metropolitana. Esto se considera una buena alternativa, ya que se encuentra inmediatamente al lado de la carretera central, vía que es un gran acceso a Lima y al centro del país, además de estar conectada con la carretera panamericana y la avenida Javier Prado, con lo cual se podría realizar una distribución sin inconvenientes y armar una red logística con buenas cualidades operativas. Finalmente, se debe decir que en esta ubicación, el desenvolvimiento fabril no 
tendrá inconvenientes, ya que se tienen a disposición los distintos requerimientos, como materia prima, recursos humanos, servicio de agua, electricidad, entre otros.

\section{Figura 3.4}

Ubicación del parque industrial "El Asesor"

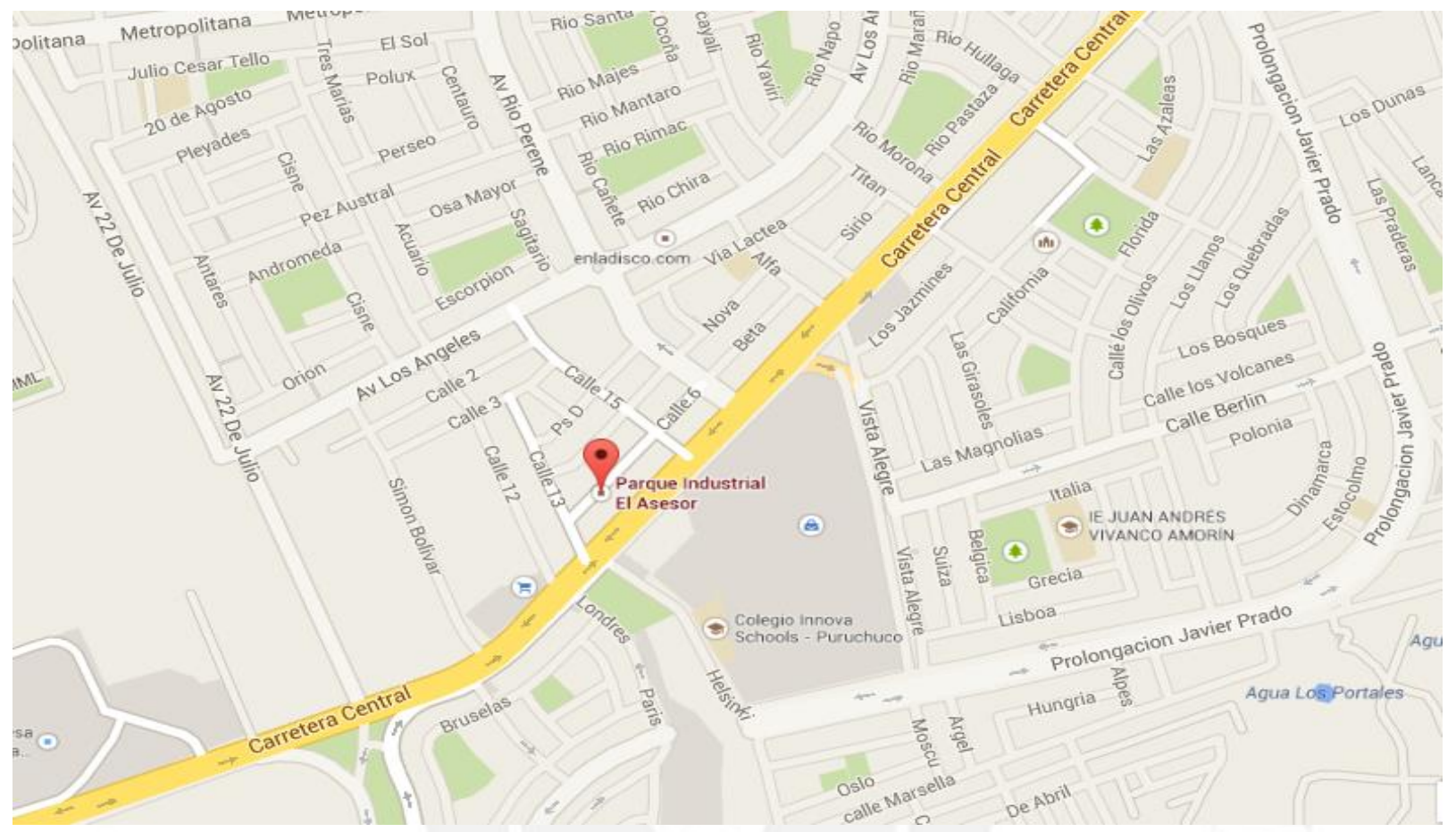

Fuente: Google Maps, (2013) 


\section{CAPÍTULO IV: TAMAÑO DE PLANTA}

Se entiende como tamaño de planta a la capacidad de producción óptima de una instalación que viene a ser determinada por las limitaciones que surgen a partir de la demanda del mercado, la tecnología disponible para el proceso productivo, punto de equilibrio, inversión o financiamiento aplicable para el proyecto y la disponibilidad de los recursos productivos.

\subsection{Relación tamaño-mercado}

Es importante tener en cuenta de que la demanda de los "Sistemas de Hidrógeno Vehicular" no sea inferior al tamaño mínimo requerido para la viabilidad del proyecto. De acuerdo a lo obtenido en el capítulo 2.4.3 "Determinación de la demanda el proyecto", el mercado no sería un factor limitante ya que dicho cálculo proviene de datos empíricos realizados a través de encuestas a los que serían los consumidores potenciales de este producto, y la cantidad determinada de la demanda del proyecto es de 125,400 unidades.

\subsection{Relación tamaño- recursos productivos}

El "Sistema de hidrógeno vehicular" consta de una celda de electrólisis seca de 21 placas, de configuración $-\mathrm{NNNN}+\mathrm{NNNN}-\mathrm{NNNN}+\mathrm{NNNN}-$, de para funcionar con $12 \mathrm{~V}$ a 13.8V DC y tapas laterales transparentes de acrílico.

El producto total está compuesto por 3 partes, las cuales son: Sistema mecánico, Sistema eléctrico y la Celda de electrólisis. A continuación se detallan los componentes de cada sistema:

Tabla 4.1

Componentes de cada sistema por separado

\begin{tabular}{|l|l|l|}
\hline \multicolumn{1}{|c|}{ Sistema mecánico } & \multicolumn{1}{c|}{ Sistema eléctrico } & \multicolumn{1}{c|}{ Celda de electrólisis } \\
\hline Manguera sanitaria (3/8") & Cables & Esparrago inóxidable (1/4") $(1 \mathrm{~m})$ \\
\hline $\begin{array}{l}\text { Manguera de alta presión } \\
\left(3 / 8^{\prime \prime}\right)\end{array}$ & $\begin{array}{l}\text { Controlador } \\
\text { electrónico }\end{array}$ & Tuercas inoxidables (1/4") \\
\hline Válvula check (3/8") & Terminales & $\begin{array}{l}\text { Eletrodo de Acero SAE 316L } \\
(1 \mathrm{~mm})\end{array}$ \\
\hline Tanque de Agua (3L) & & Aislante de neopreno \\
\hline Conexiones & & Tapa de acrílico \\
\hline Abrazaderas & & \\
\hline
\end{tabular}

Elaboración Propia 
De los materiales mencionados en la tabla anterior, los más importantes son: acero inoxidable SAE 316L, planchas de caucho de $1 \mathrm{~mm}$ de espesor (aislante de neopreno) y planchas de acrílico de $10 \mathrm{~mm}$ de espesor (tapa de acrílico). A continuación se muestra los proveedores para las 3 materias primas:

\section{Tabla 4.2}

Proveedores para los 3 componentes más importantes del "Sistema de hidrógeno vehicular"

\begin{tabular}{|l|l|l|}
\hline Acero inoxidable SAE 316L & Aislante de neopreno & \multicolumn{1}{|c|}{ Tapa de acrílico } \\
\hline Jahesa SA & Codiza SA & $\begin{array}{l}\text { Norem - Plast Peruana } \\
\text { SA }\end{array}$ \\
\hline JN Aceros SA & & \\
\hline
\end{tabular}

Elaboración Propia

Los proveedores mencionados cuentan con potencial de abastecimiento muy amplio, lo cual indica que no sería un factor limitante para el desarrollo del proyecto.

\subsection{Relación tamaño- tecnología}

La tecnología no es un factor limitante para determinar el tamaño de planta, ya que existen máquinas de distintas dimensiones, capacidades, tolerancias y características que permitirán procesar la materia prima con mayor o menor ritmo de producción según sea necesario. Por ejemplo, en el proceso de corte del acero, existen máquinas ofertadas en el mercado internacional que tienen un área de corte de $3 \mathrm{~m} \times 1.5 \mathrm{~m}$ con un avance de 12 metros por minuto, lo cual permitiría maquinar una plancha estándar en 9.1 minutos, permitiendo tener una producción diaria de aproximadamente 1894 celdas en un turno de trabajo de 8 horas, lo cual, evidentemente excede los requerimientos de producción, puesto que trabajando 360 días al año, se obtendría una producción de 681,840 unidades. Es relevante mencionar que la posibilidad de colocar máquinas en paralelo que trabajen simultáneamente es una alternativa para poder aumentar la capacidad productiva en caso que la tecnología sea el cuello de botella del proceso fabril. Como se mencionó, la maquinaria necesaria para este proceso fabril se encuentra ofertada en el mercado internacional, existiendo proveedores de China, Alemania, EEUU, entre otros países; Por otro lado, considerando que el Perú cuenta 
con distintos tratados de libre comercio y es un país abierto al comercio internacional, la importación de la maquinaria es totalmente factible.

\subsection{Relación tamaño- punto de equilibrio}

El punto de equilibrio permite conocer cuál es el tamaño mínimo de planta, es decir un nivel de producción en el que no se tenga pérdidas ni ganancias. Es imprescindible conocer este dato ya que permite tener noción del nivel de la producción y si es suficiente como para cubrir los costos fijos y variables que intervienen. Hasta este capítulo del estudio todavía no se cuenta con datos exactos sobre el costo de las operaciones, específicamente costos fijos los cuales se aproximaron de acuerdo a estimaciones. Cabe resaltar que los costos variables son exactos debido a que se obtuvieron con datos empíricos y reales.

A continuación se presentan los cálculos de los costos totales aproximados por mano de obra y el detalle de la obtención del costo variable por unidad de "Sistema de Hidrógeno Vehicular.

Tabla 4.3

Cálculo de los costos de mano de obra anual

Mano de obra Fabril

\begin{tabular}{|l|c|c|c|c|c|c|c|c|}
\hline Cargo & Cantidad & Sueldo Neto & CTS & Gratificación & SENATI (2\%) & ESSALUD(9\%) & Planilla Mensual & Planilla Anual \\
\hline Operario & 2 & $\mathrm{~S} / .1,500.00$ & $\mathrm{~S} / .125 .00$ & $\mathrm{~S} / .250 .00$ & $\mathrm{~S} / .30 .00$ & $\mathrm{~S} / .135 .00$ & $\mathrm{~S} / .4,080.00$ & $\mathrm{~S} / .48,960.00$ \\
\hline Ayudante & 3 & $\mathrm{~S} / .750 .00$ & $\mathrm{~S} / .62 .50$ & $\mathrm{~S} / .125 .00$ & $\mathrm{~S} / .15 .00$ & $\mathrm{~S} / .67 .50$ & $\mathrm{~S} / .3,060.00$ & $\mathrm{~S} / .36,720.00$ \\
\hline
\end{tabular}

Mano de obra administracion

\begin{tabular}{|l|l|l|l|l|l|l|l|l|}
\hline Jefe de operaciones & 1 & $\mathrm{~S} / .4,000.00$ & $\mathrm{~S} / .333 .33$ & $\mathrm{~S} / .666 .67$ & $\mathrm{~S} / .80 .00$ & $\mathrm{~S} / .360 .00$ & $\mathrm{~S} / .5,440.00$ & $\mathrm{~S} / .65,280.00$ \\
\hline contadora/secretaria & 1 & $\mathrm{~S} / .2,000.00$ & $\mathrm{~S} / .166 .67$ & $\mathrm{~S} / .333 .33$ & $\mathrm{~S} / .40 .00$ & $\mathrm{~S} / .180 .00$ & $\mathrm{~S} / .2,720.00$ & $\mathrm{~S} / .32,640.00$ \\
\hline Gerente General & 1 & $\mathrm{~S} / .5,000.00$ & $\mathrm{~S} / .416 .67$ & $\mathrm{~S} / .833 .33$ & $\mathrm{~S} / .100 .00$ & $\mathrm{~S} / .450 .00$ & $\mathrm{~S} / .6,800.00$ & $\mathrm{~S} / .81,600.00$ \\
\hline
\end{tabular}

Mano de obra tecnica

\begin{tabular}{|l|c|c|c|c|c|c|c|c|}
\hline Mecanico automotriz & 2 & $\mathrm{~S} / .1,200.00$ & $\mathrm{~S} / .100 .00$ & $\mathrm{~S} / .200 .00$ & $\mathrm{~S} / .24 .00$ & $\mathrm{~S} / .108 .00$ & $\mathrm{~S} / .3,264.00$ & $\mathrm{~S} / .39,168.00$ \\
\hline Practicante de mecanica & 1 & $\mathrm{~S} / .750 .00$ & $\mathrm{~S} / .62 .50$ & $\mathrm{~S} / .125 .00$ & $\mathrm{~S} / .15 .00$ & $\mathrm{~S} / .67 .50$ & $\mathrm{~S} / .1,020.00$ & $\mathrm{~S} / .12,240.00$ \\
\hline
\end{tabular}

Fuente: Ministerio del Trabajo, (2013) 


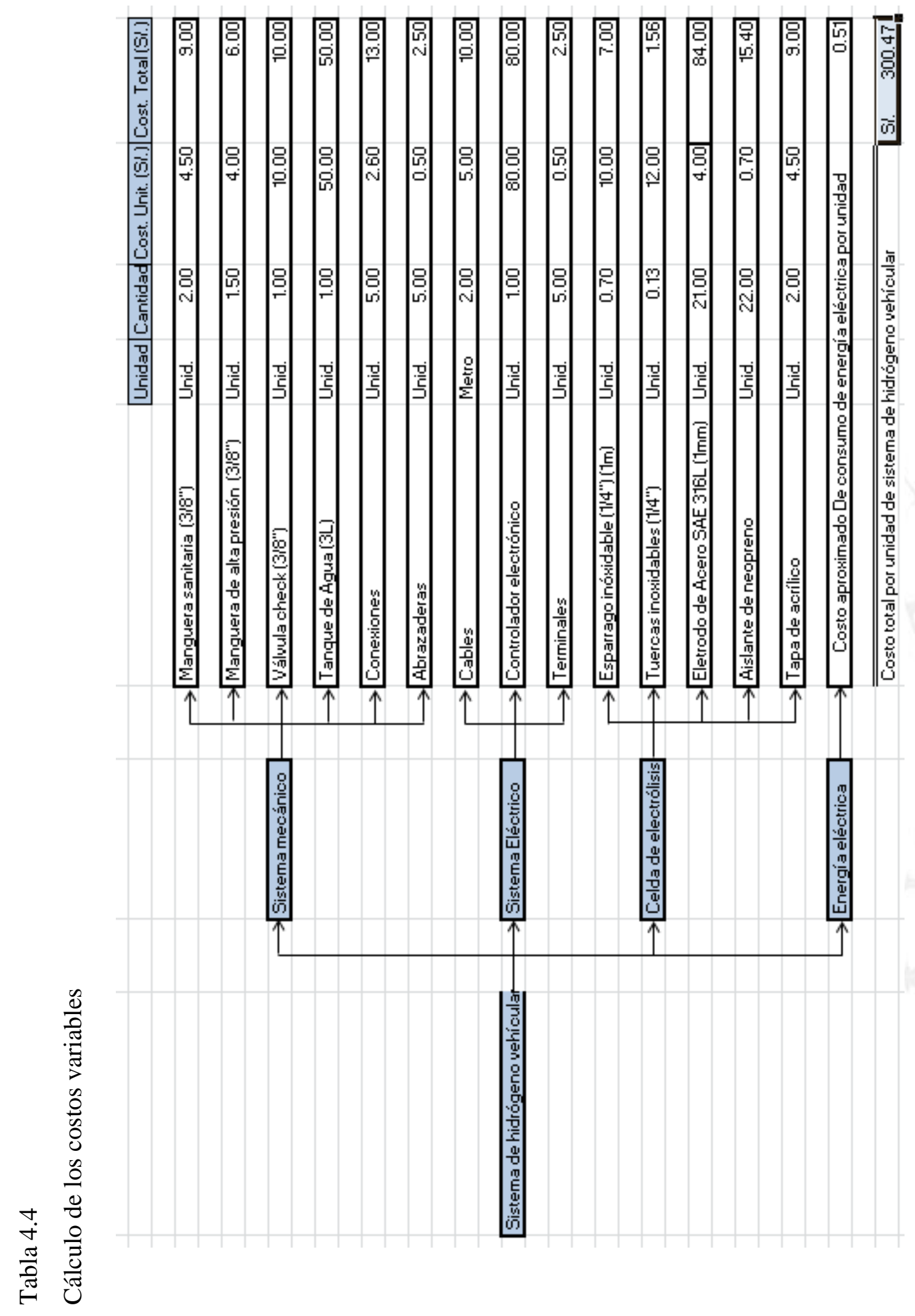

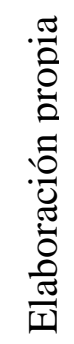


Teniendo en cuenta los costos detallados anteriormente, en la siguiente tabla se añaden los costos fijos anuales (S/.) aproximados para el proyecto.

Tabla 4.5

Estimación de los costos fijos totales anuales

\begin{tabular}{|l|c|}
\cline { 2 - 2 } \multicolumn{1}{c|}{} & Costos fijos \\
\hline Mano de obra directa & S/. 316,608.00 \\
\hline Gastos de administración & S/. 60,000.00 \\
\hline Depreciación & S/. 48,000.00 \\
\hline $\begin{array}{l}\text { Mantenimiento de } \\
\text { activos }\end{array}$ & S/. 20,000.00 \\
\hline & S/. 444,608.00 \\
\cline { 2 - 2 }
\end{tabular}

\section{\begin{tabular}{l|l|} 
Costo variable & S/.300.47
\end{tabular}}

Elaboración Propia

Posteriormente, se procederá a hallar el punto de equilibrio teniendo en cuenta que el precio de venta de una (01) unidad de "Sistema de hidrógeno vehicular" tendrá un precio en el mercado de S/. 800.

Tabla 4.6

Cálculo del margen de contribución

\begin{tabular}{|c|c|c|c|}
\hline Producto & Precio de venta & Costo variable & $\begin{array}{c}\text { Marguen de contribución Total = 1- } \\
\text { (CV/P. venta) }\end{array}$ \\
\hline $\begin{array}{c}\text { Sistema de } \\
\text { hidrógeno } \\
\text { vehicular }\end{array}$ & S/. 800.00 & S/. 300.47 & 0.62 \\
\hline
\end{tabular}

Elaboración Propia

A partir de la obtención del margen de contribución total se puede calcular el punto de equilibrio de unidades monetarias a través de la siguiente fórmula:

$$
\text { Punto de equilibrio }=\text { Costos fijos } \div \text { Contribución marginal total }
$$




\begin{tabular}{|c|c|}
\hline Punto equilibrio & S/.717,109.68 \\
\hline Punto equilibrio unidades & 897 \\
\hline
\end{tabular}

\subsection{Selección del tamaño de planta}

Para poder seleccionar el tamaño óptimo de la planta es necesario hacer una comparación de las diferentes relaciones analizadas anteriormente. El tamaño mínimo de planta estará determinado por el punto de equilibrio mientras que el tamaño máximo de planta estará definido por la demanda. A continuación se muestra una figura detallando los distintos niveles de tamaño de planta obtenidos.

Tabla 4.7

Tamaños de planta según cada criterio seleccionado

\begin{tabular}{|l|c|}
\cline { 2 - 2 } \multicolumn{1}{c|}{} & $\begin{array}{c}\text { Unidades de "Sistema de } \\
\text { Hidrógeno Vehicular anuales" }\end{array}$ \\
\hline Tamaño - Mercado & 16,634 \\
\hline Tamaño - Recursos productivos & No es limitante \\
\hline Tamaño - Tecnología & 681,849 \\
\hline Tamaño - Punto de equilibrio & 897 \\
\hline
\end{tabular}

Elaboración Propia

A partir la tabla anterior se puede observar que el tamaño de planta óptimo será determinado por el mercado, es decir, una producción anual de 16634 unidades de "Sistema de Hidrógeno Vehicular". Este dato se obtuvo en el capítulo 2.4: "Demanda para el proyecto" y que fue elegido desde el punto de vista psicográfico. El target de este mercado lo constituyen las personas naturales, específicamente taxistas. 


\section{CAPÍTULO V: INGENIERÍA DEL PROYECTO}

\subsection{Definición del producto basada en sus características de fabricación}

\subsubsection{Especificaciones técnicas del producto}

El producto a desarrollar está compuesto por dos placas de acrílico de $10 \mathrm{~mm}$ de espesor que serán colocadas a los extremos como tapas de la celda, luego estará compuesta por 21 placas de Acero inoxidable SAE 316L de $1 \mathrm{~mm}$ de espesor, que cumplirán la función de electrodos y reguladores de voltaje, estas tendrán la siguiente configuración:

$-\mathrm{NNNN}+\mathrm{NNNN}-\mathrm{NNNN}+\mathrm{NNNN}-$

Entiéndase por esto que habrá una placa conectada al polo positivo de la batería y una al negativo, habiendo entre positivo y negativo cuatro placas sin conexión directa a la batería, las cuales se conectaran eléctricamente mediante una disolución acuosa de $\mathrm{KOH}$ al 3\%. En este caso, el hidróxido de potasio $(\mathrm{KOH})$ permite el flujo de electrones a través del agua. Estas placas estarán separadas por empaquetaduras de caucho de $1 \mathrm{~mm}$ de espesor, los cuales cumplirán un rol de aislantes. Se colocarán conexiones para las mangueras de alimentación en ambos extremos. A este Tipo de celda se le conoce como celda seca o "Dry Cell".

Tabla 5.1

Composición química del acero inoxidable 316L

\begin{tabular}{|c|c|c|c|c|c|c|c|}
\hline \multicolumn{8}{|c|}{ Composición química } \\
\hline $\begin{array}{c}\text { \% C } \\
\text { (máx.) }\end{array}$ & $\begin{array}{l}\text { \%Mn } \\
\text { (máx.) }\end{array}$ & $\begin{array}{c}\text { \% Si } \\
\text { (máx.) }\end{array}$ & $\% \mathrm{Cr}$ & $\% \mathrm{Ni}$ & $\% \mathrm{Mo}$ & $\begin{array}{c}\% \mathbf{P} \\
\text { (máx.) }\end{array}$ & $\begin{array}{c}\% \mathrm{~S} \\
\text { (máx.) }\end{array}$ \\
\hline 0,035 & 2,00 & 1,00 & $16,0-18,0$ & $10,0-15,0$ & $2,0-3,0$ & 0,04 & 0,03 \\
\hline
\end{tabular}

Fuente: Aceros Otero, (2012)

Este tendrá como elemento principal la celda de electrólisis y se añadirán los siguientes elementos para ser comercializados e instalados en automóviles: 
- Reservorio de agua

Esta parte del sistema almacenará el agua destilada. Está fabricado en plástico y resiste 10 bares de presión. Su capacidad es de 3 litros. Este tiene 2 conexiones para líquidos con las cuales se conectara con el generador, una conexión para gases que estará conectada con la admisión de aire y una boquilla, por donde se alimentará de agua y se repondrá el electrolito. La boquilla se cierra con una tapa plástica de color negro.

\section{Figura 5.1}

Reservorio de agua

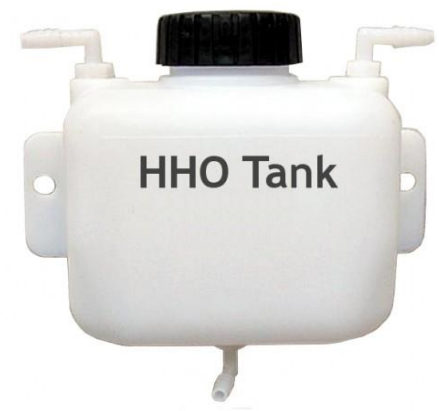

Fuente: HHO Plus Lda., (2008)

- Manguera de alta presión:

Por esta manguera fluye el agua desde el reservorio hacia la celda, el gas desde la celda hacia el reservorio y hacia la admisión de aire. Está diseñada para soportar hasta 653 PSI.

\section{Figura 5.2}

Manguera de alta presión

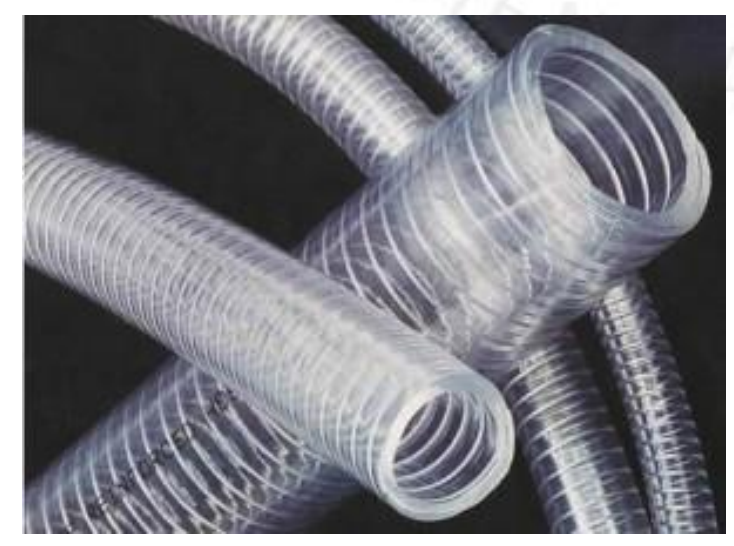

Fuente: Insumos Global, (2014) 
- Controlador electrónico:

Este dispositivo controla que solo exista flujo de electricidad hacia la celda de electrólisis cuando el motor esté encendido. Además, es un controlador de tipo PWM (Pulse Width Modulation), el cual convierte la corriente directa en corriente pulsante de $100 \mathrm{~Hz}$, lo cual permite elevar la eficiencia de la generación de hidrógeno al evitar el pasivamiento electroquímico de la superficie activa. Más aun, es controlado por un potenciómetro para variar la intensidad de corriente y el flujo de hidrógeno generado por la celda. Finalmente, sirve como porta fusible para prevenir la sobre carga del sistema, cortando el flujo eléctrico cuando supere los 15 amperios. Ha sido diseñado con un circuito integrado que permite detectar cuando el vehículo está prendido o apagado, de esta manera, enciende automáticamente el sistema de hidrógeno cuando el carro esté en funcionamiento.

Figura 5.3

Controlador electrónico

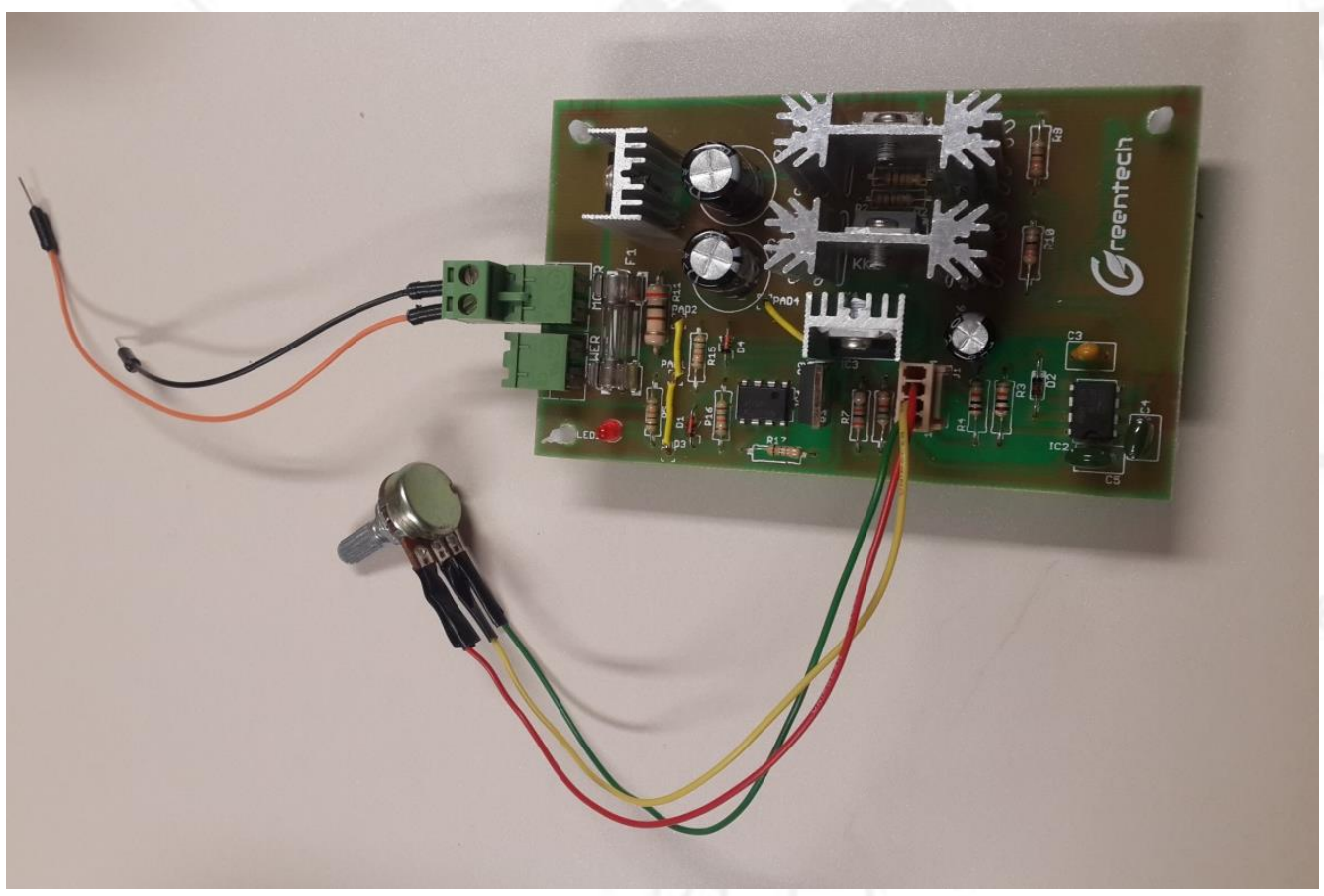

Elaboración Propia

- Cable 10 AWG:

Cable de $5.261 \mathrm{~mm}^{2}$ de sección transversal. Útil para las conexiones eléctricas. Compuesto por varios cables delgados, lo que permite que sea flexible. Admite hasta 30A. 
Figura 5.4

Cable 10 AWG

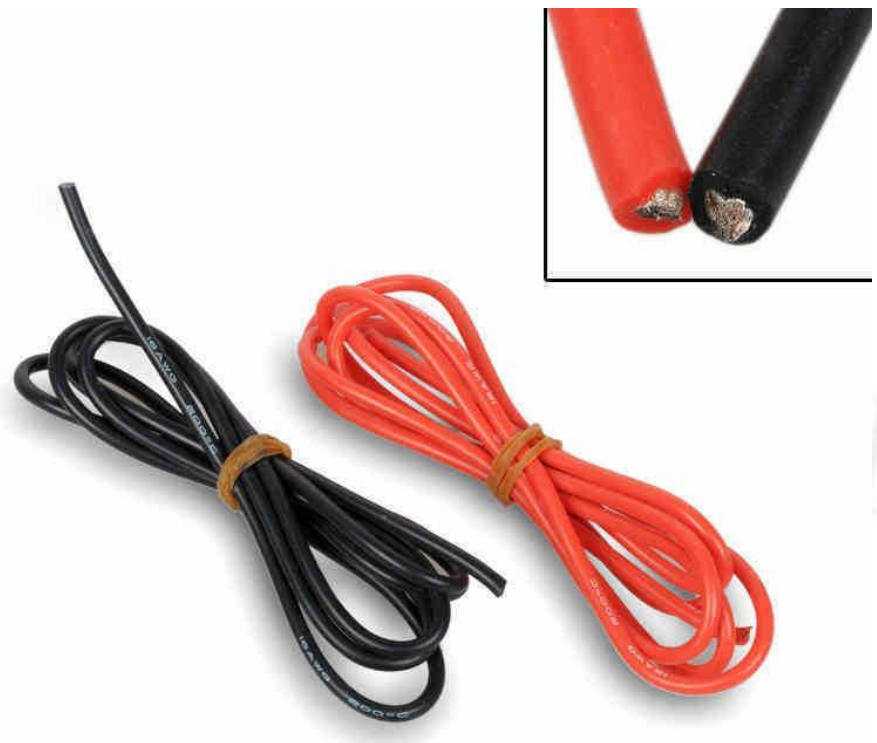

\section{AWG}

Fuente: Google images, (2012)

- Válvula check:

Este dispositivo se conecta en la manguera que va del reservorio hacia la admisión de aire. Permite que el flujo de gases sea solo en sentido hacia la admisión de aire y no de otra manera.

Figura 5.5

Válvula check

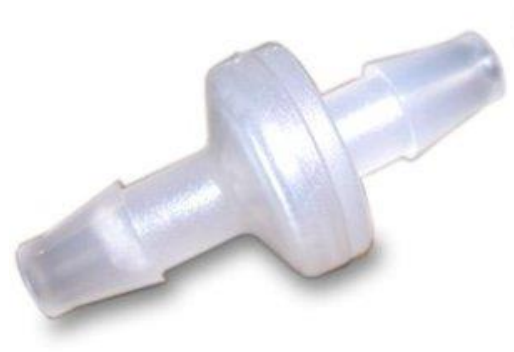

Fuente: HHO Plus Lda., (2008) 
Se debe mencionar que los productos que no sean parte de la celda de electrólisis se comprarán ya fabricados.

El sistema instalado se diagrama de la siguiente manera:

Figura 5.6

Sistema mecánico

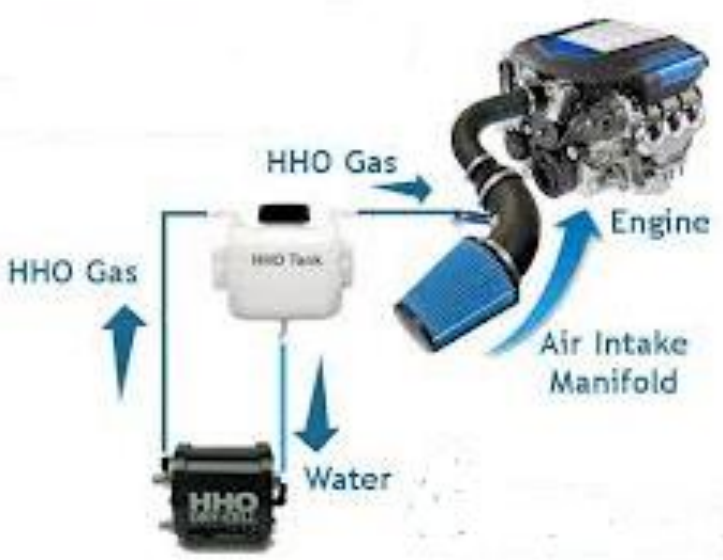

Fuente: HHO Plus Lda., (2008)

Figura 5.7

Sistema eléctrico

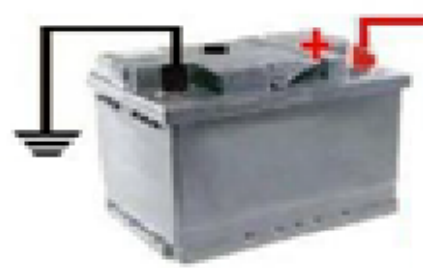

Bateria

Celda de electrólisis

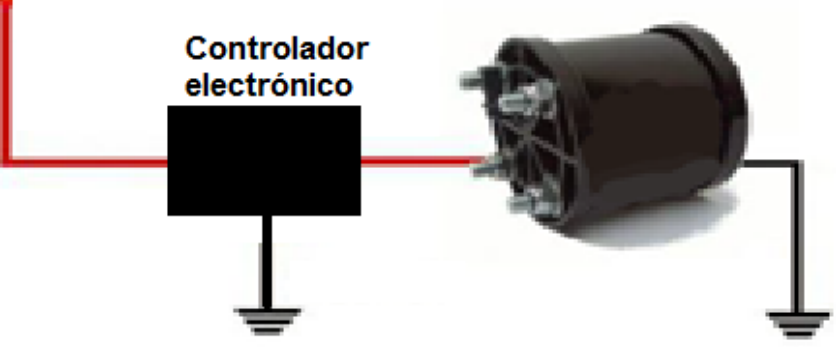

Elaboración Propia 


\subsection{Tecnologías existentes y procesos de producción}

\subsubsection{Naturaleza de la tecnología requerida}

\subsubsection{Descripción de la tecnología existente}

El producto a fabricar se forma a partir del corte y unión de distintas piezas de distintos materiales (plásticos, metales, etc.) y por ello se hará una breve referencia a las tecnologías existentes para el corte de los distintos materiales.

Corte de metales:

- Corte plasma

Es una técnica de corte que se efectúa mediante la creación de un arco eléctrico entre el electrodo y la pieza metálica a cortar (elemento conductor). Este arco eléctrico produce una elevada temperatura (por encima de los 20000 grados Celsius) en un punto focalizado del material llevando, al mismo tiempo, se libera un gas (gas plasma) que sirve como agente térmico para fundir y expulsar el material logrando el corte deseado. En el mercado mundial existen maquinas con distinta superficie de corte. Su ventaja son que su costo es mucho menor costo en comparación a la tecnología láser y tienen una velocidad de maquinado mucho mayor $(12 \mathrm{~m} / \mathrm{min})$; pero tienen una menor precisión de corte $(0.2-0.5 \mathrm{~mm})$, que cuando se maquinan espesores anchos suelen aparecer rebabas y consumen una cantidad significativa de corriente eléctrica $(100-200 A)$ al utilizar un arco eléctrico. (Sawa enterprice Broushoure, China, 2010)

\section{Figura 5.8}

Esquema del corte plasma

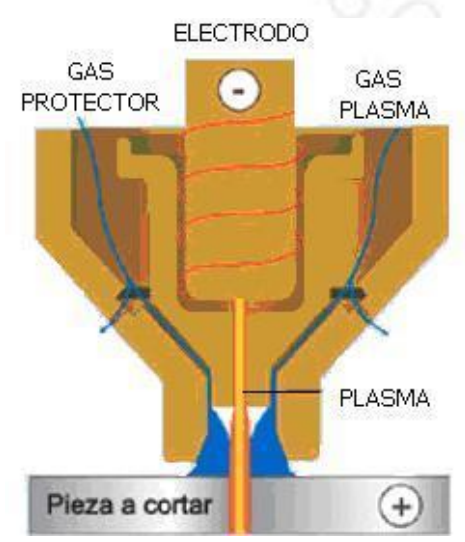

Fuente: ARTINAID, (2010) 
- Corte laser

Es una técnica de corte que se caracteriza por concentrar luz en la superficie de trabajo, el cual viene acompañado por un gas a presión para evacuar el material cortado, el cual puede ser oxígeno, nitrógeno o argón. Puede maquinar espesores de hasta $6 \mathrm{~mm}$. Su ventaja es que utiliza poca energía eléctrica y puede maquinar materiales no conductores (máximo $5000 \mathrm{~W})$, tiene mayor precisión $(0.1 \mathrm{~mm})$, pero tienen un costo muy elevado y una menor velocidad de corte ( $3 \mathrm{~m} / \mathrm{min})$. (Sawa enterprice Broushoure, China, 2010)

Figura 5.9

Esquema del corte láser

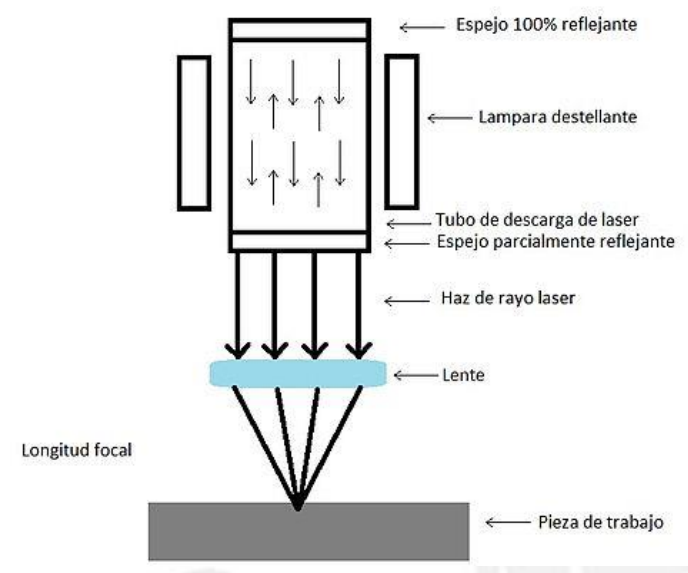

Fuente: ARTINAID, (2010)

- Corte mecánico

Este método consiste en el prensado del metal por una máquina llamada prensa excéntrica. Además, es necesario fabricar una matriz, la cual servirá para cortar el material de una forma deseada con cada uno de los impactos del cabezal de la maquina sobre la plancha de metal. 
Figura 5.10

Ilustración del corte mecánico

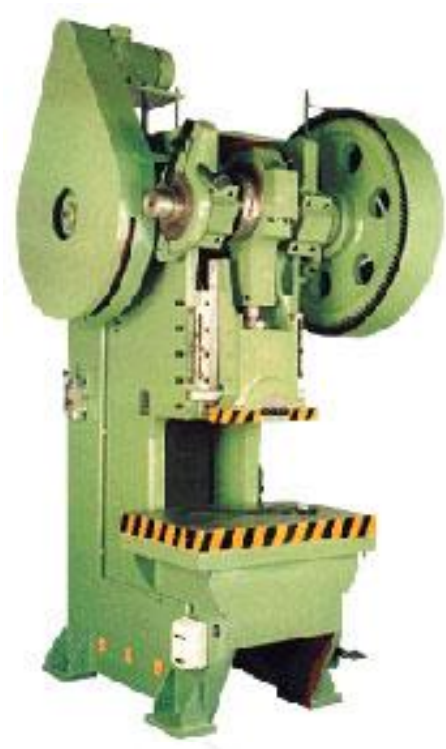

Fuente: Matricerías Line, (2011)

- Corte manual

En este tipo de corte la herramienta es manipulada por un operario. Este método supone que se debe adiestrar al operario y que se está sujeto a errores humanos. 
Figura 5.11

Ilustración del corte manual

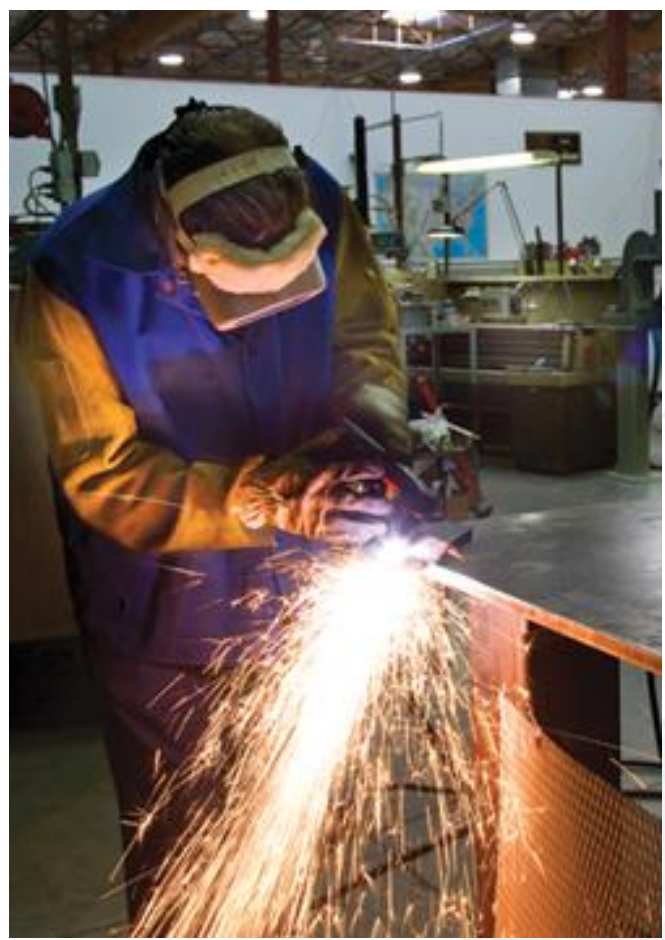

Fuente: Fabricators and Manufacturers Association, (2014)

- Corte CNC

Es una técnica de control computarizado que utiliza ejes de coordenadas para ubicar y guiar al husillo de corte. Para la comunicación hombre - máquina se tiene una interfaz a través de un programa informático por el cual se introducen los planos a la máquina de corte, se programa su corte y se acciona. Este método supone la capacitación de operarios para la operación de la máquina y contar con una computadora que sea compatible con su software. Lo ventajoso es que reduce la probabilidad de errores, aumenta considerablemente la exactitud del acabado y ahorra horas hombre de trabajo. 
Figura 5.12

Ilustración del corte $\mathrm{CNC}$

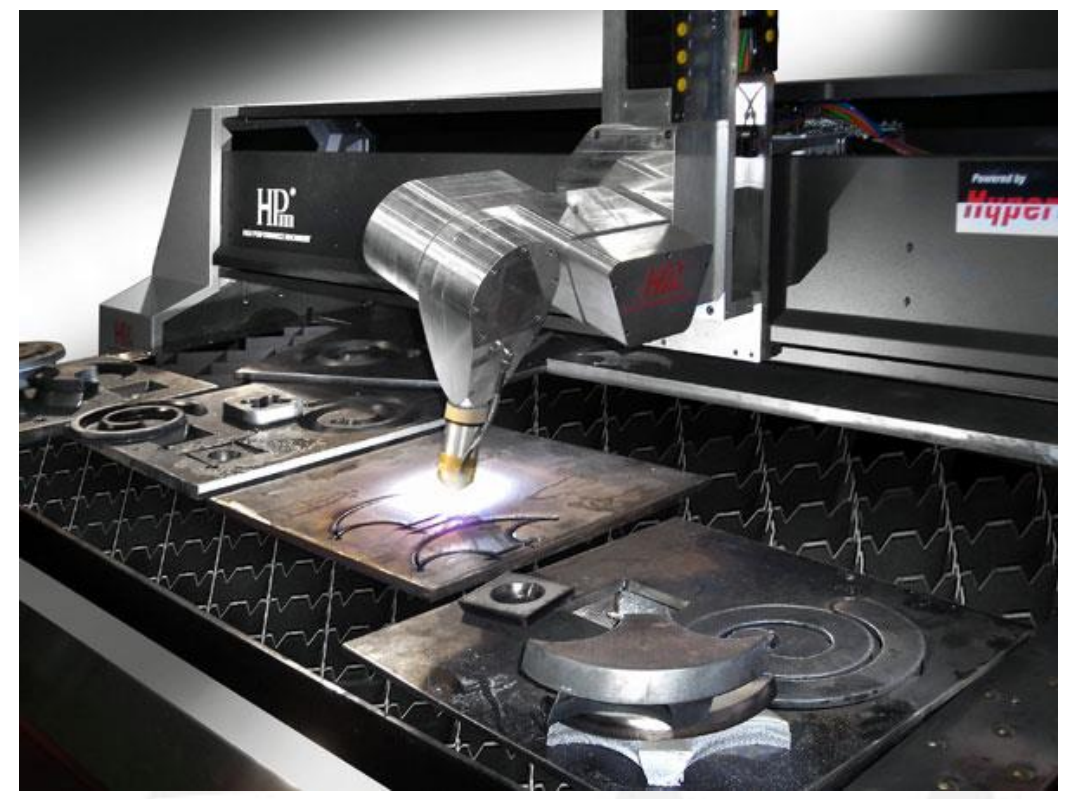

Fuente: Fabricators and Manufacturers Association, (2014)

Corte de no metales:

- Corte láser

Es una técnica de corte que se caracteriza por concentrar luz en la superficie de trabajo, el cual viene acompañado por un gas a presión para poder evacuar el material cortado, el cual es CO2. Puede maquinar cualquier material no metálico (máximo 200W), tiene una precisión de $(0.1 \mathrm{~mm})$ y tienen su costo bajo. Su velocidad de corte es de $3 \mathrm{~m} / \mathrm{min}$. (Sawa Enterprice Broushoure, China, 2010) 
Figura 5.13

Ilustración del corte láser

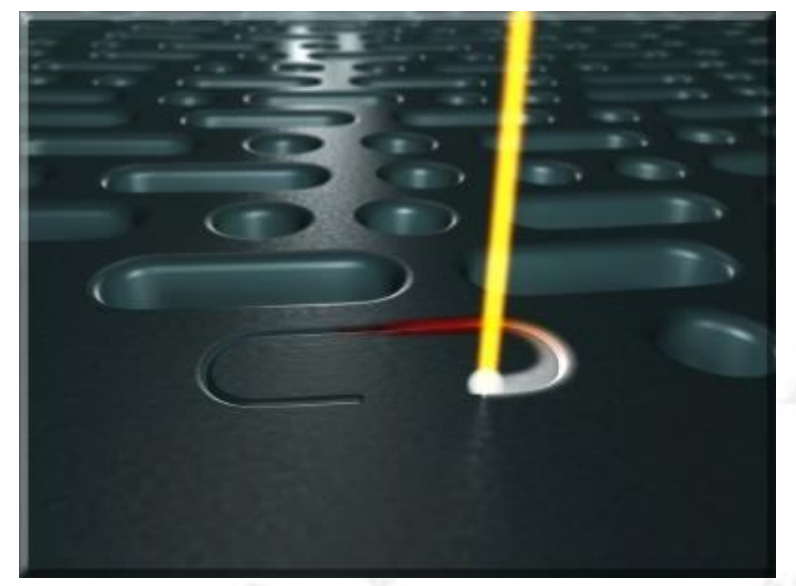

Fuente: Plásticos Bogoan, (2013)

- Corte por prensado

Esta técnica supone la fabricación de una matriz que tenga la forma del corte deseado. Esta matriz es usada en una prensa donde se ubica sobre el material y se aplica presión para cortarlo de la forma de la matriz. Es un método bastante económico, pero tiene una baja velocidad de producción, además de poder cortar solamente materiales que sean maleables y no rígidos. 
Figura 5.14

Ilustración de la máquina de prensa hidráulica

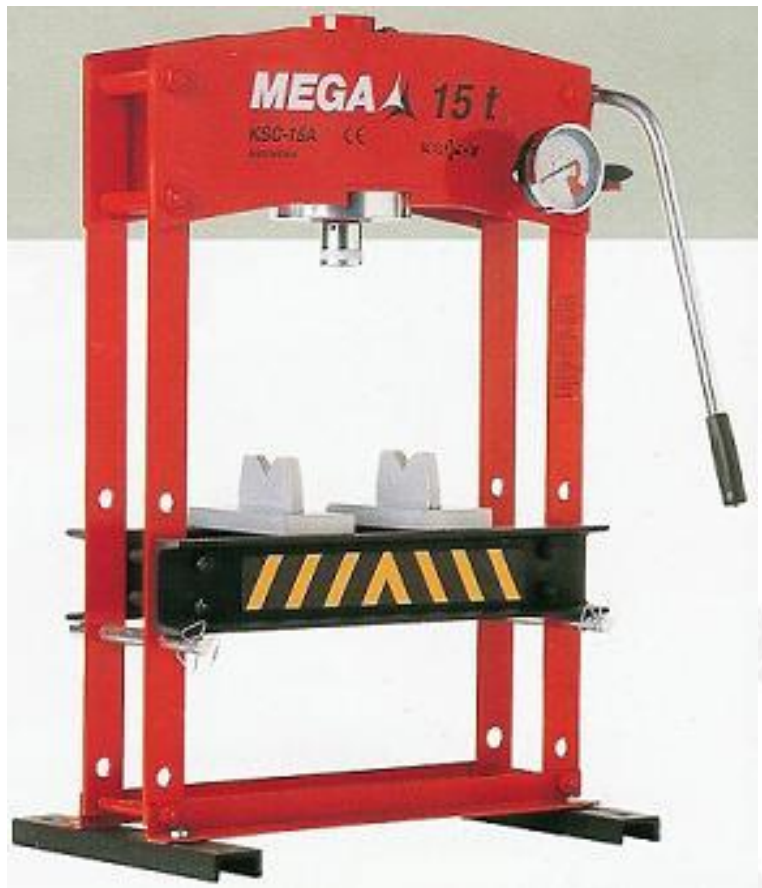

Fuente: MPW Industriales, (2015)

- Corte manual

Este procedimiento fabril consiste en la fabricación de una matriz plana con el contorno de la pieza a fabricar, que servirá de guía para que un operario corte el material. La desventaja es la posibilidad de errores y la baja tasa de producción.

\subsubsection{Selección de la tecnología}

Para la selección de la tecnología a utilizar se tomarán en cuenta los siguientes factores:

- Velocidad de producción

- Precio

- Calidad de acabado

Además, la tecnología selecta, deberá contar con una capacidad fabril que permita cumplir con el tamaño de planta y permitir el aumento de la producción en caso que la demanda aumente. 
Para este proyecto industrial, se escogieron las siguientes tecnologías:

- Corte de metales: Corte plasma CNC

Se eligió esta tecnología ya que tiene un costo significativamente inferior al corte laser CNC de metales. Por otro lado, es cierto que cuando se maquinan metales gruesos suelen aparecer rebabas, pero cuando se cortan metales de poco espesor (como en este caso, $1 \mathrm{~mm}$ ) el maquinado tiende a ser bastante prolijo. Además, la tolerancia es apropiada, ya que no se trata de un trabajo de precisión y un error de $0.5 \mathrm{~mm}$ es aceptable ya que no afecta en lo absoluto el funcionamiento del producto. Finalmente, es el método que ofrece la mayor velocidad de corte. Es importante mencionar también que al ser la máquina controlada por control computacional $\mathrm{CNC}$, la posibilidad de errores se reduce drásticamente.

- Corte de no metales: Corte laser CNC

Se escogió esta tecnología, ya que su precio es bajo. Además, permite maquinar sin problemas los materiales mencionados, ofreciendo una buena precisión, una velocidad de trabajo aceptable y una baja probabilidad de error al ser gobernada por software computarizado CNC.

\subsubsection{Proceso de producción}

\subsubsection{Descripción del proceso}

El proceso empieza con la recepción de la materia prima y partes del sistema mecánico y eléctrico. Estas son entregadas al almacén de materias primas por el proveedor. Las materias primas son: Planchas de $1.5 \mathrm{~m}$ x $1 \mathrm{~m}$ x $1 \mathrm{~cm}$ de acrílico transparente, planchas de $1 \mathrm{~m}$ x $2 \mathrm{~m}$ de caucho de $3 \mathrm{~mm}$ de espesor, planchas de Acero inoxidable de calidad $316 \mathrm{~L}$ de $3 \mathrm{~m} \times 1.5 \mathrm{~m}$ de $1 \mathrm{~mm}$ de espesor, pernos esparrago de $1 / 8$ " de diámetro y $100 \mathrm{~cm}$ de longitud, tuercas de $1 / 8$ " de diámetro y las cajas que cumplen la función de contenedor del producto.

Para iniciar el proceso productivo, se debe maquinar las distintas planchas de distintos materiales. La plancha de acero es cortada por corte plasma CNC en piezas que serán los electrodos de la celda. Estos deben ser lijados por ambas caras para aumentar su superficie de contacto.

Paralelamente, las planchas de caucho son cortadas en empaquetaduras por otra máquina $\mathrm{CNC}$ a laser. Esta máquina también es utilizada para cortar las planchas de acrílico 
en pedazos más pequeños respetando las especificaciones dadas, los cuales serán las tapas de las celdas. Acto seguido, se debe realizar la rosca a los agujeros centrales de las tapas.

Por otra parte, el perno esparrago de $100 \mathrm{~cm}$ debe ser tronzado en piezas de $10 \mathrm{~cm}$ de longitud.

Una vez que todos los productos han sido maquinados, cada uno debe de pasar por un control de calidad para asegurar que las medidas asean las correctas y pasar al ensamble.

Las piezas son acomodadas en el orden que se detalla en las especificaciones técnicas y se aseguran con los pernos y tuercas para dar como producto finalizado a la celda de electrólisis.

Por último las celdas de electrólisis se encajan junto con las partes del sistema mecánico y eléctrico y se guardan en el almacén. 


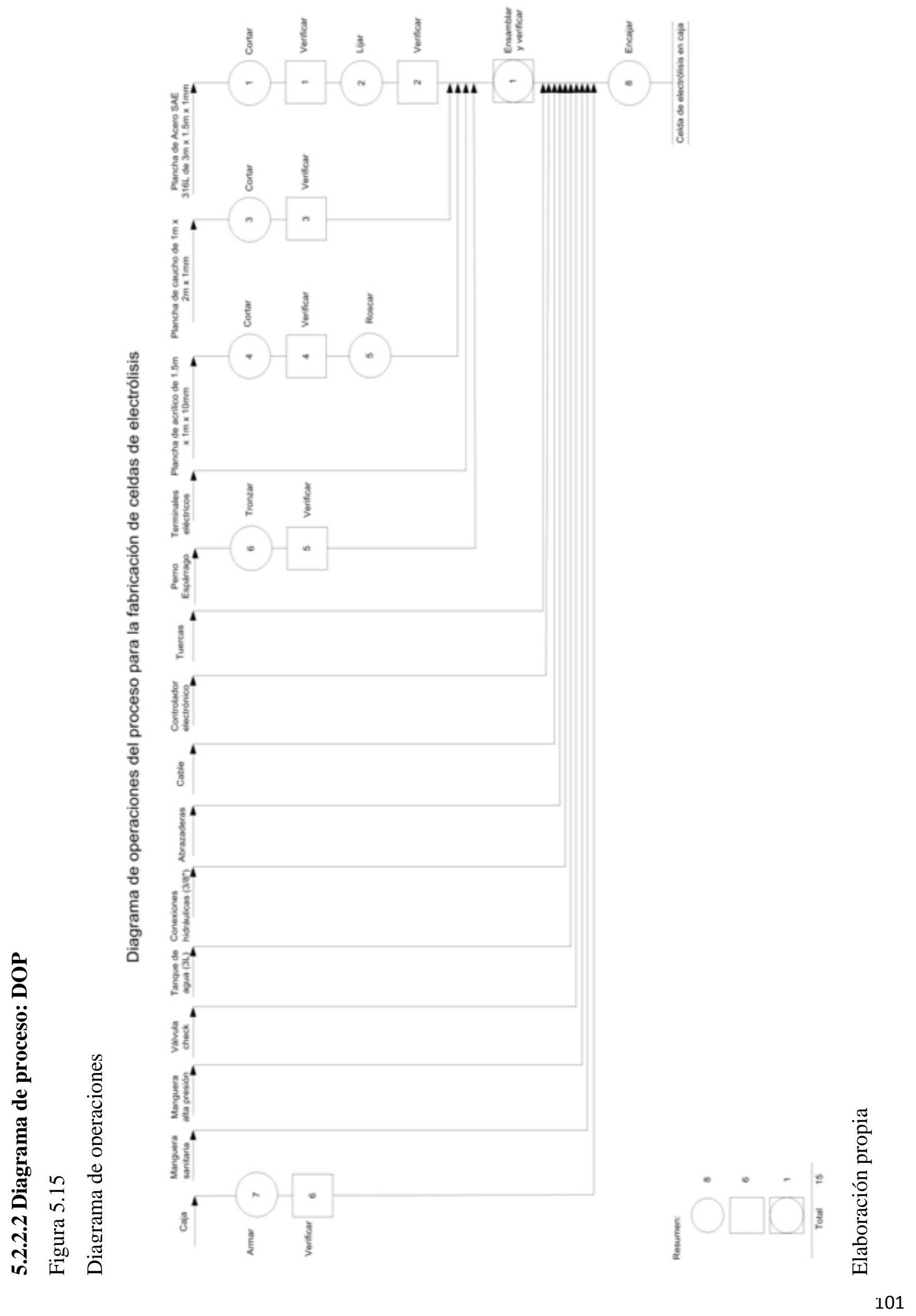




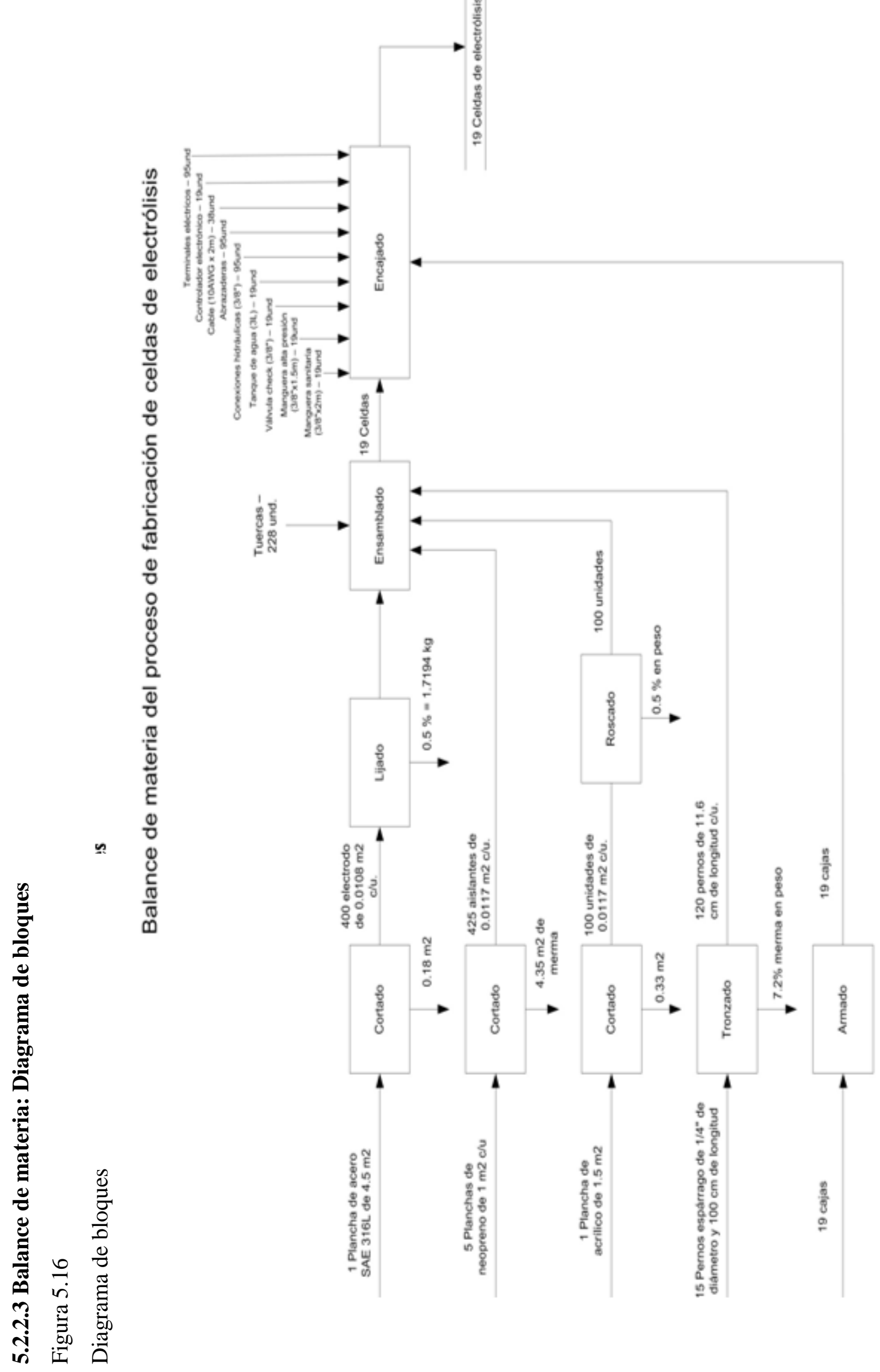

$\frac{\pi}{2}$
0
0
0
$\frac{1}{0}$
$\frac{0}{0}$
$\frac{\pi}{0}$
$\frac{0}{\pi}$
$\frac{\pi}{1}$ 


\subsection{Características de las instalaciones y equipo}

\subsubsection{Selección de la maquinaria y equipo}

Se seleccionaron dos (02) máquinas para elaborar el proceso de corte. La primera máquina utiliza la tecnología láser siendo el modelo SW-200HZ fabricada por la compañía "LINHAN SCIENCE \& TECHNOLOGY".

Figura 5.17

Máquina de corte a láser modelo SW-200HZ fabricada por la compañía "LINHAN SCIENCE \& TECHNOLOGY"

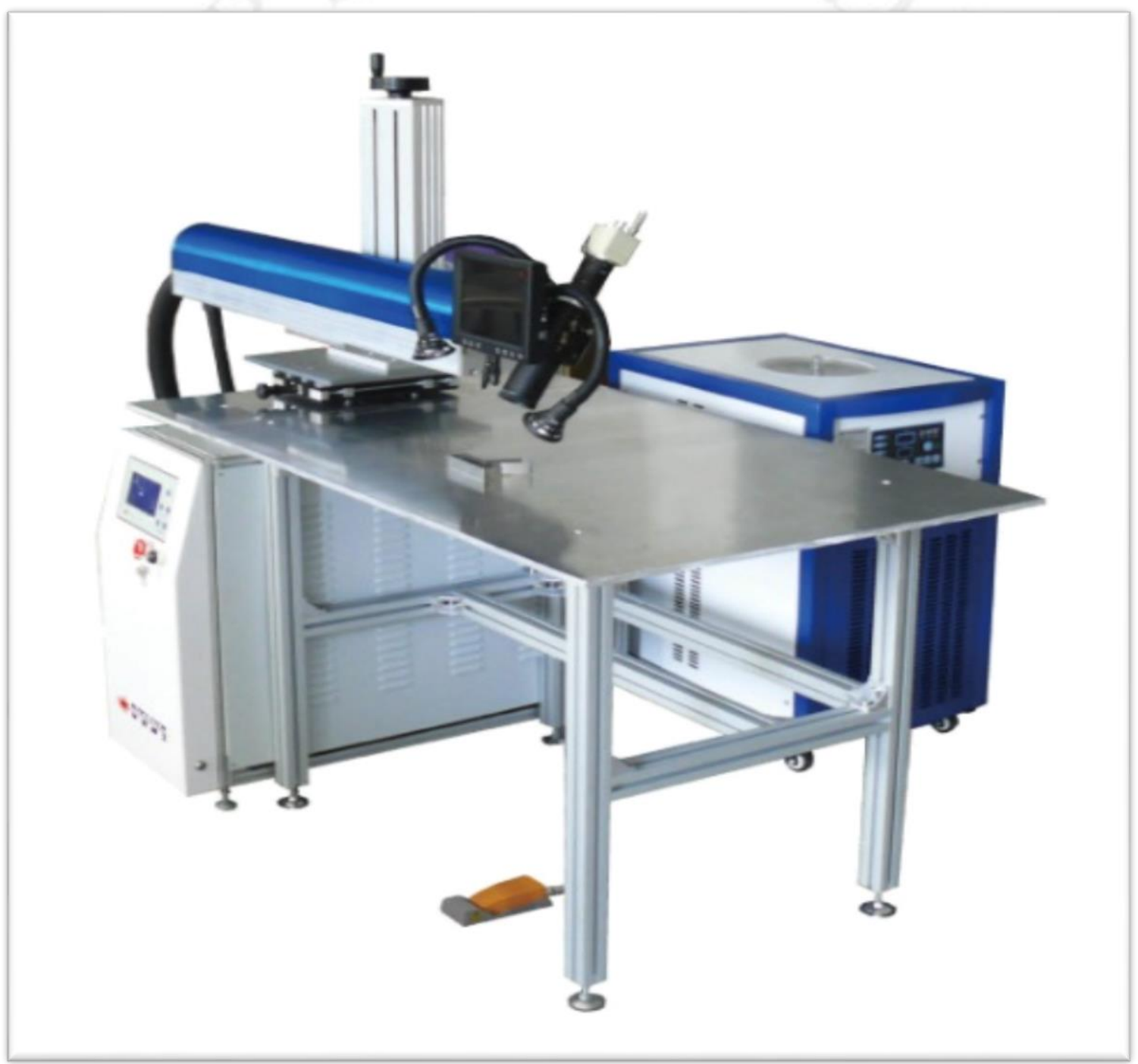

Fuente: lh-kj Corp, (2012) 
La segunda máquina seleccionada utiliza la tecnología por corte plasma siendo el modelo SW-1530S fabricada por la compañía "LINHAN SCIENCE \& TECHNOLOGY".

Figura 5.18

Máquina de corte plasma modelo SW-1530S fabricada por la compañía "LINHAN SCIENCE \& TECHNOLOGY"

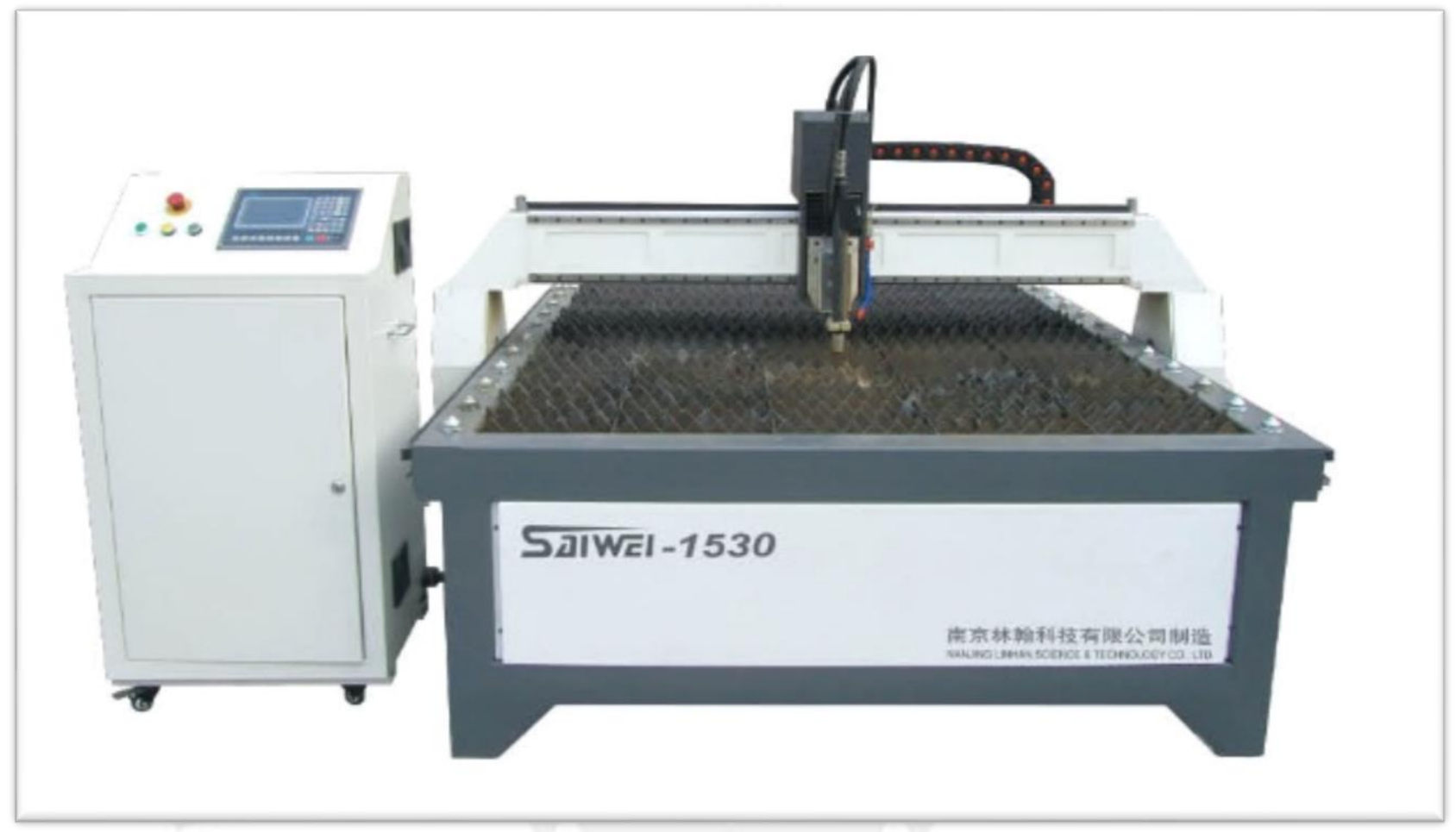

Fuente: lh-kj Corp, (2012)

Ambas máquinas fueron seleccionadas debido a que su precio en el mercado es competitivo y sus consumos de energía son moderados, lo cual significaría un ahorro significativo. 


\subsubsection{Especificaciones de la maquinaria}

- Máquina de corte a láser modelo SW-200HZ fabricada por la compañía "LINHAN SCIENCE \& TECHNOLOGY"

\section{Tabla 5.2}

Características de la máquina de corte láser modelo SW-200HZ

\begin{tabular}{|l|}
\hline \multicolumn{1}{|c|}{ Características } \\
\hline $\begin{array}{l}\text { La luz roja puede comprobar rápido y automáticamente el punto } \\
\text { de soldadura, la observación directa a través de la CCD o alterar } \\
\text { microscopio. }\end{array}$ \\
\hline $\begin{array}{l}\text { De acuerdo a sus necesidades para cambiar la mesa de trabajo } \\
\text { para cumplir con los diferentes tipos de letras. }\end{array}$ \\
\hline $\begin{array}{l}\text { Procesamiento de la velocidad rápida probando rápidamente el } \\
\text { punto de soldadura por enfoque automático sin CCD ni } \\
\text { microscopio. }\end{array}$ \\
\hline Distorsión temperatura pequeña y efecto termomecánico. \\
\hline $\begin{array}{l}\text { También se puede utilizar para el tratamiento térmico local de } \\
\text { las cartas de los metales. }\end{array}$ \\
\hline $\begin{array}{l}\text { Componentes del patrón esta diseñados para estructuras } \\
\text { complicadas y pequeñas palabras. }\end{array}$ \\
\hline No emite ruido, tampoco contaminación. \\
\hline $\begin{array}{l}\text { Con la varilla de posicionamiento superfino interior, el punto de } \\
\text { luz no tiene que ajustar sus posiciones en los puntos de } \\
\text { inflexión de los caracteres. }\end{array}$ \\
\hline $\begin{array}{l}\text { Debido a la habilidad de procesamiento de avanzada, mejora } \\
\text { considerablemente la calidad de las letras en los metales. }\end{array}$ \\
\hline
\end{tabular}

Fuente: lh-kj Corp, (2012) 


\section{Tabla 5.3}

Especificaciones técnicas de la máquina de corte láser modelo SW-200HZ

\begin{tabular}{|l|c|}
\hline \multicolumn{1}{|c|}{ Modelo } & SW-200HZ \\
\hline Partes mecánicas & $\begin{array}{c}\text { Banco óptico intervalo de extensión de } 750 \mathrm{~mm}, \\
\text { giratorio } 90^{\circ} \mathrm{C} .\end{array}$ \\
\hline X, Y, Z Proceso de Trabajo & \begin{tabular}{c}
$750 x 1000 \mathrm{~mm}$ \\
\hline Límite Soporte giratorio
\end{tabular} \\
\hline Voltaje de alimentación & 220V $\pm 10 \% / 50 / 60 \mathrm{~Hz}$ o 380V $\pm 10 \% / 50 / 60 \mathrm{~Hz}$ \\
\hline Láser Nd Modelo & YAG Lámpara impulsiva \\
\hline $\begin{array}{l}\text { Rango de Ajuste del } \\
\text { Margen }\end{array}$ & $0.1 \sim 0.3 \mathrm{MM}$ \\
\hline Rango de Gama & $0.2 \sim 3.0 \mathrm{MM}$ \\
\hline Longitud de onda del láser & $1064 \mathrm{MM}$ \\
\hline Ancho de pulso & $\leq 15 \mathrm{M} / \mathrm{S}$ \\
\hline Potencia máxima & $200 \mathrm{~W}$ \\
\hline Frecuencia de impulsos & $\leq 15 \mathrm{~Hz}$ \\
\hline Enfoque de salida de láser & $110 \mathrm{MM} / 150 \mathrm{MM}($ Opcional $)$ \\
\hline Sistema de refrigeración & Refrigeración por agua \\
\hline Sistema de Observación & CCD o Microscopio \\
\hline Proceso Vertical & $300 \mathrm{MM}$ \\
\hline Proceso Horizontal & $200 \mathrm{MM}$ \\
\hline
\end{tabular}

Fuente: lh-kj Corp, (2012) 
- Máquina de corte plasma modelo $S W-1530 S$ fabricada por la compañía "LINHAN SCIENCE \& TECHNOLOGY"

Tabla 5.4

Características de la máquina de corte plasma modelo SW-1530S

\section{Características}

Diseño estructural adoptado único de pórtico de acero que tiene las características de una fuerte rigidez, bajo peso y baja inercia.

Importada TBI carril de guía linear original del eje $\mathrm{X}$, Y, en el eje de $\mathrm{Z}$ utiliza la alta precisión original de transmisión de tornillo de la bola de TBI, para asegurar conseguir el nivel de liderazgo total en la precisión de corte.

Sistema de control aplicado de alto nivel industrial, de fácil aprendizaje y operación.

Encendido automático y sistema de control de altura de antorcha hecha en Beijing, libres de ajuste de corte dependiendo de la posición de los materiales, los cuales mantienen la antorcha de corte constante y la distancia de placa, lo que asegura el éxito

Con la estructura avanzada de la cama torno industrial, asegurara la rigidez de acero y sin distorsión.

$\mathrm{X}$, el eje Y adopta el doble - transmisión servo motor y el accionamiento, para asegurar constantemente el funcionando sin problemas.

Modo USB interfaz del controlador, operación simplificada y fácil aprendizaje.

Fuente maestra de alimentación EE.UU. 120A CUT plasma importado, (opcional EE.UU. HYPERTERMS o hecho en China), el espesor de corte máxima es de $30 \mathrm{~mm}$, tales como acero al carbono y otros metales, etc.

Sistema adoptado avanzado de módulo óptico y señal escudo antiinterferencia, para asegurar la transmisión constante durante el corte.

Material: Placa de aluminio, zinc Placa, placa de titanio, placa de acero al carbono y otros metales, etc. Múltiples aplicaciones.

Fuente: lh-kj Corp, (2012) 


\section{Tabla 5.5}

Especificaciones técnicas de la máquina de corte plasma modelo SW-1530S

\begin{tabular}{|l|c|}
\hline \multicolumn{1}{|c|}{ Modelo } & SW-1530S \\
\hline Dimensiones de la máquina & 2050x3600x1300 mm \\
\hline Área de trabajo & $1500 \times 3000 \mathrm{~mm}$ \\
\hline \multirow{2}{*}{ Espesor } & $(40 \mathrm{~A})$ de $0.5-10 \mathrm{~mm}$ \\
\cline { 2 - 2 } & $(120 \mathrm{~A}) 3-25 \mathrm{~mm}$ \\
\hline Velocidad de corte & $0-12 \mathrm{~m} / \mathrm{min}$ \\
\hline Velocidad de regreso (vacío) & $0-50 \mathrm{~m} / \mathrm{min}$ \\
\hline Potencia & $0.8 \mathrm{~kW}-10.5 \mathrm{~kW}$ \\
\hline Voltaje de entrada & $380 \mathrm{~V}$ (trifásica) \\
\hline Frecuencia de red & $50 \mathrm{HZ}$ \\
\hline Corriente de plasma & $40-120 \mathrm{~A}$ \\
\hline Formato de archivo & USB o un ordenador \\
\hline Tipo de trabajo & Sin contacto de arco \\
\hline
\end{tabular}

Fuente: lh-kj Corp, (2012)

\subsection{Capacidad instalada}

\subsubsection{Cálculo de la capacidad instalada}

La capacidad instalada de una planta representa el ritmo potencial máximo de producción en un lapso de tiempo determinado. Esto se ve afectado por los recursos fabriles disponibles como las máquinas, operarios, conocimientos, etc. Lo usual es que en la práctica no se utilice la total capacidad instalada, ya que debe existir un margen que permita responder a incrementos en la demanda del mercado. Dentro de todos los recursos existe uno que limitará la producción, este es el que menor tasa de producción, a este se le denomina "cuello de botella".

Dentro de esta línea fabril, el proceso de ensamble es el más lento, ya que tiene una velocidad de una celda cada 20 minutos en promedio. Con fines prácticos se va a asumir una eficiencia del $80 \%$ (no se considera utilización ya que se trata de un proceso manual). Además, se trabajarán 8 horas al día, un turno por día, 5 días a la semana, 52 semanas al año. Conociendo este tiempo y los demás datos, se puede calcular la capacidad instalada: 
Capacidad instalada $=3$ operarios $x \frac{1 \text { celdas } / \text { operario }}{20 \mathrm{~min}} \times \frac{60 \mathrm{~min}}{\text { hora }} \times \frac{8 \text { horas }}{\text { turno }} \times \frac{1 \text { turnos }}{\text { día }} \times \frac{5 \text { días }}{\text { semana }} \times \frac{52 \text { semana }}{\text { año }} \times 0.8=18720 \frac{\text { celdas }}{\text { año }}$

Se debe concluir que la capacidad instalada es de 18,720 celdas de electrólisis.

\subsubsection{Cálculo detallado del número de máquinas requeridas}

La cantidad de máquinas requerida depende de la demanda de producción que se necesite en el lapso de un año para cada máquina, el tiempo estándar que involucra la fabricación de una unidad, la eficiencia de la máquina, su factor de utilización y determinación del régimen de turnos de trabajo y política laboral de la empresa. Matemáticamente, el número de máquinas se expresa de la siguiente manera:

Número de máquinas $=\frac{\text { Producción requerida } x \text { Tiempo estándar }}{\text { Factor de utilización } x \text { Factor de eficiencia } x \text { Horas reales }}$

En la siguiente tabla se detalla el cálculo del número de máquinas:

Tabla 5.6

Cálculo de número de máquinas

\begin{tabular}{|c|c|c|c|c|c|c|c|c|c|}
\hline Máquina & $\begin{array}{c}\text { Producción } \\
\text { requerida }\end{array}$ & $\begin{array}{c}\text { Tiempo } \\
\text { estándar } \\
\text { (h/celda) }\end{array}$ & $\mathbf{U}$ & $\mathbf{E}$ & $\begin{array}{c}\text { Horas/ } \\
\text { turno }\end{array}$ & $\begin{array}{c}\text { Días/ } \\
\text { semana }\end{array}$ & $\begin{array}{c}\text { Semanas/ } \\
\text { año }\end{array}$ & $\begin{array}{c}\text { Número } \\
\text { teórico de } \\
\text { máquinas }\end{array}$ & $\begin{array}{c}\text { Número } \\
\text { real de } \\
\text { máquinas }\end{array}$ \\
\hline $\begin{array}{c}\text { Corte laser } \\
\text { CNC }\end{array}$ & 4492 & 0.0325 & 1 & 1 & 8 & 5 & 52 & 0.0701875 & 1 \\
\hline $\begin{array}{c}\text { Corte } \\
\text { plasma } \\
\text { CNC }\end{array}$ & 4492 & 0.004375 & 1 & 1 & 8 & 5 & 52 & 0.0094483 & 1 \\
\hline
\end{tabular}

Elaboración Propia 


\subsection{Resguardo de la calidad}

\subsubsection{Calidad de la materia prima, de los insumos, del proceso y del producto}

\section{Calidad de la materia prima}

La calidad de la materia prima es un factor clave para el éxito del producto, por ello se deben de determinar procedimientos para asegurar la composición y propiedades de las distintas materias primas. Los procedimientos según tipo de materiales es el siguiente:

- Metales:

En el diseño del producto se determinó que estos debían de ser inoxidable, ya que van a ser sometidos a soluciones altamente corrosivas. Por ello el control de calidad se efectuará tomando una muestra de $1 \mathrm{~cm}$ de longitud de cada parte metálica y sometiéndola a una prueba de ácidos estándar para aceros inoxidables. Si estas piezas muestran signo de haberse corroído (se tornan de color negro), es porque no cumple las especificaciones determinadas y por consiguiente no han pasado el control. Caso contrario, son materiales aptos para el ensamble.

- No metales:

En el caso de los plásticos, las principales características a controlar son al resistividad eléctrica y la resistencia mecánica. Para ello, se comprará una muestra de cada proveedor y se tercerizará las pruebas al laboratorio de materiales de la Universidad Nacional de Ingeniería para que emita un reporte técnico y así poder escoger el producto de mejor calidad. Más aun, se exigirá a los proveedores contar con estudios y certificaciones de su producto.

- Calidad del proceso:

Se debe recalcar de que debe haber un control por inspecciones de las dimensiones de las piezas cortadas para asegurar que los cortes realizados por las máquinas $\mathrm{CNC}$ esté bien calibrado y produciendo piezas según las especificaciones técnicas. Se realizará una inspección de previa al corte, ordenando a la máquina a que recorra el espacio físico por donde cortará la primera pieza. 
Esta inspección será cualitativa. Luego, cada vez que una plancha haya sido terminada de cortar, se debe tomar una muestra para determinar si las dimensiones del corte fueron las correctas.

Con respecto al ensamble, se deben realizar inspecciones visuales a todas las celdas para determinar si se han incluido todas las piezas a unir. Para apoyar este proceso se podría aplicar graficas de control que controlen el peso de las celdas (la ausencia de un elemento repercutirá en el peso del elemento).

Además, se buscará implantar las siguientes filosofías de trabajo:

- Las 5S:

Clasificar, ordenar, limpiar, estandarizar y disciplina.

- Poka Yoke:

Es un mecanismo que ayuda a prevenir los errores antes de que sucedan, o los hace que sean muy obvios para que el trabajador se dé cuenta y lo corrija a tiempo. Busca desarrollar una cultura basada en "cero errores".

- Six Sigma:

Filosofía de mejoramiento, que utiliza el mejor talento humano así como herramientas estadísticas para incorporar la voz del cliente en los procesos del negocio, de forma tal que los compradores de concentrado incrementen su satisfacción debido a un mayor valor añadido.

- Metodología de los 7 pasos para la mejora continua:

Es un ciclo de proceso a aplicar para definir problemas que impacten la productividad y profundizarse en ellos de manera que se encuentren soluciones propicias que permitan garantizar que no se repita en el futuro.

Figura 5.19

Método de los 7 pasos

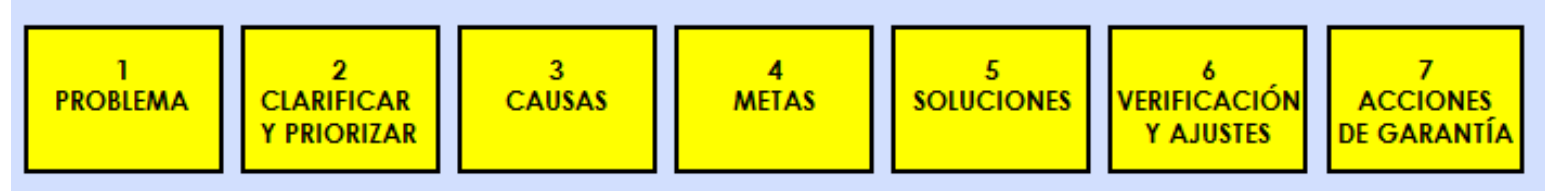

Elaboración Propia 


\section{- SEDAC:}

Permite hacer mejoras en los procesos en el día a día, con el uso de un tablero visible para todos en la planta, y la aplicación de los 7 pasos en proyectos de corta duración, trabajando simultáneamente el análisis de problemas y acciones de mejora directamente sobre el diagrama causa-efecto y observando a la vez su efecto en el indicador.

\section{- Calidad del producto}

Para controlar la calidad de las celdas de electrólisis, se debe medir su eficiencia. Para realizar dicha medición, se analizará una celda por cada plancha de acero cortada (1 de cada 50), para ello se debe montar la celda junto al sistema mecánico y eléctrico para poder hacer generar gas oxhídrico. Se debe rellenar el sistema con agua destilada con hidróxido de potasio disuelto en una proporción de $3 \%$ en peso, luego se debe alimentar la celda con una fuente de $13.6 \mathrm{~V}$ y debe producir 0.5 litros por minuto o más para poder afirmar que es una celda que cumple las especificaciones. Para llevar un control más idóneo, se debe utilizar graficas de control.

\subsubsection{Medidas de resguardo de la calidad en la producción}

Para resguardar la calidad del producto, este debe ser guardado en una caja en un ambiente seguro de almacenamiento libre de polvo. Debido a las características de los materiales escogidos, el producto resiste condiciones de alta humedad y temperatura (tomando en cuenta de que ha sido diseñado para ser instalado cerca al motor del carro), por lo que aun en condiciones malas de almacenamiento, las propiedades técnicas del producto se van a mantener, tan solo se vería afectada las características estéticas del mismo.

\subsection{Estudio de impacto ambiental}

La responsabilidad del diseño de un proyecto industrial no solo recae en la adecuada selección tecnológica o en un planeamiento financiero correcto, sino, también el impacto en la ecología y medio ambiente es un factor clave para el desarrollo de cualquier negocio en el ámbito actual dentro del territorio del Perú. Más aun, existen regulaciones y entidades encargadas de velar por el medio ambiente, esto es una motivación extra para que una empresa se encuentre en 
armonía con su entorno. Las empresas que logren un funcionamiento ecológicamente amigable, contarán con una ventaja competitiva en el mercado, y estarán lejos de causar daños que a largo plazo sean irreversibles.

Para empezar el análisis se debe considerar los requisitos legales y las normativas o procedimientos que debe cumplir cualquier industria, en este caso se trata de un certificado o permiso ambiental otorgado por el estado. Este permiso varía con respecto a la categoría de impacto ambiental que el proceso industrial genere. En la tabla se muestran las categorías en mención.

Tabla 5.7

Requisitos legales por categoría de impacto ambiental

\begin{tabular}{|c|l|l|}
\hline Categoría & \multicolumn{1}{|c|}{ Tipo de impacto ambiental } & \multicolumn{1}{c|}{ Documento exigido } \\
\hline I & Impacto negativo poco significativo & $\begin{array}{l}\text { Declaración de Impacto } \\
\text { Ambiental }\end{array}$ \\
\hline II & $\begin{array}{l}\text { Impacto negativo moderado y } \\
\text { susceptible a ser minimizado mediante } \\
\text { medidas fácilmente aplicables }\end{array}$ & $\begin{array}{l}\text { Estudio de Impacto } \\
\text { Ambiental Semidetallado } \\
\text { (EIA-sd) }\end{array}$ \\
\hline III & $\begin{array}{l}\text { Impacto negativo significativo } \\
\text { cuantitativa o cualitativamente }\end{array}$ & $\begin{array}{l}\text { Estudio de impacto } \\
\text { Ambiental Detallado (EIA-d) }\end{array}$ \\
\hline
\end{tabular}

Fuente: Diaz, B.; Jarufe, B; Noriega, M.T., (2007)

Este proyecto tan solo genera como merma pequeños retazos plásticos y metálicos además de breves humos propios de los cortes anteriormente descritos. Debido a esto, el proyecto caería dentro de la calificación de "Categoría I" y el único requisito sería la "Declaración de Impacto Ambiental".

\subsection{Seguridad y salud ocupacional}

Los recursos humanos son claves para el desenvolvimiento de esta industria, y más aún, la vida humana debe ser respetada y protegida en toda situación, es por ello que la seguridad y salud en el trabajo son claves para este proyecto, y en general para cualquier proyecto industrial. Más aun, se debe cumplir el marco legar estipulado en la lay de seguridad y salud en el trabajo $\mathrm{N}$ 29783. 
Con fines prácticos, se recomienda implantar un sistema de gestión de seguridad y salud en el trabajo (SGSST) siguiendo los lineamientos de las siguientes normas internacionales:

- OHSAS 18001: Especifica los requisitos que el SGSST deberá cumplir para que pueda controlar y prevenir los riesgos.

- OHSAS 18002: Orienta sobre la implementación de la norma OHSAS 18002

- Organización general del SGSST

La política de seguridad y salud debe seguir como lineamientos principales los siguientes objetivos:

- Cumplimiento obligatorio de las normas de seguridad y salud en el trabajo.

- Protección integral de todas las personas que trabajen dentro de las instalaciones.

- Buscar la mejora continua del desempeño del SGSST.

- Procurar la integración del SGSST con los demás sistemas de gestión.

- Formar y mantener un comité de SGSST cuyas actividades serán:

- Elaborar planes de capacitación, reglamentos, protocolos de auditorías, entre otras cosas.

- Velar por el cumplimiento de las normas, procedimientos y controles del SGSST, adoptando acciones correctivas o preventivas.

- Registrar sucesos como accidentes e incidentes o enfermedades.

- Crear brigadas para combatir ciertas contingencias como incendios, primeros auxilios, entre otras.

- El reglamento interno de SST debe considerar la siguiente información:

○ Objetivos y alcance.

- Política de seguridad y salud en el trabajo.

- Manual de funciones y obligaciones de todos los trabajadores.

- Estándares de seguridad y salud en las operaciones, y control de peligros existentes y riesgos evaluados.

○ Preparación y respuesta a emergencias. 
- Análisis de riesgos

Con el objetivo de mapear los riesgos y poder tener un vasto conocimiento sobre los posibles peligros presentes dentro de este proyecto industrial, se procedió a elaborar la siguiente lisa donde se analizan los riesgos.

Tabla 5.8

Análisis de riesgos para el proyecto

\begin{tabular}{|c|c|c|c|c|}
\hline Riesgo & Operaciones & Causas & Consecuencias & Medidas preventivas \\
\hline Electrocución & $\begin{array}{l}\text { Corte (láser y } \\
\text { plasma) }\end{array}$ & $\begin{array}{l}\text { Contacto con terminal } \\
\text { energizado. Falla en } \\
\text { puesta a tierra }\end{array}$ & $\begin{array}{l}\text { Lesión física, } \\
\text { quemaduras, } \\
\text { falla cardiaca, } \\
\text { muerte. }\end{array}$ & $\begin{array}{l}\text { Revisión periódica de } \\
\text { puesta a tierra y } \\
\text { utilización de botas y } \\
\text { guantes aislantes }\end{array}$ \\
\hline Quemadura & Corte (plasma) & $\begin{array}{l}\text { Exposición a escoria } \\
\text { contacto con material } \\
\text { recién cortado }\end{array}$ & $\begin{array}{l}\text { Lesión física, } \\
\text { quemadura }\end{array}$ & $\begin{array}{l}\text { Implementar barreras } \\
\text { aparta - cuerpo y } \\
\text { utilizar guantes } \\
\text { aislantes }\end{array}$ \\
\hline Corte & $\begin{array}{l}\text { Corte (laser) y } \\
\text { Ensamble }\end{array}$ & $\begin{array}{l}\text { Contacto con bordes } \\
\text { filosos, contacto con } \\
\text { haz de corte }\end{array}$ & $\begin{array}{l}\text { Sangrado, lesión } \\
\text { física }\end{array}$ & $\begin{array}{l}\text { Utilización de } \\
\text { guantes }\end{array}$ \\
\hline $\begin{array}{l}\text { Deterioro de } \\
\text { ojos }\end{array}$ & $\begin{array}{l}\text { Corte (laser y } \\
\text { plasma) }\end{array}$ & Exposición a radiación & $\begin{array}{l}\text { Pérdida parcial } \\
\text { de visión }\end{array}$ & $\begin{array}{l}\text { Implementación de } \\
\text { barreras UV en } \\
\text { cobertura de maquina } \\
\text { Utilización de lentes } \\
\text { con protección UV a } \\
\text { la hora de } \\
\text { inspeccionar } \\
\text { operación de corte }\end{array}$ \\
\hline
\end{tabular}

Elaboración Propia

\subsection{Sistema de mantenimiento}

La actividad de mantenimiento dentro del ámbito industrial tiene como fin mantener las capacidades y características de la maquinaria fabril y la seguridad de las instalaciones, para que la operación y el desarrollo productivo se desenvuelvan de la manera más adecuada. Para ello, es importante ubicar defectos, reemplazar partes y prevenir fallas. La gestión del mantenimiento 
propiamente dicha para este proyecto se encargará de planificar, organizar, dirigir y controlar las actividades necesarias para obtener y conservar un apropiado costo de ciclo de vida de los activos del proyecto tratando de asegurar la competitividad de la empresa para lograr los objetivos fabriles y estratégicos que se planteen a lo largo del proyecto. Con respecto a la toma de decisiones en la administración del mantenimiento, es importante analizar el punto óptimo en el cual la inversión en mantenimiento genera la mayor rentabilidad, y los costos sean menores que los beneficios obtenidos. Debido a que la instalación industrial no es tan vasta sólo se contará con una cuadrilla de mantenimiento correctivo y reactivo.

\section{Tabla 5.9}

Cuadrillas de mantenimiento correctivo y reactivo

\begin{tabular}{|l|l|l|}
\hline \multicolumn{1}{|c|}{ Cuadrilla } & \multicolumn{1}{c|}{ Responsabilidades } & \multicolumn{1}{c|}{$\begin{array}{c}\text { Mantenimiento correctivo y } \\
\text { reactivo }\end{array}$} \\
\hline $\begin{array}{l}\text { Mantenimiento } \\
\text { general }\end{array}$ & $\begin{array}{l}\text { Maquinaria, instalaciones } \\
\text { eléctricas e instalaciones } \\
\text { sanitarias }\end{array}$ & $\begin{array}{l}\text { Reparaciones de averías y fallas } \\
\text { Ajustes y calibraciones }\end{array}$ \\
\hline
\end{tabular}

Elaboración Propia

- Mantenimiento preventivo

Este incluye todos los esfuerzos dirigidos a prevenir la ocurrencia de fallas en los equipos, por ejemplo: lubricación, ajustes, calibración, nivelación, sustitución de piezas y repuestos e inspecciones. 
Tabla 5.10

Procedimiento de implementación de mantenimiento preventivo

\begin{tabular}{|l|}
\hline Actividades requeridas para implementar un sistema de mantenimiento \\
\hline Elaborar un plan de mantenimiento \\
\hline Motivar y comprometer al personal \\
\hline Determinar requerimientos de mantenimiento \\
\hline Diseñar sistema de documentación \\
\hline Crear registro de paralizaciones \\
\hline Prever recursos necesarios \\
\hline Realizar "Overhauling" cuando sea necesario \\
\hline Seleccionar y capacitar inspectores \\
\hline Establecer procedimientos de determinación de averías \\
\hline Proyectar descenso de productividad \\
\hline Prever seguimiento y evaluación del programa \\
\hline
\end{tabular}

Elaboración Propia

Luego de la implementación del mantenimiento preventivo de deberá desarrollar la programación de actividades de inspección en cada máquina, componente, repuestos e instalaciones a través de las siguientes acciones:

- Determinar los indicadores de disponibilidad, fiabilidad, tasa de fallos $(\chi)$, tiempo medio entre fallas (MTBF), mantenibilidad (M), tiempo medio de reparación (MTTR) y costos de mantenimiento.

- Establecer hoja de control de inspección (tarjeta de inspección).

- Determinar tiempo de inspección.

- Fijar carga de trabajo.

- Elaborar programa de inspección.

- Ejecutar programación.

- Realizar seguimiento. 
- Mantenimiento proactivo

Las máquinas de corte escogidas para la manufactura, láser y plasma $\mathrm{CNC}$, pueden ir viendo afectado su funcionamiento debido a la contaminación o ensuciamiento del husillo de corte, efecto que atenta contra la calidad de corte y eficiencia de la máquina. Es por esta razón que también se recomienda la implantación de una política de mantenimiento proactivo, en la cual los propios operarios, luego de operar la máquina correspondiente, le realizan un breve mantenimiento con el propósito de evitar que la contaminación de los lentes afecte la calidad y productividad de la manufactura.

Figura 5.20

Limpieza de husillo de corte láser

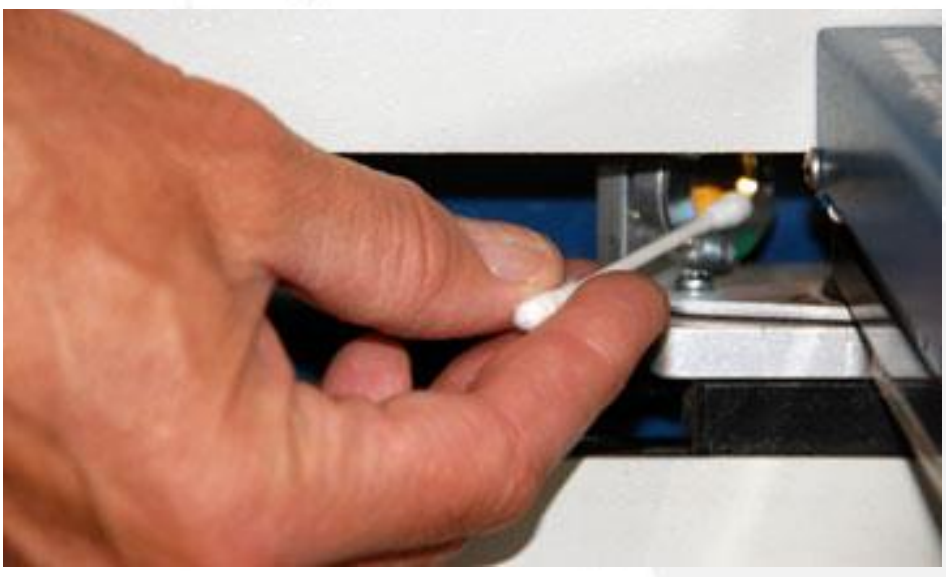

Fuente: Blog corte y grabado, (2013)

\subsection{Programa de producción para la vida útil del proyecto}

\subsubsection{Consideraciones sobre la vida útil del proyecto}

Se ha determinado que la vida útil del proyecto es de 5 años. En este caso, la proyección del tiempo de vida del proyecto se estimó por una perspectiva tecnológica, ya que la tecnología que se va a manufacturar funciona para la tecnología automotriz actual, pero el futuro tecnológico (utilización masiva de carros eléctricos o híbridos, etc) en un horizonte mayor a 5 años es difícil de predecir y por ende la validez futura de la tecnología en mención. 


\subsubsection{Programa de producción para la vida útil del proyecto}

Durante estos años de funcionamiento fabril la producción anual será determinada por la demanda anual proyectada.

Tabla 5.11

Plan de producción del proyecto

\begin{tabular}{|c|c|c|c|c|c|}
\hline Item & Año 1 & Año 2 & Año 3 & Año 4 & Año 5 \\
\hline $\begin{array}{c}\text { Celdas de } \\
\text { electrólisis }\end{array}$ & 13,790 & 14,452 & 15,146 & 15,873 & 16,643 \\
\hline
\end{tabular}

Elaboración Propia

Se debe mencionar también que la producción será por lotes (batch). El planeamiento y control productivo presentará un rol fundamental para que la operatividad industrial no presente ningún inconveniente a la hora de responder frente a las demandas del mercado, de tal manera que los requerimientos de materiales estén correctamente diseñados, respetando las especificaciones del producto.

\subsection{Requerimiento de insumos, personal y servicios}

\subsubsection{Materia prima, insumos y otros materiales}

Este proyecto busca dar un alto valor agregado a los materiales que serán procesados para que formen los sistemas de hidrógeno vehicular, en tal sentido, es necesario calcular los requerimientos para poder abastecer la producción en el tiempo de vida del proyecto. Estos cálculos se obtuvieron multiplicando la cantidad de unidades a fabricar por año por el valor respectivo para cada material descrito en el "Bill of Materials" anteriormente. 
Tabla 5.12

Plan de requerimiento de materia prima

\begin{tabular}{|l|l|c|c|c|c|c|c|}
\hline \multicolumn{1}{|c|}{ Ítem } & Unidad & $\begin{array}{c}\text { Cantidad por } \\
\text { celda }\end{array}$ & Año 1 & Año 2 & Año 3 & Año 4 & Año 5 \\
\hline $\begin{array}{l}\text { Esparrago } \\
\text { inoxidable } \\
(1 / 4 ")\end{array}$ & metro & 0.7 & 9,653 & 10,116 & 10,602 & 11,111 & 11,650 \\
\hline $\begin{array}{l}\text { Tuercas de } \\
\text { acero } \\
\text { inoxidable } \\
(1 / 4 ")\end{array}$ & unid. & 12.0 & 165,480 & 173,424 & 181,752 & 190,476 & 199,716 \\
\hline $\begin{array}{l}\text { Electrodo } \\
\text { de Acero } \\
\text { SAE 316L } \\
(1 \mathrm{~mm})\end{array}$ & unid. & 21.0 & 289,590 & 303,492 & 318,066 & 333,333 & 349,503 \\
\hline $\begin{array}{l}\text { Aislante de } \\
\text { neopreno }\end{array}$ & unid. & 22.0 & 303,380 & 317,944 & 333,212 & 349,206 & 366,146 \\
\hline $\begin{array}{l}\text { Tapa de } \\
\text { acrílico }\end{array}$ & unid & 2.0 & 27,580 & 28,904 & 30,292 & 31,746 & 33,286 \\
\hline
\end{tabular}

Elaboración Propia

Además, se deberán comprar los demás insumos que se deberán adicionar a la celda de electrólisis para formar el sistema de hidrógeno vehicular. 


\section{Tabla 5.13}

Plan de requerimiento de insumos directos

\begin{tabular}{|l|c|c|c|c|c|c|c|}
\hline \multicolumn{1}{|c|}{ Ítem } & Unidad & $\begin{array}{c}\text { Cantidad } \\
\text { por } \\
\text { sistema }\end{array}$ & Año 1 & Año 2 & Año 3 & Año 4 & Año 5 \\
\hline Manguera sanitaria (3/8") & metro & 2 & 27,580 & 28,904 & 30,292 & 31,746 & 33,286 \\
\hline $\begin{array}{l}\text { Manguera de alta presión } \\
\left(3 / 8^{\prime \prime}\right)\end{array}$ & metro & 1.5 & 20,685 & 21,678 & 22,719 & 23,810 & 24,965 \\
\hline Válvula check (3/8") & unid. & 1 & 13,790 & 14,452 & 15,146 & 15,873 & 16,643 \\
\hline Tanque de Agua (3L) & unid. & 1 & 13,790 & 14,452 & 15,146 & 15,873 & 16,643 \\
\hline Conexiones & unid. & 5 & 68,950 & 72,260 & 75,730 & 79,365 & 83,215 \\
\hline Abrazaderas & unid. & 5 & 68,950 & 72,260 & 75,730 & 79,365 & 83,215 \\
\hline Cables & metro & 2 & 27,580 & 28,904 & 30,292 & 31,746 & 33,286 \\
\hline Controlador electrónico & unid. & 1 & 13,790 & 14,452 & 15,146 & 15,873 & 16,643 \\
\hline Terminales & unid. & 5 & 68,950 & 72,260 & 75,730 & 79,365 & 83,215 \\
\hline
\end{tabular}

Elaboración Propia

\subsubsection{Servicios: energía eléctrica, agua, vapor, combustible, etc.}

En este proyecto la única fuente de energía utilizada será la eléctrica. Para poder proyectar el consumo eléctrico, se multiplicó la potencia del activo utilizado por el tiempo del periodo de uso, de tal modo que se expresará en kilowatts hora. La siguiente tabla representa dicho pronóstico:

Tabla 5.14

Consumo de electricidad

\begin{tabular}{|c|c|c|c|c|c|}
\hline Año & $\mathbf{1}$ & $\mathbf{2}$ & $\mathbf{3}$ & $\mathbf{4}$ & $\mathbf{5}$ \\
\hline KW-h & $51,220.66$ & $53,679.55$ & $56,257.29$ & $58,957.61$ & $61,817.65$ \\
\hline
\end{tabular}

Elaboración Propia 
Con respecto al consumo de agua, se presume que su uso será en baja cantidades, ya que básicamente se utilizará en el aseo de los trabajadores y la limpieza de la fábrica ya que el proceso fabril no requiere de este insumo.

\subsubsection{Determinación del número de operarios y trabajadores indirectos}

Para la operación de este proceso fabril, se necesitan operarios que realicen las operaciones manuales y que programen las máquinas CNC. A continuación se detallan los cálculos respectivos para determinar la cantidad de operarios por actividad.

Tabla 5.15

Cálculo del número de operarios

\begin{tabular}{|c|c|c|c|c|c|c|c|c|c|}
\hline Proceso & $\begin{array}{c}\text { Tamaño de } \\
\text { producción } \\
\text { requerido } \\
\text { (celdas) }\end{array}$ & $\begin{array}{c}\text { Tiempo } \\
\text { estándar } \\
\text { (h/celda) }\end{array}$ & $\begin{array}{c}\text { Horas/ } \\
\text { turno }\end{array}$ & $\begin{array}{c}\text { Turnos } \\
\text { /día }\end{array}$ & $\begin{array}{c}\text { Días/ } \\
\text { semana }\end{array}$ & $\begin{array}{c}\text { Semanas } \\
\text { /año }\end{array}$ & Eficiencia & $\begin{array}{c}\text { Número } \\
\text { teórico de } \\
\text { Operarios } \\
\text { requeridos }\end{array}$ & $\begin{array}{c}\text { Número } \\
\text { real de } \\
\text { operarios } \\
\text { requeridos }\end{array}$ \\
\hline Ensamble & $16,643.00$ & 0.33 & 8 & 1 & 5 & 52 & 0.8 & 2.11 & 3 \\
\hline Lijado & $16,643.00$ & 0.15 & 8 & 1 & 5 & 52 & 0.8 & 0.96 & 1 \\
\hline Roscado & $16,643.00$ & 0.08 & 8 & 1 & 5 & 52 & 0.8 & 0.53 & 1 \\
\hline Encajado & $16,643.00$ & 0.02 & 8 & 1 & 5 & 52 & 0.8 & 0.11 & 1 \\
\hline Cortado & $16,643.00$ & 0.02 & 8 & 1 & 5 & 52 & 0.8 & 0.11 & 1 \\
\hline $\begin{array}{c}\text { Programación } \\
\text { de máquina de } \\
\text { corte }\end{array}$ & - & 4.03 & 8 & 1 & 5 & 52 & 0.8 & 0.00155 & 1 \\
\hline
\end{tabular}

Elaboración Propia

Se puede determinar que se requerirá de tres operarios de ensamble (siendo esta la operación cuello de botella. Mientras que solo se requerirá de un solo trabajador para realizar las operaciones de lijado, roscado, encajado, cortado y programación de máquinas de corte CNC. No se ha optado por tener un operario por cada actividad que no sea el ensamble, ya que representaría un exceso de tiempo ocioso por los trabajadores. 
Además de la mano de obra directa, se debe tomar en cuenta los recursos humanos indirectos necesarios. En la siguiente tabla se detallan los recursos humanos necesarios que laborarán en planta.

Tabla 5.16

Mano de obra directa e indirecta para la planta

\begin{tabular}{|c|c|c|c|c|c|}
\hline & Personal de Planta & $\begin{array}{c}\text { Cantidad } \\
\text { requerida por } \\
\text { turno }\end{array}$ & $\begin{array}{c}\text { Número de } \\
\text { turnos por día }\end{array}$ & $\begin{array}{l}\text { Cantidad total } \\
\text { requerida }\end{array}$ & TOTAL \\
\hline \multirow[b]{2}{*}{$\begin{array}{l}\text { Mano } \\
\text { de obra } \\
\text { directa }\end{array}$} & Operarios de ensamble & 3 & 1 & 3 & \multirow[b]{2}{*}{4} \\
\hline & $\begin{array}{c}\text { Operarios lijado, } \\
\text { roscado, encajado y } \\
\text { cortado }\end{array}$ & 1 & 1 & 1 & \\
\hline \multirow{3}{*}{$\begin{array}{c}\text { Mano } \\
\text { de obra } \\
\text { indirecta }\end{array}$} & Gerente de operaciones & 1 & 1 & 1 & \multirow{3}{*}{3} \\
\hline & $\begin{array}{c}\text { Supervisor de } \\
\text { operaciones }\end{array}$ & 1 & 1 & 1 & \\
\hline & $\begin{array}{c}\text { Técnico de } \\
\text { mantenimiento }\end{array}$ & 1 & 1 & 1 & \\
\hline & TOTAL & 7 & - & 7 & 7 \\
\hline
\end{tabular}

Elaboración Propia

En la siguiente tabla se detallan los recursos humanos necesarios que laborarán en el área administrativa. 
Tabla 5.17

Trabajadores administrativos requeridos para el proyecto

\begin{tabular}{|c|c|c|}
\hline Personal administrativo & $\begin{array}{l}\text { Número } \\
\text { de turnos } \\
\text { al día }\end{array}$ & $\begin{array}{l}\text { Cantidad } \\
\text { requerida }\end{array}$ \\
\hline Gerente general & 1 & 1 \\
\hline Gerente comercial & 1 & 1 \\
\hline Jefe de Contabilidad y Finanzas & 1 & 1 \\
\hline Jefe de recursos humanos & 1 & 1 \\
\hline Asistentes & 1 & 3 \\
\hline Secretarias & 1 & 1 \\
\hline Vendedores & 1 & 3 \\
\hline TOTAL & - & 11 \\
\hline
\end{tabular}

Elaboración Propia

\subsubsection{Servicios de terceros}

- Telecomunicaciones

Se debe contar con los servicios de telefonía e internet para poder comunicarse interna y externamente. Se deberá contar con anexos, correo electrónico para el personal administrativo.

- Electricidad

Este servicio servirá para energizar la maquinaria y todos los activos que necesiten suministro eléctrico, al igual que la iluminación de la planta.

- Seguridad

La vigilancia de la maquinaria, instalaciones y, en general, los activos de la empresa será también tercerizada. Este servicio será crucial para evitar pérdidas económicas o disminuciones en la productividad debido a contingencias como robos, asaltos, saqueos, enfrentamientos u otros. Se debe contar con personal calificado en seguridad, al igual que cámaras de video vigilancia. 
- Salud

Es de suma importancia contar con personal capacitado para atender emergencias y realizar exámenes médicos periódicos en el personal para asegurar la salud de los trabajadores.

- Transporte

El traslado de los sistemas de hidrógeno vehicular se deberá transportar a los distintos puntos de distribución. Esta actividad será realizada por una empresa logística. Para proteger la integridad del producto, se recomienda que este se realice en un vehículo de cubierta tapada, para evitar exponerlo a la intemperie.

\subsection{Características físicas del proyecto}

\subsubsection{Factor edificio}

Si se busca lograr una apropiada distribución de áreas en una planta es necesario estudiar la edificación para que la infraestructura contribuya al aumento de la productividad de los procesos o en todo caso no represente una interferencia o estorbo que límite las operaciones. Se debe considerar el tipo de suelo, la construcción de los niveles y material de los pisos dentro de la planta, el material de construcción de paredes, las vías de circulación para trabajadores y medios de acarreo, vías de acceso y salida, techo y su altura y anclaje de maquinaria.

- Tipos de suelo

Si bien se debe contar con un local que posea una edificación de dos niveles que tenga una buena cimentación para que de esta manera pueda soportar altos niveles de peso que será ejercido

por la maquinaria. Afortunadamente, el área donde va a construirse la planta, presenta un tipo de suelo adecuado para las condiciones mencionadas

- Niveles, pisos y paredes de la planta

En relación al piso de la planta deberá ser llano y duro para soportar altos niveles de cargas. Para el área de producción y patio de maniobras el piso debe ser de concreto armado ya 
que este material es el de mayor resistencia a fuerzas mecánicas. Por otro lado, el área administrativa y de servicios puede tener piso de cemento o concreto simple. En vista de que las paredes no soportan mayores cargas que las del techo, pueden ser hechas de madera delgada, polipropileno más fibra de madera o concreto.

- El techo y su altura

La presencia de un techo es necesaria debido a las lluvias que puede haber en temporadas de invierno. Este debe ser de un material impermeable y liviano al mismo tiempo. Un buen material son las calaminas que brindan un techo resistente, anticombustible, liviano y a bajo costo. Este debe estar a una altura de 6 metros con respecto al piso.

- Vías de circulación

Estas vías son usadas por trabajadores y medio de acarreo móviles dentro de la planta. Estas vías deben ser combinadas, es decir, serán usadas para carretillas, trabajadores y de pequeños montacargas. Considerando el ancho de las carretillas y la cantidad de trabajadores se acordó diseñar todas las vías de circulación con 4m de ancho.

\subsubsection{Factor servicio}

- Servicios relativos al personal

Incluye todos los servicios e instalaciones orientadas a satisfacer necesidades de los trabajadores.

\section{- Instalaciones sanitarias}

Son instalaciones indispensables que deben incluir duchas, inodoros, lavamanos y vestuario. Asimismo, se debe equipar con espejos, toalleros, jabones líquidos, papel higiénico, basureros y lockers individuales. Se calcula que el número de trabajadores estará dentro de un rango entre 8 y 12, por tal motivo, por recomendaciones de la OSHA se instalará 1 baño con 2 inodoros, 2 duchas, 2 urinarios, 1 lavamanos con 2 dispensadores de agua y tantos lockers como trabajadores hayan. Este baño es solo para planta. Adicionalmente, habrá un baño individual en la zona de patio de maniobras para ser usado por trabajadores de esa área, personal de seguridad, transportistas y proveedores que visiten la planta. En la zona administrativa, que cuenta con un 
rango entre 5 - 10 trabajadores, se decidió instalar un baño similar al de planta, pero sin duchas y en vez de 1 lavamanos con 2 caños instalar dos individuales más formales.

- Servicios de alimentación

Este servicio es muy importante y corre a cuenta de la empresa. La comida será comprada a un proveedor local. El comedor será usado por trabajadores de planta en un turno y oficina en un segundo turno. Por lo tanto, el área será diseñada para atender como máximo 20 personas a la misma vez. Esta holgura permite atender a terceros contratados que ocasionalmente podrían trabajar en la planta. Además, adicionalmente se planea usar el comedor para reuniones o conferencias ocasionales con trabajadores.

El comedor deber tener 3 lavamanos con papel toalla y jabón líquido y basureros. El reglamente nacional de construcción establece que por cada comensal halla $1.5 \mathrm{~m} 2$ de área. Si consideramos que el comedor está lleno (20 usuarios) el área sería de $30 \mathrm{~m} 2$. En relación a las mesas serán 4 unidades para 6 personas cada una. La cocina estará junto al comedor e incluirá cocina, una mesa grande, lavamanos y refrigerados. Trabajarán 2 personas que serán las mismas que servirán la comida. Se calcula un área de $15 \mathrm{~m} 2$. Por lo tanto, toda la zona medirá $45 \mathrm{~m} 2$.

- Servicios médicos

Es indispensable que la planta cuente con un departamento médico privado. Este debe estar equipado para tratar lesiones de gravedad y de cualquier tipo por el médico particular. Además, periódicamente se contará con los servicios de médicos ocupacionales para evaluar la salud de los trabajadores. Las instalaciones incluirán una sala de emergencia, un cuarto para exámenes y oficinas para el personal médico.

- Iluminación y ventilación

Una adecuada iluminación es importante para que los trabajadores no tengan problemas de visión y pueda identificar y prevenir cualquier riesgo inherente al proceso. En este caso, las lámparas a usar serán de techo y deben emitir flujo luminoso bastante alto ya que el este tiene una altura de 6 metros. Para estos caso, la mejor opción son lámparas de vapor de mercurio o vapor de sodio de alta presión ya que a pesar de tener un precio alto, a largo plazo son bastante eficientes por tener un costo operativo bajo y ser de alta durabilidad ya que su vida útil oscila 
entre 15000 y 25000 horas de uso y pueden llegar a tener una eficiencia de hasta 140 lumen/watt.

- Servicios relativos al edificio

Se refiere a características especiales que debe tener la infraestructura en beneficio de los trabajadores.

- Señalización

Se instalarán señales de seguridad e información en zonas estratégicas de la planta y tendrán distintos colores según el tipo de información que se está dando. Estas pueden ser de advertencia, obligación, indicaciones, peligro, etc.

Las señales deberán presentar mensajes breves y concretos. Por otro lado, las señales acústicas son necesarias para informar sobre un acontecimiento importante a varias personas alrededor. Estas se deben usar para advertir sobre incendios, explosiones, fuga de algún gas, anomalías en el proceso de producción, etc.

- Calidad de ambiente en el trabajo

Para que una empresa tenga resultados exitosos tiene que esforzarse en lograr un ambiente propicio en el trabajo. Para esto la organización se compromete a aplicar la metodología de las 5 "S" que se enfoca en desarrollar planes de mejoramiento del ambiente de trabajo.

\subsection{Disposición de planta}

\subsubsection{Determinación de las zonas físicas requeridas}

Se determinaron las siguientes zonas físicas:

I. Almacén de materia prima, insumos y suministros

II. Almacén de productos terminados

III. Patio de maniobras de descarga de MP y carga de PT

IV. Oficinas

V. Comedor 
VI. Servicios higiénicos

VII. Tópico

\subsubsection{Cálculos de áreas para cada zona}

Para determinar el espacio idóneo para las operaciones se analizarán los requerimientos de superficies para el área de producción y el área administrativas. En el primer caso, se aplicará el método de Guerchet, para lo cual se necesitará el número total de cada tipo de máquina y la cantidad de elementos móviles y operarios que trabajen en la planta para luego hallar el área optima requerida para las operaciones. Se deben considerar los 3 tipos de área exigidos por el método: el área estática, la superficie de gravitación y de evolución.

Tabla 5.18

Cálculo del coeficiente de evolución

\begin{tabular}{|l|c|c|c|c|c|}
\hline $\begin{array}{c}\text { Para elementos } \\
\text { estáticos }\end{array}$ & $\mathbf{S S *} \mathbf{n} * \mathbf{h}$ & $\mathbf{S S} * \mathbf{n}$ & Para elementos móviles: & $\mathbf{S S *} \mathbf{n} \mathbf{h}$ & $\mathbf{S S * n}$ \\
\hline $\begin{array}{l}\text { Máquina de } \\
\text { corte a láser }\end{array}$ & 3.00 & 1.50 & Montacargars & 11.00 & 5.00 \\
\hline $\begin{array}{l}\text { Máquina de } \\
\text { corte plasma }\end{array}$ & 9.59 & 7.38 & Operarios & 6.60 & 4.00 \\
\hline Total & $\mathbf{1 2 . 5 9}$ & $\mathbf{8 . 8 8}$ & Total & $\mathbf{1 7 . 6 0}$ & $\mathbf{9 . 0 0}$ \\
\hline Hee & $\mathbf{1 . 4 2}$ & & Hem & $\mathbf{1 . 9 6}$ & \\
\hline
\end{tabular}

Elaboración Propia

Se calculó el coeficiente de evolución según la siguiente formula:

$$
k=\frac{1.96}{2 \times 1.42}=0.69
$$

Elaboración Propia 


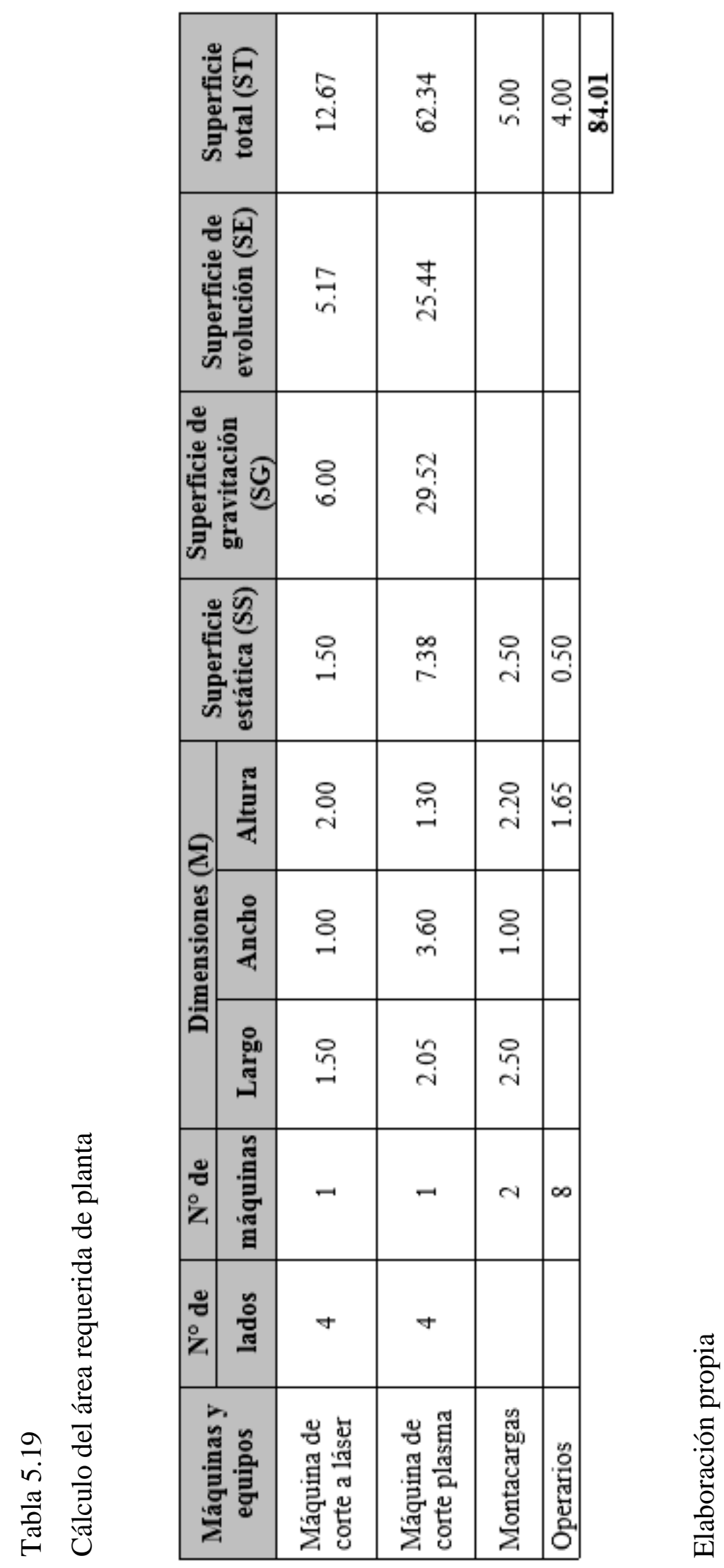


El área total requerida para la planta es de $84.01 \mathrm{~m} 2$.

Ya con el área de producción determinada se debe calcular los espacios que ocuparan las otras zonas para hallar el tamaño total.

- Almacén de materia prima, insumos y suministros

Los almacenes no se consideraron en el Guerchet ya que están separados de la planta. Se estima un tamaño de almacén de $38 \mathrm{~m} 2$.

- Almacén de productos terminados

Se estima un tamaño de almacén de $38 \mathrm{~m} 2$.

- Área de mantenimiento

Se estima un área de $38 \mathrm{~m} 2$.

- Patio de maniobras de descarga de MP y carga de PT Se estima un área de $50 \mathrm{~m} 2$.

- Oficinas

Se estima un área de $70 \mathrm{~m} 2$.

- Comedor

Como se calculó anteriormente, el espacio que ocupará este será de $85 \mathrm{~m} 2$.

- Servicios higiénicos

Se estima un área de $55 \mathrm{~m} 2$. 
- Tópico

El departamento médico ocupará un área de $45 \mathrm{~m} 2$.

Tabla 5.20

Área total requerida para la planta

\begin{tabular}{|c|c|}
\hline Zona & Área \\
\hline Producción & 85 \\
\hline Comedor & 85 \\
\hline Oficinas & 70 \\
\hline Servicios higiénicos & 55 \\
\hline Patio de maniobras & 50 \\
\hline Tópico & 45 \\
\hline Almacén MP, insumos y suministros & 38 \\
\hline Almacén productos terminados & 38 \\
\hline Área de mantenimiento & 38 \\
\hline Total en $\mathbf{m} 2$ & 504 \\
\hline
\end{tabular}

Elaboración Propia

\subsubsection{Dispositivos de seguridad industrial y señalización}

En caso de alguna emergencia, los empleados deben seguís las señalizaciones que permiten un acceso directo al patio de maniobras. En el caso del personal administrativo, este debe salir por las puertas principales de cada una de las tres estancias en que se divide dicha área.

Se considera como zona segura 1, aquella circunferencia en el centro del patio de maniobras con un radio menor a 1.5 metros; y zona segura 2 cuando aquel radio supera ese valor. También se considera como Zona segura 1, el área afuera de la empresa, ubicada a 3 metros de distancia de la puerta principal del local, y Zona segura 2 si esta distancia es menor a 3 metros.

Para la alerta de emergencia se utilizarán las alarmas automáticas activadas por sensores de detección de humo (1 en total en el almacén de productos terminados), las 
alarmas manuales ( 2 en total; uno en producción y otro en el área administrativa) y megáfonos (1 para toda la empresa).

A continuación, se muestran los colores de seguridad los cuales deben ser conocidos por los trabajadores de la planta para identificar y/o tener cuidado sobre los materiales, equipos o actividades que podrían presentar un peligro.

\section{Tabla 5.21}

Colores empleados en señales de seguridad

\begin{tabular}{|c|c|}
\hline $\begin{array}{c}\text { Color empleados } \\
\text { en las señales de } \\
\text { seguridad }\end{array}$ & Significado y finalidad \\
\hline ROJO & Prohibición, material de prevención y de lucha contra incendios \\
\hline AZUL ${ }^{1}$ & Obligación \\
\hline AMARILLO & Riesgo de peligro \\
\hline VERDE & Información de Emergencia \\
\hline 1. El azul se considera como color de seguridad únicamente cuando se utiliza en forma circular. \\
\hline
\end{tabular}

Fuente: NORMA TÉCNICA PERUANA NTP 399.010-1, (2004)

Como se puede observar estos fondos colores en la imagen anterior tienen colores de contraste que están presentes en las letras. Ejm: color de contraste del rojo es blanco y el color de contraste del Amarillo es Negro.

\subsubsection{Disposición general}

Para determinar la distribución de las áreas se utilizará una tabla relacional. En esta se mostrarán las relaciones de proximidad entre cada una de las áreas además de su respectivo nivel de importancia.

Las características de cada relación estarán representadas en un rombo, el cual tendrá en la parte superior una letra que determinará el valor de proximidad y en la parte inferior un número que indicará la razón de su relación. En la siguiente figura se muestra como se representa lo explicado anteriormente. 
Figura 5.21

Representación de un rombo de la tabla relacional

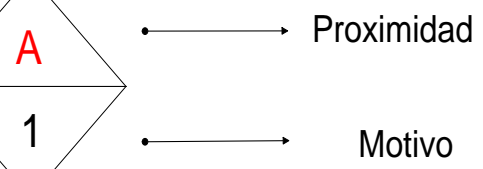

Fuente: Diaz, B.; Jarufe, B; Noriega, M.T., (2007)

La escala de valores para la proximidad de las actividades queda indicada por las letras A, E, I, O, U, X.

Tabla 5.22

Tabla de valor de la proximidad

\begin{tabular}{|c|l|c|c|}
\hline Código & \multicolumn{1}{|c|}{ Valor de proximidad } & Color & $\mathbf{N}^{\circ}$ de líneas \\
\hline A & Absolutamente necesario & rojo & 4 \\
\hline E & Especialmente necesario & amarillo & 3 \\
\hline I & Importante & verde & 2 \\
\hline O & Normal u ordinario & azul & 1 \\
\hline U & Sin importancia & - & - \\
\hline X & No recomendado & plomo & 1 (zigzag) \\
\hline
\end{tabular}

Fuente: Diaz, B.; Jarufe, B; Noriega, M.T., (2007)

Tabla 5.23

Relación de motivos

\begin{tabular}{|c|l|}
\hline Código & \multicolumn{1}{|c|}{ Motivos } \\
\hline 1 & Secuencia del proceso \\
\hline 2 & No es necesario o importante \\
\hline 3 & Utilización de mismo personal \\
\hline 4 & Condiciones ambientales \\
\hline 5 & Por inspección o control \\
\hline 6 & Por el polvo u olor \\
\hline 7 & Por el ruido excesivo \\
\hline 8 & Para reducir el recorrido de personas \\
\hline 9 & Para reducir traslado de material \\
\hline
\end{tabular}

Fuente: Diaz, B.; Jarufe, B; Noriega, M.T., (2007) 
A partir de estos datos se procedió a diseñar la tabla relacional mostrada.

Figura 5.22

Tabla relacional

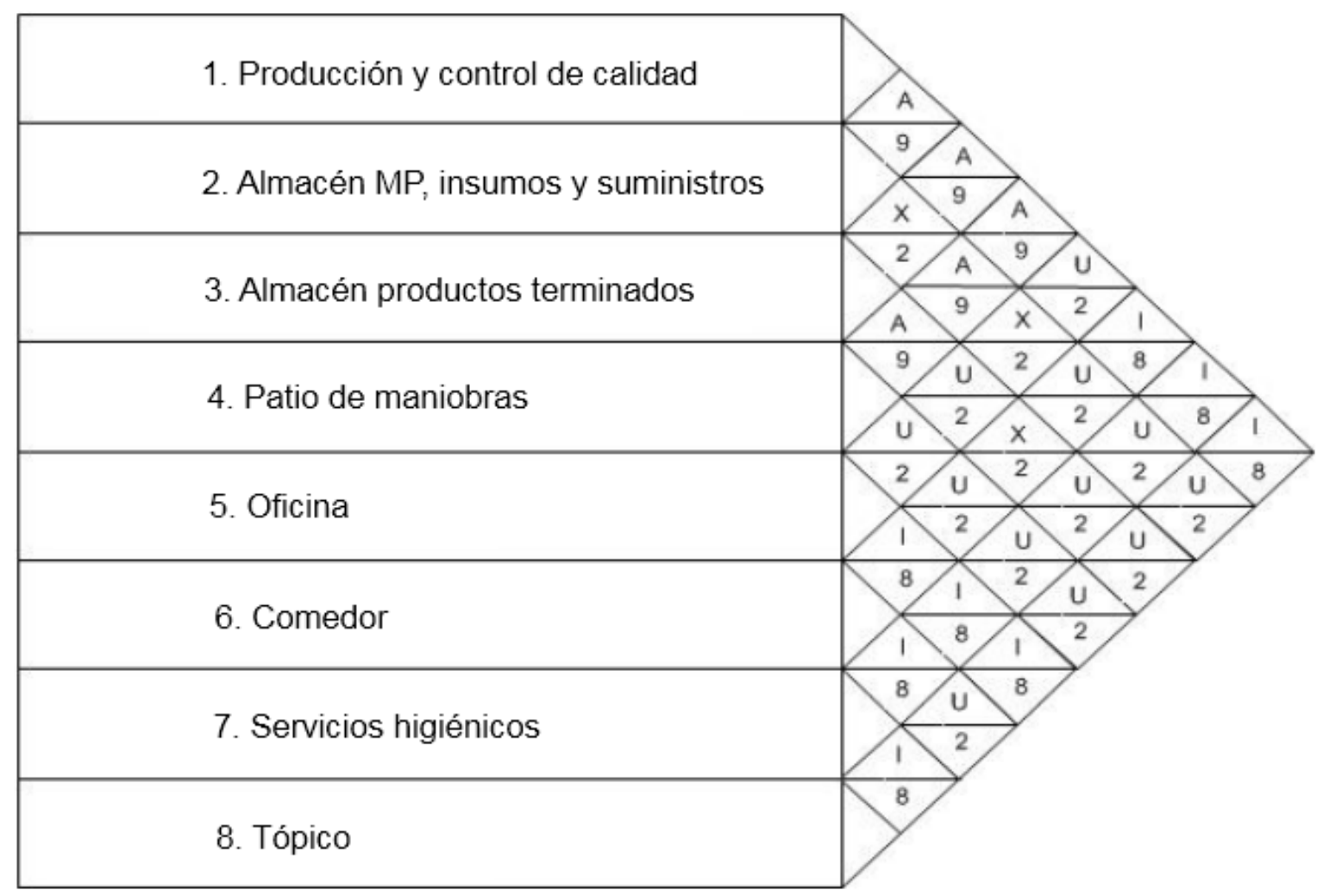

Elaboración Propia

Del diagrama podemos extraer la información que servirá para elaborar un bosquejo con las posiciones relativas que cada área va a ocupar. Para esto primero se representan las zonas con símbolos arbitrarios y se unen según el grado de proximidad. 


\section{Tabla 5.24}

Identificación de actividades

\begin{tabular}{|c|c|}
\hline Símbolo & Actividad \\
\hline & $\begin{array}{c}\text { Operación } \\
\text { (montaje) }\end{array}$ \\
\hline & $\begin{array}{c}\text { Operación } \\
\text { (operación) }\end{array}$ \\
\hline & Alamacenaje \\
\hline & Control \\
\hline & Administración \\
\hline
\end{tabular}

Fuente: Diaz, B.; Jarufe, B; Noriega, M.T., (2007)

Figura 5.23

Diagrama relacional de actividades

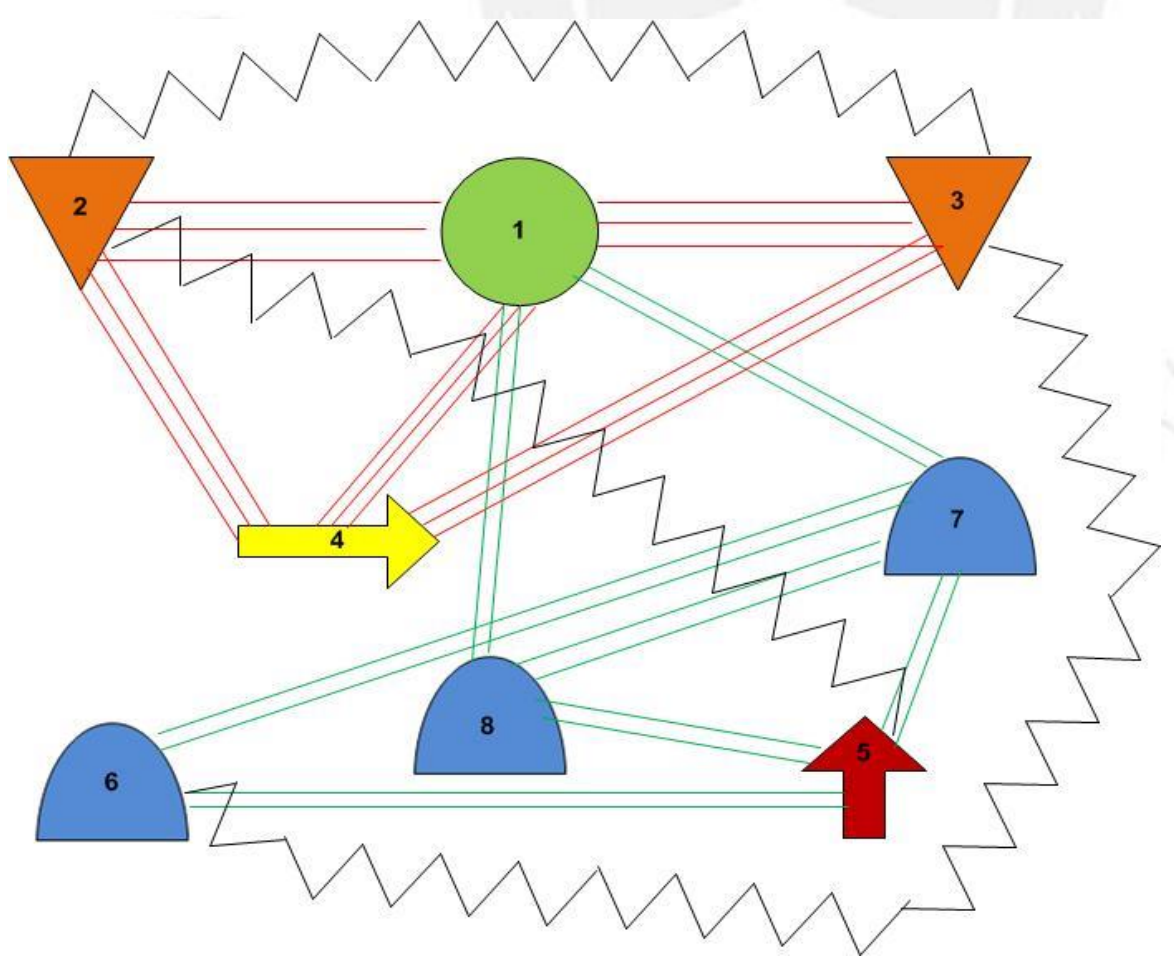




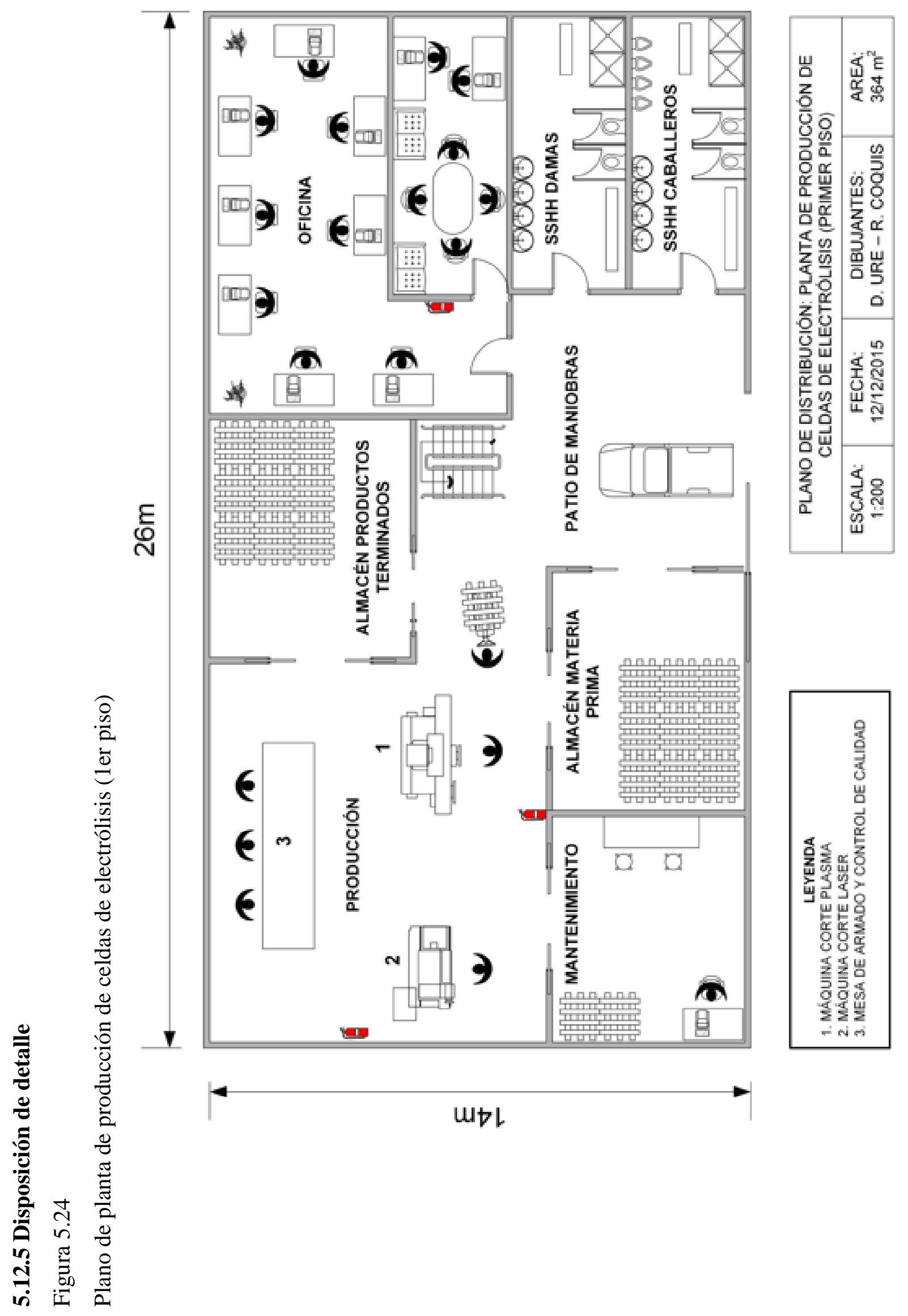

$\frac{\pi}{2}$
0
0
0
$\frac{0}{0}$
$\frac{0}{0}$
$\frac{0}{0}$
$\frac{0}{0}$
$\frac{0}{1}$ 

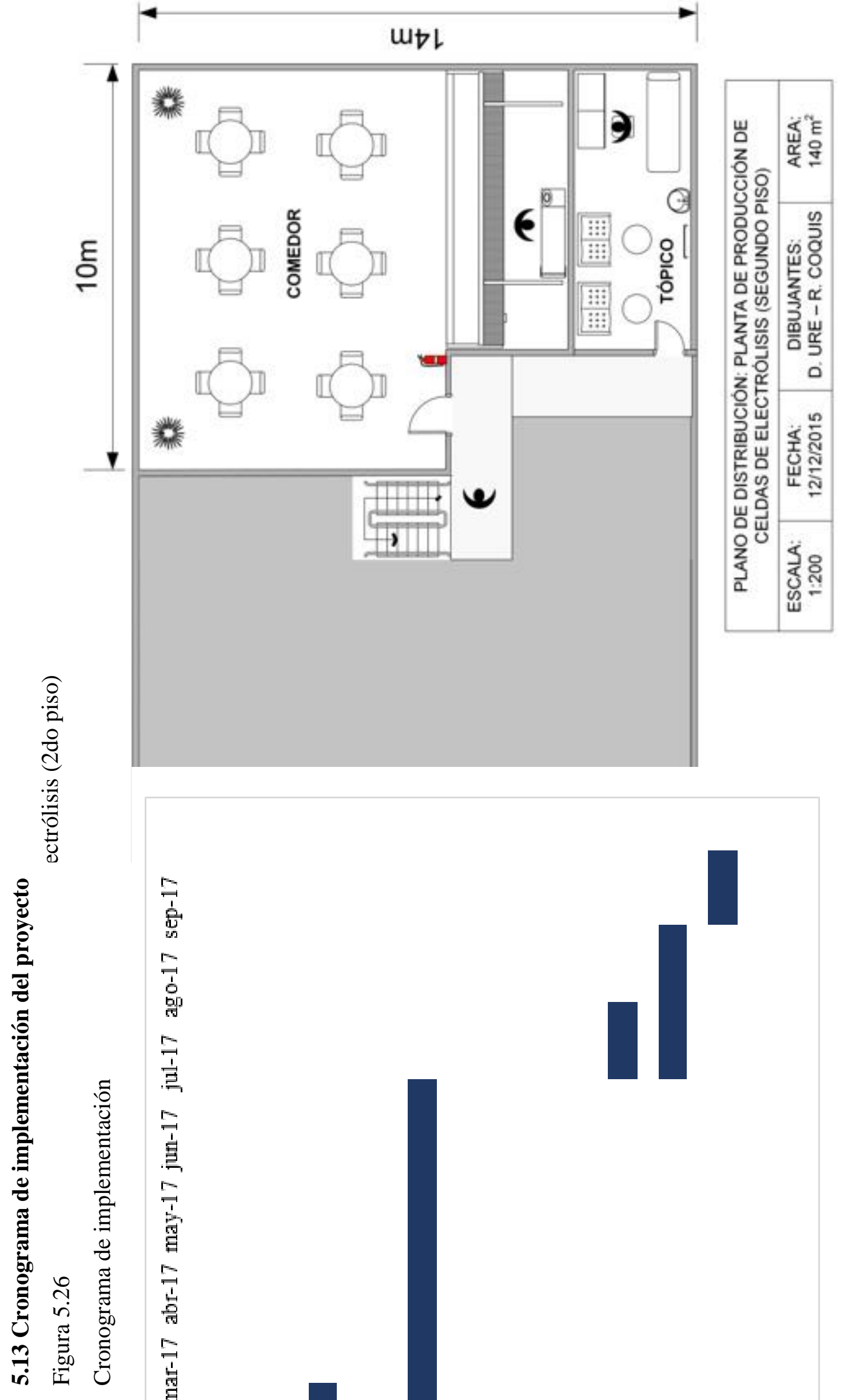


\section{CAPÍTULO VI: ORGANIZACIÓN ADMINISTRATIVA}

\subsection{Organización empresarial}

El presente proyecto funcionará bajo el formato empresarial de una sociedad anónima cerrada.

Para su correcta operación se han definido puestos de trabajo referentes a la gestión y operación de las distintas actividades del proyecto. Estas están enfocadas principalmente en la administración de los procesos, manufactura y comercialización de los bienes.

\subsection{Requerimiento de personal directo, administrativo y de servicios}

En la siguiente tabla se detallan los recursos humanos necesarios que laborarán en la empresa área administrativa.

Tabla 6.1

Trabajadores requeridos para el proyecto

\begin{tabular}{|l|r|r|}
\hline Personal administrativo & Número de turnos al día & $\begin{array}{l}\text { Cantidad } \\
\text { requerida }\end{array}$ \\
\hline Gerente general & 1 & 1 \\
\hline Gerente comercial & 1 & 1 \\
\hline Gerente de operaciones & 1 & 1 \\
\hline Jefe de Contabilidad y Finanzas & 1 & 1 \\
\hline Jefe de recursos humanos & 1 & 1 \\
\hline Supervisor de operaciones & 1 & 1 \\
\hline Técnico de mantenimiento & 1 & 1 \\
\hline Asistentes & 1 & 3 \\
\hline Secretarias & 1 & 1 \\
\hline Vendedores & 1 & 3 \\
\hline Operarios & 1 & 4 \\
\hline TOTAL & - & 18 \\
\hline
\end{tabular}

Elaboración Propia 


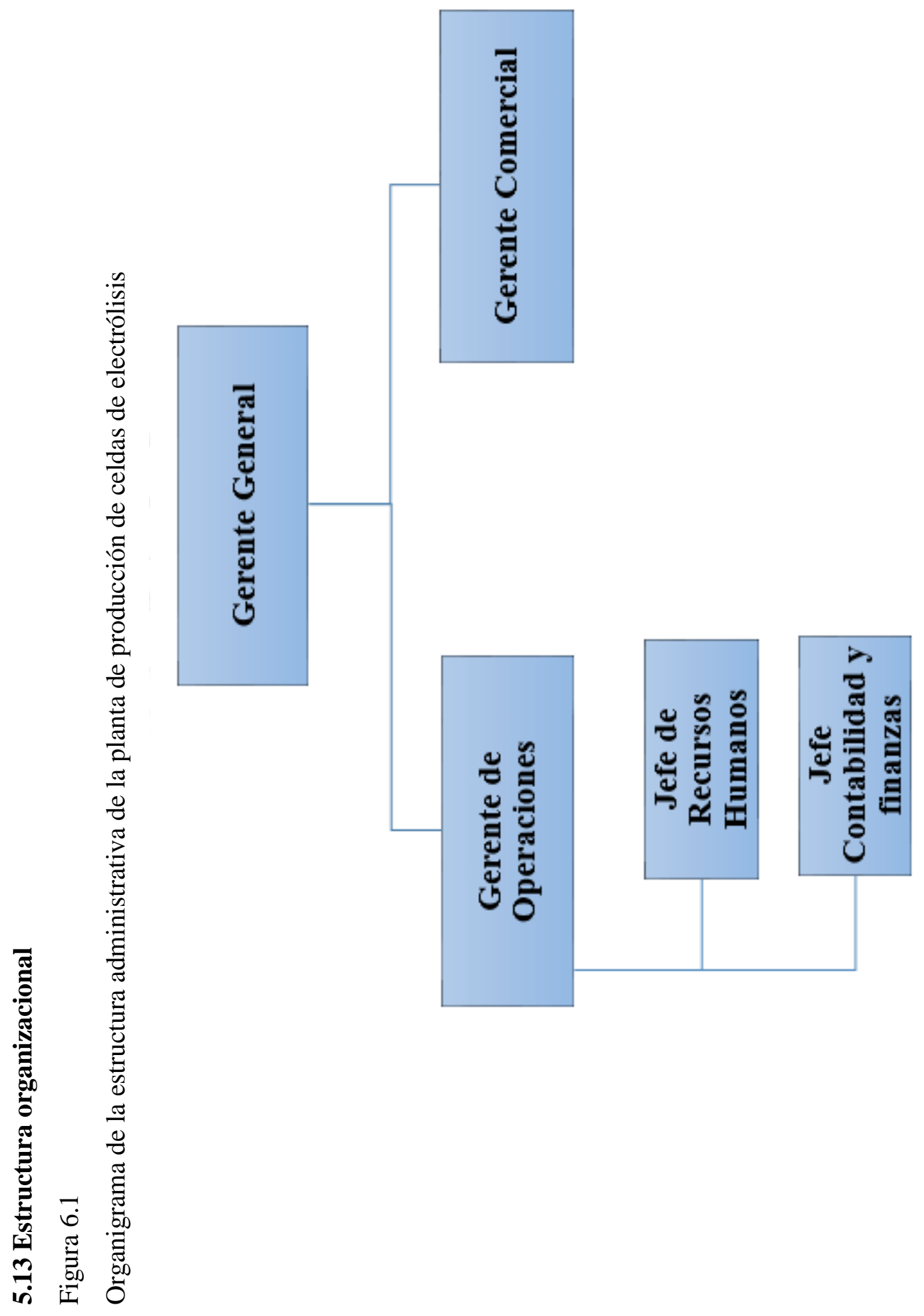

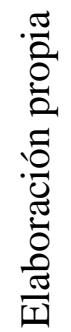




\section{CAPÍTULO VII.: ASPECTOS ECONÓMICOS Y FINANCIEROS}

\subsection{Inversiones}

\subsubsection{Estimación de las inversiones}

- Activos fijos tangibles: Son las inversiones físicas necesarias para realizar las operaciones.

a) Maquinaria y equipos de planta:

La mayoría de los bienes de capital son importados de un mismo proveedor ubicado en la China. Este realiza sus cotizaciones a valor CIF, por lo tanto, los gastos relacionados al flete y seguros ya están siendo tomados en cuenta, por ello es necesario costear los trámites de aduana y transporte hasta la planta. Aproximadamente, estos gastos en conjunto suman S/.11200 para las 2 máquinas importadas.

Tabla 7.1

Relación de inversiones en máquinas y equipos fabriles

\begin{tabular}{|l|c|c|c|c|}
\hline \multicolumn{1}{|c|}{ Nombre } & Precio S/. & Cantidad & $\begin{array}{c}\text { Gastos de } \\
\text { importación S/. }\end{array}$ & Total \\
\hline Corte laser CNC & 14,500 & 1 & 5,600 & 20,100 \\
\hline Corte plasma CNC & 14,500 & 1 & 5,600 & 20,100 \\
\hline Tronzadora & 500 & 1 & & 500 \\
\hline Macho de roscar & 100 & 4 & & 400 \\
\hline Llave de tuercas & 50 & 10 & & 500 \\
\hline Instalación (15\%) & & & & 6,240 \\
\hline \multicolumn{1}{|c|}{ Total } & & & & $\mathbf{4 7 , 8 4 0}$ \\
\hline
\end{tabular}

Elaboración Propia

b) Terreno:

El terreno que se necesita para implementar la planta requiere $364 \mathrm{~m} 2$. Dado que el precio promedio del $\mathrm{m} 2$ en el parque industrial escogido es de 350 dólares, la inversión asciende a 127,400 dólares o 420,420 soles. 
c) Construcción e infraestructura:

Se deben realizar obras civiles que habiliten el espacio físico donde se albergará este proyecto industrial. En tal sentido, las obras necesarias son las siguientes:

- Zona Fabril:

En esta zona se instalarán las máquinas, por ello es necesario tener una buena ingeniería de los materiales utilizados ya que las máquinas sueles generar ciertas vibraciones.

- Oficinas:

Esta inversión incluye el ambiente acondicionado para instalar todo el inmobiliario para que el personal administrativo pueda ejercer sus labores.

- Tópico y otros:

Incluye solo las construcciones. Los equipos e implementos se consideran en el listado de equipos de oficina.

- Comedor:

Aquí se instalarán las mesas para que los trabajadores puedan ingerir sus alimentos de manera cómoda.

- Almacenes:

Será la zona destinada a guardas las materias primas y productos terminados.

Tabla 7.2

Relación de inversiones en infraestructura

\begin{tabular}{|l|c|c|c|}
\hline Edificio y construcciones & $\begin{array}{c}\text { Tamaño } \\
\text { (M2) }\end{array}$ & Costo (S/ x M2) & Costo Total S/. \\
\hline Almacenes & 112 & 1073 & 120,120 \\
\hline Oficinas administrativas & 90 & 1568 & 140,448 \\
\hline Comedor & 34 & 1122 & 37,699 \\
\hline Zona Fabril & 224 & 1271 & 284,592 \\
\hline Contingencias & 45 & 1155 & 51,744 \\
\hline \multicolumn{1}{|c|}{ Total } & & & $\mathbf{6 3 4 , 6 0 3}$ \\
\hline
\end{tabular}

Elaboración Propia 
d) Equipo e implementos de oficina:

Tabla 7.3

Inversión en equipos e implementos de oficina

\begin{tabular}{|c|c|c|c|}
\hline Equipos de oficina & Precio S/. & Cantidad & Total \\
\hline Computadoras & 1,500 & 13 & 15,000 \\
\hline Impresoras & 650 & 2 & 1,200 \\
\hline Escritorios & 350 & 13 & 12,250 \\
\hline Mesas para comedor & 80 & 3 & 480 \\
\hline Sillas para comedor & 25 & 18 & 1,250 \\
\hline Archivadores & 200 & 3 & 2,000 \\
\hline Libreros & 300 & 1 & 1,500 \\
\hline Equipos para tópico & 10,000 & 1 & 10,000 \\
\hline Instalación (10\%) & 4,368 & 1 & 4,368 \\
\hline Otros & 15,000 & 1 & 15,000 \\
\hline Total & & 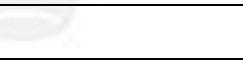 & 63,048 \\
\hline
\end{tabular}

Elaboración Propia

- Activos intangibles:

Son activos que no pueden materializarse, pero ayudan a producir beneficios tangibles. También incluye inversiones en etapa pre-operativa.

Tabla 7.4

Relación de inversiones en activos intangibles

\begin{tabular}{|l|l|c|}
\hline \multirow{4}{*}{ Marco Legal } & \multicolumn{1}{|c|}{ Activos intangibles } & Costo (S/.) \\
\cline { 2 - 3 } & Inscripción de minuta en registros públicos & 600 \\
\cline { 2 - 3 } & Obtención del RUC y registro unificado & 300 \\
\cline { 2 - 3 } & Obtención de licencia de funcionamiento & 3,000 \\
\cline { 2 - 3 } & $\begin{array}{l}\text { Adquisición y legalización de libros } \\
\text { contables }\end{array}$ & 300 \\
\hline \multirow{2}{*}{ Puesta en marcha } & Estudio de proyecto de planta & 20,000 \\
\hline Licencias & Software & 6,000 \\
\hline Otros & Otros gastos u contingencias & $\mathbf{3 5 , 2 0 0 0}$ \\
\cline { 2 - 3 } & \multicolumn{1}{|c}{ Total } &
\end{tabular}

Elaboración Propia 


\subsubsection{Capital de trabajo}

El capital de trabajo es el monto de dinero que una empresa necesita para desarrollar sus actividades en el corto plazo. Particularmente, cuando recién inicia sus operaciones, debe financiarlas con dinero no generado por las ventas ya que, en la mayoría de los casos, el periodo de cobranza se da varios días e incluso meses después de adquirir las materias primas, procesarlas y ejecutar la venta. Se consideró adecuado, debido al rubro (automotriz) y al modelo de negocio adoptado (desarrollo de una red de distribuidores o revendedores) en el que se encuentra la planta de producción de celdas de electrólisis, que este periodo denominado ciclo de caja, sea de 30 días. Para llegar a este dato se consideraron los principales ingresos y egresos que existirán a la hora de la operación dentro de los cuales están el pago a proveedores, el cual se realizará en el momento de la compra de la materia prima (0 días), el pago por concepto de sueldo de trabajadores que se realizará al final de cada mes (30 días) al igual que el pago por servicios; por otro lado, se cobrará a los distribuidores a los 30 días de haber emitido la factura en el momento de entrega de la mercadería. Por consiguiente, se calculó el capital necesario para solventar las operaciones durante ese tiempo. Para hallar el valor, se tomó como referencia los presupuestos de costo de producción y gastos generales para calcular los gastos operativos en que se incurren de manera diaria. Estos gastos son solo los desembolsables, es decir, no incluyen las depreciaciones ni amortizaciones. El gasto diario se multiplica por el ciclo de caja que en este caso es de 30 días y de este modo se obtiene un capital de trabajo tentativo.

Tabla 7.5

Cálculo del capital de trabajo

\begin{tabular}{|c|c|c|c|c|}
\cline { 2 - 5 } \multicolumn{1}{c|}{ Anuales } & Diarios & $\begin{array}{c}\text { Ciclo de } \\
\text { caja } \\
\text { (días) }\end{array}$ & $\begin{array}{c}\text { Capital de } \\
\text { trabajo }\end{array}$ \\
\hline Gastos operativos & $8,008,829.40$ & $22,246.75$ & 30.00 & $667,402.45$ \\
\hline
\end{tabular}

Elaboración Propia 
Tabla 7.6

Cálculo de la inversión total

\begin{tabular}{|c|c|}
\hline Rubro & Monto S/. \\
\hline Activos fijos & $\mathbf{1 , 2 0 1 , 1 1 1 . 2 0}$ \\
\hline Activo fijo tangible & $745,491.20$ \\
\hline Activo fijo intangible & $455,620.00$ \\
\hline Capital de trabajo & $\mathbf{6 6 7 , 4 0 2 . 4 5}$ \\
\hline Total & $\mathbf{1 , 8 6 8 , 5 1 3 . 6 5}$ \\
\hline
\end{tabular}

Elaboración Propia

\subsection{Costos de producción}

\subsubsection{Costos de materias primas, insumos y otros materiales}

Los costos de materia prima para este proyecto industrial se centran principalmente en los insumos que se requieran para fabricar las celdas de electrólisis de manera directa. Además, se tomarán en consideración distintos insumos que se utilizarán de manera cotidiana para la manufactura y gestión del proyecto. Algo interesante para una operación sencilla de este proyecto es que todos los insumos serán comprados a proveedores locales. En las siguientes tablas se detallan los costos de los materiales e insumos directos por año en el proyecto. 
Tabla 7.7

Costo de materia prima directa (S/.)

\begin{tabular}{|l|c|c|c|c|c|c|}
\hline \multicolumn{1}{|c|}{ Item } & $\begin{array}{c}\text { Precio } \\
\text { unitario (S/.) }\end{array}$ & Año 1 & Año 2 & Año 3 & Año 4 & Año 5 \\
\hline $\begin{array}{l}\text { Espárrago } \\
\text { inóxidable } \\
(1 / 4 ")(1 \mathrm{~m})\end{array}$ & 10 & 96,530 & 101,164 & 106,022 & 111,111 & 116,501 \\
\hline $\begin{array}{l}\text { Tuercas } \\
\text { inoxidables } \\
(1 / 4 ")\end{array}$ & 0.13 & 21,512 & 22,545 & 23,628 & 24,762 & 25,963 \\
\hline $\begin{array}{l}\text { Electrodo } \\
\text { de Acero } \\
\text { SAE 316L } \\
(1 \mathrm{~mm})\end{array}$ & 4 & $1,158,360$ & $1,213,968$ & $1,272,264$ & $1,333,332$ & $1,398,012$ \\
\hline $\begin{array}{l}\text { Aislante de } \\
\text { neopreno }\end{array}$ & 0.7 & 212,366 & 222,561 & 233,248 & 244,444 & 256,302 \\
\hline $\begin{array}{l}\text { Tapa de } \\
\text { acrílico }\end{array}$ & 4.5 & 124,110 & 130,068 & 136,314 & 142,857 & 149,787 \\
\hline
\end{tabular}

Elaboración Propia

Tabla 7.8

Costo de insumos directos (S/.)

\begin{tabular}{|l|c|c|c|c|c|c|}
\hline \multicolumn{1}{|c|}{ Ítem } & $\begin{array}{c}\text { Precio } \\
\text { unitario(S/.) }\end{array}$ & Año 1 & Año 2 & Año 3 & Año 4 & Año 5 \\
\hline Manguera sanitaria & 4.5 & 124,110 & 130,068 & 136,314 & 142,857 & 149,787 \\
\hline Manguera de alta presión & 4.0 & 82,740 & 86,712 & 90,876 & 95,238 & 99,858 \\
\hline Válvula chek & 10.0 & 137,900 & 144,520 & 151,460 & 158,730 & 166,430 \\
\hline Tanque de agua & 50.0 & 689,500 & 722,600 & 757,300 & 793,650 & 832,150 \\
\hline Conexiones & 2.6 & 179,270 & 187,876 & 196,898 & 206,349 & 216,359 \\
\hline Abrazaderas & 0.5 & 34,475 & 36,130 & 37,865 & 39,683 & 41,608 \\
\hline Cables & 5.0 & 137,900 & 144,520 & 151,460 & 158,730 & 166,430 \\
\hline Controlador electrónico & 80.0 & $1,103,200$ & $1,156,160$ & $1,211,680$ & $1,269,840$ & $1,331,440$ \\
\hline Terminales & 0.5 & 34,475 & 36,130 & 37,865 & 39,683 & 41,608 \\
\hline & Total & $\mathbf{2 , 5 2 3 , 5 7 0}$ & $\mathbf{2 , 6 4 4 , 7 1 6}$ & $\mathbf{2 , 7 7 1 , 7 1 8}$ & $\mathbf{2 , 9 0 4 , 7 5 9}$ & $\mathbf{3 , 0 4 5 , 6 6 9}$ \\
\hline
\end{tabular}


Elaboración Propia

7.2.2 Costo de los servicios (energía eléctrica, agua, combustible, etc.)

Es importante tener una noción de los gastos por el suministro de energía eléctrica y agua potable. De manera preliminar se conoce que esta planta no requiere de una gran cantidad de energía eléctrica para operar, mientras que el consumo de agua responde tan solo al uso de los trabajadores para actividades sanitarias.

Por otra parte, el régimen tarifario eléctrico es el siguiente:

Tabla 7.9

Tarifa MT3 de energía eléctrica

\begin{tabular}{|l|l|l|r|}
\hline $\begin{array}{l}\text { Tarifa } \\
\text { MT3: }\end{array}$ & $\begin{array}{c}\text { Tarifa con doble medición de energía } \\
\text { activa y contratación o medición de una } \\
\text { potencia de hora punta }\end{array}$ & & \\
\hline & $\begin{array}{c}\text { Cargo fijo mensual } \\
\text { Cargo por energía activa en punta }\end{array}$ & St./mes & 2.86 \\
\hline & ctm. S/./kW.h & 16.10 \\
\hline & $\begin{array}{l}\text { Cargo por potencia activa de generación } \\
\text { para usuarios: }\end{array}$ & ctm. S/./kW.h & 13.80 \\
\hline & Presentes en punta & S/./kW-mes & 23.70 \\
\hline & Presentes fuera de punta & S/./kW-mes & 14.60 \\
\hline & $\begin{array}{l}\text { Cargo por potencia activa de redes de } \\
\text { distribución para usuarios: }\end{array}$ & \\
\hline & Presentes en punta & S/./kW-mes & 9.99 \\
\hline & Presentes fuera de punta & S/./kW-mes & 10.40 \\
\hline & $\begin{array}{l}\text { Cargo por energía reactiva que exceda el } \\
\text { 30\% del total de la energía activa }\end{array}$ & ctm. S/./kVar.h & 3.40 \\
\hline
\end{tabular}

Fuente: Osinermin, (2015) 
También es relevante mencionar que, tomando en consideración la potencia eléctrica de las máquinas de corte y el tiempo que estas son usadas para fabricar una celda, se puede inferir que se consumen $3.71 \mathrm{~kW}$-h por cada celda fabricada lo que se traduce en términos económicos a S/. 0.51 en promedio como costo en energía unitario. Este servicio de suministro será contratado a Edelnor.

Además, el abastecimiento de agua se contratará a Sedapal, teniendo un costo de S/. 0.15 por cada $\mathrm{m} 3$ de agua consumido. Se conoce que una persona utiliza en promedio 150 litros de agua al día, esto equivale a $0.15 \mathrm{~m} 3$, por ende, teniendo 18 empleados, el gasto anual de la planta seria aproximadamente de S/. 700.

Con respecto al costo logístico, se contratará a la empresa SMP COURRIER. Cada caja pesa alrededor de $1.5 \mathrm{~kg}$ y el costo por transportar un kilo dentro de la ciudad de Lima es de 1.5 soles, por lo que el costo de transportar cada caja es de S/.2.25.

Con respecto a las telecomunicaciones, la Telefonía fija e internet será a través de paquetes dúos de negocio que incluyen servicios de voz e internet compuestos por una línea telefónica de tarifa plana local de negocios (llamadas locales ilimitadas) y un Speedy negocios avanzado con velocidad de $5 \mathrm{MB}$, los cuales incluyen equipos, instalación y servicios de valor agregado para ambos servicios. El costo mensual del paquete es de S/. 980 mensuales traducidos en S/.11, 760 anuales. El personal de seguridad y los equipos de vigilancia implicarán un costo de S/. 7,000 mensuales por el servicio prestado. Por último, se contratará a una empresa para que brinde los servicios de preparación de alimentos para todo el personal abarcando un costo de S/. 3,750 mensuales.

\section{Tabla 7.10}

Costo de servicios consumidos y contratados (S/.)

\begin{tabular}{|l|c|r|r|r|r|r|}
\hline \multicolumn{1}{|c|}{ Servicio } & $\begin{array}{c}\text { Costo } \\
\text { (S/.) }\end{array}$ & Año 1 & Año 2 & Año 3 & Año 4 & Año 5 \\
\hline $\begin{array}{l}\text { Energía } \\
\text { eléctrica }\end{array}$ & $\begin{array}{c}0.104 \\
\text { /Kw-h }\end{array}$ & 5,327 & 5,583 & 5,851 & 6,132 & 6,429 \\
\hline Agua & $0.15 / \mathrm{m} 3$ & 700 & 700 & 700 & 700 & 700 \\
\hline Transporte & $2.25 /$ caja & 31,064 & 32,555 & 34,118 & 35,756 & 37,490 \\
\hline $\begin{array}{l}\text { Teléfono, } \\
\text { internet y } \\
\text { cable }\end{array}$ & $980 /$ mes & 11,760 & 11,760 & 11,760 & 11,760 & 11,760 \\
\hline Seguridad & $3000 /$ mes & 36,000 & 36,000 & 36,000 & 36,000 & 36,000 \\
\hline Salud & $1500 /$ mes & 18,000 & 18,000 & 18,000 & 18,000 & 18,000 \\
\hline
\end{tabular}




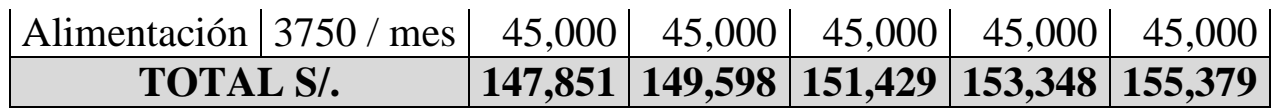

Elaboración Propia

\subsubsection{Costo de la mano de obra}

En capítulos anteriores se hizo mención de que se iba a trabajar un turno por día durante 8 horas. También, se mencionó que se iba a contar con 4 operarios, 3 personas que conforman la mano de obra indirecta y 11 personas que forman el equipo administrativo.

\subsubsection{Mano de obra directa}

En las siguientes tablas se muestran la remuneración de los operarios y el costo en el que se incurre al contar con sus servicios.

Tabla 7.11

Remuneración de la mano de obra directa (S/.)

\begin{tabular}{|l|c|c|c|c|c|c|c|}
\hline Puesto & $\begin{array}{c}\text { Grado de } \\
\text { instrucción } \\
\text { requerido }\end{array}$ & $\begin{array}{c}\text { Remuneración } \\
\text { básica mensual }\end{array}$ & Gratificaciones & CTS & $\begin{array}{c}\text { Remuneración } \\
\text { anual }\end{array}$ & $\begin{array}{c}\text { Essalud } \\
\text { (9\%) }\end{array}$ & $\begin{array}{c}\text { Total } \\
\text { gasto } \\
\text { anual }\end{array}$ \\
\hline Operario & Ninguno & 2,500 & 5,000 & 2,500 & 37,500 & 3,375 & 40,875 \\
\hline
\end{tabular}

Elaboración Propia

Tabla 7.12

Costos de mano de obra directa

\begin{tabular}{|c|c|c|c|c|c|c|c|}
\hline Puesto & Nro. de personas & Turnos al día & Año 1 & Año 2 & Año 3 & Año 4 & Año 5 \\
\hline Operarios & 4 & 1 & 163,500 & 163,500 & 163,500 & 163,500 & 163,500 \\
\hline \multicolumn{3}{|c|}{ TOTAL S/. } & 163,500 & 163,500 & 163,500 & 163,500 & 163,500 \\
\hline
\end{tabular}

Elaboración Propia

\subsubsection{Mano de obra indirecta}


Dentro de este campo se encuentran las personas que se encargarán de supervisar y asegurar de que el proceso fabril se desarrolle sin ningún inconveniente. Además, del personal dedicado a dar mantenimiento a las máquinas. A continuación, se detallan los salarios y los costos relativos a estos empleados.

Tabla 7.13

Remuneración de la mano de obra indirecta (S/.)

\begin{tabular}{|l|c|c|c|c|c|c|c|}
\hline \multicolumn{1}{|c|}{ Puesto } & $\begin{array}{c}\text { Grado de } \\
\text { instrucción } \\
\text { requerido }\end{array}$ & $\begin{array}{c}\text { Remuneración } \\
\text { básica mensual }\end{array}$ & Gratificaciones & CTS & $\begin{array}{c}\text { Remuneración } \\
\text { anual }\end{array}$ & $\begin{array}{c}\text { Essalud } \\
\text { (9\%) }\end{array}$ & $\begin{array}{c}\text { Total } \\
\text { gasto } \\
\text { anual }\end{array}$ \\
\hline $\begin{array}{l}\text { Gerente de } \\
\text { operaciones }\end{array}$ & Maestría & 30,000 & 60,000 & 30,000 & 450,000 & 40,500 & 490,500 \\
\hline $\begin{array}{l}\text { Técnico de } \\
\text { mantenimiento }\end{array}$ & Técnico & 3,800 & 7,600 & 3,800 & 57,000 & 5,130 & 62,130 \\
\hline Supervisor & Técnico & 3,800 & 7,600 & 3,800 & 57,000 & 5,130 & 62,130 \\
\hline
\end{tabular}

Elaboración Propia

Tabla 7.14

Costo de mano de obra indirecta (S/.)

\begin{tabular}{|c|c|c|c|c|c|c|c|}
\hline Puesto & $\begin{array}{c}\text { Nro. de } \\
\text { personas }\end{array}$ & $\begin{array}{l}\text { Turnos } \\
\text { al día }\end{array}$ & Año 1 & Año 2 & Año 3 & Año 4 & Año 5 \\
\hline $\begin{array}{l}\text { Gerente de } \\
\text { operaciones }\end{array}$ & 1 & 1 & 490,500 & 490,500 & 490,500 & 490,500 & 490,500 \\
\hline $\begin{array}{l}\text { Técnico de } \\
\text { mantenimiento }\end{array}$ & 1 & 1 & 62,130 & 62,130 & 62,130 & 62,130 & 62,130 \\
\hline Supervisor & 1 & 1 & 62,130 & 62,130 & 62,130 & 62,130 & 62,130 \\
\hline \multicolumn{3}{|c|}{ TOTAL S/. } & 614,760 & 614,760 & 614,760 & 614,760 & 614,760 \\
\hline
\end{tabular}

Elaboración Propia 
Tabla 7.15

Remuneración del personal administrativo (S/.)

\begin{tabular}{|c|c|c|c|c|c|c|c|}
\hline Puesto & $\begin{array}{c}\text { Grado de } \\
\text { instrucción } \\
\text { requerido }\end{array}$ & $\begin{array}{c}\text { Remuneració } \\
\text { n básica } \\
\text { mensual }\end{array}$ & $\begin{array}{c}\text { Gratificacione } \\
\text { s }\end{array}$ & CTS & $\begin{array}{c}\text { Remuneració } \\
\text { n anual }\end{array}$ & $\begin{array}{l}\text { Essalu } \\
\text { d }(9 \%)\end{array}$ & $\begin{array}{l}\text { Total } \\
\text { gasto } \\
\text { anual }\end{array}$ \\
\hline $\begin{array}{l}\text { Gerente } \\
\text { general }\end{array}$ & MBA & 38,000 & 76,000 & $\begin{array}{c}38,00 \\
0\end{array}$ & 570,000 & 51,300 & $\begin{array}{c}621,30 \\
0\end{array}$ \\
\hline $\begin{array}{l}\text { Gerente } \\
\text { comercial }\end{array}$ & Maestría & 30,000 & 60,000 & $\begin{array}{c}30,00 \\
0\end{array}$ & 450,000 & 40,500 & $\begin{array}{c}490,50 \\
0\end{array}$ \\
\hline $\begin{array}{l}\text { Jefe de } \\
\text { contabilida } \\
\text { d y } \\
\text { finanzas } \\
\end{array}$ & Maestría & 30,000 & 60,000 & $\begin{array}{c}30,00 \\
0\end{array}$ & 450,000 & 40,500 & $\begin{array}{c}490,50 \\
0\end{array}$ \\
\hline $\begin{array}{l}\text { Jefe de } \\
\text { recursos } \\
\text { humanos }\end{array}$ & Maestría & 30,000 & 60,000 & $\begin{array}{c}30,00 \\
0\end{array}$ & 450,000 & 40,500 & $\begin{array}{c}490,50 \\
0\end{array}$ \\
\hline $\begin{array}{l}\text { Vendedore } \\
\text { s }\end{array}$ & $\begin{array}{c}\text { Técnico / } \\
\text { Universitari } \\
\text { o } \\
\end{array}$ & 12,000 & 24,000 & $\begin{array}{c}12,00 \\
0\end{array}$ & 180,000 & 16,200 & $\begin{array}{c}196,20 \\
0\end{array}$ \\
\hline Asistentes & $\begin{array}{c}\text { Universitari } \\
\text { o }\end{array}$ & 4,300 & 8,600 & 4,300 & 64,500 & 5,805 & 70,305 \\
\hline Secretarias & Técnico & 3,300 & 6,600 & 3,300 & 49,500 & 4,455 & 53,955 \\
\hline
\end{tabular}

Elaboración Propia 
Tabla 7.16

Sueldos y salarios del personal administrativo

\begin{tabular}{|l|c|c|c|c|c|c|}
\hline \multicolumn{1}{|c|}{ Puesto } & $\begin{array}{c}\text { Nro. De } \\
\text { personas }\end{array}$ & Año 1 & Año 2 & Año 3 & Año 4 & Año 5 \\
\hline $\begin{array}{l}\text { Gerente } \\
\text { general }\end{array}$ & 1 & 621,300 & 621,300 & 621,300 & 621,300 & 621,300 \\
\hline $\begin{array}{l}\text { Gerente } \\
\text { comercial }\end{array}$ & 1 & 490,500 & 490,500 & 490,500 & 490,500 & 490,500 \\
\hline $\begin{array}{l}\text { Jefe de } \\
\text { contabilidad y } \\
\text { finanzas }\end{array}$ & 1 & 490,500 & 490,500 & 490,500 & 490,500 & 490,500 \\
\hline $\begin{array}{l}\text { Jefe de gestión } \\
\text { humana y } \\
\text { responsabilidad } \\
\text { social }\end{array}$ & 1 & 490,500 & 490,500 & 490,500 & 490,500 & 490,500 \\
\hline Vendedores & 3 & 588,600 & 588,600 & 588,600 & 588,600 & 588,600 \\
\hline Asistentes & 3 & 210,915 & 210,915 & 210,915 & 210,915 & 210,915 \\
\hline Secretarias & 1 & 53,955 & 53,955 & 53,955 & 53,955 & 53,955 \\
\hline \multicolumn{2}{|c|}{ TOTAL S/. } & $\mathbf{2 , 9 4 6 , 2 7 0}$ & $\mathbf{2 , 9 4 6 , 2 7 0}$ & $\mathbf{2 , 9 4 6 , 2 7 0}$ & $\mathbf{2 , 9 4 6 , 2 7 0}$ & $\mathbf{2 , 9 4 6 , 2 7 0}$ \\
\hline
\end{tabular}

Elaboración Propia

\subsection{Presupuesto de ingresos y egresos}

\subsubsection{Presupuesto de ingreso por ventas}

Tabla 7.17

Ventas netas totales por año

\begin{tabular}{|l|c|c|c|c|c|}
\hline \multicolumn{1}{|c|}{ Item } & Año 1 & Año 2 & Año 3 & Año 4 & Año 5 \\
\hline $\begin{array}{l}\text { Celdas de electrólisis } \\
\text { (Unidades) }\end{array}$ & 13,790 & 14,452 & 15,146 & 15,873 & 16,643 \\
\hline Precio de Venta Unitario & 800 & 800 & 800 & 800 & 800 \\
\hline
\end{tabular}


Elaboración Propia

\subsubsection{Presupuesto operativo de costos}

Para elaborar los presupuestos de costos de producción y luego el de gastos administrativos es importante determinar la depreciación y amortización de los activos: 


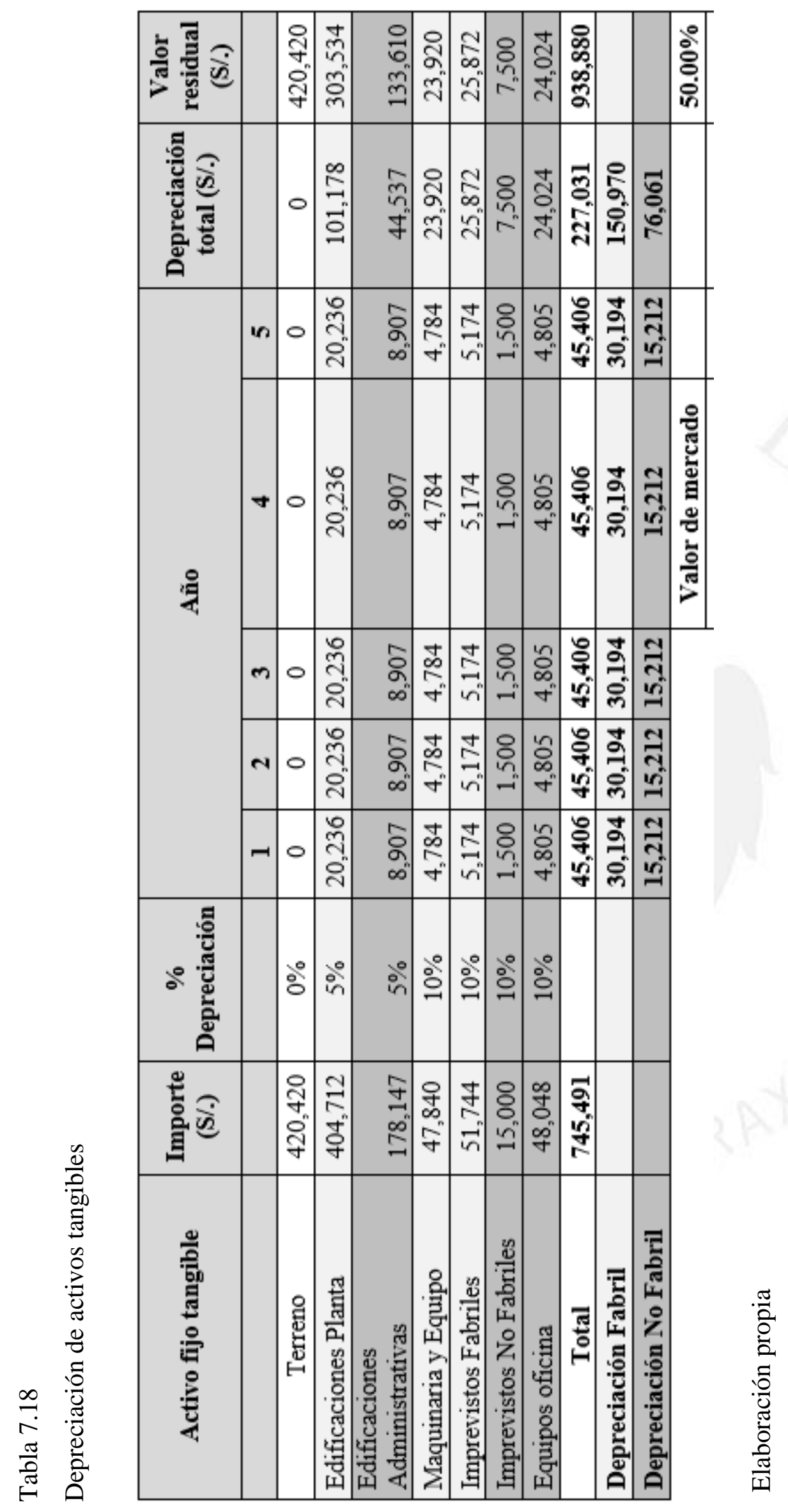




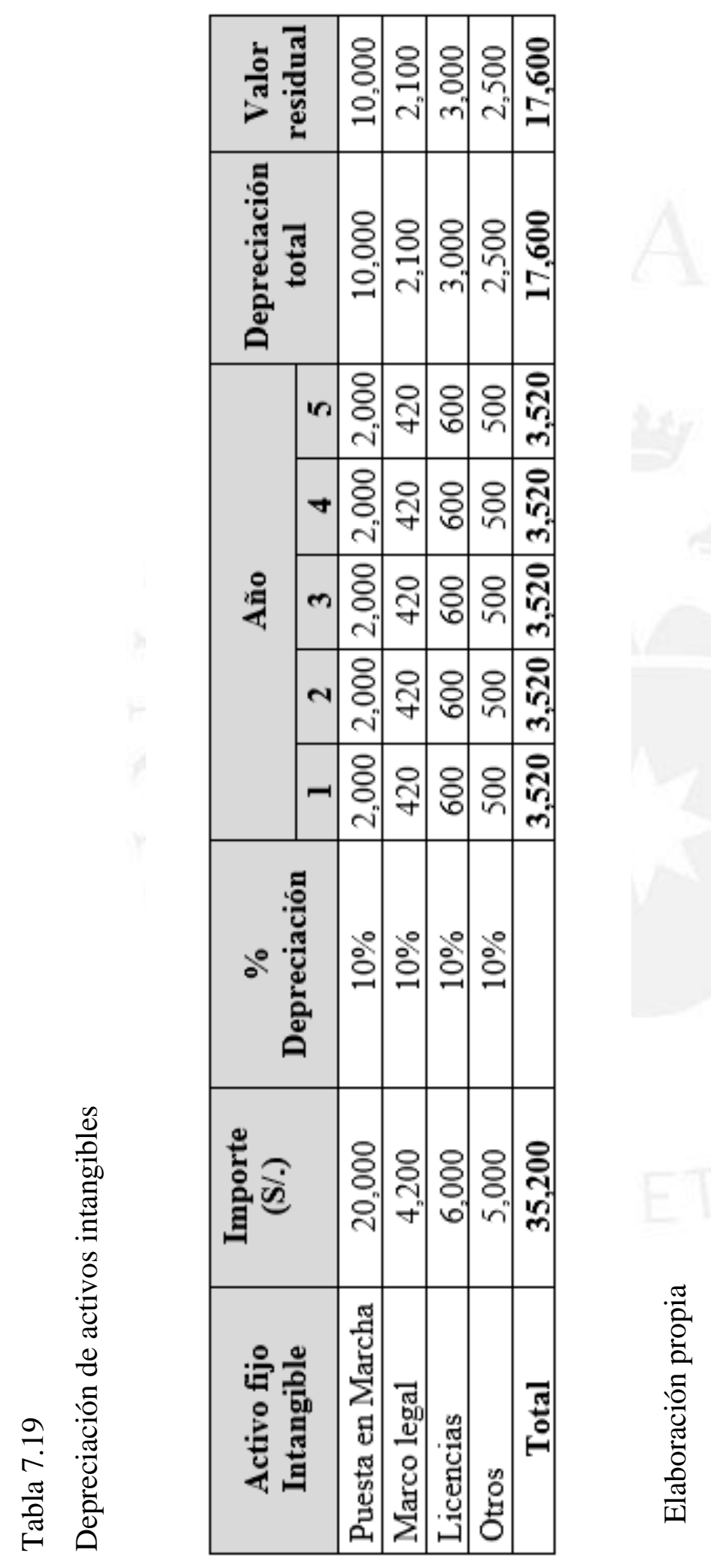


Luego de hallar la depreciación de los activos tangibles y amortización de intangibles, se procede a calcular el costo total de producción:

Tabla 7.20

Presupuesto anual de costo de producción

\begin{tabular}{|l|c|c|c|c|c|}
\hline \multicolumn{1}{|c|}{ Rubro } & Año 1 & Año 2 & Año 3 & Año 4 & Año 5 \\
\hline Materiales directos & $4,136,448$ & $4,335,022$ & $4,543,194$ & $4,761,265$ & $4,992,234$ \\
\hline Mano de obra directa & 163,500 & 163,500 & 163,500 & 163,500 & 163,500 \\
\hline Costos Directos & $\mathbf{4 , 2 9 9 , 9 4 8}$ & $\mathbf{4 , 4 9 8 , 5 2 2}$ & $\mathbf{4 , 7 0 6 , 6 9 4}$ & $\mathbf{4 , 9 2 4 , 7 6 5}$ & $\mathbf{5 , 1 5 5 , 7 3 4}$ \\
\hline Mano de obra indirecta & 614,760 & 614,760 & 614,760 & 614,760 & 614,760 \\
\hline Servicios a planta & 118,281 & 119,678 & 121,143 & 122,678 & 124,304 \\
\hline Otros & 50,000 & 50,000 & 50,000 & 50,000 & 50,000 \\
\hline Depreciación fabril & 30,194 & 30,194 & 30,194 & 30,194 & 30,194 \\
\hline $\begin{array}{c}\text { Costos indirectos de } \\
\text { fabricación (CIF) }\end{array}$ & $\mathbf{8 1 3 , 2 3 5}$ & $\mathbf{8 1 4 , 6 3 2}$ & $\mathbf{8 1 6 , 0 9 7}$ & $\mathbf{8 1 7 , 6 3 2}$ & $\mathbf{8 1 9 , 2 5 8}$ \\
\hline $\begin{array}{c}\text { Costo total de } \\
\text { Producción }\end{array}$ & $\mathbf{5 , 1 1 3 , 1 8 3}$ & $\mathbf{5 , 3 1 3 , 1 5 4}$ & $\mathbf{5 , 5 2 2 , 7 9 1}$ & $\mathbf{5 , 7 4 2 , 3 9 7}$ & $\mathbf{5 , 9 7 4 , 9 9 2}$ \\
\hline
\end{tabular}

Elaboración Propia

7.3.3 Presupuesto operativo de gastos administrativos (ventas, marketing, distribución, atención a clientes y gastos generales)

Este presupuesto, mostrado en la página anterior, abarca todos los gastos ocasionados por las operaciones de la parte administrativa de la empresa. Además, se incluye la depreciación de los activos fijos no fabriles tales como las oficinas, el comedor, escritorios, etc. y la amortización de los activos intangibles que por reglas contables se deben incluir en este presupuesto. 
Tabla 7.21

Presupuesto de gastos administrativos

\begin{tabular}{|l|c|c|c|c|c|}
\hline \multicolumn{1}{|c|}{ Rubro } & Año 1 & Año 2 & Año 3 & Año 4 & Año 5 \\
\hline Sueldos y salarios & $2,946,270$ & $2,946,270$ & $2,946,270$ & $2,946,270$ & $2,946,270$ \\
\hline Servicios & 29,570 & 29,920 & 30,286 & 30,670 & 31,076 \\
\hline $\begin{array}{l}\text { Gastos comercialización } \\
\text { y publicidad }\end{array}$ & 100,000 & 100,000 & 100,000 & 100,000 & 100,000 \\
\hline Otros & 100,000 & 100,000 & 100,000 & 100,000 & 100,000 \\
\hline Depreciación no fabril & 15,212 & 15,212 & 15,212 & 15,212 & 15,212 \\
\hline Amortización Intangibles & 3,520 & 3,520 & 3,520 & 3,520 & 3,520 \\
\hline Total Gastos Generales & $\mathbf{3 , 1 9 4 , 5 7 2}$ & $\mathbf{3 , 1 9 4 , 9 2 2}$ & $\mathbf{3 , 1 9 5 , 2 8 8}$ & $\mathbf{3 , 1 9 5 , 6 7 2}$ & $\mathbf{3 , 1 9 6 , 0 7 8}$ \\
\hline
\end{tabular}

Elaboración Propia

\subsection{Flujo de fondos netos}

Antes de realizar el análisis de flujo de fondos neto, se debe tener en cuenta el cálculo del costo promedio ponderado del capital pues este es un factor clave utilizado para tomar la decisión sobre la viabilidad o no viabilidad de un proyecto de inversión. Para poder estimar este indicador, se debe tener en cuenta los valores de inversión por aporte propio y por financiamiento además del porcentaje que compone cada uno sobre el total de la inversión. Así mismo, se debe tener en cuenta el costo de dinero. Para este caso el costo de oportunidad esperado por los accionistas es de $18 \%$ mientras que la TEA del préstamo será de $7.5 \%$. El cálculo del CPPC se muestra a continuación.

Tabla 7.22

Cálculo de costo promedio ponderado de capital

\begin{tabular}{|c|c|c|c|}
\hline Importe & $\begin{array}{c}\text { \% } \\
\text { Participación }\end{array}$ & Costo dinero & Tasa de descuento \\
\hline S/. 747,405.46 & $40.00 \%$ & $18.00 \%$ & $7.20 \%$ \\
\hline S/. 1,121,108.19 & $60.00 \%$ & $7.50 \%$ & $4.50 \%$ \\
\hline S/. 1,868,513.65 & $\mathbf{1 0 0 . 0 0 \%}$ & $\mathbf{2 5 . 5 0 \%}$ & $\mathbf{1 1 . 7 0 \%}$ \\
\hline
\end{tabular}

Elaboración Propia 
Otros requisitos previos a la elaboración del flujo de fondos del proyecto, es la elaboración la tabla de servicio a la deuda o cronograma de pagos del financiamiento y el estado de resultados. De acuerdo a COFIDE, se conoce que se puede acceder a un financiamiento de hasta US\$20’000,000 por 5 años y dos de gracia total en cuotas crecientes semestrales a una TEA 7.5\%. Se optó por asumir el pago del préstamo en cuotas crecientes ya que las cuotas en los primeros años del proyecto serán menores, lo cual será ventajoso pues el proyecto recién estará adaptándose al mercado. Luego se procedió a elaborar el estado de resultados para los 5 años de vida útil del proyecto pues se necesita saber cuál sería la utilidad antes de reserva legal para poder estimar los flujos de fondo. Todo esto se muestra a continuación. 


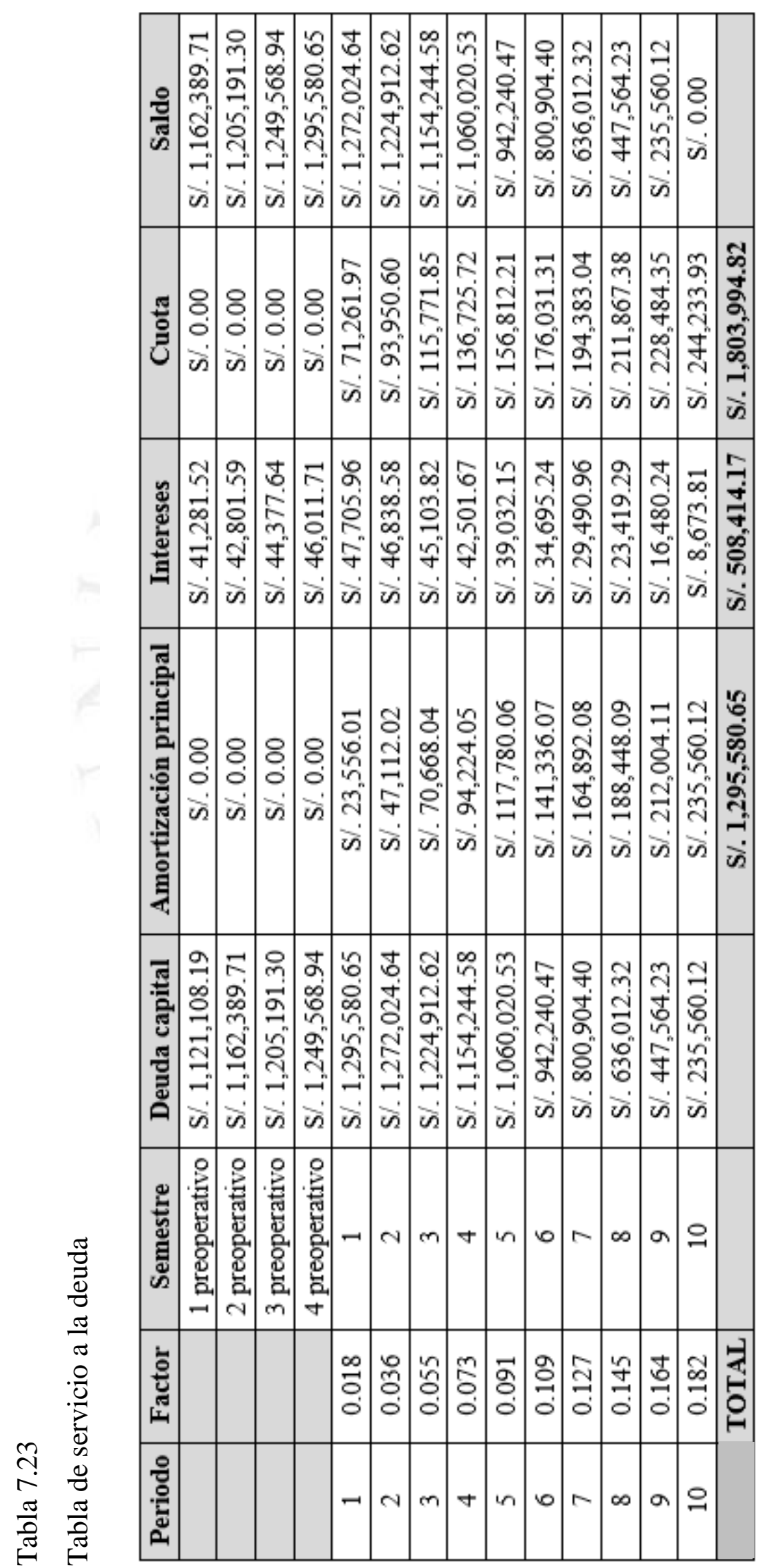

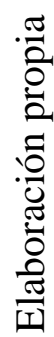


Tabla 7.24

Condiciones del financiamiento

\begin{tabular}{|l|c|}
\hline \multicolumn{1}{|c|}{ Concepto } & Cantidad \\
\hline Intereses preoperativos & S/. 174,472.46 \\
\hline Deuda total & S/. 1,121,108.19 \\
\hline Tasa de interés anual & $7.50 \%$ \\
\hline Tasa de interés semestral & $3.68 \%$ \\
\hline Amortización años & 5 \\
\hline Amortización semestres & 10 \\
\hline Plazo de gracia años & 2 \\
\hline Plazo de gracia semestres & 4 \\
\hline
\end{tabular}

Elaboración propia 


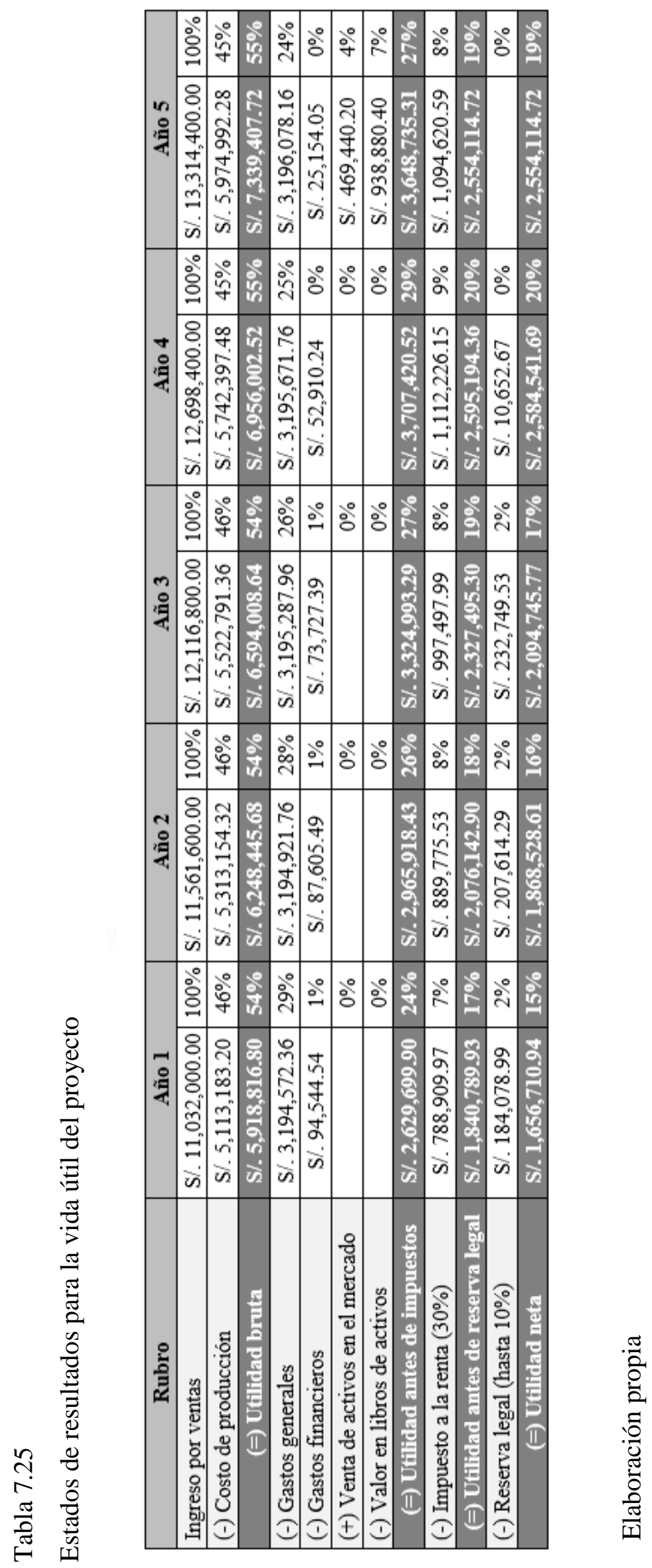




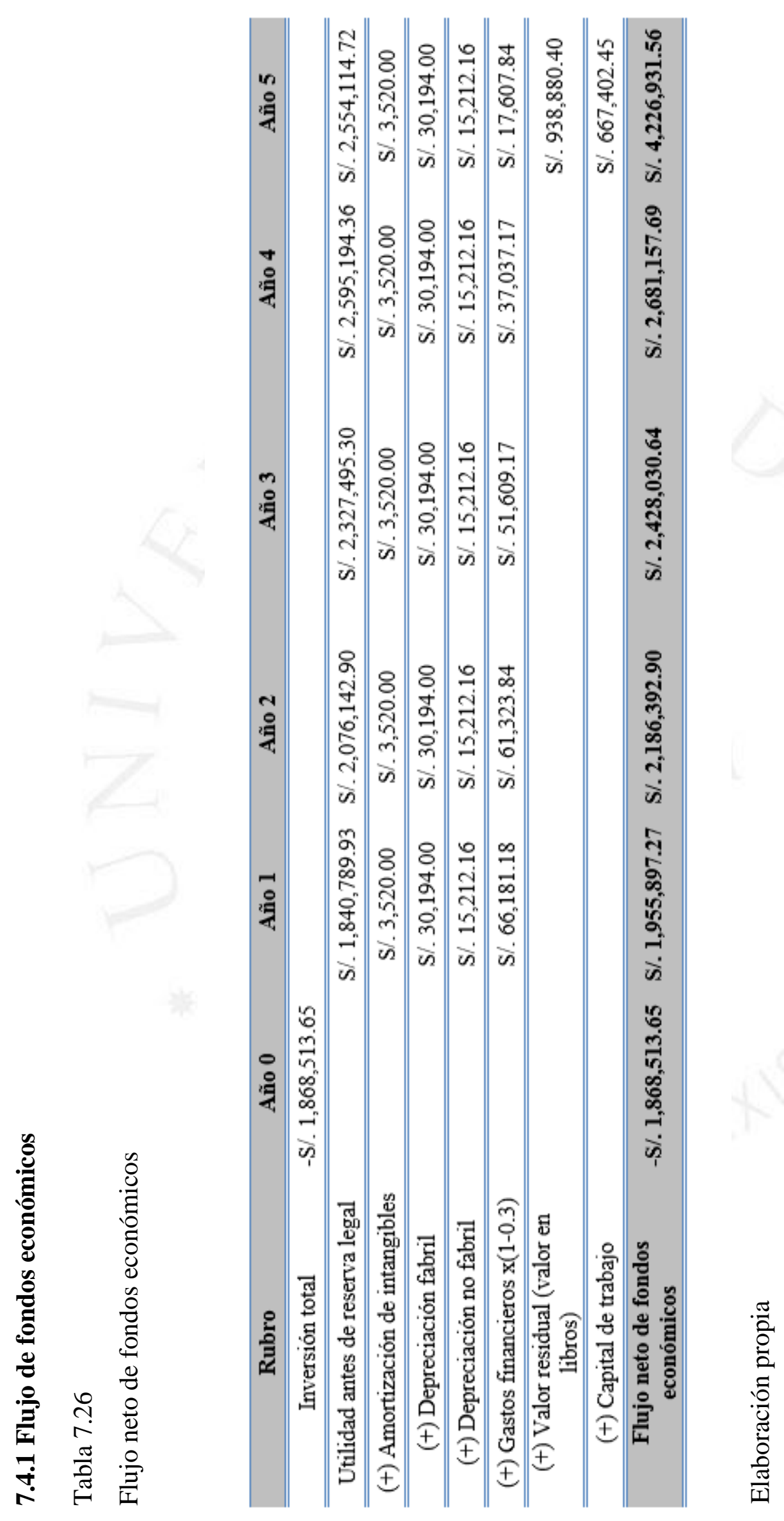




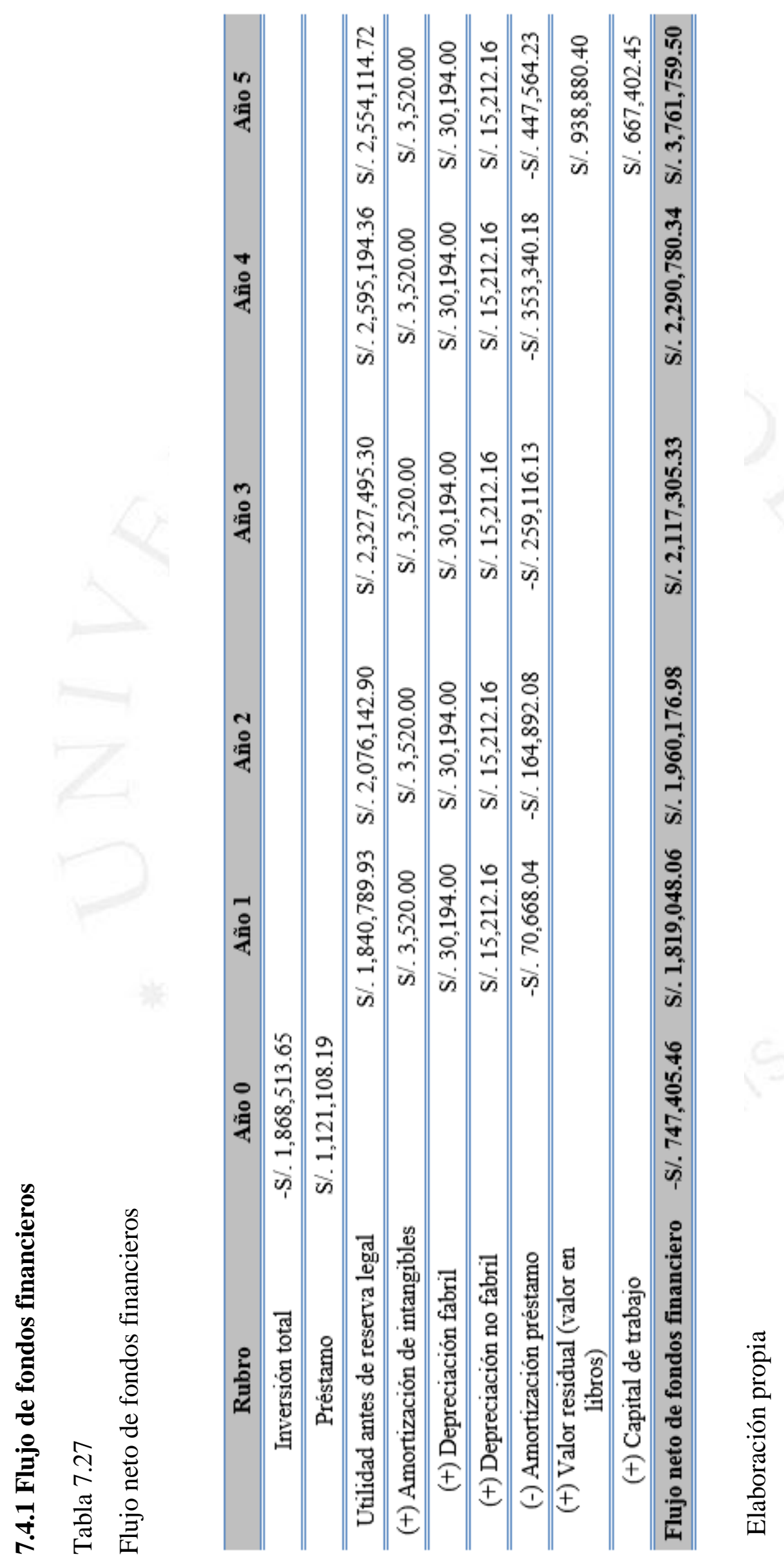




\section{CAPÍTULO VIII: EVALUACIÓN ECONÓMICA Y FINANCIERA DEL PROYECTO}

\subsection{Evaluación económica: VAN, TIR, B/C, PR}

Luego de haber determinado el flujo neto de fondos económicos se debe determinar si el proyecto para la implementación de la planta de producción de celdas de electrólisis es viable o no. Para ello se deben determinar y analizar los indicadores de rentabilidad económicos teniendo en cuenta que el costo de oportunidad estimado por los accionistas es de $18 \%$. El cálculo de estos indicadores se detalla a continuación.

Tabla 8.1

Determinación del valor actual neto económico del proyecto

\begin{tabular}{|c|c|c|c|c|c|c|}
\hline Concepto & Año 0 & Año 1 & Año 2 & Año 3 & Año 4 & Año 5 \\
\hline Factor de actualización & 1 & 0.85 & 0.72 & 0.61 & 0.52 & 0.44 \\
\hline Valor actual al Kc (18\%) & $-1,868,514$ & $1,657,540$ & $1,570,233$ & $1,477,774$ & $1,382,911$ & $1,847,631$ \\
\hline Flujo de caja acumulado & & $1,657,540$ & $3,227,773$ & $4,705,548$ & $6,088,459$ & $7,936,090$ \\
\hline Valor actual neto & $\mathbf{- 1 , 8 6 8 , 5 1 4}$ & $\mathbf{- 2 1 0 , 9 7 4}$ & $\mathbf{1 , 3 5 9 , 2 6 0}$ & $\mathbf{2 , 8 3 7 , 0 3 4}$ & $\mathbf{4 , 2 1 9 , 9 4 5}$ & $\mathbf{6 , 0 6 7 , 5 7 6}$ \\
\hline
\end{tabular}

Elaboración Propia

Tabla 8.2

Indicadores económicos de rentabilidad

\begin{tabular}{|c|c|}
\hline Indicador & Cantidad \\
\hline VAN económico & S/. 6,067,576.21 \\
\hline Relación B / C & 4.25 \\
\hline TIR económico & $113.56 \%$ \\
\hline Periodo de recupero (años) & 1.13 \\
\hline
\end{tabular}

Elaboración Propia 


\subsection{Evaluación financiera: VAN, TIR, B/C, PR}

Al igual que el flujo neto de fondos económico, se debe determinar los indicadores rentabilidad, pero en este caso será a partir de los flujos financieros del proyecto. Todo esto para tener noción de la viabilidad financiera de la instalación de la planta de producción de celdas de electrólisis.

Tabla 8.3

Determinación del valor actual neto financiero del proyecto

\begin{tabular}{|c|c|c|c|c|c|c|}
\hline \multicolumn{1}{|c|}{ Concepto } & Año 0 & Año 1 & Año 2 & Año 3 & Año 4 & Año 5 \\
\hline Factor de actualización & 1 & 0.85 & 0.72 & 0.61 & 0.52 & 0.44 \\
\hline Valor actual al Kc (18\%) & $-747,405$ & $1,541,566$ & $1,407,769$ & $1,288,657$ & $1,181,559$ & $1,644,300$ \\
\hline Flujo de caja acumulado & & $1,541,566$ & $2,949,335$ & $4,237,992$ & $5,419,551$ & $7,063,851$ \\
\hline Valor actual neto & $\mathbf{- 1 , 0 9 0 , 1 6 5}$ & $\mathbf{7 9 4 , 1 6 1}$ & $\mathbf{2 , 2 0 1 , 9 2 9}$ & $\mathbf{3 , 4 9 0 , 5 8 7}$ & $\mathbf{4 , 6 7 2 , 1 4 6}$ & $\mathbf{6 , 3 1 6 , 4 4 5}$ \\
\hline
\end{tabular}

Elaboración Propia

Tabla 8.4

Indicadores financieros de rentabilidad

\begin{tabular}{|c|c|}
\hline Indicador & Cantidad \\
\hline VAN financiero & S/. $6,316,445.43$ \\
\hline Relación B / C & 9.45 \\
\hline TIR financiero & $251.35 \%$ \\
\hline Periodo de recupero (años) & 0.58 \\
\hline
\end{tabular}

Elaboración Propia 


\subsection{Análisis de los resultados económicos y financieros del proyecto}

- Evaluación económica

El proyecto después de operar por 5 años y de pagar todos los costos de producción y gastos de operación, obtendrá un excedente actualizado de S/. 6,067,576.21 (Valor actual Neto). En consecuencia, es altamente recomendable ejecutarlo. Si los accionistas cubrieran toda la inversión inicial, se obtendría S/. 4.25actualizados por cada nuevo sol invertido en el proyecto (relación beneficio costo). Adicionalmente, el proyecto ofrece una TIR de $113.56 \%$ la cual es mucho mayor al Costo de oportunidad de $18 \%$.

- Evaluación financiera

Al finalizar el quinto año de operación, el proyecto presentará un saldo positivo de S/. S/. 6,316,445.43 después de pagar los costos de fabricación, los gastos de operación, la amortización del préstamo obtenido y los intereses del crédito. Por lo tanto, es recomendable su ejecución. El proyecto es muy atractivo pues ofrece una tasa interna de retorno financiera de $251.35 \%$, mucho mayor al costo de oportunidad de $18 \%$. La TIRF da una mejor impresión porque al considerar a la deuda se está invirtiendo menos capital de los inversionistas para obtener utilidades. Finalmente, se obtuvo una relación Beneficio/Costo de 9.45.

Finalmente, con dichas evaluaciones se puede afirmar que la hipótesis planteada en el inicio del estudio se cumple, es decir, la instalación de una planta de producción de celdas de electrólisis es factible debido a que su comercialización está garantizada. Además de ser un producto muy innovador debido a que su implementación significaría un gran ahorro, también se cuenta con los recursos, tecnología y mano de obra, que facilitarían que este proyecto se lleve a cabo con gran éxito.

\subsection{Análisis de sensibilidad del proyecto}

Para elaborar el análisis de sensibilidad del proyecto se escogieron 3 posibilidades, cada una de estas con su respectiva probabilidad. La suma de los 3 escenarios nos dará el VAN Esperado, cuyo valor ya se calculó en el capítulo anterior.

Para el análisis de sensibilidad, consideramos los siguientes datos obtenidos de la web de la Bolsa de Valores de Lima (BVL), BCRP y el diario "la República".

- $\mathrm{Rm}=12,50$ 

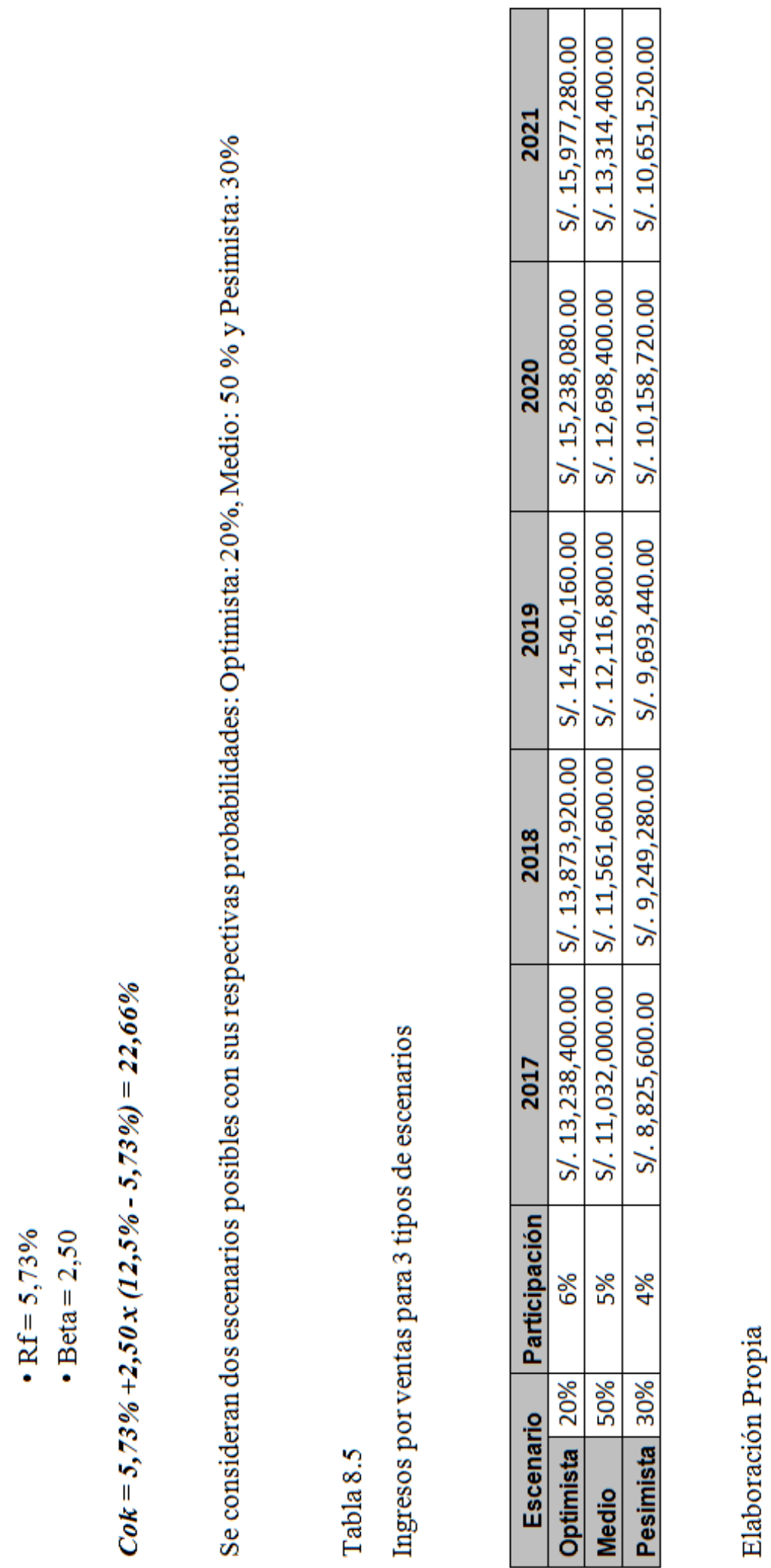


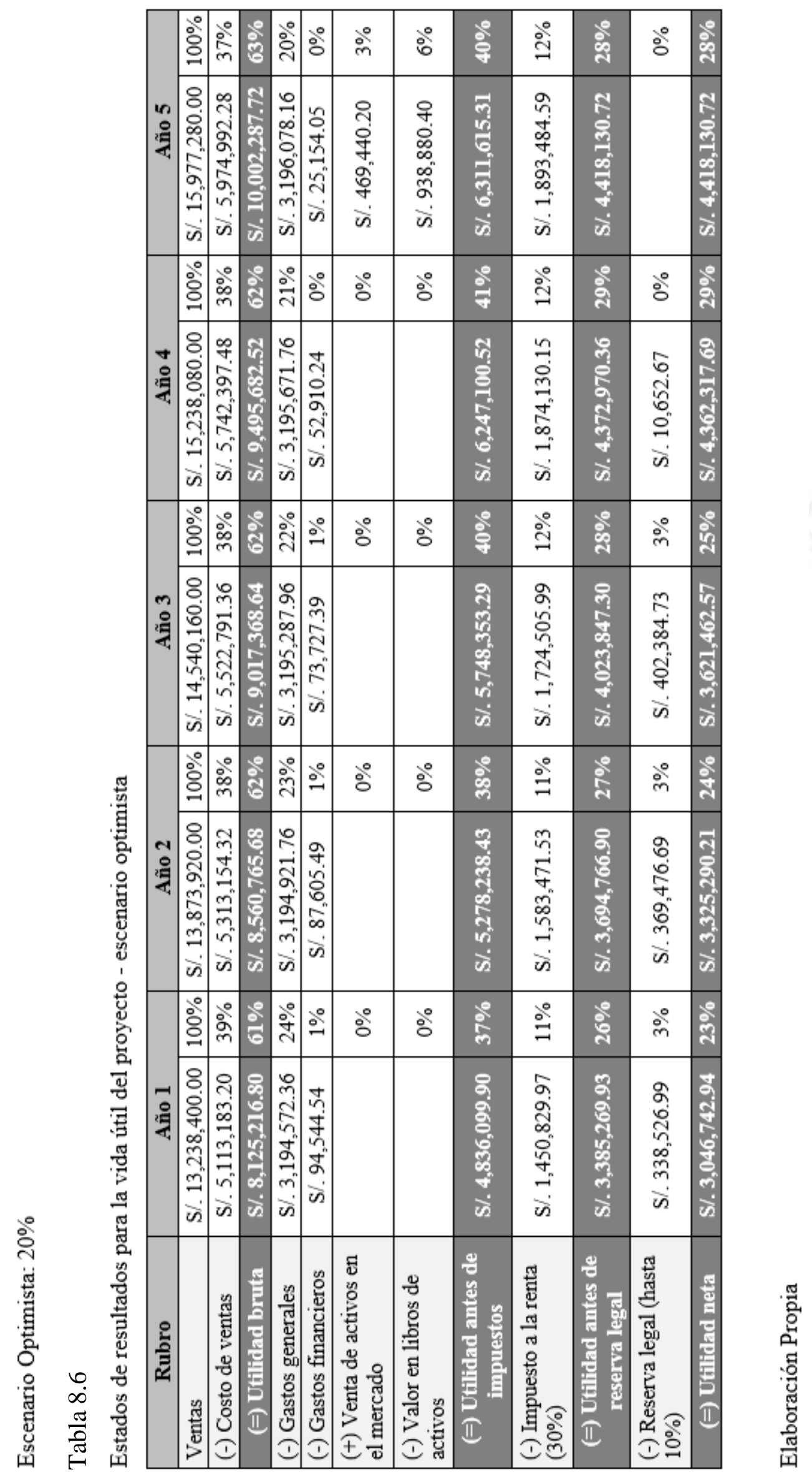



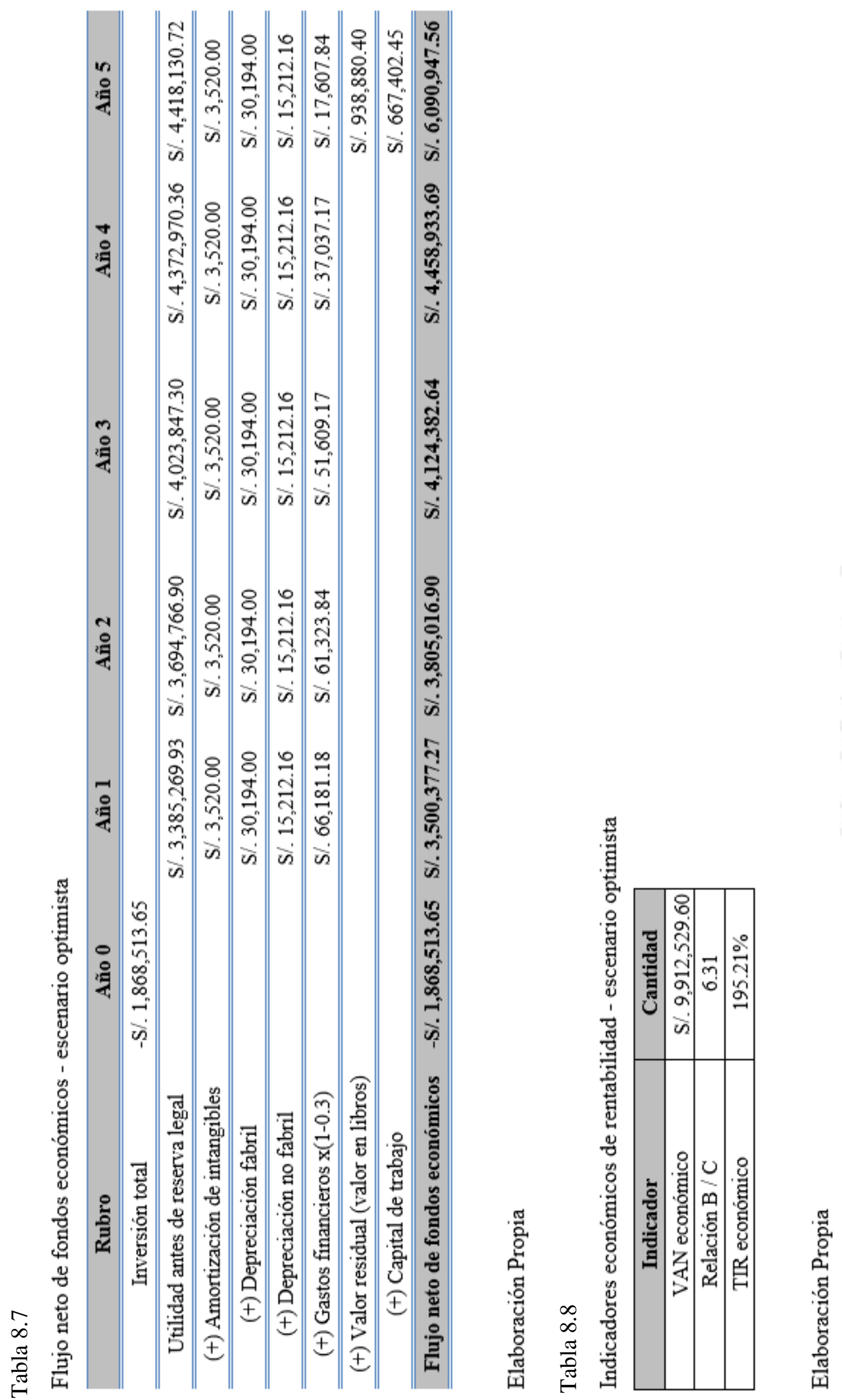


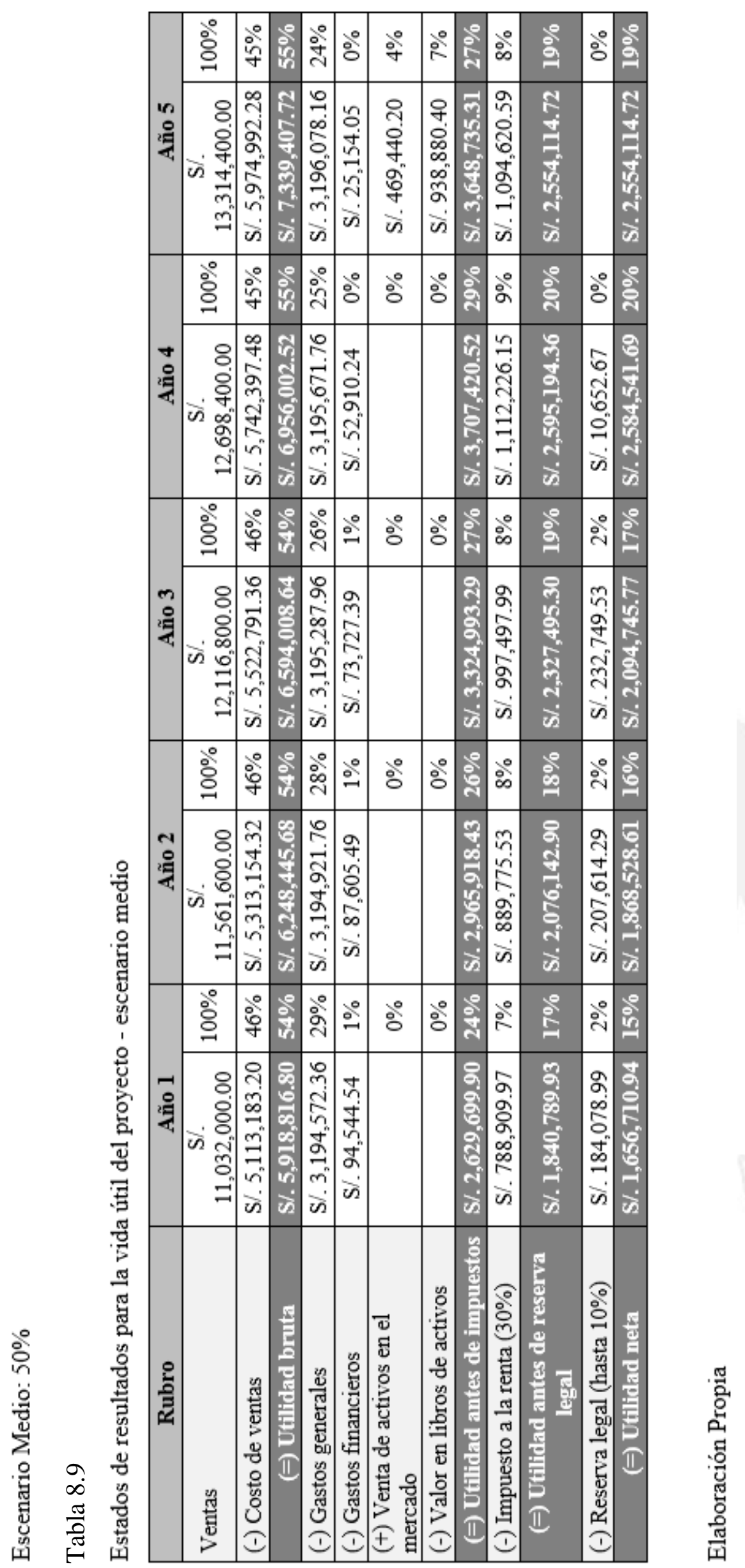



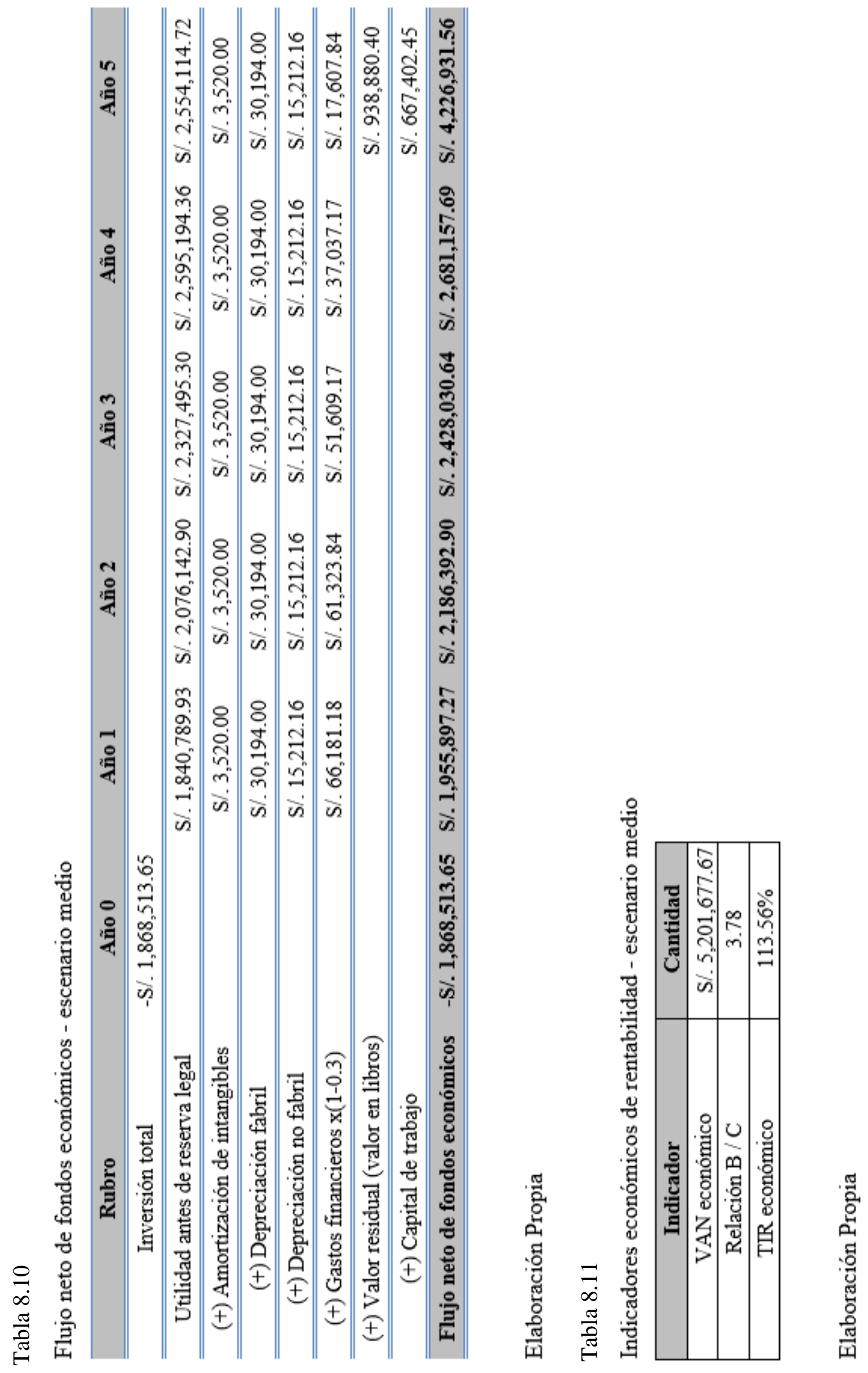


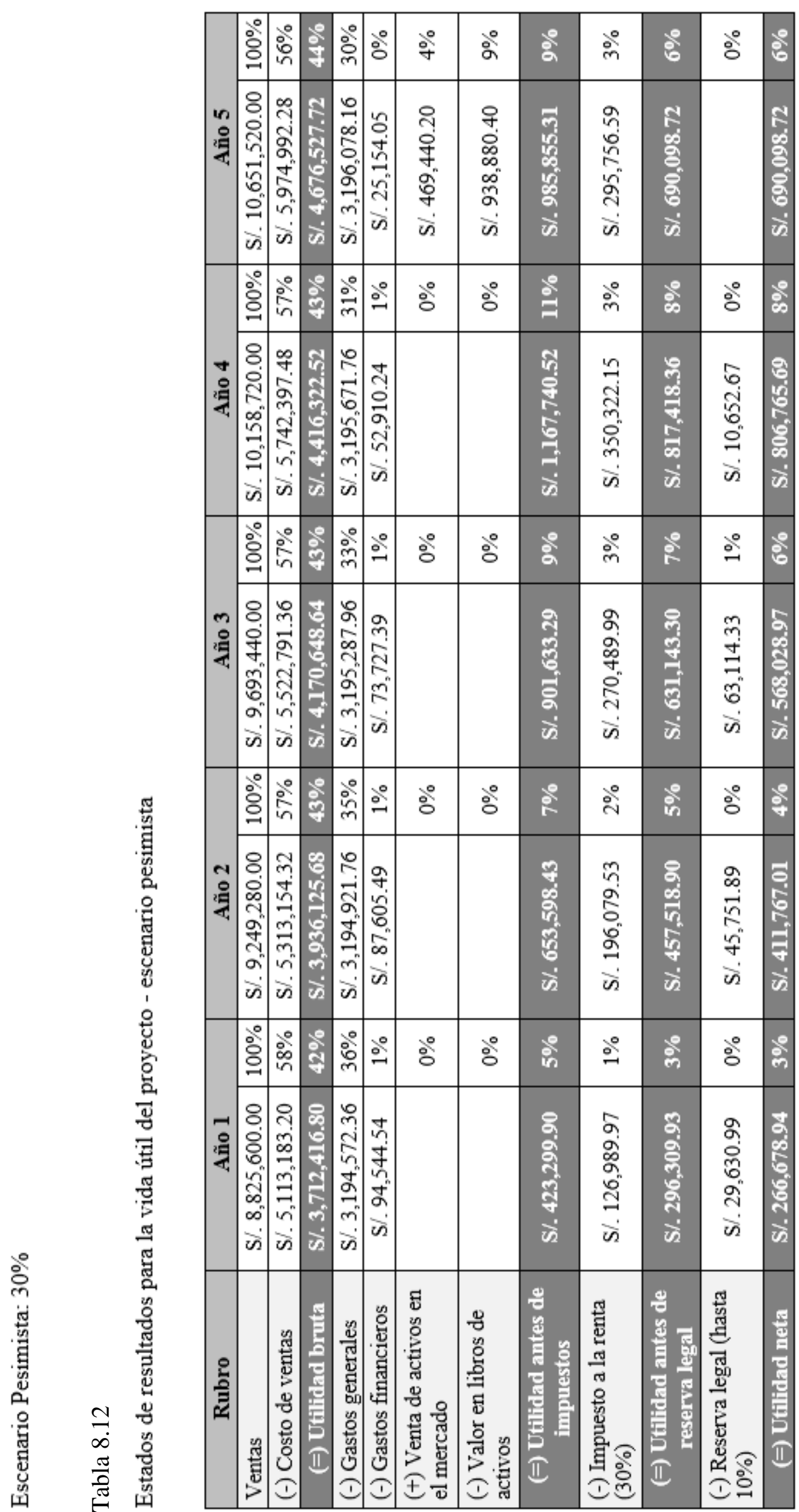

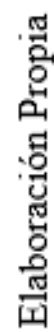



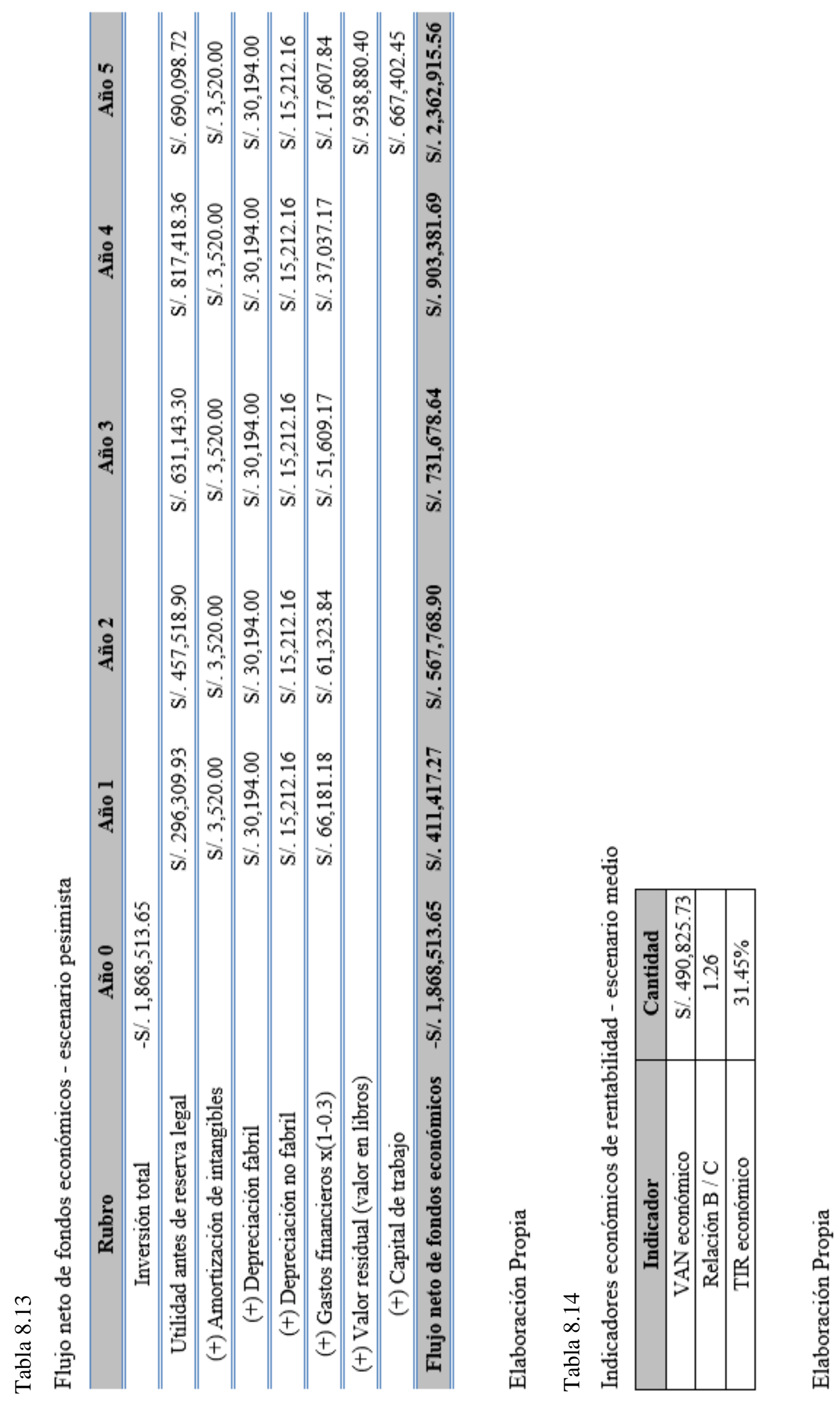


\section{CAPÍTULO IX: EVALUACIÓN SOCIAL DEL PROYECTO}

\subsection{Identificación de las zonas y comunidades de influencia del proyecto}

Las urbanizaciones que están dentro de la zona de influencia del proyecto son:

- Sapotal 1era etapa

- Sapotal 2da etapa

- Pachacutec

- El trébol

- San Carlos

- Residencial Santa Anita

- Andahuaylas

- Los productores

- La encalada

- Los ángeles

- $\quad$ Sol de Vitarte Sector E

- Virgen del Carmen

- Las brisas de Ate

- Los portales de Javier Prado 2da etapa

- Los portales de Javier Prado 1ra etapa

Pertenecientes a los distritos de Ate Vitarte y Santa Anita.

Además, se encuentra la zona arqueológica de Puruchuco, el hospital Hermilio Valdizán y el Gran mercado Mayorista de Lima.

\subsection{Impacto en la zona de influencia del proyecto}

La instalación de la planta de producción de celdas de electrólisis tendrá un impacto altamente positivo en la zona donde operará. Esto es debido a que la comercialización de los productos terminados será dinámica y fácil. 
Desde la perspectiva económica, el proyecto al ser viable, tendrá un impacto positivo en la economía de la zona debido a que se generarán nuevos puestos de trabajo y se reinvertirá cierto margen de utilidades en labores sociales para la prosperidad de las comunidades inmersas.

\subsection{Impacto social del proyecto}

El proyecto a investigar tiene un impacto social positivo, ya que se crearán puestos de trabajo, lo que conlleva a aumentar el bienestar social. Por otro lado, un beneficio que tiene la instalación de estos equipos en carros a combustión interna es que se reducen las emisiones de gases contaminantes, por lo que se tiene un impacto medio ambiental al poder funcionar los carros sin contaminar a sobremanera el medio ambiente.

Por otro lado, la instalación de esta fábrica aportaría a uno de los objetivos del país que extender el sector industrial.

Tabla 9.1

Evaluación social del proyecto

\begin{tabular}{|l|r|r|r|r|r|}
\hline \multicolumn{1}{|c|}{ Evaluación Social (S/) } & \multicolumn{1}{c|}{$\mathbf{2 0 1 7}$} & \multicolumn{1}{c|}{$\mathbf{2 0 1 8}$} & \multicolumn{1}{c|}{$\mathbf{2 0 1 9}$} & \multicolumn{1}{c|}{$\mathbf{2 0 2 0}$} & \multicolumn{1}{c|}{$\mathbf{2 0 2 1}$} \\
\hline Sueldos y salarios & $3,724,530$ & $3,724,530$ & $3,724,530$ & $3,724,530$ & $3,724,530$ \\
\hline Depreciación & 45,406 & 45,406 & 45,406 & 45,406 & 45,406 \\
\hline Servicios & 229,570 & 229,920 & 230,286 & 230,670 & 231,076 \\
\hline Gastos financieros & 94,545 & 87,605 & 73,727 & 52,910 & 25,154 \\
\hline Utilidad antes impuesto & $\mathbf{2 , 8 0 1 , 5 0 1}$ & $\mathbf{3 , 1 3 9 , 1 1 7}$ & $\mathbf{3 , 4 9 9 , 6 5 6}$ & $\mathbf{3 , 8 8 3 , 6 1 9}$ & $\mathbf{4 , 2 9 6 , 0 0 0}$ \\
\hline Impuesto a la renta & 840,450 & 941,735 & $1,049,897$ & $1,165,086$ & $1,288,800$ \\
\hline Utilidad después imp. & $\mathbf{1 , 9 6 1 , 0 5 0}$ & $\mathbf{2 , 1 9 7 , 3 8 2}$ & $\mathbf{2 , 4 4 9 , 7 6 0}$ & $\mathbf{2 , 7 1 8 , 5 3 3}$ & $\mathbf{3 , 0 0 7 , 2 0 0}$ \\
\hline Valor Agregado & $6,895,552$ & $7,226,578$ & $7,573,605$ & $7,937,135$ & $8,322,166$ \\
\hline Valor Agregado Actual & $5,746,293$ & $6,022,148$ & $6,311,338$ & $6,614,279$ & $6,935,138$ \\
\hline $\begin{array}{l}\text { Valor Agregado Actual } \\
\text { Acumulado }\end{array}$ & $\mathbf{5 , 7 4 6 , 2 9 3}$ & $\mathbf{1 1 , 7 6 8 , 4 4 1}$ & $\mathbf{1 8 , 0 7 9 , 7 8 0}$ & $\mathbf{2 4 , 6 9 4 , 0 5 9}$ & $\mathbf{3 1 , 6 2 9 , 1 9 7}$ \\
\hline
\end{tabular}

Elaboración Propia 
Cálculo de la Densidad de Capital: Relación de la inversión del capital, versus empleo generado. Este indicador nos muestra el monto de inversión que se necesita para crear un puesto de trabajo.

$$
\begin{aligned}
& \text { Densidad de } \\
& \text { Capital }
\end{aligned}=\frac{\text { Inversión Total }}{\# \text { de Empleados }}=\frac{1,868,513}{18}=103,806 \quad \mathrm{~S} / . / \text { Empleo }
$$

A partir de dicho cálculo se concluye que por cada 103, 806 soles invertidos se generará un puesto de trabajo.

Intensidad de Capital: Nos muestra la relación de la inversión total versus el valor agregado del proyecto. Nos permitirá medir cual es el grado de aporte del proyecto a través del nivel de la inversión para generar valor agregado sobre los insumos.

$$
\begin{aligned}
& \text { Intensidad de } \\
& \text { Capital }
\end{aligned}=\frac{\text { Inversión Total }}{\text { Valor Agregado }}=\frac{1,868,513}{31,629,197}=0.05907557
$$

A partir de dicho cálculo se concluye que se requiere 0.06 soles de inversión para generar una retribución a la sociedad con el valor agregado equivalente a un sol.

Producto/Capital: Llamado coeficiente de Capital. Mide la relación entre el valor agregado generado en el proyecto, versus el monto de la inversión total.

$$
\text { Producto }- \text { Capital }=\frac{\text { Valor Agregado }}{\text { Inversión Total }}=\frac{31,629,197}{1,868,513}=16.9275
$$

A partir de dicho cálculo se concluye que, por cada sol invertido en el proyecto, se retribuirá a la sociedad con el valor agregado equivalente a 16.93 soles.

En consecuencia, se puede afirmar que el proyecto tiene una significativa contribución a la sociedad. 


\section{CONCLUSIONES}

Se concluye que es factible invertir en la instalación de una fábrica para manufacturar celdas de electrólisis debido a que existe la materia prima necesaria, mano de obra calificada, y tecnología disponible en el mercado para ser adquirida, de tal manera que sus operaciones no tendrían inconveniente alguno.

Además, el impacto social que generaría este proyecto es positivo, ya que se generarán puestos de trabajo, y mediante la utilización del producto en el parque automotor, las emisiones contaminantes se reducirán, beneficiando la salud de muchas personas.

Con respecto al impacto ambiental, se puede mencionar que se ha diseñado un proceso que requiere de poca energía y agua para operar generando, a su vez, pocos desperdicios que pueden ser posteriormente procesadas y recicladas, teniendo un funcionamiento ecológico, coherente con el producto que ayuda a generar combustiones completas en el funcionamiento automotriz, aumentando su eficiencia energética.

Se puede también llegar a la conclusión de que es un momento sinérgico para la inversión en este proyecto ya que el parque automotor crece cada vez a una tasa más acelerada, existiendo mayor preocupación por el medio ambiente y el ahorro.

La instalación de una planta de producción de celdas de electrólisis es factible debido a que su comercialización está garantizada y los resultados de la evaluación económica lo respaldan. Además de ser un producto muy innovador debido a que su implementación significaría un gran ahorro, también se cuenta con los recursos, tecnología y mano de obra, que facilitarían que este proyecto se lleve a cabo con gran éxito. 


\section{RECOMENDACIONES}

Se deben realizar cálculos en los cuales se haga un análisis de sensibilidad teniendo como variable independiente el precio y como respuesta la demanda.

Además, se recomienda realizar un estudio más exhaustivo para ampliar el mix de marketing para ofrecer distintas presentaciones del sistema de hidrógeno vehicular, de tal modo que cumpla con los requerimientos de distintos tipos de máquinas como generadores eléctricos, camiones, buses, etc., de tal modo que el mercado objetivo sea más amplio.

También, se recomienda evaluar distintos materiales para optimizar el funcionamiento del sistema, de tal manera que se ofrezca un producto con mayor competitividad al mercado.

Debido a que este trabajo es preliminar y aun no se han revelado los cuellos de botella en la operación real, se recomienda que una vez instalado el proyecto, se realicen estudios de tiempos y movimientos para poder dar mayor precisión al diseño de las operaciones.

En un mundo globalizado, es importante tener noción de la demanda a nivel global que pueda tener un producto si es que se promociona a través de medios como el internet, de tal manera que se recomienda evaluar el costo que se incurriría en establecer esta unidad de negocio dentro del presente proyecto, y los beneficios que generaría para su desarrollo comercial.

Es recomendable también, realizar estudios sobre la factibilidad de, realizando una integración vertical hacia atrás, importar la materia prima requerida para el proyecto, para determinar si es costo beneficioso para los resultados económicos y financieros.

Es recomendable asumir un financiamiento con cuotas crecientes para poder hacer frente con mayor holgura al riesgo existente en el primer año, ya que se trata de un producto nuevo y existe la posibilidad de que exista resistencia al cambio o a la aceptación de nuevas tecnologías por parte del público objetivo.

El desarrollo de un proyecto de inversión deberá ser gestionado por procesos y no por áreas o departamentos para la ejecución de tareas. La gestión por procesos permitirá descubrir las fortalezas y debilidades del núcleo del negocio desde todos los puntos de vista integrando las distintas áreas que los componen y partir de ello facilitará elaborar estrategias de mejora, control y seguimiento. 
A lo largo de la implementación del proyecto, la innovación tecnológica debe ser evaluada, de tal manera que la tecnología evolucione a la par de las utilidades generadas. 


\section{REFERENCIAS}

Aceros Otero, (2012). Productos. Recuperado de: http://www.acerosotero.cl/productos.html

Blog corte y grabado, (2013). Limpieza de husillo de corte láser. Recuperado de: http://www.perezcamps.com/es/strong-mantenimiento-strong-para-las-strongfresadoras-cnc-strong_8311

Campos Morote, M. A. (2006). Metodología para la implantación eficaz de un sistema de gestión de la calidad en una mediana empresa del sector metalmecánico. (Tesis para optar por el título de Ingeniero Industrial). Universidad de Lima.

Cassidy, J. (1977). Emissions and total energy consumption of a multi cylinder piston engine running on gasoline and a hydrogen-gasoline mixture. [versión PDF] Recuperado de: http://ntrs.nasa.gov/archive/nasa/casi.ntrs.nasa.gov/19770016170.pdf

Córdova Ramos, H. (2012). Implementación de una planta de fabricación y comercialización de electrodos. (Tesis para optar por el título de Ingeniero Industrial). Universidad de Lima.

Díaz, B, Jarufe, B., y Noriega, M. T. (2007). Disposición de planta (2.a ed.). Lima: Fondo Editorial Universidad de Lima

El Comercio (Productor). (2013). A un mes de la revocación: la gestión de Villarán en el transporte urbano. Recuperado de http://elcomercio.pe/sociedad/lima/mes-revocaciongestion-villaran-transporte-urbano-noticia-1539457

El Comercio (Productor). (2012). Conversión de vehículos a gas natural crecería a 25.000 unidades por año. Recuperado de: http://elcomercio.pe/economia/peru/conversionvehiculos-gas-natural-creceria-25000-unidades-ano-noticia-1383597

Fabricators and Manufacturers Association, (2014). Metal Cutting Types. Recuperado de: https://www.fmanet.org/

HHO Plus Lda., (2008). Alternative Energies. Recuperado de: http://www.hhoplus.com/content/19-tecnologia 
Indeci (Productor), (2004). Norma Técnica Peruana NTP 399.010-1, (2004). [versión PDF] Recuperado de: http://bvpad.indeci.gob.pe/doc/pdf/esp/doc709/doc709-8.pdf

INEI (Productor), (2011). Perú: Proyecciones Del parque vehicular estimado, según clase Del vehículo: 2012-2013. Recuperado de: https://www.inei.gob.pe

Insumos Global, (2014). Manguera Trenzada Transparente de PVC. Recuperado de: http://www.insumosglobal.com/manguera-trenzada-transparente-de-pvc/

Klinge Ambrosini, F. (2000). Estudio de pre-factibilidad para la implementación de una empresa de sistemas duales de GLP en vehículos a gasolina. (Tesis para optar por el título de Ingeniero Industrial). Universidad de Lima.

Lh-kj Corp, (2012). Custom Industrial Laser Cutting Services. Recuperado de: http://kjlasermicromachining.com/capabilities/laser-cutting/

Meyer S., (1991). Inertial confinement fusion with advanced ignition schemes: Fast ignition and shock ignition. [versión PDF] Recuperado de: http://gaps.ing2.uniroma1.it/ atzeni/Presentations/AtzeniSUSSP68_lectures_1and_2_rev1.pdf

Ministerio Del Trabajo, (2013). Elementos Para La Determinación Del Costo Horario De Los Equipos y La Maquinarias Del Sector Construcción. [versión PDF] Recuperado de: http://www3.vivienda.gob.pe/dnc/archivos/difusion/eventos/iquitos/Norma_Elementos _para_la_Determinacion_Costo_Horario.pdf

MPW Industriales, (2015). Máquina de Prensa Hidráulica. Recuperado de: http://www.directindustry.es/fabricante-industrial/prensa-hidraulica-63048.html

MTC, (2015). Anuario Estadístico 2015. Recuperado de: https://www.mtc.gob.pe/estadisticas/publicaciones/anuarios/ANUARIO_ESTADISTI CO_2015.pdf

Ocean Go Ltda. (2014). Hydrogen System. Recuperado de: https://ocean-go.en.made-inchina.com/ 
Osinermin, (2015). Regulación Tarifaria de Electricidad. [versión PDF] Recuperado de: http://www.osinergmin.gob.pe/seccion/institucional/regulacion-tarifaria/procesosregulatorios/electricidad

Peña Valladares, C. E. (2011). Estudio preliminar para la instalación de una planta metalmecánica para la fabricación de tubos casing para la industria petrolera (Tesis para optar por el título de Ingeniero Industrial). Universidad de Lima.

Plásticos Bogoan, (2013). Corte Láser. Recuperado de: http://www.plasticosbogoan.es/cortelaser

Yilmaz, A. C. (2010). Effect of hydroxy (HHO) gas addition on performance and exhaust emissions in compression ignition engines. [versión PDF] Recuperado de: http://www.sciencedirect.com/science/article/pii/S0360319910013595 


\section{BIBLIOGRAFÍA}

Malhotra, N (2008) Investigación de mercados. México: Prentice Hall

John O'M. Bockris, y Amulya K. N. Reddy (1978) Electroquímica moderna. (Vol 1-2) Barcelona: Editorial Reverte

Goñi J.C. (2009) Máquinas hidráulicas y térmicas. Lima: Fondo Editorial Universidad de Lima

Goñi J.C. (2009) Máquinas, instrumentos y procesos de manufactura. Lima: Fondo Editorial Universidad de Lima 
ANEXOS 


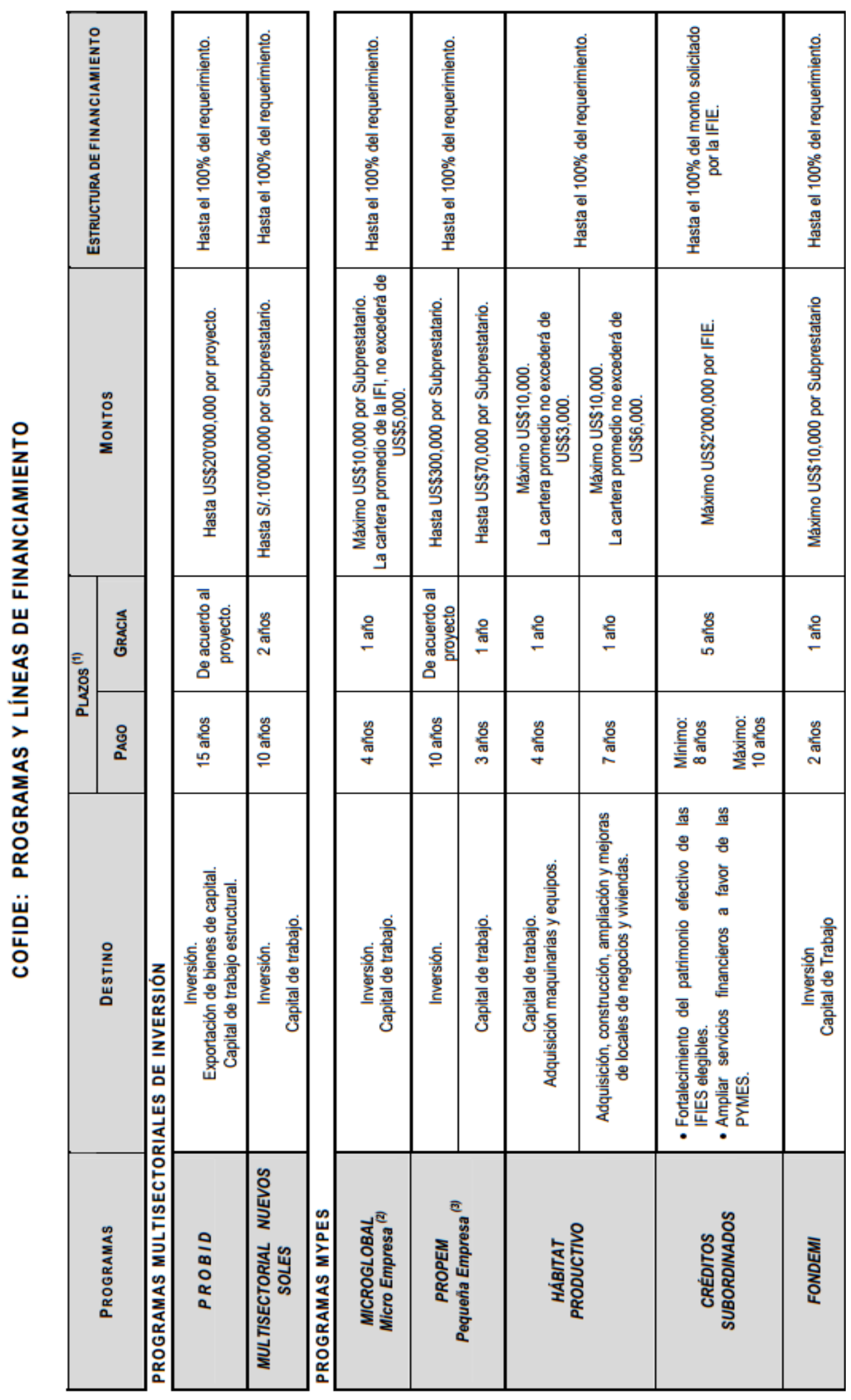




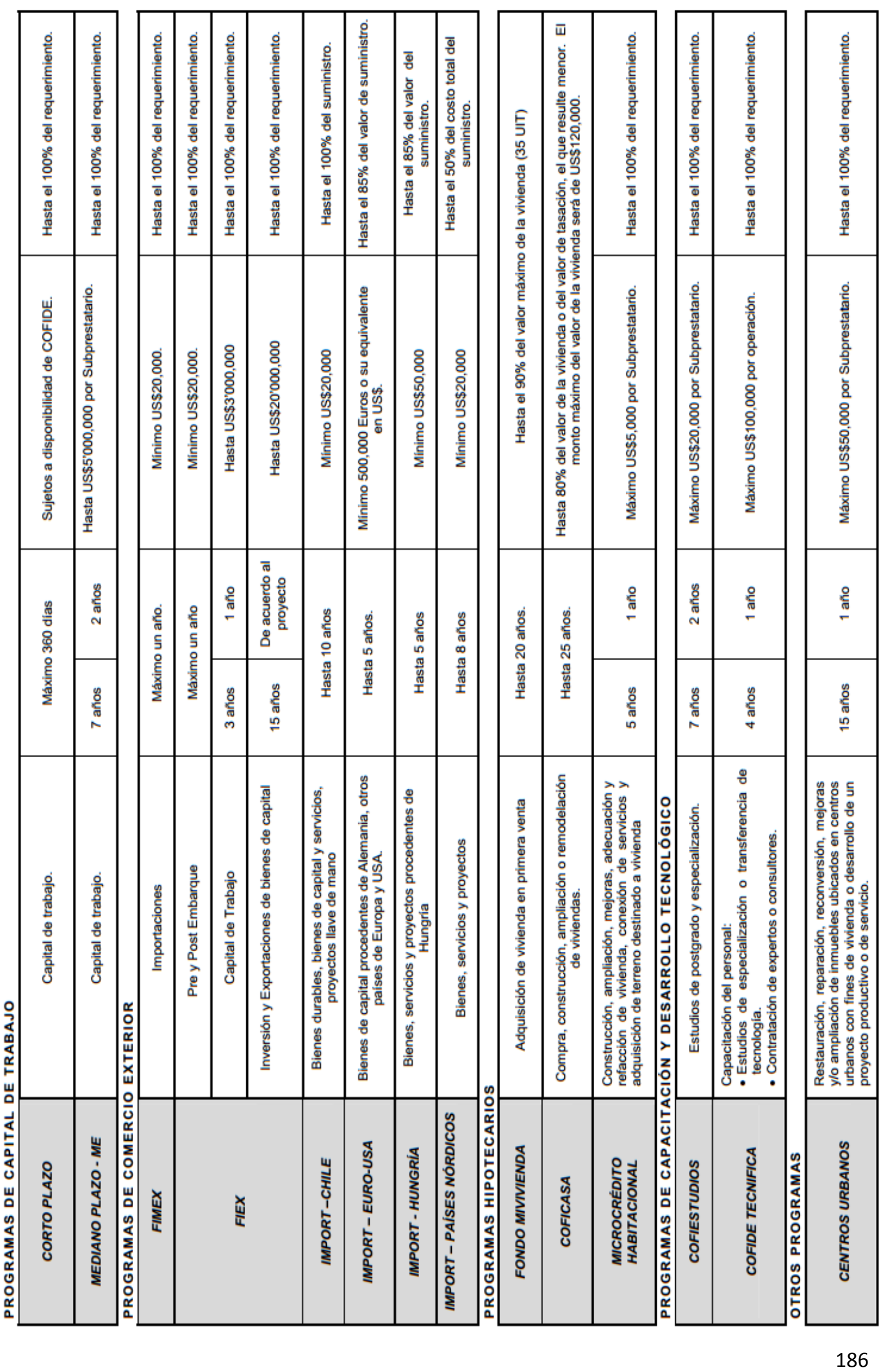

